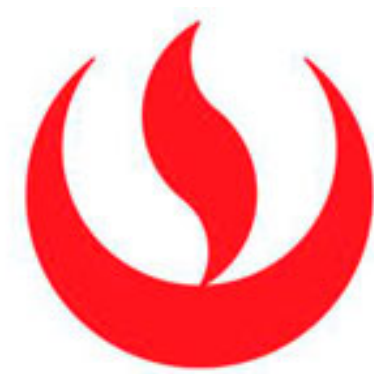

UNIVERSIDAD PERUANA DE CIENCIAS APLICADAS

FACULTAD DE INGENIERÍA

CARRERA DE INGENIERÍA INDUSTRIAL

\title{
PROPUESTA DE MEJORA DEL PROCESO DE TEÑIDO DE TELAS EN UNAEMPRESA TEXTIL
}

\author{
TESIS \\ Para optar por el título profesional de: Ingeniero Industrial \\ AUTOR \\ Arce Castro, Elena Beatriz (0000-0003-1874-7834) \\ ASESOR DE TESIS \\ Eyzaguirre Munarriz, Juan Carlos (0000-0003- 4617-4412)
}

Lima, 05 de Abril de 2018 
Dedicatoria

Mi tesis la dedico con todo mi amor a mi madre, Guillermina Castro Ferruzo y a mi padre, Francisco Arce Salina; quienes se han sacrificado y esforzado por darme una carrera profesional. La ayuda que me han brindado ha sido vital, han estado conmigo incluso en los momentos en el que estuve a punto de darme por vencida. Este proyecto no fue fácil, pero estuvieron motivándome y ayudándome hasta que logre mi objetivo. 


\section{AGRADECIMIENTO}

Agradezco, en primer lugar a Dios por permitirme lograr la culminación de unos de los objetivos que me he propuesto en la vida. Agradezco, a mis padres, ya que ellos fueron los que me incentivaron he hicieron suya mi meta. Cada uno de mis logros se los debo a ustedes. Y un especial agradecimiento, a mi madre por enseñarme y transmitirme su responsabilidad e integridad. Muchas gracias Mamá y Papá porque sin ustedes no hubiese sido posible culminar este proyecto. 


\section{RESUMEN}

El presente proyecto de investigación se encuentra estructurado en cinco capítulos los cuales son los siguientes: Marco teórico y estado del arte, descripción y análisis del proceso actual, propuesta de mejora, validación de la propuesta de mejora, conclusiones y recomendaciones.

El objetivo principal del presente proyecto fue identificar las principales causas de los retrasos del proceso de teñido de tela de una empresa peruana dedicada a la producción de telas de alta calidad; ya que al incumplir con las fechas de despacho se incurren no solo en costos operativos adicionales, sino también en pagos de penalización especificados en los contratos de servicio. El análisis del proceso diagnosticó que las causas principales se debían a la deficiente programación de la producción y al desorden de los productos en proceso.

Es por ello que se elaboró una propuesta de mejora para reducir los tiempos de espera que presenta actualmente el proceso de tela teñida. Para el diseño de la propuesta se utilizó las herramientas de gestión de la producción, tales como SMED y MRPII. De ese modo, con la implementación de la propuesta se podría reducir el tiempo del proceso de 6.21 a 3.71 horas, disminuyendo el tiempo de espera de 4.75 a 2.59 horas. Asimismo, la propuesta mejoraría la utilización del servidor de $82.54 \%$ a $49.24 \%$, lo que indica que el $49.24 \%$ de todas las bobinas que ingresan al proceso de teñido sólo tienen colas. Con los nuevos resultados se espera alcanzar la meta de eliminar costos adicionales de producción así como la eliminación de penalidades contractuales.

Palabras claves: SMED, MRPII, VSM, Teoría de colas, mejora de procesos 


\begin{abstract}
The present research project is structured into five chapters which are the following: Theoretical framework and state of the art, description and analysis of the current process, proposal for improvement, validation of the improvement proposal, conclusions and recommendations.

The main objective of this project was to identify the main causes of the delays of the cloth dyeing process of a Peruvian company dedicated to the production of high quality fabrics; since by not complying with the dispatch dates, not only additional operating costs are incurred, but also penalization payments specified in the service contracts. The analysis of the process diagnosed that the main causes were due to the poor programming of the production and to the disorder of the products in process.

For this reason, an improvement proposal was drawn up to reduce the waiting times currently presented by the dyed cloth process. For the design of the proposal, production management tools were used, such as SMED and MRPII. Thus, with the implementation of the proposal, the time of the process could be reduced from 6.21 to 3.71 hours, reducing the waiting time from 4.75 to 2.59 hours. Also, the proposal would improve server utilization from $82.54 \%$ to $49.24 \%$, which indicates that $49.24 \%$ of all the coils that enter the dyeing process only have tails. With the new results, it is expected to reach the goal of eliminating additional production costs as well as the elimination of contractual penalties.
\end{abstract}

Keywords: SMED, MRPII, VSM, Queue theory, process improvement 


\section{Lista de Contenido}

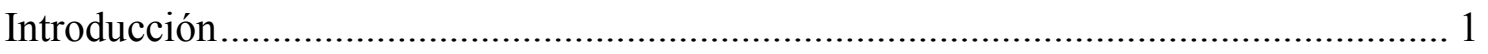

CAPÍTULO I: MARCO TEÓRICO Y ESTADO DEL ARTE ....................................... 2

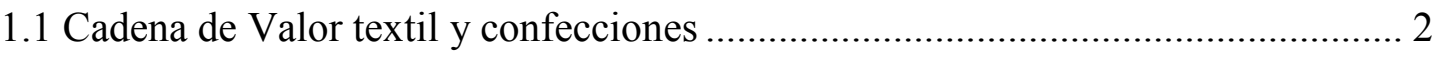

1.2 Entorno de la Industria Textil y Confecciones ...................................................... 4

1.3 Clasificación CIIU de las empresas del rubro textil y confecciones ...................... 6

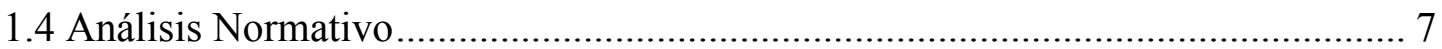

1.4.1Clasificación de las empresas en el Perú ....................................................... 7

1.4.2 Distribución de las empresas según tipo de contribuyente............................ 8

1.4.3 Decreto Ley $\mathrm{N}^{\circ} 22342$ Promoción de las exportaciones No tradicionales ..... 9

1.5 Marco Teórico: Metodologías y herramientas de análisis para la definición del

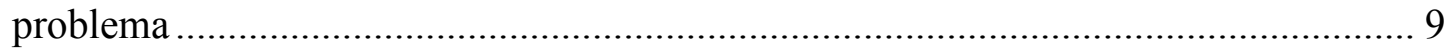

1.5.1 MRP II - Manufacturing Resources Planning - Planeamiento de Recursos de

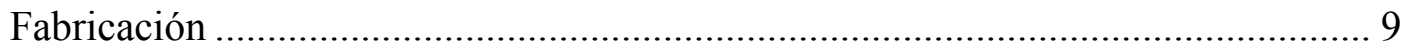

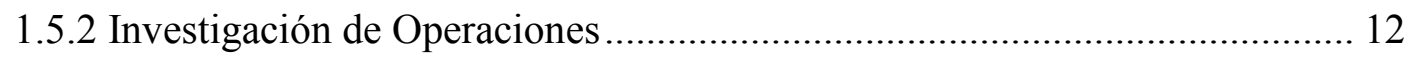

1.5.3 Una introducción a la Simulación de Arena................................................... 19

1.5.4 Análisis de datos: Herramientas estadísticas ............................................. 21

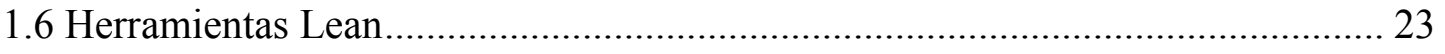

1.6.1 Implementación de Lean Manufacturing................................................... 24

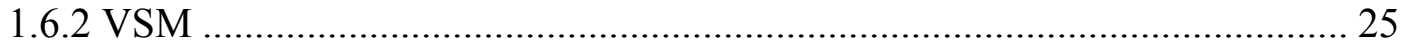

1.6.3 SMED - Single Minute Exchange of Dies ................................................... 28

CAPÍTULO II: DESCRIPCIÓN Y ANALISIS DEL PROCESO ACTUAL ................. 29

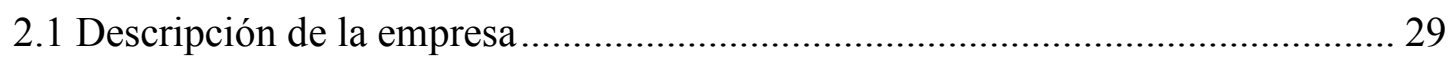

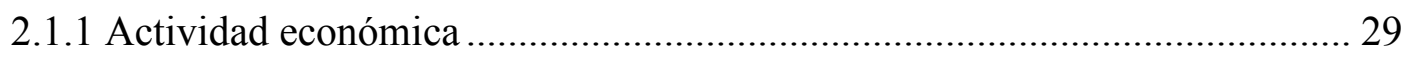

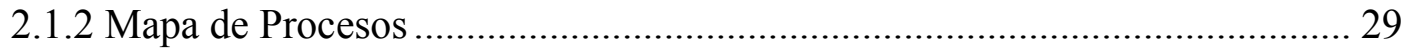

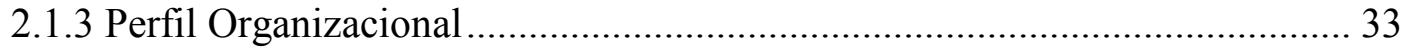

2.4.1 Participación en el modelo de negocio ......................................................... 36

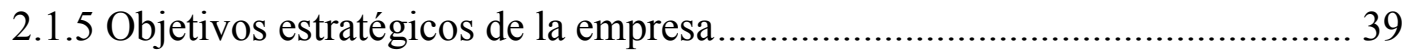

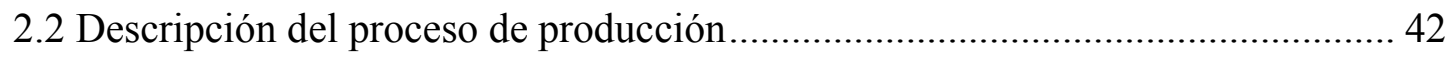

2.3 Identificación del problema actual: Oportunidad de mejora ................................ 46

2.3.1 Análisis de la matriz estratégica: Objetivos de ventas ............................... 46

2.3.2 Análisis del cumplimiento de despacho a tiempo del producto tela ............. 48 
2.4 Diagnóstico de las posibles causas que originan el problema ............................. 56

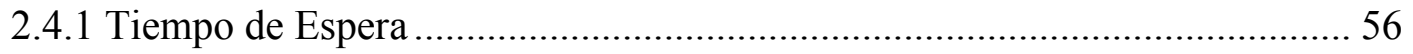

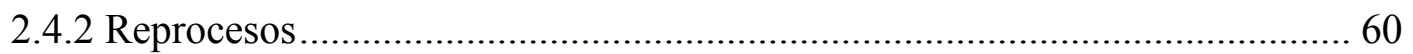

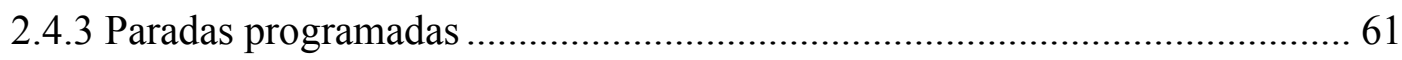

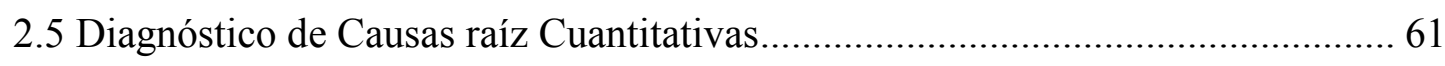

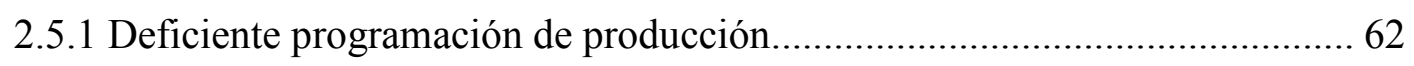

2.5.2 Desorden de bobinas en el proceso ........................................................... 73

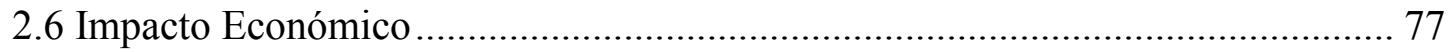

2.6.1 Impacto económico de las Penalidades por entregas fuera de tiempo .......... 77

2.6.2 Impacto Económico por Retrasos en el Proceso de Teñido del Equipo Jigger 78

2.6.3 Impacto Económico Total ....................................................................... 80

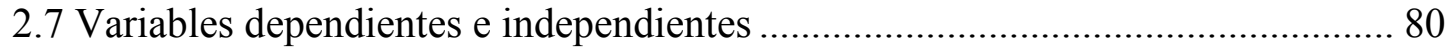

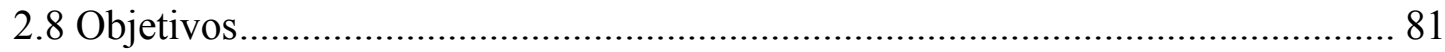

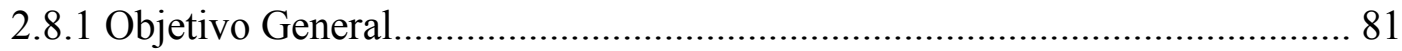

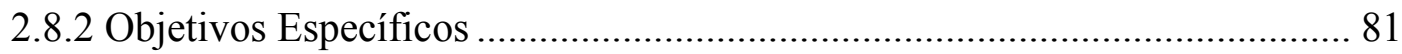

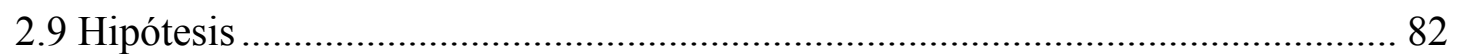

2.10 Indicadores

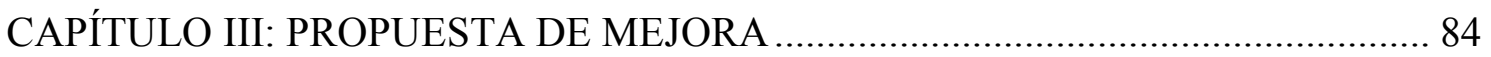

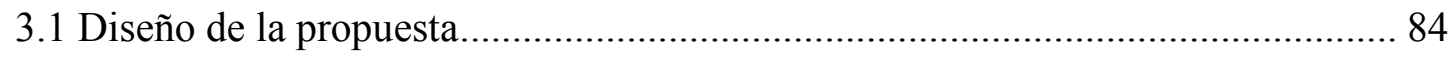

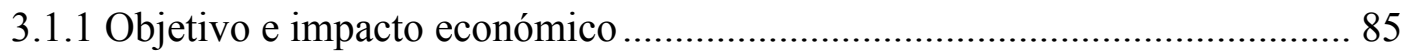

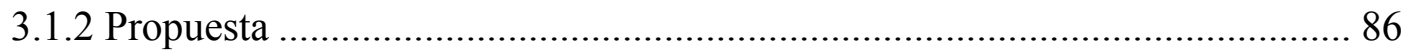

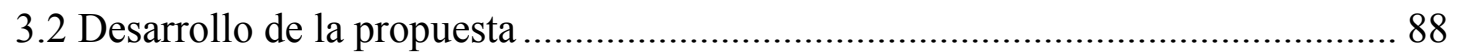

3.2.1 Optimización del subproceso de reposo en el proceso de teñido .................. 95

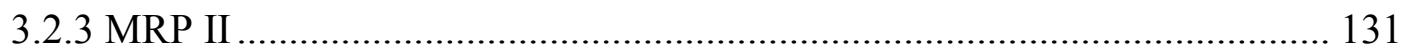

3.3 Consideraciones para la implementación ...................................................... 137

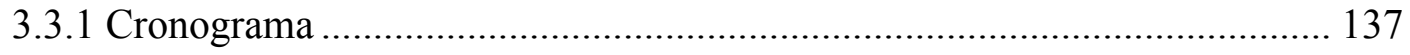

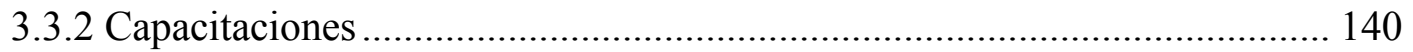

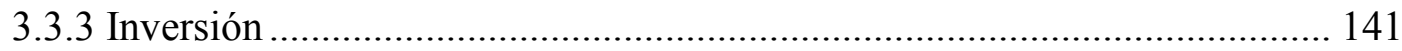

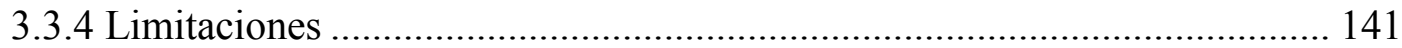

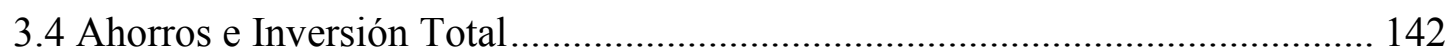

CAPÍTULO IV: VALIDACIÓN DE LA PROPUESTA DE MEJORA ....................... 144

4.1 Validación de los tiempos de los Procesos ......................................................... 144

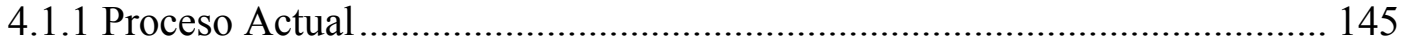


4.1.2 Proceso de la propuesta de Mejora

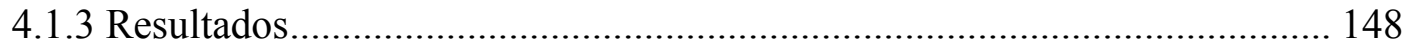

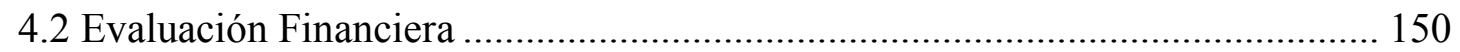

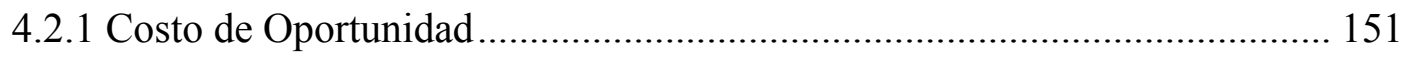

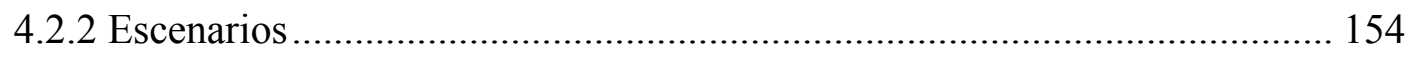

CAPÍTULO V: CONCLUSIONES Y RECOMENDACIONES ............................... 157

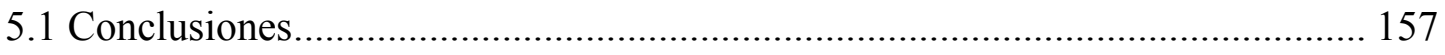

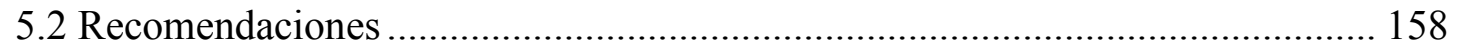

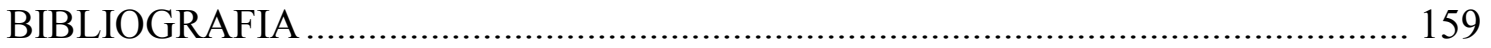

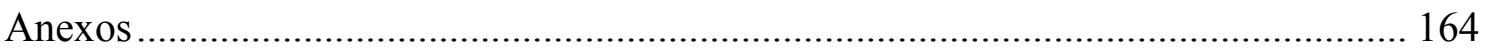




\section{Índice de Tablas}

Tabla 1: Clasificación de empresas del rubro textil y confeccione según CIIU, revisión 4

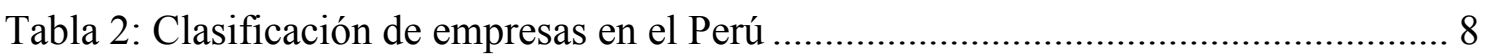

Tabla 3: Herramientas avanzadas de Manufactura o Fábrica.......................................... 11

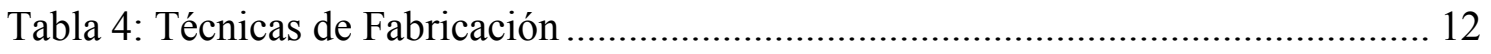

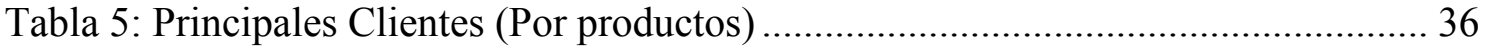

Tabla 6: Número de colaboradores de la empresa textil bajo estudio 2014- 2016 _........ 39

Tabla 7: Principales proveedores por tipo de insumo o recurso ....................................... 39

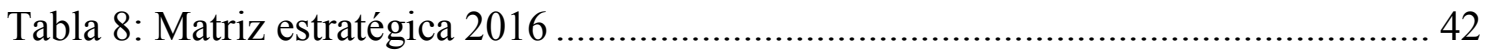

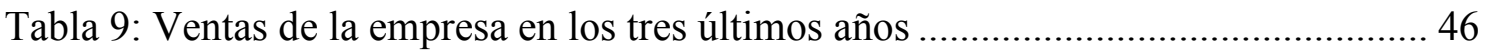

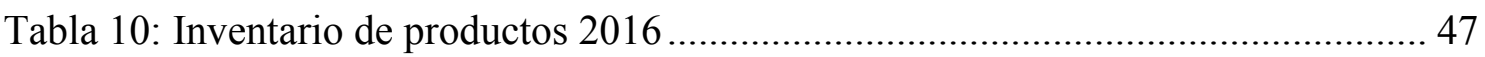

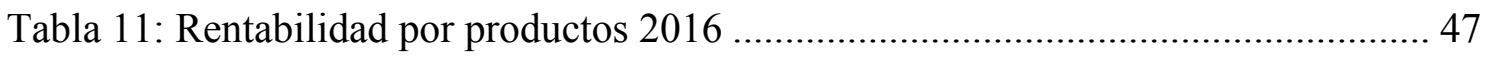

Tabla 11: Comparación Tipo de Producto de acuerdo con su nivel de cumplimiento... 54

Tabla 12: Resultados del Análisis de entregas tardías................................................... 55

Tabla 13: Diagrama de análisis del proceso teñido de telas ......................................... 57

Tabla 14: Comparación de Promedio de tiempos entre los 3 procesos ........................... 58

Tabla 15: Relación de tiempos de proceso y tiempo de espera ..................................... 59

Tabla 16: Relación horas programadas vs horas colas (tiempo de espera) ..................... 59

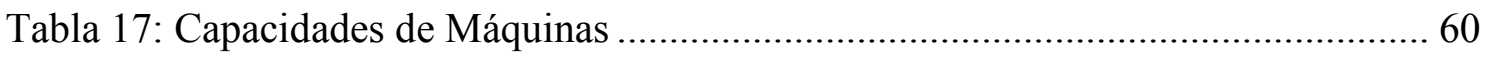

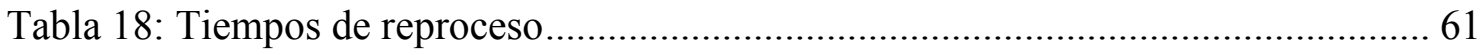

Tabla 19: Horas programadas vs. Horas disponibles .................................................... 61

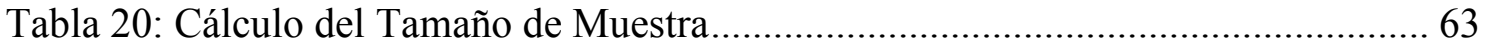

Tabla 21: Procesos y pedidos del tamaño de la muestra ....................................................6 63

Tabla 23: M/M/1- Modelo de colas del proceso de teñido para el proceso de teñido.... 70 
Tabla 22: Distribuciones en el sistema y tiempo en cola ......................................... 71

Tabla 23: Distribución del tiempo en cola para $\mathrm{t}(\mathrm{en}$ días) $>=1$ día ................................. 72

Tabla 24: Distribución del tiempo en cola para $\mathrm{t}(\mathrm{en}$ días) $>=10$ días............................. 72

Tabla 25: Clasificación de porta bobinas de tela......................................................... 75

Tabla 26: Penalidades por entrega fuera de tiempo del tamaño de la muestra................ 77

Tabla 27: Extracto de Tiempos de la muestra del proceso de teñido del equipo Jigger. 78

Tabla 28: Cálculo del Límite Superior del Proceso......................................................... 79

Tabla 29: Cálculo del tiempo de espera en el proceso de teñido del equipo Jigger ....... 79

Tabla 30: Impacto económico por retrasos en el proceso de teñido del equipo Jigger .. 80

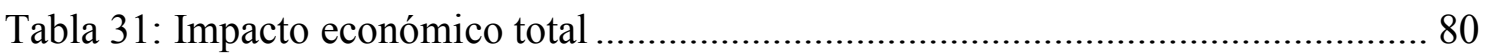

Tabla 32: Variables independientes y dependientes.................................................. 81

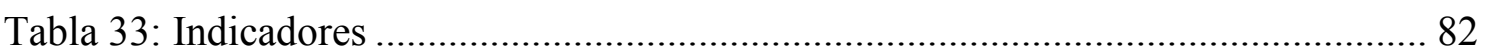

Tabla 35: Relación del problema, objetivo e impacto económico .................................. 85

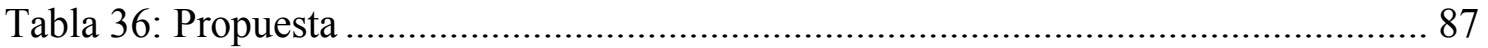

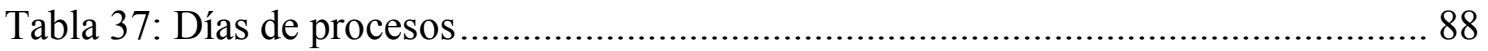

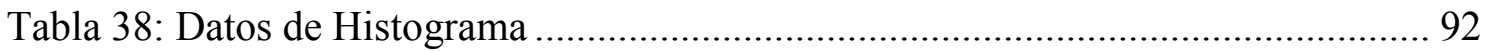

Tabla 39: Control de Orden de Porta bobinas ................................................................. 97

Tabla 40: DAP - Subproceso de Reposo - Mejora 1 ................................................ 100

Tabla 41: DAP - Proceso General de Teñido - Mejora Parte 1 .................................. 103

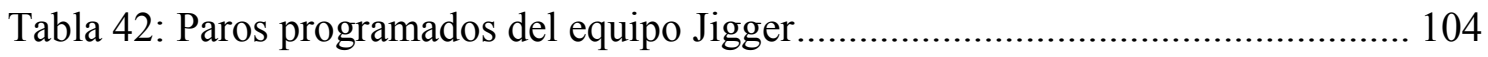

Tabla 43: Extracto de los tiempos de la propuesta de mejora 1 .................................. 107

Tabla 44: Rangos del Histograma del Subproceso de Reposo - Mejora 1.................. 108

Tabla 45: Estadísticas para los tiempos de la propuesta de mejora 1.......................... 109

Tabla 46: Cálculo de horas en exceso del objetivo por proceso - Mejora 1 ................ 110

Tabla 47: Cálculo de ahorros de la propuesta Mejora Parte 1 ..................................... 111

Tabla 48: Cálculo de colas - Propuesta de Mejora 1 ................................................. 112

Tabla 49: Distribución del número en el sistema y del tiempo en cola de la propuesta de

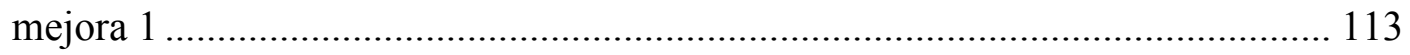

Tabla 50: Distribución del tiempo en cola para $\mathrm{t}(\mathrm{en}$ días) $>=1$ días.............................. 114

Tabla 51: Distribución del tiempo en cola para $t$ (en días) $>=10$ días .......................... 114

Tabla 52: Comparación de bobinas en el sistema Actual vs. Mejora 1....................... 115

Tabla 53: Comparación de distribución del tiempo en cola Actual Vs. Mejora 1 ....... 115

Tabla 54: DAP - Proceso General de Teñido - Mejora Parte 2 .................................. 119

Tabla 55: Extracto de los tiempos de la propuesta de mejora parte2 …....................... 123 
Tabla 56: Estadísticas para los tiempos de la propuesta de mejora 2......................... 123

Tabla 57: Cálculo de horas en exceso del objetivo por proceso - Mejora 2 ................ 125

Tabla 58: Cálculo de ahorros de la propuesta Mejora Parte 2 ..................................... 126

Tabla 59: Cálculo de colas - Propuesta de Mejora 2 ................................................ 127

Tabla 60: Distribución del número en el sistema y del tiempo en cola de la propuesta de

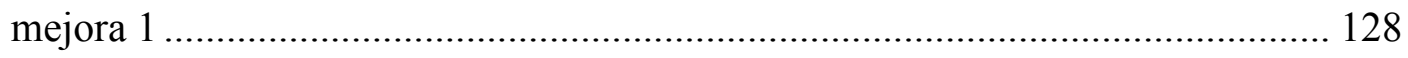

Tabla 61: distribución del tiempo en cola para $\mathrm{t}$ (en días) >=1 días............................ 128

Tabla 62: distribución del tiempo en cola para $\mathrm{t}(\mathrm{en}$ días) $>=10$ días............................. 129

Tabla 63: Comparación de bobinas en el sistema Actual vs. Mejora 2 ....................... 129

Tabla 64: Comparación de distribución del tiempo en cola Actual Vs. Mejora 2 ........ 130

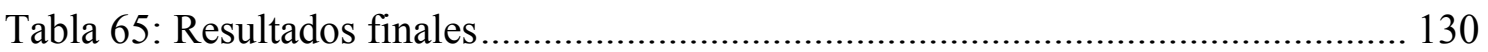

Tabla 66: Indicadores de la Propuesta de Mejora................................................... 131

Tabla 67: Comparación MRPII - Proceso Actual vs. Mejora ....................................... 136

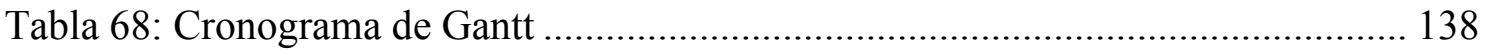

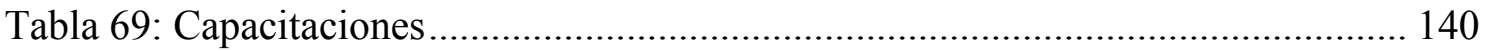

Tabla 70: Inversión de tangibles/Activos ................................................................. 141

Tabla 71: Inversión y Ahorros Total de la implementación de mejora......................... 142

Tabla 72: Distribuciones de los tiempos de las actividades del proceso de teñido actual y

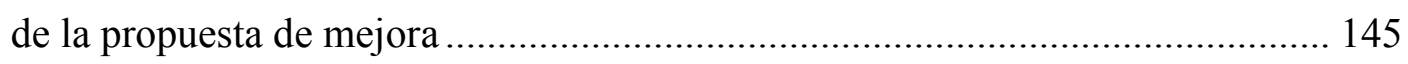

Tabla 73: Resultados de la simulación para los procesos actual y propuesta de mejora.

Tabla 74: Comparación resultados de simulación vs. Cálculos de implementación.... 150

Tabla 75: Cálculo del Costo de Oportunidad .................................................................. 153

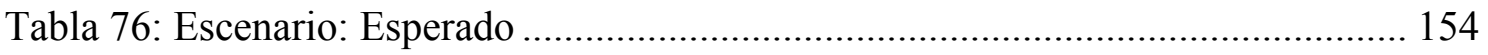

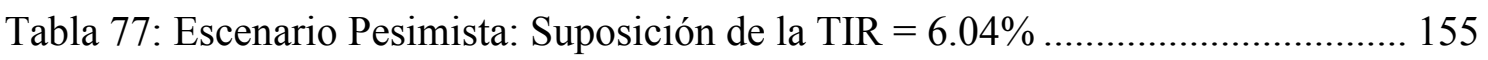

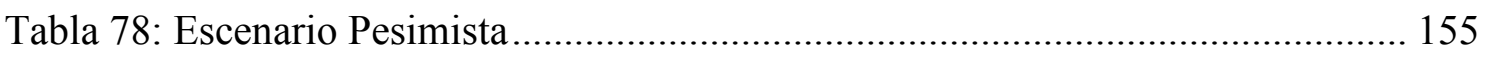

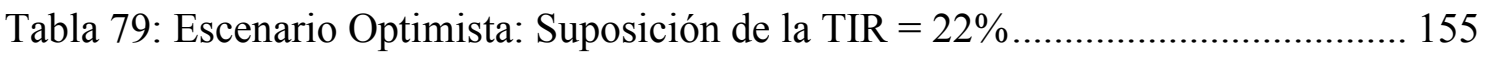

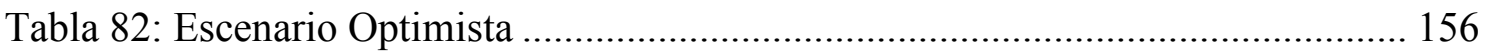




\section{Índice de Figuras}

Figura 1: La cadena de valor textil y de confecciones .................................................. 4

Figura 2: Demanda de productos textiles ................................................................... 5

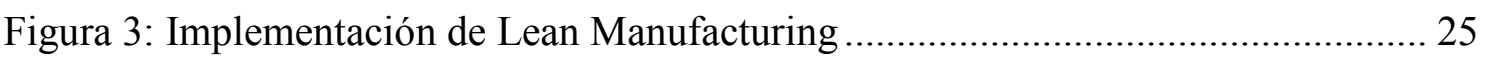

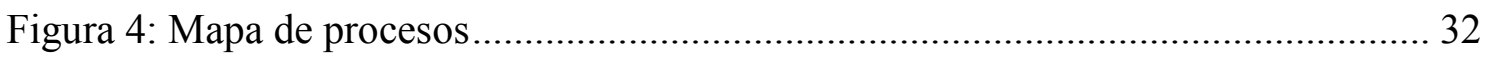

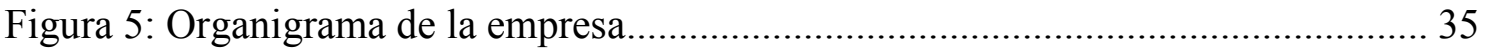

Figura 6: Mapa estratégico de la empresa textil 2016 ................................................. 41

Figura 7: Proceso de producción y productos finales....................................................... 45

Figura 8: Telas Despachos con demoras de entrega vs. Despachos programados a tiempo.

Figura 9: Nivel de cumplimiento de despacho de tela. 49

Figura 10: Tela con Hilo de Color: Despachos con demoras vs. Despachos programados a tiempo 50

Figura 11: Nivel de cumplimiento de despacho de tela con hilo de color. 50

Figura 12: Tela cruda: Despachos con demora vs. Despachos programados a tiempo.. 51

Figura 13: Nivel de cumplimiento de despacho de tela cruda. 51

Figura 14: Tela estampada: Despachos con demoras y despachos programados a tiempo 52

Figura 15: Nivel de cumplimiento de despacho de tela estampada. 52

Figura 16: Tela Teñida: Despachos con demoras vs. Despachos programados a tiempo

Figura 17: Nivel de cumplimiento de despacho de tela teñida..................................... 53

Figura 18: Comparación de Promedio de tiempos entre los 3 procesos.......................... 58

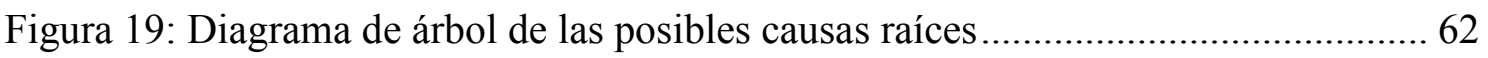




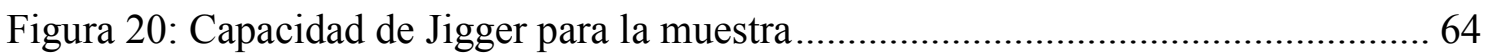

Figura 21: Diagrama de control del proceso de teñido.................................................. 65

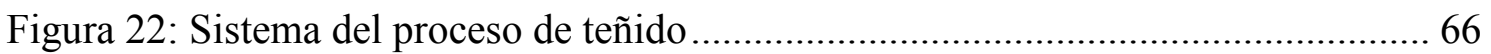

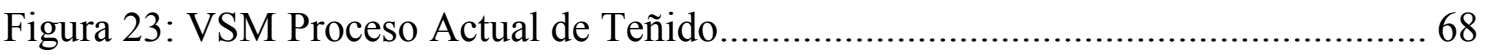

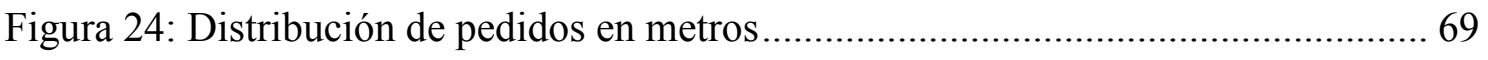

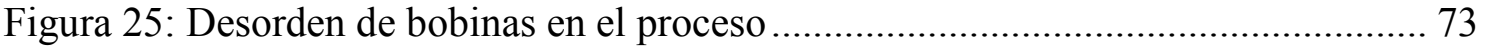

Figura 26: Gráfico: Layout de la planta de producción de teñido de hilos y telas .......... 76

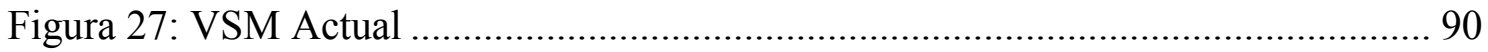

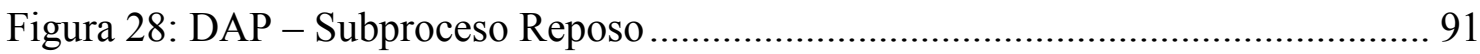

Figura 29: Histograma del subproceso de reposo........................................................... 93

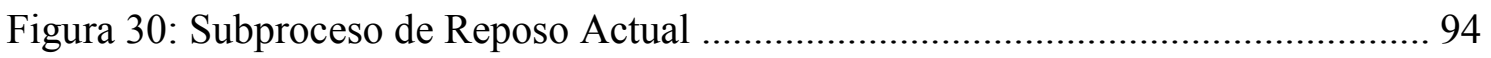

Figura 31: FIFO, ingreso y salida de portabobinas en el proceso de teñido................... 96

Figura 32: Orden de Portabobinas en el proceso de Teñido........................................... 96

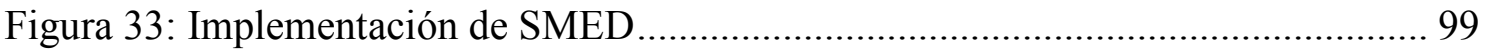

Figura 34: Cálculo de reducción de tiempos de espera en el proceso de teñido por

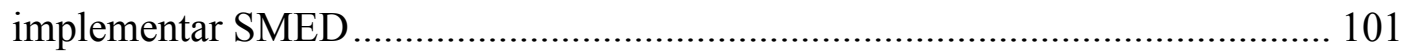

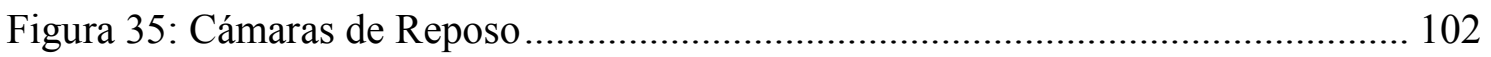

Figura 36: VSM Proceso de Teñido - Mejora Parte 1 ................................................ 105

Figura 37: Cálculo de tiempos para la propuesta de mejora 1 ..................................... 106

Figura 38: Histograma - Subproceso de Reposo - Mejora 1 ..................................... 108

Figura 39: Cálculo de tiempos de la mejora 1 del subproceso de reposo en exceso al

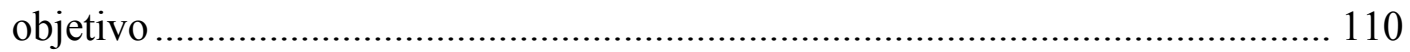

Figura 40: Cálculo de los tiempos de espera para los subprocesos de teñido y revisión

Figura 41: VSM Proceso de Teñido - Mejora Parte 2 ….......................................... 121

Figura 42: Cálculo de tiempos para la propuesta de mejora 2 ................................... 122

Figura 43: Cálculo de tiempos de la mejora 2 del subproceso de reposo en exceso al

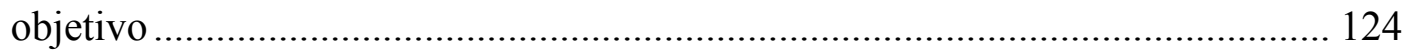

Figura 44: Elaboración de MRPII Proceso actual - Paso 1......................................... 132

Figura 45: Elaboración de MRPII Proceso actual - Paso 2 ........................................ 132

Figura 46: Elaboración de MRPII Proceso actual - Paso 3....................................... 133

Figura 47: Elaboración de MRPII Proceso actual - Paso 4........................................ 134

Figura 48: Elaboración de MRPII Proceso actual - Paso 5 ........................................ 135

Figura 49: Elaboración de MRPII Proceso actual- Paso 6 .......................................... 135 
Figura 50: Elaboración de MRPII Proceso actual - Paso 7

Figura 51: Modelo de simulación del proceso actual de teñido - Operaciones.....

Figura 52: Modelo de simulación del proceso actual de teñido - Tiempos de espera . 146

Figura 53: Modelo de simulación del proceso actual de teñido.....

Figura 54: Modelo de simulación del proceso de mejora de teñido - Operaciones...... 147

Figura 55: Modelo de simulación del proceso actual de teñido - Tiempos de espera . 148

Figura 56: Modelo de simulación del proceso actual de teñido 148

Figura 57: Tasa libre de riesgo 151

Figura 58: Beta no apalancada 152

Figura 59: Prima de Riesgo 153

Figura 60: Riesgo país Perú 


\section{Introducción}

Debido a que los tejidos elaborados por los hombres primitivos no se han podido conservar es imposible identificar la fecha exacta de los orígenes de la hilandería y la textura. Sin embargo, la industria textil fue una de las primeras industrias en desarrollarse. A lo largo de su evolución, la industria textil conoció importantes innovaciones entre las cuales se destaca el teñido de las telas elaboradas a partir de lana y de algodón. En la actualidad, el avance de la tecnología ha ayudado a la industria textil en diferentes aspectos, sobre todo en la necesidad de producir eficientemente. No obstante; en la era de la globalización, la competitividad empresarial es sinónimo de diferenciación, ya que el mercado actual exige respuestas rápidas y cumplimientos en calidad, cantidad y tiempos de entrega. Debido a ello, la implementación de la filosofía de mejora continua ha llegado a ser un factor crucial para las plantas manufactureras, las cuales se encuentran en la búsqueda constante de eficiencia y eficacia en cada uno de sus procesos.

La empresa en estudio es una entidad privada dedicada al diseño, confección y comercialización de telas y prendas de vestir, cuya matriz se encuentra en Lima. Actualmente su proceso productivo de tintorería de telas presenta tiempos improductivos que impide que la organización sea lo suficientemente competitiva a largo plazo en el mercado nacional, razón por la cual la presente investigación aplicada propone una mejora basada en herramientas de ingeniera industrial: MRP II y estandarización de procesos. Asimismo, se presenta una simulación de la propuesta en el proceso de teñido de telas utilizando el software Arena. Finalmente, se presentaran los resultados obtenidos así como una evaluación financiera de la propuesta de mejora. 


\section{CAPÍTULO I: MARCO TEÓRICO Y ESTADO DEL ARTE}

En el presente capítulo se detallará las definiciones básicas necesarias para comprender y sustentar el problema abordado en el presente trabajo de investigación. Asimismo, se presentará información sobre el entorno de la industria y el marco normativo del cual pertenece la empresa en estudio. Además, se planteará el estado del arte, exponiendo a detalle la o las metodologías a utilizar para resolver el problema de investigación planteado. Finalmente, se presentará los casos de éxitos vinculados al problema y al entorno industrial de la empresa en estudio.

\subsection{Cadena de Valor textil y confecciones}

La cadena de valor o cadena productiva está conformada por procesos interconectados, mediante la unión entre producción, transformación y consumo. Las cadenas pueden ser: (a) completas: Todos los componentes y eslabones interactúan. (b) Integrada: El producto final de una cadena se convierte en la materia prima de otra cadena. (c) Incompleta: Los componentes se encuentran identificados, pero no se encuentran relacionados. ${ }^{1}$

Existen dos macro procesos dentro de la cadena de valor que constituye industria manufacturera textil: la industria textil propiamente dicha y la industria de la confección; por lo que de esa forma la cadena textil y de confecciones viene a ser una cadena productiva completa e integral ${ }^{2}$.

La industria textil inicia con la producción materia prima. Las materias primas pueden ser naturales: algodón y lana, artificiales: rayón o sintéticas: poliamidas o poliésteres. En el caso del algodón este se cultiva, desmonta y embala para su comercialización. Los otros insumos pasan por actividades como lavado, cardado y peinado; según sea el caso, hasta obtener una mezcla óptima. Luego se da paso al proceso hilandería el cual consiste en transformar fibras en hilos de características bien definidas, para ello se debe de seguir ciertos parámetros como el grosor, regularidad, resistencia, torsión y flexibilidad. El proceso de tejeduría consiste en transformar la serie de hilos en una superficie uniforme.

\footnotetext{
${ }^{1}$ Cfr. CERVERA, H. M., HERRERA, T. F., \& De La Hoz Granadillo, E. (2011). 19(3), 429-441

${ }^{2}$ Cfr. Instituto De Estudios Económicos Y Sociales De La Sociedad Nacional De Industrias (2016).)
} 
Existen dos tipos de tejeduría: tejido plano y tejido de punto. Finalmente, el acabado textil es un proceso que se realiza para modificar el tacto, apariencia o comportamiento, ya que durante los procesos anteriores las fibras han perdido sus ceras y grasas naturales.

De esa forma se brinda a las telas un aspecto más definido ${ }^{34}$.

La industria de confecciones inicia con el diseño y desarrollo del producto, la cual tiene como fin convertir los requisitos de los clientes en especificaciones técnicas, para luego ser empleados en diferentes procesos de confección. Asimismo, el diseño del producto es clave dentro de la cadena de valor, debido a que, en estos tiempos de globalización y cambios significativos, la productividad del proceso de confecciones toma mayor relevancia para todo tipo de organización empresarial. Por su parte, el proceso de confección se efectúa el armado de la indumentaria, la cual une las piezas previamente cortadas. El acabado es el proceso adicional, en el cual se realizan actividades tales como bordados, teñidos, estampados y tratamientos especiales solicitados por el cliente en la orden de producción. ${ }^{5}$

\footnotetext{
${ }^{3}$ Cfr. CERVERA, H. M., HERRERA, T. F., \& De La Hoz Granadillo, E. (2011). 19(3), 429-441

${ }^{4}$ Cfr. Instituto De Estudios Económicos Y Sociales De La Sociedad Nacional De Industrias (2016).)

${ }^{5}$ Cfr. PADILLA, Ernesto (2013).
} 
Figura 1: La cadena de valor textil y de confecciones

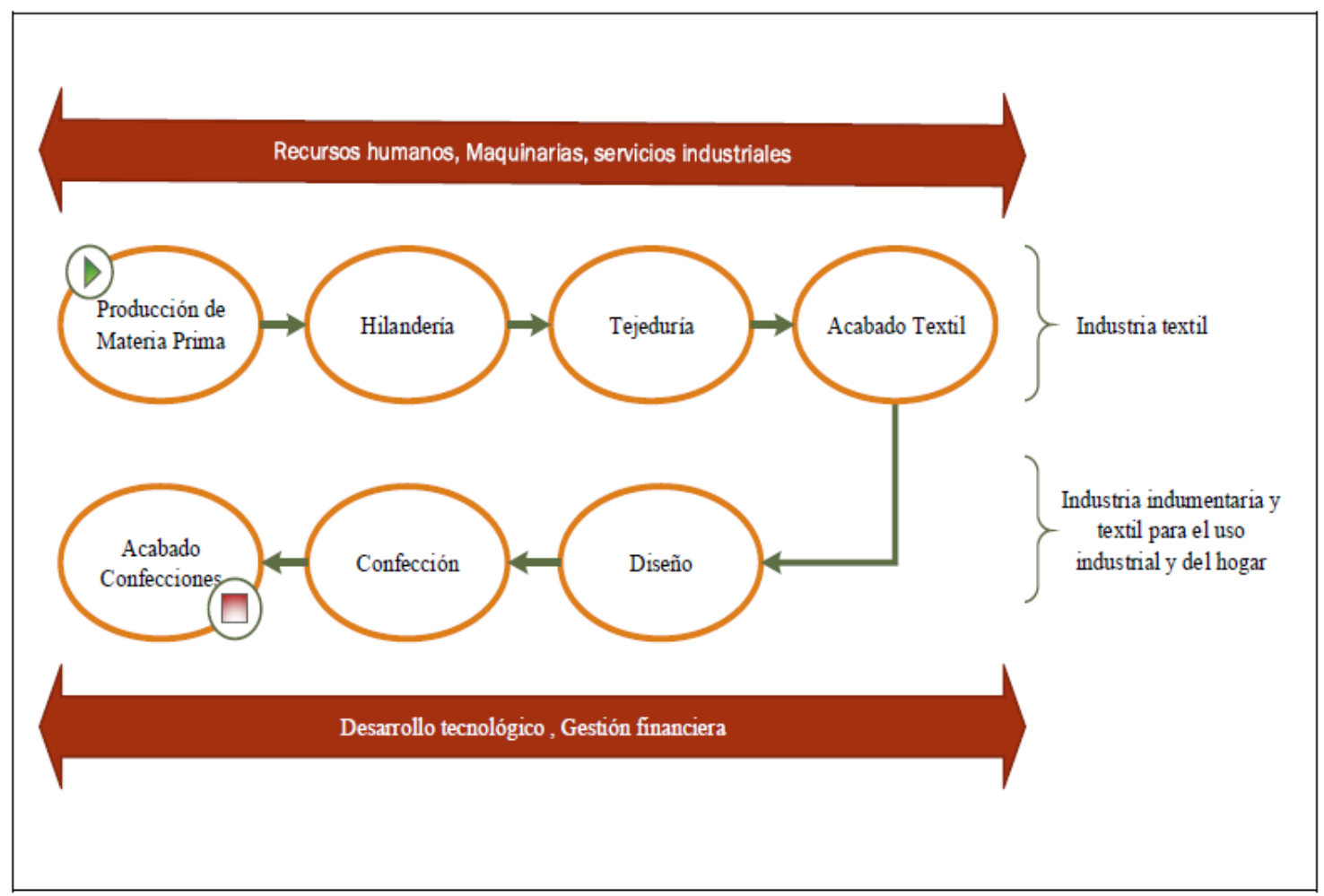

Elaboración propia adaptado de Cervera, H. M., Herrera, T. F., \& De La Hoz Granadillo, E. (2011). Instituto De Estudios Económicos Y Sociales De La Sociedad Nacional De Industrias (2016). Padilla, Ernesto (2013).

\subsection{Entorno de la Industria Textil y Confecciones}

Hoy por hoy la industria peruana se encuentra atravesando por una situación difícil y crucial, ya que el PBI Industrial en los últimos años sigue en una caída constante. De la misma manera la producción de textiles ha mostrado una tendencia decreciente durante los últimos 4 años. Aun así, la industria textil confecciones se caracteriza por tener un rol estratégico para el desarrollo de la economía nacional. Actualmente, la industria en mención aporta el $10 \%$ del Producto Bruto Interno del sector manufacturero, generando más de 400,000 puestos de trabajo directo ${ }^{6}$

A nivel internacional, los países como Alemania, Estados Unidos y China lideran la producción de la industria de textiles, y por el lado de Perú, la balanza comercial de la industria textil lo posiciona como un país importador neto, ya que, en el 2015, el monto exportado fue de US\$ 464 millones, mientras las importaciones sumaron un total de US\$ 1153 millones de dólares. Entre los principales países de destino se encuentran: Ecuador (18\%), Chile (13\%), Colombia (10\%), Bolivia (9\%) y Brasil (8\%); mientas lo que respeta

\footnotetext{
${ }^{6}$ Cfr. Instituto De Estudios Económicos Y Sociales De La Sociedad Nacional De Industrias (2016).)
} 
a las importaciones los países a quienes compramos más son China (37\%), Estados Unidos (22\%), India (21\%) y en menor medida Brasil, Indonesia y Colombia cada uno con el $2 \%{ }^{7}$

Por otro lado, la industria textil genera demanda a otros sectores, tales como el agrícola (Cultivos de algodón), el ganadero (Obtención de pelos finos y lanas), industria del plástico (Obtención de botones, cierres, entre otros) y la industria química (uso de insumos) ${ }^{8}$

Respecto a la demanda de productos textiles, el $87 \%$ de estos se consumen en el mercado interno (El 74.3\% como demanda interna y el 13.1\% como demanda final), mientras el $12.5 \%$ de los productos textiles es demandado por el mercado externo. ${ }^{9}$

Figura 2: Demanda de productos textiles

\section{Demanda Externa \\ (Exportaciones)}

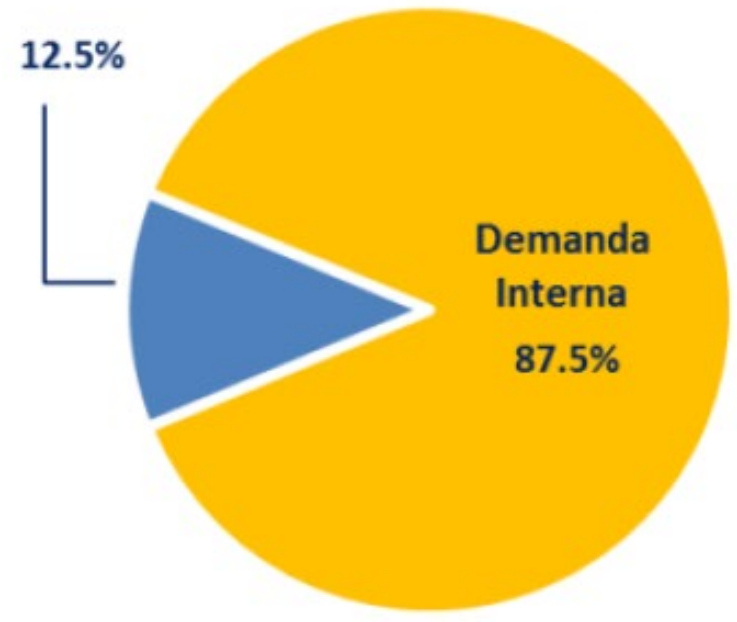

Fuente: INEI

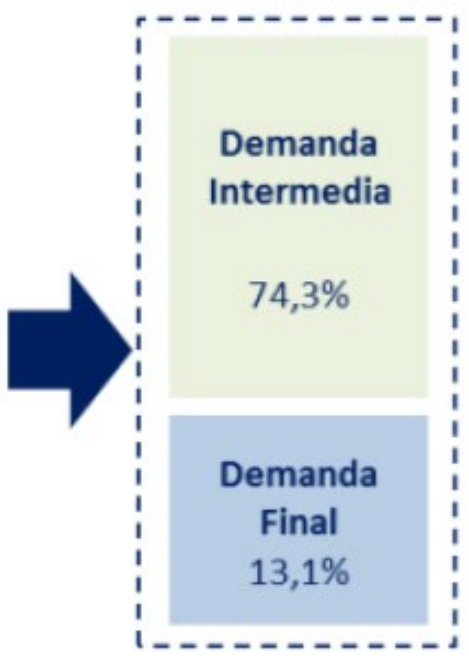

Elaboración: IEES - SNI

Fuente: Instituto De Estudios Económicos Y Sociales De La Sociedad Nacional De Industrias (2016)

\footnotetext{
${ }^{7}$ Cfr. Instituto De Estudios Económicos Y Sociales De La Sociedad Nacional De Industrias (2016).)

${ }^{8}$ Cfr. Instituto De Estudios Económicos Y Sociales De La Sociedad Nacional De Industrias (2016).)

${ }^{9}$ Cfr. Instituto De Estudios Económicos Y Sociales De La Sociedad Nacional De Industrias (2016).)
} 


\subsection{Clasificación CIIU de las empresas del rubro textil y confecciones}

La organización de las Naciones Unidas -ONU- tiene la Clasificación Internacional Uniforme CIIU revisión 4, que ubica a la actividad económica de textil y de confecciones dentro de la sección industria manufacturera. Esta sección abarca la transformación física o química de materiales, sustancias o componentes en productos nuevos. Asimismo, la actividad textil y de confecciones se divide en dos grupos, la división 13: fabricación de productos textiles y la división 14: Fabricación de prendas de vestir. La división 13 está compuesta por dos grupos y ocho clases de actividades que comprende la preparación e hilatura de fibras textiles y la tejedura y el acabado de productos textiles y prendas de vestir, así como la fabricación de artículos confeccionados de materias textiles, excepto prendas de vestir (ropa de casa, frazadas, alfombras, cuerdas, etcétera). Por otra parte, la división 14 cuenta con tres grupos, tres clases y alcanza todas las actividades de confección (prêt-à-porter, a medida), en todo tipo de materiales (cuero, tela, tejidos de punto y ganchillo, etcétera), de todo tipo de prendas de vestir (ropa exterior e interior para hombres, mujeres y niños, ropa de trabajo, ropa formal y deportiva, etcétera) y accesorios.

Igualmente, la división 14 abarca la industria peletera (producción de pieles y fabricación de prendas de vestir de piel). ${ }^{10}$

${ }^{10}$ Cfr. Instituto De Estudios Económicos Y Sociales De La Sociedad Nacional De Industrias (2016).) 
Tabla 1: Clasificación de empresas del rubro textil y confeccione según CIIU, revisión 4

\begin{tabular}{|c|c|}
\hline 13 & Fabricación de Productos Textiles \\
\hline 131 & Hilatura, Tejedura y acabado de productos textiles \\
\hline 1311 & Preparación e hilatura de fibras textiles \\
\hline 1312 & Tejedura de productos textiles \\
\hline 1313 & Acabado de productos textiles \\
\hline 139 & Fabricación de otros productos textiles \\
\hline 1391 & Fabricación de tejidos de punto y ganchillo \\
\hline 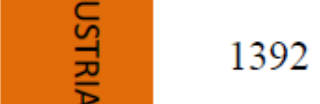 & $\begin{array}{l}\text { Fabricación de artículos confeccionados de materiales } \\
\text { textiles, excepto prendas de vestir }\end{array}$ \\
\hline 1393 & Fabricación de tapices y alfombras \\
\hline 1394 & Fabricación de cuerdas, cordeles, bramantes y redes \\
\hline 1399 & Fabricación de otros productos textiles n.c.p. \\
\hline 14 & $\underline{\text { Fabricación de prendas de vestir }}$ \\
\hline 141 & Fabricación de prendas de vestir, excepto prendas de piel \\
\hline 1410 & Fabricación de prendas de vestir, excepto prendas de piel \\
\hline 142 & Fabricación de artículos de piel \\
\hline 1420 & Fabricación de artículos de piel \\
\hline 143 & Fabricación de artículos de punto y ganchillo \\
\hline 1430 & Fabricación de artículos \\
\hline
\end{tabular}

Fuente: Elaboración propia con datos de [2]

\subsection{Análisis Normativo}

\subsubsection{Clasificación de las empresas en el Perú}

El Estado Peruano, con la finalidad de incentivar la inversión, impulsar el desarrollo productivo y el crecimiento empresarial cambio la cantidad de parámetros para categorizar a una empresa a solo uno: Ventas totales. De acuerdo a la ley $\mathrm{N}^{\circ} 30056$, promulgada el mes de junio del 2013, para determinar si una empresa es micro, pequeña, mediana o gran empresa solo basta determinar el valor de sus ventas expresado en 
Unidades Impositivas Tributarias (UIT) ${ }^{11}$. Actualmente, una UIT tiene el valor de S/. 4, 050 nuevos soles 1 .

Tabla 2: Clasificación de empresas en el Perú

\begin{tabular}{|l|l|l|l|}
\hline \multicolumn{1}{|c|}{$\begin{array}{c}\text { Estrato } \\
\text { empresarial }\end{array}$} & \multicolumn{1}{|c|}{ Sunat (2011) } & \multicolumn{1}{c|}{ Ley 30056 (2013) } \\
\cline { 2 - 4 } & $\begin{array}{c}\text { Número de } \\
\text { empleados }\end{array}$ & $\begin{array}{c}\text { Ventas anuales ( en } \\
\text { UIT ) }\end{array}$ & $\begin{array}{c}\text { Ventas anuales ( en } \\
\text { UIT ) }\end{array}$ \\
\hline Micro empresa & 1 a 10 & Hasta 150 & Hasta 150 \\
\hline Pequeña empresa & 11 a 100 & $\begin{array}{l}\text { Mayor a 150 y hasta } \\
1700\end{array}$ & $\begin{array}{l}\text { Mayor a 150 y hasta } \\
1700\end{array}$ \\
\hline Mediana empresa & 101 a 250 & $\begin{array}{l}\text { Mayor a 1700 y hasta } \\
2300\end{array}$ & $\begin{array}{l}\text { Mayor a 1700 y hasta } \\
2300\end{array}$ \\
\hline Gran Empresa & 251 a más & Mayor a 2300 & Mayor a 2300 \\
\hline
\end{tabular}

Fuente: Elaboración propia adaptado de Dirección General de Estudios Económicos, Evaluación y Competitividad Territorial Del Viceministerio de Mype E Industria. Ministerio de la Producción (2017)

\subsubsection{Distribución de las empresas según tipo de contribuyente}

Clasificación de las empresas en el Perú Las organizaciones empresariales se han clasificado tomando como base la Ley N²6887 “Ley General de Sociedades". Por consiguiente, una empresa puede estar constituida legalmente como persona natural o jurídica. En el caso de constituir una empresa como persona natural, el individuo ejerce los derechos y obligaciones, así como la responsabilidad de las deudas de la empresa; en cambio cuando una empresa es constituida como persona jurídica es la empresa quien asume los derechos, obligaciones.

Asimismo, una empresa establecida como persona natural está formada por solo una persona y no requiere demostrar de capital de trabajo para comenzar su actividad económica. Sin embargo, una empresa jurídica puede tener una o más personas y necesita acreditar los recursos económicos para su constitución. Finalmente, una empresa formada como persona natural funciona solo bajo ese término, en contraste una empresa jurídica puede desarrollarse como Sociedad anónima cerrada, Empresa individual con responsabilidad limitada, Sociedad comercial de responsabilidad limitada, Sociedad anónima abierta, Sociedad irregular, Sociedad civil, Sociedad conyugal, Sucesión Indivisa, sociedad en comandita simple, sociedad colectiva univers. centro educat y cult., comunidad campesina nativa comunal, cooperativas Sais. Caps, empresa de propiedad

11 Cfr. Dirección General De Estudios Económicos, Evaluación Y Competitividad Territorial Del Viceministerio De Mype E Industria. Ministerio De La Producción (2017) 
social, sociedad en comandita por acciones y sociedad minera de responsabilidad limitada.

\subsubsection{Decreto Ley $\mathrm{N}^{\circ} 22342$ Promoción de las exportaciones No tradicionales}

De acuerdo con el decreto $\mathrm{N}^{\circ}$ 22342, las empresas exportadoras de productos no tradicionales cuentan con la posibilidad de contratar de forma permanente, pero como si fuera "Ocasional o eventual", la mencionada ley fue creada con el fin de incentivar la exportación no tradicional y promover el empleo formal. La normativa ofrece beneficios para los empresarios, tales como el reintegro tributario compensatorio, una depreciación especial de los bienes activos de la empresa, exoneración de impuestos a la renta por capitalización de utilidades invertidas y beneficios laborales. En otras palabras, las empresas del sector exportador textil tienen el beneficio de contratar "Temporalmente" una indeterminada cantidad de trabajadores por un plazo indefinido, habiendo de esa forma personas que trabajan bajo esa modalidad por más de 5, 10 hasta 20 años ${ }^{12}$.

\subsection{Marco Teórico: Metodologías y herramientas de análisis para la definición del problema}

\subsubsection{MRP II - Manufacturing Resources Planning - Planeamiento de Recursos de Fabricación}

Los sistemas de planificación de producción populares y ampliamente utilizados, como la planificación de recursos de fabricación (MRPII), requieren tener la parte correcta, en el lugar correcto, en el momento adecuado y en la cantidad adecuada a un costo mínimo. Desafortunadamente, el razonamiento fundamental de esos sistemas es defectuoso. En otras palabras, la programación de producción de partes, componentes, subconjuntos, elementos finales se basa en tiempos de entrega fijos con capacidad infinita y lógica de programación. ${ }^{13}$

Dado que la función de planificación de necesidades de materiales (MRP) de los sistemas MRPII no puede proporcionar planes de producción factibles, esto inevitablemente causa serios problemas en planta, como cargas de trabajo variables, cambios de cuellos de

\footnotetext{
${ }^{12}$ Cfr. Lescano, Yonny (2012).

${ }^{13}$ Cfr. Öztürk, C., \& Ornek, A. M. (2014). 38(1), 181-195.
} 
botella, altos niveles de trabajo en proceso (WIP), menor utilización de la máquina, menos rendimiento, entregas tardías que no se pueden resolver fácilmente a corto plazo. Es decir, MRPII no puede evitar que ocurran problemas de capacidad en planta. Por lo tanto, esto lleva a la conclusión de que los problemas de capacidad deben ser resueltos y prevenidos en los niveles superiores como un modelo de optimización. Sin lugar a duda, el MRP y la programación de producción está estrechamente relacionada, y deben integrarse para generar cronogramas de producción realistas para la planta, lo que lleva al problema de la planificación y programación avanzada con un modelo de optimización. ${ }^{14}$

Sin embargo, la planificación de recursos de fabricación (MRPII) es el método de planificación más extendido en el mundo. MRP y luego MRPII se desarrollaron en la década de 1970. Requiere pronósticos de demanda y planifica todas las actividades de fabricación: es un método de flujo de empuje. MRPII es "un método para la planificación eficaz de todos los recursos de una empresa de fabricación. Lo ideal sería abordar la planificación operativa en unidades, la planificación financiera en dólares, y tiene una capacidad de simulación para responder preguntas que suponen. Se compone de una variedad de procesos, cada uno vinculado: planificación comercial, planificación de producción (planificación de ventas $\mathrm{y}$ operaciones), programación maestra de producción, planificación de necesidades de materiales (MRP), planificación de necesidades de capacidad y soporte de ejecución. sistemas de capacidad y material. ${ }^{15}$ La planificación de recursos de fabricación es una consecuencia directa y una extensión de MRP de circuito cerrado. El comportamiento general del mercado ha evolucionado en los últimos 30 años generando más inestabilidades de la demanda, de los suministros y de los procesos internos. Estas variabilidades resultan en la creación de más dificultades para establecer pronósticos precisos, generando nerviosismo en el comportamiento de MRP, lo que es una fuente de efecto de látigo, ya que la demanda depende de la comercialización de la empresa. ${ }^{16}$

\subsubsection{Relación MRPII y Herramientas de Lean Manufacturing}

Los autores Ocampo, Hernández-Matías, y Vizán, (2017), en su investigación llamada "A method for estimating the influence of advanced manufacturing tools on the manufacturing competitiveness of Maquiladoras in the apparel industry in Central

\footnotetext{
${ }^{14}$ Cfr. Öztürk, C., \& Ornek, A. M. (2014). 38(1), 181-195.

${ }^{15}$ Cfr. Miclo, R., Fontanili, F., Lauras, M., Lamothe, J., \& Milian, B. (2016). 49(12), 1725-1730.

${ }^{16}$ Cfr. Miclo, R., Fontanili, F., Lauras, M., Lamothe, J., \& Milian, B. (2016). 49(12), 1725-1730.
} 
America" consideran al MRP II como una gestión de procesos, procesos que se mejoran con las herramientas de la Filosofía Lean como VSM y SMED, como se muestra a continuación (tabla

Tabla 3: Herramientas avanzadas de Manufactura o Fábrica.

\begin{tabular}{|c|c|c|c|}
\hline $\begin{array}{l}\text { Advanced Manufacturing Tools (tec } \\
\text { Design and Engineering }\end{array}$ & $\begin{array}{l}\text { hnologies and methodologies) } \\
\text { Management }\end{array}$ & Automated Manufacturing & Process Improvement \\
\hline $\begin{array}{l}\text { CAD (Computer Aided Design) } \\
\text { CAM (Computer Aided } \\
\text { Manufacturing) } \\
\text { CAE (Computer Aided } \\
\text { Engineering) } \\
\text { CAPP (Computer Aided Process } \\
\text { Planning) } \\
\text { PLM (Product Lifecycle } \\
\text { Management) } \\
\text { Concurrent Engineering } \\
\text { FMEA (Failure Mode and Effects } \\
\text { Analysis) } \\
\text { DOE (Design of Experiments) }\end{array}$ & $\begin{array}{l}\text { ERP(Enterprise Resource Planning) } \\
\text { - MRP (Material Requirement } \\
\text { Planning } \\
\text { - MRP II (Manufacturing Resource } \\
\text { Planning) } \\
\text { MES (Manufacturing Execution } \\
\text { Systems) } \\
\text { - Preventive maintenance } \\
\text { - Quality management } \\
\text { - Inventory management } \\
\text { - Supervisory control } \\
\text { - Productivity analysis } \\
\text { SCM (Supply Chain Management) } \\
\text { CRM (Customer Relationship } \\
\text { Management) }\end{array}$ & $\begin{array}{l}\text { CNC (Computer Numerical Control) } \\
\text { PLC (Programmable Logic Controllers) } \\
\text { FMS (Flexible Manufacturing Systems) } \\
\text { AGV (Automatic Guided Vehicles) } \\
\text { ASRS (Automatic Storage and Retrieval Systems) } \\
\text { Robots } \\
\text { Automatic Quality Inspection (machine vision, } \\
\text { sensors, etc.) } \\
\text { Bar code/RFID Systems }\end{array}$ & $\begin{array}{l}\text { SPC (Statistical Process Control) } \\
\text { - Control charts } \\
\text { - Process capability (Cp, Cpk, etc.) } \\
\text { TQM (Total Quality Management) } \\
\text { - Ishikawa diagram } \\
\text { - Pareto diagram } \\
\text { - Flow diagram } \\
\text { - Brainstorming } \\
\text { - Focus groups } \\
\text { - Scatter plots } \\
\text { - Pie chart and histogram } \\
\text { Jidoka (Error detection autonomation) } \\
\text { DMAIC (Define, Measure, Analyze, } \\
\text { Improve, Control) } \\
\text { VSM (Value Stream Mapping) } \\
\text { ANDON (warning signs or alarms) } \\
\text { TPM (Total Productive Maintenance) } \\
\text { Methods Engineering (ATM, TMM) } \\
\text { JIT } \\
\text { - Kaizen events - Cellular flow } \\
\text { - Kanban (pull system) - Visual controls } \\
\text { - SOP (standardization) - 5-S } \\
\text { - SMED (Single Minute Exchange Die) }\end{array}$ \\
\hline
\end{tabular}

Fuente: Ocampo, J. R., Hernández-Matías, J. C., \& Vizán, A. (2017). 87, 31-51.

En la tabla precedente se muestra a las herramientas de la filosofía Lean como las herramientas que mejoran el proceso al identificar los despilfarros de ellos, eliminándolos o reduciéndolos bajo una metodología de gestión de procesos como MRPII.

Asimismo, los autores, Goyal, A., \& Agrawal, R. (2017) en su investigación llamado “Advanced Manufacturing Management System for Environmental Sustainability” y relacionan directamente la herramienta SMED directamente con el MRPII, como se muestra a continuación: 
Tabla 4: Técnicas de Fabricación

\begin{tabular}{|l|l|}
\hline Managerial system & Technologies \\
\hline Value stream mapping & Computer aided design (CAD) \\
\hline Plant certification & Local area networks \\
\hline SMED & MRP, MRP-II AND ERP \\
\hline Poka-Yoke & Rapid prototyping system (Additive manufacturing) \\
\hline TQM & Concurrent engineering \\
\hline TPM & Computer integrated manufacturing (CIM) \\
\hline 5-S & Automated guided vehicles \\
\hline Cellular manufacturing & Automatic material handling system (AMHS) \\
\hline Just in Time (JIT) & Robots \\
\hline Six sigma & Computer driven material handling \\
\hline & Flexible manufacturing system (FMS) \\
\hline
\end{tabular}

Fuente: Goyal, A., \& Agrawal, R. (2017). 496-504

En la tabla precedente, se muestra que el sistema del proceso es SMED con la tecnología MRPII, ya que los autores lo observan desde el punto de vista un activo o componente elaborado como programa o aplicación interconectado con las bases de datos de una organización.

\subsubsection{Investigación de Operaciones}

Investigación de Operaciones (OR por sus siglas en inglés Operations Research) aplica un método científico a la administración de sistemas organizados en negocios, industria, gobierno y otras empresas. O se aplica regularmente en áreas tales como: gestión de la cadena de suministro, sistemas de comercialización y gestión de ingresos, plantas de fabricación, Ingeniería financiera, redes de telecomunicación, administración de salubridad, redes de transporte, energía y el medio ambiente, sistemas de servicio, comercio web, defensa militar, entre otros. ${ }^{17}$

Los autores Settanni, E., Harrington, T. S., \& Srai, J. S. (2017), indican que típicamente, las aplicaciones de la investigación de operaciones en estas y otras áreas se ocupan de las decisiones involucradas en la planificación de la asignación eficiente de recursos escasos, como material, trabajadores calificados, máquinas, dinero y tiempo, para alcanzar las metas y objetivos establecidos en condiciones de incertidumbre y durante un lapso de tiempo. La asignación eficiente de recursos puede implicar establecer políticas, diseñar procesos o reubicar activos. Los analistas resuelven tales problemas de decisión de gestión con una variedad de metodologías matemáticas. Como el objetivo de esta

\footnotetext{
${ }^{17}$ Cfr. Settanni, E., Harrington, T. S., \& Srai, J. S. (2017). 4, 74-95.
} 
investigación es el modelado, es necesario definir qué se entiende por 'modelo' en este contexto. ${ }^{18}$

En campos como Investigación de Operaciones (OR), el analista construye una imagen mental de una situación problemática a menudo se descuida. El analista desarrolla tal imagen mediante un acto de apreciación a partir de las percepciones no organizadas adquiridas mediante la observación, y procede de dicha imagen para representar formalmente la situación en términos simbólicos. Haciendo referencia a los sistemas industriales, se indica que los modelos representan solo lo que el analista cree que es la naturaleza del sistema que se estudia, y cada modelo finalmente se configura mediante una clase específica de preguntas sobre dichos sistemas. ${ }^{19}$

\subsubsection{Tiempo de Espera}

El tiempo promedio de espera se refiere a la cantidad de tiempo que un proceso debe esperar antes de que se procese el pedido, por cola o se configure la máquina. El tiempo de espera afecta tanto al cliente como al fabricante. En una configuración de fabricación, no todos los pedidos se procesan de inmediato. Muchas veces las máquinas deben configurarse para trabajos específicos antes de que se puedan ejecutar las órdenes y las piezas personalizadas deben pedirse a proveedores externos. Esta cantidad de tiempo entre el momento en que el cliente hace un pedido y cuando la fabricación realmente produce el producto a menudo se denomina tiempo de espera. ${ }^{20}$

La administración intenta disminuir el tiempo de espera tanto como sea posible, ya que los clientes generalmente quieren sus pedidos lo antes posible. Algunos clientes no están dispuestos a esperar y en realidad comprarán a otro proveedor en lugar de esperar. Aunque los fabricantes intentan minimizar los tiempos de espera de producción tanto como sea posible, siempre habrá un elemento de tiempo de espera en la producción. ${ }^{21}$

Por ejemplo, el tiempo de espera promedio es simplemente el promedio de todos los tiempos de espera en una categoría de producto. Por ejemplo, un fabricante de relojes personalizados puede tener un tiempo de espera que oscila entre 5 días y 10 días para un reloj modelo A dependiendo de las opciones. El tiempo promedio de espera para el reloj del modelo A es de 7.5 días. Algunos fabricantes que están atrasados con los pedidos cobran una tarifa acelerada para los clientes que quieren que sus productos se fabriquen

\footnotetext{
${ }^{18}$ Cfr. Settanni, E., Harrington, T. S., \& Srai, J. S. (2017). 4, 74-95.

${ }^{19}$ Cfr. Settanni, E., Harrington, T. S., \& Srai, J. S. (2017). 4, 74-95.

${ }^{20}$ Cfr. Lv, L., Ren, F. Y., Wang, J., \& Xiao, J. (2015). 422, 101-106.

${ }^{21}$ Cfr. Lv, L., Ren, F. Y., Wang, J., \& Xiao, J. (2015). 422, 101-106.
} 
primero. No todos los clientes están dispuestos a pagar una tarifa adicional como esta, pero les permite a algunos clientes evitar el problema del tiempo de espera promedio. ${ }^{22}$

\subsubsection{Teoría de Colas}

La teoría de colas se ocupa de problemas que implican cola (o espera). Ejemplos típicos podrían ser: ${ }^{23}$

- bancos / supermercados - esperando servicio

- computadoras - esperando una respuesta

- $\quad$ situaciones de falla - esperando a que no ocurra, p. en una pieza de maquinaria

- transporte público - esperando un tren o un autobús

Las colas son una experiencia común de todos los días. Las colas se forman porque los recursos son limitados. De hecho, tiene sentido económico tener colas. Por ejemplo, ¿cuántos supermercados necesita para evitar hacer cola? ¿Cuántos autobuses o trenes serían necesarios si se evitaran o eliminaran las colas? Al diseñar sistemas de colas, debemos buscar un equilibrio entre el servicio a los clientes (colas cortas que implican muchos servidores) y consideraciones económicas (no demasiados servidores). ${ }^{24}$

En esencia, todos los sistemas de colas pueden dividirse en subsistemas individuales formados por entidades que hacen cola para alguna actividad (como se muestra a continuación). Por lo general, podemos hablar de este subsistema individual como tratar con clientes que hacen cola para el servicio. Para analizar este subsistema, se requiere la información relacionada $\operatorname{con}^{25}$ :

\section{Proceso de llegada:}

Cómo llegan los clientes, p. individualmente o en grupos (llegadas por lotes o en bloque) cómo se distribuyen las llegadas a tiempo (por ejemplo, cuál es la distribución de probabilidad de tiempo entre las llegadas sucesivas (la distribución de tiempo entre llegadas))

Si hay una población finita de clientes o (efectivamente) un número infinito

\footnotetext{
${ }^{22}$ Cfr. Lv, L., Ren, F. Y., Wang, J., \& Xiao, J. (2015). 422, 101-106.

${ }^{23}$ Cfr. Tanaka, M., Yanagisawa, D., \& Nishinari, K. (2018). 490, 1481-1492.

${ }^{24}$ Cfr. Boucher, J. P., \& Couture-Piché, G. (2015). 64, 67-76.

${ }^{25}$ Cfr. Jin, W. L. (2015). 77, 1-16.
} 
El proceso de llegada más simple es aquel en el que tenemos llegadas completamente regulares (es decir, el mismo intervalo de tiempo constante entre las llegadas sucesivas). Una corriente de llegadas de Poisson corresponde a las llegadas al azar. En una corriente de Poisson, los clientes sucesivos llegan después de intervalos que de forma independiente se distribuyen exponencialmente. El flujo de Poisson es importante ya que es un modelo matemático conveniente de muchos sistemas de colas de la vida real y se describe mediante un único parámetro: la tasa de llegada promedio. Otros procesos de llegada importantes son llegadas programadas; llegadas por lotes; y tasas de llegada dependientes del tiempo (es decir, la tasa de llegada varía de acuerdo con la hora del día).

\section{Mecanismo de servicio: ${ }^{26}$}

- Una descripción de los recursos necesarios para que el servicio comience

- Cuánto durará el servicio (la distribución del tiempo del servicio)

- La cantidad de servidores disponibles

- Si los servidores están en serie (cada servidor tiene una cola separada) o en paralelo (una cola para todos los servidores)

- Si se permite la preferencia (un servidor puede dejar de procesar a un cliente para tratar con otro cliente de "emergencia")

Asumir que los tiempos de servicio para los clientes son independientes y no dependen del proceso de llegada es común. Otra suposición común sobre los tiempos de servicio es que están distribuidos exponencialmente.

\section{Características de cola: ${ }^{27}$}

Cómo, del conjunto de clientes que esperan el servicio, elegimos el que se servirá a continuación (por ejemplo, FIFO (primero en entrar, primero en salir), también conocido como FCFS (primero en ser atendido), LIFO (último en entrar primero en salir); al azar) (esto a menudo se denomina disciplina de cola) tenemos:

- Rechazo (los clientes deciden no unirse a la cola si es demasiado larga)

\footnotetext{
${ }^{26}$ Cfr. Akdogan, M. A., Bayındır, Z. P., \& Iyigun, C. (201722, 430-439.

${ }^{27}$ Cfr. Jin, W. L. (2015). 77, 1-16.
} 
- renegociar (los clientes abandonan la cola si han esperado demasiado tiempo por el servicio)

- maniobras (los clientes cambian de cola si creen que les servirán más rápido al hacerlo)

- una cola de capacidad finita o (efectivamente) de capacidad infinita

Cambiar la disciplina de cola (la regla por la cual seleccionamos al próximo cliente que se servirá) a menudo puede reducir la congestión. A menudo, la disciplina de cola "elige al cliente con el menor tiempo de servicio" da como resultado el valor más pequeño para el tiempo (en promedio) que un cliente gasta en la cola.

Aquí se debe tener en cuenta que la integral a las situaciones de colas es la idea de incertidumbre en, por ejemplo, tiempos entre llegadas y tiempos de servicio. Esto significa que la probabilidad y las estadísticas son necesarias para analizar situaciones de espera.

\subsubsection{Modelo de Optimización}

Los algoritmos de optimización que hemos discutido hasta ahora son problemas sin restricciones. Las siguientes tres secciones tratan problemas limitados. Muchos de los problemas limitados se derivan de modelos teóricos donde la solución se encuentra al encontrar la configuración donde una cierta cantidad alcanza un máximo o un mínimo. Para facilitar el trabajo con dichos modelos, las Bibliotecas Numéricas de Optimización Extrema para .NET incluyen un marco para definir dichos modelos que permite una contabilidad más sencilla y la gestión de los resultados. ${ }^{28}$

\section{Componentes de un modelo de optimización}

Todas las clases que implementan problemas de optimización con restricciones heredan de una clase base abstracta, Un modelo de optimización tiene tres componentes principales: ${ }^{29}$

- Una función objetiva. Esta es la función que debe optimizarse.

${ }^{28}$ Cfr. Luquini, E., \& Nizam, O. (2017).

${ }^{29}$ Cfr. Zhang, W., Zhou, Y., \& Zhu, J. (2017). 325, 289-313. 
- Una colección de variables de decisión. La solución al problema de optimización es el conjunto de valores de las variables de decisión para las cuales la función objetivo alcanza su valor óptimo.

- Una colección de restricciones que restringen los valores de las variables de decisión.

\section{Tipos de modelos de optimización}

Los problemas de optimización se pueden clasificar en términos de la naturaleza de la función objetivo y la naturaleza de las restricciones. Las formas especiales de la función objetivo y las restricciones dan lugar a algoritmos especializados que son más eficientes. Desde este punto de vista, hay cuatro tipos de problemas de optimización, de complejidad creciente. Un problema de optimización no restringida es un problema de optimización donde la función objetivo puede ser de cualquier tipo (lineal o no lineal) y no hay restricciones. $^{30}$

Un programa lineal es un problema de optimización con una función objetivo que es lineal en las variables, y todas las restricciones son también lineales. Un programa cuadrático es un problema de optimización con una función objetivo que es cuadrática en las variables (es decir, puede contener cuadrados y productos cruzados de las variables de decisión), y todas las restricciones son lineales. Un programa cuadrático sin cuadrados o productos cruzados en la función objetivo es un programa lineal. ${ }^{31}$

Un programa no lineal es un problema de optimización con una función objetivo que es una función arbitraria no lineal de las variables de decisión, y las restricciones pueden ser lineales o no lineales.

- Variables de decisión: Encontrar los valores óptimos de las variables de decisión es el objetivo de resolver un modelo de optimización. Los modelos específicos pueden tener versiones especializadas de las variables de decisión. ${ }^{32}$

- Restricciones: Limitan los valores posibles para las variables de decisión en un modelo de optimización. Hay varios tipos de restricciones. Las clases que los implementan heredan de la clase Restricción. ${ }^{33}$

\footnotetext{
${ }^{30}$ Cfr. Akbari, M., Gheysari, M., Mostafazadeh-Fard, B., \& Shayannejad, M. (2018). 201, 46-57.

${ }^{31}$ Cfr. Akbari, M., Gheysari, M., Mostafazadeh-Fard, B., \& Shayannejad, M. (2018). 201, 46-57.

${ }^{32}$ Cfr. DeCarolis, J. F., Babaee, S., Li, B., \& Kanungo, S. (2016). 79, 300-310.

${ }^{33}$ Cfr. DeCarolis, J. F., Babaee, S., Li, B., \& Kanungo, S. (2016). 79, 300-310.
} 
Hay dos tipos de restricciones: lineal y no lineal. Las restricciones lineales expresan que una combinación lineal de las variables de decisión debe estar dentro de un cierto rango. Las restricciones no lineales expresan que el valor de alguna función arbitraria de las variables de decisión debe estar dentro de un cierto rango. ${ }^{34}$

Para los modelos también se puede utilizar el componente de Excel, llamado SOLVER. ${ }^{35}$

\subsubsection{Modelo y Simulación}

Se debe definir Sistema, Modelo y Simulación como se muestra a continuación: ${ }^{36}$

Sistema: Un sistema existe y opera en tiempo y espacio.

Modelo: Un modelo es una representación simplificada de un sistema en un punto particular en el tiempo o espacio destinado a promover la comprensión del sistema real.

Simulación: Una simulación es la manipulación de un modelo de tal manera que opera en tiempo o espacio para comprimirlo, lo que permite percibir las interacciones que de otro modo no serían evidentes debido a su separación en el tiempo o el espacio.

Modelado y simulación es una disciplina para desarrollar un nivel de comprensión de la interacción de las partes de un sistema y del sistema como un todo. El nivel de comprensión que puede desarrollarse a través de esta disciplina rara vez se puede lograr a través de cualquier otra disciplina. ${ }^{37}$

Se entiende que un sistema es una entidad que mantiene su existencia a través de la interacción de sus partes. Un modelo es una representación simplificada del sistema real destinado a promover la comprensión. Si un modelo es un buen modelo o no depende de la medida en que promueva la comprensión. Dado que todos los modelos son simplificaciones de la realidad, siempre hay una compensación en cuanto a qué nivel de detalle se incluye en el modelo. Si se incluyen muy pocos detalles en el modelo, se corre el riesgo de perder interacciones relevantes y el modelo resultante no promueve la comprensión. Si se incluyen demasiados detalles en el modelo, el modelo puede volverse demasiado complicado y, de hecho, imposibilitar el desarrollo de la comprensión. ${ }^{38}$

\footnotetext{
${ }^{34}$ Cfr. DeCarolis, J. F., Babaee, S., Li, B., \& Kanungo, S. (2016). 79, 300-310.

${ }^{35}$ Cfr. Jablonsky, J. (2014). 12, 251-258.

${ }^{36}$ Cfr. Proudlove, N. C., Bisogno, S., Onggo, B. S. S., Calabrese, A., \& Ghiron, N. L. (2017). 263(2), 583595.

${ }^{37}$ Cfr. Proudlove, N. C., Bisogno, S., Onggo, B. S. S., Calabrese, A., \& Ghiron, N. L. (2017). 263(2), 583595.

${ }^{38}$ Cfr. Kikolski, M. (2017). 182, 321-328.
} 
Una simulación generalmente se refiere a una versión computarizada del modelo que se ejecuta en el tiempo para estudiar las implicaciones de las interacciones definidas. Las simulaciones son generalmente iterativas en su desarrollo. Uno desarrolla un modelo, lo simula, aprende de la simulación, revisa el modelo y continúa las iteraciones hasta que se desarrolla un nivel adecuado de comprensión. Modelar y simular es una disciplina, también es una forma de arte. Uno puede aprender a andar en bicicleta leyendo un libro. Modelado y simulación sigue la misma realidad. La habilidad y el talento en el desarrollo de modelos y la realización de simulaciones solo se desarrollan a través de la construcción de modelos y su simulación. Es un proceso de aprender sobre la marcha. De la interacción del desarrollador y los modelos surge una comprensión de lo que tiene sentido y lo que no. ${ }^{39}$

\subsubsection{Una introducción a la Simulación de Arena ${ }^{40}$}

La simulación es una de las herramientas de análisis más potentes disponibles para los responsables del diseño y la operación de procesos o sistemas complejos. En un mundo cada vez más competitivo, la simulación se ha convertido en una herramienta muy poderosa para la planificación, el diseño y el control de sistemas. Ya no se considera el enfoque de "último recurso", hoy se considera una metodología de resolución de problemas indispensable para ingenieros, diseñadores y gerentes.

Este artículo presenta algunas características importantes del software ARENA. Esto ayudaría al principiante a comprender los conceptos básicos necesarios para construir un modelo simple. Esto a su vez podría proporcionar un trampolín para construir complejos modelos del mundo real.

\subsubsection{Un modelo de simulación simple ${ }^{41}$}

Consideremos un modelo de simulación simple. Supongamos que tenemos un sistema de cola de un solo canal (línea de espera), como un mostrador de caja en una farmacia. El tiempo entre la llegada de los clientes se distribuye uniformemente de 1 a 10 minutos. Esto se obtiene mediante un dial giratorio (como los que se usan en algunos juegos de mesa). El tiempo requerido para atender a un cliente se distribuye de manera uniforme entre 1 y 6 minutos. Se puede usar un solo dado para generar tiempos de servicio. El

\footnotetext{
${ }^{39}$ Cfr. Santos, F., Nunes, I., \& Bazzan, A. L. (2017

${ }^{40}$ Cfr. Arena Simulation (2018).

${ }^{41}$ Cfr. Arena Simulation (2018).
} 
sistema tiene dos variables aleatorias y si es necesario generar un gran número de lecturas, se necesita una computadora para generar las variables aleatorias y para llevar a cabo la contabilidad. Para simular adecuadamente los sistemas del mundo real, también debemos ser capaces de generar características de comportamiento que sean realistas. Por ejemplo, el tiempo entre las llegadas y los tiempos de servicio generados debe permitir que algo diferente a la distribución uniforme se redondee al número entero más cercano.

\subsubsection{Selección de distribución ${ }^{42}$}

Para probar la compatibilidad de un conjunto de frecuencias observadas con cierta frecuencia teórica, primero debemos identificar la distribución teórica que deseamos probar. Si se trata de una variable discreta, registramos la frecuencia que ocurre dentro de cada valor individual. Si la variable es continua, dividimos el rango de valores en intervalos o clases iguales. La frecuencia relativa en cada intervalo es entonces el conteo de frecuencia observado en cada clase dividido por el número total de puntos de datos [7].

Después de que hayamos obtenido una distribución de frecuencia relativa, la selección de la posible distribución de probabilidad de la cual puede derivarse se convierte en una cuestión de juicio y experiencia.

Algunos ejemplos de distribuciones continuas son uniformes, triangulares, exponenciales negativas, Erlang, gamma, Weibull, normal, lognormal y beta. Algunos ejemplos de distribuciones discretas son discretos uniformes, binomiales, geométricos y de Poisson.

\subsubsection{Prueba de ajuste de distribución ${ }^{43}$}

Una vez que se ha seleccionado una distribución (basada en la inspección visual y los fundamentos teóricos), debemos evaluar la calidad de nuestro ajuste. Esto se puede hacer usando pruebas estadísticas formales o empleando un método gráfico simple en el que se muestra una superposición de la distribución teórica en un histograma de los datos y se realiza una evaluación visual para determinar la calidad del ajuste. Una prueba de bondad de ajuste intenta medir y evaluar la desviación de la distribución de la muestra desde el punto de vista teórico. Los ejemplos de estas pruebas incluyen tanto Chi-Square $\left(\mathrm{x}^{\wedge} 2\right)$ como las pruebas de Kolmogrov-Smirnov.

\footnotetext{
${ }^{42}$ Cfr. Arena Simulation (2018).

${ }^{43}$ Cfr. Arena Simulation (2018).
} 


\subsubsection{Conceptos básicos de modelado ${ }^{44}$}

En el entorno ARENA, la palabra "entidad" es un término genérico que se utiliza para designar a cualquier persona, objeto o cosa, cuyo movimiento a través del sistema causa cambios en el estado del sistema. Cada entidad posee algunas características únicas referidas como atributos. Por ejemplo, en una fábrica, un trabajo puede tener atributos que especifiquen el número de pieza, la fecha de vencimiento y la prioridad del trabajo. El término variables se refiere al conjunto de valores modificables que caracterizan los componentes del sistema como un todo. Ejemplo de una variable es TNOW. Especifica el valor actual del tiempo simulado.

En el marco de modelado ARENA, hay una distinción fundamental entre el Modelo y el Experimento. El modelo es una descripción funcional de los componentes del sistema y sus interacciones. El experimento define las condiciones experimentales bajo las cuales se ejerce el modelo para generar datos de salida específicos. Un programa de simulación ARENA genera un modelo y experimentos correspondientes.

Los procesos se modelan utilizando un diagrama de bloques. Un diagrama de bloques es un diagrama de flujo que representa el proceso a través del cual se mueven las entidades en el sistema. El diagrama de bloques se construye como una secuencia de bloques, cuyas formas y nombres indican su función general. La sección experimental del programa consta de elementos que se especifican de forma interactiva en el entorno de modelado de Arena.

\subsubsection{Análisis de datos: Herramientas estadísticas}

Todo proceso productivo genera datos, los cuales mediante el uso de herramientas estadísticas pueden convertirse en información útil para el funcionamiento de los sistemas de producción y el cumplimiento de los requisitos específicos de productos y servicios. Cabe señalar que es importante emplear las diferentes herramientas estadísticas de forma secuencial, ya que de ello dependerá la detención de los puntos débiles del proceso productivo ${ }^{45},{ }^{46}$

\footnotetext{
${ }^{44} \mathrm{Cfr}$. Arena Simulation (2018).

${ }^{45}$ Cfr. LÓPEZ, María Isabel; LÓPEZ, Patricia (2014)

${ }^{46}$ Cfr. PULIDO, Alexander, BOCANEGRA, Carlos (2015).
} 


\subsubsection{Diagrama de Pareto}

El diagrama de Pareto es una herramienta estadística que consiente en identificar las causas principales del problema objeto de análisis o reconocer la frecuencia en la ocurrencia de las no conformidades (defectos), ayudando así en la toma de decisiones 4748

\subsubsection{Gráficos de control}

De acuerdo con López Rodríguez y López Linares los gráficos de control son herramientas efectivas para reducir la variabilidad, ya que se permite observar si el proceso se encuentra bajo condiciones estables. Asimismo, afirman que los gráficos de control están conformados por tres líneas horizontales y paralelas entre ellas. La línea central (LC) muestra el valor promedio del parámetro de la característica de calidad que se desea controlar. Por otra parte, las otras dos líneas denominadas línea de control superior (LCS) y línea de control inferior (LCI) marcan el rango dentro del cual se espera que estén el $99.73 \%$ de las observaciones para un proceso bajo control estadístico. Cuando todos los puntos se sitúen dentro de los límites superior e inferior y además no se observará ningún comportamiento anómalo (rachas, ciclos, inestabilidad) el proceso estaría operando bajo control y sin anomalías; caso contrario sería necesario determinar las causas asignables que provocan el comportamiento. Existen tres clases de gráficos de control. El primero llamado control por variables, este tipo de grafico se utiliza cuando la característica de calidad es medible. El segundo, llamado control por atributo, se emplea cuando el producto no es mediable y el producto se clasifica como conforme o no conforme. Y, por último, el grafico de control por número de defectos se utiliza cuando el objetivo es analizar el número de defectos que se producen. Cabe mencionar que cuando se realiza un control por variables es necesario controlar el valor medio de la característica de calidad y su variabilidad ${ }^{49}$.

\subsubsection{Análisis de capacidad de un proceso}

La capacidad de un proceso es útil para comprobar que un proceso (bajo control) sea capaz de producir piezas que verifiquen especificaciones. La definición de la capacidad de un proceso se calcula a través de los límites de tolerancia del proceso. Siendo X una característica de calidad medible con $=$ valor objetivo, de diseño o nominal; LTI $=$ límite

\footnotetext{
${ }^{47}$ Cfr. LÓPEZ, María Isabel; LÓPEZ, Patricia (2014)

${ }^{48}$ Cfr. PULIDO, Alexander, BOCANEGRA, Carlos (2015).

${ }^{49}$ Cfr. LÓPEZ, María Isabel; LÓPEZ, Patricia (2014)
} 
de tolerancia inferior; LTS = límite de tolerancia superior y [LTI, LTS] = intervalo de tolerancia, entonces se cumplirán especificaciones si LTI $\leq X \leq$ LTS. Se suele utilizar para analizar la capacidad unos índices que reciben el nombre de índices de capacidad, concretamente el índice de capacidad potencial (en procesos centrados) y el índice de capacidad real (en procesos descentrados) que tienen las siguientes expresiones ${ }^{50}$

$$
\begin{gathered}
C p=\frac{L T S-L T I}{6 \sigma} \\
C p k=\min \left(\frac{L T S-\mu}{3 \sigma} ; \frac{\mu-L T I}{3 \sigma}\right)
\end{gathered}
$$

\subsection{Herramientas Lean}

Lean es una filosofía empresarial que acorta continuamente el tiempo entre el pedido del cliente y el envío al eliminar todo lo que aumenta el costo de producción y el tiempo de entrega a los clientes. Lean Manufacturing es una estrategia operacional orientada a lograr el tiempo de ciclo más corto posible al eliminar el desperdicio. La filosofía de reducir continuamente el desperdicio en todas las áreas y en todas las formas; una frase en inglés acuñada para resumir las técnicas de fabricación japonesas (específicamente, el sistema de producción de Toyota). ${ }^{51}$

Prácticamente, donde sea que vaya en su búsqueda de la definición ideal de Lean Manufacturing, existen aspectos comunes. Los siguientes indicadores tienden a aparecer $^{52}$ :

- Eliminación de despilfarros en el proceso

- Acortar los plazos de entrega

- Estrategia o Filosofía

\footnotetext{
${ }^{50}$ Cfr. López, María Isabel; LÓPEZ, Patricia (2014)

${ }^{51}$ Cfr. Botti, L., Mora, C., \& Regattieri, A. (2017). 111, 481-491.

${ }^{52}$ Cfr. Sartal, A., Llach, J., Vázquez, X. H., \& de Castro, R. (2017). 45, 260-272.
} 
Lean debe ser estratégico: debe implementarse como parte de una estrategia comercial y, por lo tanto, implementarse en la organización utilizando un enfoque estructurado. Este avance lleva tiempo, ya que debe abordar la parte más difícil: el cambio cultural. ${ }^{53}$

\subsubsection{Implementación de Lean Manufacturing}

La implementación de Lean Manufacturing se realiza de acuerdo con los principios de Lean de mejora continua:

1. Especificar los valores del cliente

2. Graficar el Mapa de Valor (VSM)

3. Establecer el flujo continuo

4. Utilizar un sistema PULL

5. Lograr la perfección (se inicia nuevamente en 1$)^{54}$

El diagrama se muestra a continuación:

${ }^{53}$ Cfr. D’Antonio, G., Bedolla, J. S., \& Chiabert, P. (2017). 11, 2243-2251.

${ }^{54}$ Cfr. Godinho Filho, M. (2017). 90(5-8), 1897-1910. 
Figura 3: Implementación de Lean Manufacturing

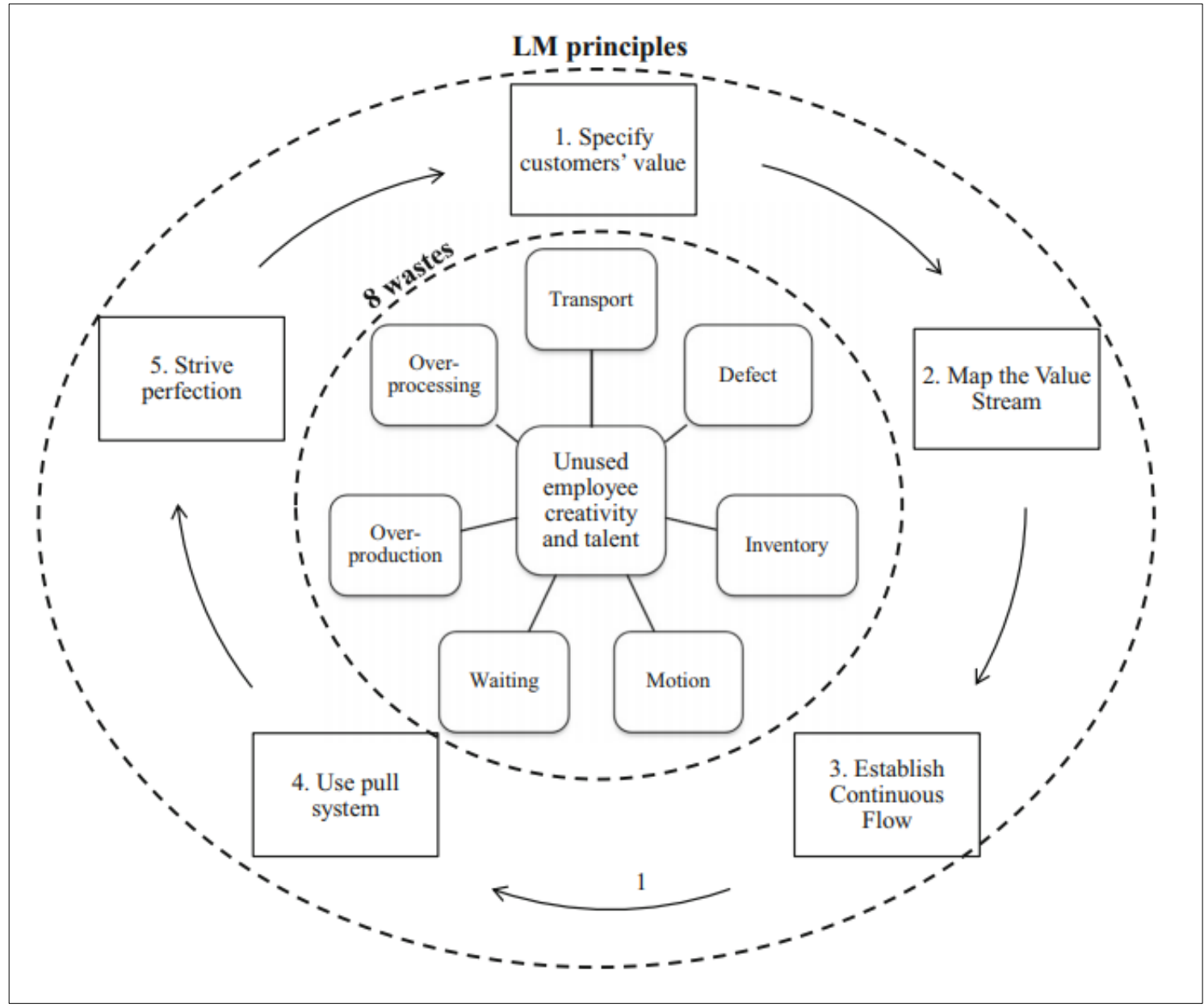

Fuente: Godinho Filho, M. (2017). 90(5-8), 1897-1910.

Los autores indican que la implementación de Lean Manufacturing, debe considerar principalmente la mejora continua y la mejor herramienta para poder identificar los 7 despilfarros (transporte, defecto, inventario, movimiento, tiempo de espera, sobreproducción y sobre procesamiento) es el VSM o mapa de valor. Sin embargo, los autores indican que de acuerdo con el autor Liker, existe un despilfarro más la creatividad y talento no utilizado de los empleados. ${ }^{55}$

\subsubsection{VSM}

El mapeo del flujo de valor es una técnica de manufactura esbelta o lean usada para documentar, analizar y mejorar el flujo de información o materiales requeridos para producir un producto o servicio para un cliente. Es decir, el mapeo del flujo de valor es

${ }^{55}$ Cfr. Godinho Filho, M. (2017). 90(5-8), 1897-1910. 
una herramienta de papel y lápiz que le ayuda a ver y entender el flujo de material e información a medida que un producto o servicio avanza por el flujo de valor ${ }^{56}$.

El mapeo del flujo de valor: ${ }^{57}$

1. Recolecta y muestra un rango de información mucho más amplio que un mapa de proceso típico.

2. Tiende a estar en un nivel más alto (5-10 cajas) que muchos mapas de procesos.

3. Tiende a ser utilizado en un nivel más amplio, es decir, desde la recepción de la materia prima hasta la entrega de los productos terminados.

4. Tiende a ser utilizado para identificar dónde enfocar futuros proyectos, subproyectos $\mathrm{y} / \mathrm{o}$ eventos kaizen.

Un mapa de flujo de valor (también conocido como mapa de sistema de extremo a extremo) tiene en cuenta no solo la actividad del producto, sino también los sistemas de gestión e información que respaldan el proceso básico. Esto es especialmente útil cuando se trabaja para reducir el tiempo del ciclo, porque se obtiene una idea del flujo de toma de decisiones además del flujo del proceso. ${ }^{58}$

\subsubsection{Generación y transferencia de datos ${ }^{59}$ :}

Este grupo incluye un proceso continuo desde la selección de datos, la calidad de los datos y la recopilación de datos hasta la transferencia de datos. A través de este proceso se establece una base para el procesamiento adicional y la utilización de los datos.

La selección de datos describe la selección adaptada a los fines de la información de los datos a recopilar, especialmente con vistas a la utilización de los datos en sí (perspectiva del cliente). Lo que significa recopilar tantos datos como sea necesario y lo menos posible.

La calidad de los datos requiere una evaluación según su contenido, significado, origen, uso, granularidad, frecuencia de recopilación, consistencia, etc. en cada caso de un proceso.

\footnotetext{
${ }^{56}$ Cfr. Kuhlang, P., Hempen, S., Edtmayr, T., Deuse, J., \& Sihn, W. (2013) 46(9), 993-997.

${ }^{57}$ Cfr. Abdulmalek, F. A., \& Rajgopal, J. (2007). 107(1), 223-236.

${ }^{58}$ Cfr. Sihn, W., \& Pfeffer, M. (2013). 62(1), 427-430.

${ }^{59}$ Cfr. Meudt, T., Metternich, J., \& Abele, E. (2017). 66(1), 413-416.
} 
La recopilación de datos considera el grado de automatización y si la recopilación de datos es completamente automática, semiautomatizada (es decir, con una máscara de entrada) o manual / en papel. Especialmente las actividades manuales deben evitarse y verse como acciones derrochadoras.

La transferencia de datos incluye todos los medios y sistemas involucrados en el transporte de datos y especialmente considera la coherencia de los datos. Se deben evitar las discontinuidades de los medios y el sistema.

\subsubsection{Procesamiento de datos y almacenamiento de datos ${ }^{60}$}

En LP (Lean Production), uno de los temas principales es permitir un flujo de material continuo, por ejemplo, para reducir el tiempo de entrega. Este problema puede ser respaldado por un flujo de información constante. Por lo tanto, algunos tipos de desechos LP se pueden transmitir en un nuevo contexto dentro de este grupo.

Residuos en forma de períodos de espera y cuestiones de inventario, particularmente con respecto a la disponibilidad de datos en tiempo real. Las latencias en el sistema y los datos no procesados provocan demoras que pueden afectar los procesos de fabricación.

La transferencia, el movimiento y la búsqueda incluyen especialmente actividades manuales causadas por IL ineficiente a través de rutas de transporte complejas y parcialmente no agregadas, intervenciones manuales o procesos de búsqueda. La información no está disponible en tiempo real, especialmente cuando está escrita en papel.

\subsubsection{Utilización de datos ${ }^{61}$}

Finalmente, los desechos se resumen en este grupo junto con las tareas generales de apoyo a la decisión.

En el marco del análisis de datos, los residuos tienen un papel importante que jugar al omitir el análisis de datos. Nuevos conocimientos, que permiten la mejora continua dentro de los procesos de fabricación, solo pueden obtenerse vinculando los datos con análisis adicionales.

Toma de decisiones-soporte. Solo cuando los datos y otros análisis son adecuados para la toma de decisiones, es posible mejorar los procesos de forma continua. Idealmente, los datos se prepararán de forma tal que las acciones de los humanos se muestren o se visualicen de forma intuitiva para seleccionar la mejor. La toma de decisiones basada en

\footnotetext{
${ }^{60}$ Cfr. Meudt, T., Metternich, J., \& Abele, E. (2017). 66(1), 413-416.

${ }^{61}$ Cfr. Meudt, T., Metternich, J., \& Abele, E. (2017). 66(1), 413-416.
} 
evidencia está determinada por una buena base de datos que puede mejorarse continuamente mediante una mejor selección de datos.

\subsubsection{SMED - Single Minute Exchange of Dies}

Shingo inventó el sistema Single-Minute Exchange of Dies para Toyota, ayudando a las empresas a reducir sus cambios y logrando mejoras rápidas en sus resultados como: reducción del tiempo de entrega, disminución de los inventarios que mejorarán la calidad, la productividad, las ganancias y los resultados globales. Single Minute Exchange of Dies, es una metodología utilizada para reducir el tiempo que las máquinas paran durante los cambios. En primer lugar, el enfoque SMED busca identificar los pasos que se pueden realizar mientras la máquina opera (operaciones de configuración externas) y los que solo pueden tener lugar mientras la máquina para (operaciones de configuración internas). La forma más sólida de obtener valor con esta metodología es comenzar a transformar las operaciones internas en operaciones externas, reduciendo el tiempo de inactividad durante los cambios y estandarizando el proceso. La metodología SMED distingue en un cambio dos tipos de operaciones: Operaciones internas (IED) - Intercambio de entrada de matrices que solo se puede realizar con la máquina inmovilizada y Operaciones externas (OED - Intercambio de salidas de matrices) que se pueden realizar mientras la máquina opera. El método SMED ha permitido a numerosas empresas reducir considerablemente sus tiempos de cambio. Las empresas ahora pueden pasar de varias horas a unos minutos. La definición de los estándares para el cambio juega aquí un papel clave. La aplicación de SMED es indispensable, ya que los largos cambios de una serie de producción son problemas críticos para garantizar la fluidez de la circulación de los productos. Mejore la calidad del mantenimiento mediante el establecimiento de criterios periódicos de inspección y reemplazo basados en estándares provisionales de limpieza e inspección. ${ }^{62}$ La metodología desarrollada por Shigeo Shingo, denominada SMED (intercambio de un solo minuto de la matriz) propone que las configuraciones se lleven a cabo dentro de un período de tiempo máximo de 10 minutos. Esto se puede lograr mediante la racionalización de tareas realizada por el operador de la máquina. ${ }^{63}$

\footnotetext{
${ }^{62}$ Cfr. Rosa, C., Silva, F. J. G., Ferreira, L. P., \& Campilho, R. (2017). 13, 1034-1042.

${ }^{63}$ Cfr. Rosa, C., Silva, F. J. G., Ferreira, L. P., \& Campilho, R. (2017). 13, 1034-1042.
} 


\section{CAPÍTULO II: DESCRIPCIÓN Y ANALISIS DEL PROCESO ACTUAL}

En el presente capítulo detallará las definiciones básicas necesarias para comprender y sustentar el problema abordado en el presente trabajo de investigación. Asimismo, se presentará información sobre el entorno de la industria y el marco normativo del cual pertenece la empresa en estudio.

\subsection{Descripción de la empresa}

La empresa textil es una empresa que se encuentra en el mercado peruano hace 37 años. La empresa en mención se caracteriza por ser la compañía textil con mayor integración vertical en el país, ya que ofrece a sus clientes productos "full package". En otras palabras la empresa textil puede fabricar productos textiles que van desde el desmontado, hilado, tejido, teñido, acabado, confección de los mismos y, en general, todas las actividades relacionadas con el procesamiento industrial de las fibras naturales y sintéticas, así como la comercialización, distribución y representación de productos textiles, fibra de algodón, hilado, tela y prendas de vestir, tanto a nivel local como en el exterior.

\subsubsection{Actividad económica}

Según la clasificación internacional uniforme CIIU, la empresa textil pertenece la actividad económica respectiva a la sección C (Industrias manufactureras), división 13 y 14, grupo 131 y 141 y clase 1311,1312 y 1410.

\subsubsection{Mapa de Procesos}

Actualmente el mapa de procesos a nivel organizacional de la empresa está compuesto por cuatro procesos estratégicos, cinco procesos operativos y cuatro procesos de soporte. Líneas posteriores se brindará una breve descripción de cada proceso (Véase figura 4).

\subsubsection{Procesos Estratégicos:}

- Planeamiento Estratégico: este proceso direcciona las actividades del negocio, implica establecer objetivos, estrategias y proyectos que permitan a la organización responder los cambios dinámicos del mercado. Asimismo, involucra la elaboración 
de planes estratégicos que prevén el futuro del negocio y su entorno, y los procedimientos que se requieren para alcanzar los resultados deseados.

- Dirección: Proporciona una guía, dirección y límites de la organización para decidir sobre el camino que tomará la compañía para lograr la visión propuesta.

- Gestión de la Calidad: Encargado de la planeación, control y mejora de la calidad de los procesos de la empresa. Verifica la gestión de calidad desde la recepción de materia prima hasta el servicio brindado al cliente teniendo como objetivo principal la satisfacción plena de las necesidades de este.

- Mejora continua: proceso en el cual se analiza los procesos de toda la cadena productiva a fin de proponer la optimización de los mismos a través de proyectos basados en la metodología DMAIC.

\subsubsection{Procesos Operativos:}

- Planeamiento y Control de la Producción: se maneja todo lo referente a la planificación antes de producir y a la manera en cómo mantenerla bajo control.

- Comercial: Responsable de maximizar los resultados de la empresa a través de la venta, políticas de precios y descuentos.

- Producción: El proceso de producción de la empresa se encuentra dividido en nueve subprocesos de producción, los cuales hacen referencia a la fabricación de hilos, telas y confecciones.

- Pre producción: encargada de investigar, desarrollar y reproducir tejidos requeridos por los clientes. En este proceso se crea la muestra de telas o de prendas para que sean enviadas a través del área comercial al cliente.

- Control de calidad: Proceso encargado de verificar y asegurar que la calidad de los productos en proceso y terminados cumplan con los estándares y certificaciones técnicas.

\subsubsection{Procesos Apoyo:}

- Logística: Evalúa y selecciona a los proveedores a utilizar para la entrega de un pedido, previo estudio a los requerimientos del cliente. Asimismo, gestiona las compras de materias primas e insumos de acuerdo a las especificaciones que cumpla con las expectativas del cliente Por otro lado, vela por el almacenamiento de materia 
prima y de productos terminados, inventarios del proceso productivo, distribución y transporte

- Mantenimiento: está encargada de asegurar que toda la maquinaria de producción se encuentre operativa y en estado óptimo para ello hacen uso de la planificación de los mantenimientos a nivel predictivo y preventivo.

- Recursos Humanos (RRHH): se encarga desde la selección del personal hasta su cese, su principal rol es difundir la importancia del personal, realizar buen reclutamiento e integración de ellos.

- Informática: se encarga de la recolección, almacenamiento, procesamiento y distribución de la información a las distintas áreas que conforman su sistema con el fin de mejorar la productividad. 
Figura 4: Mapa de procesos

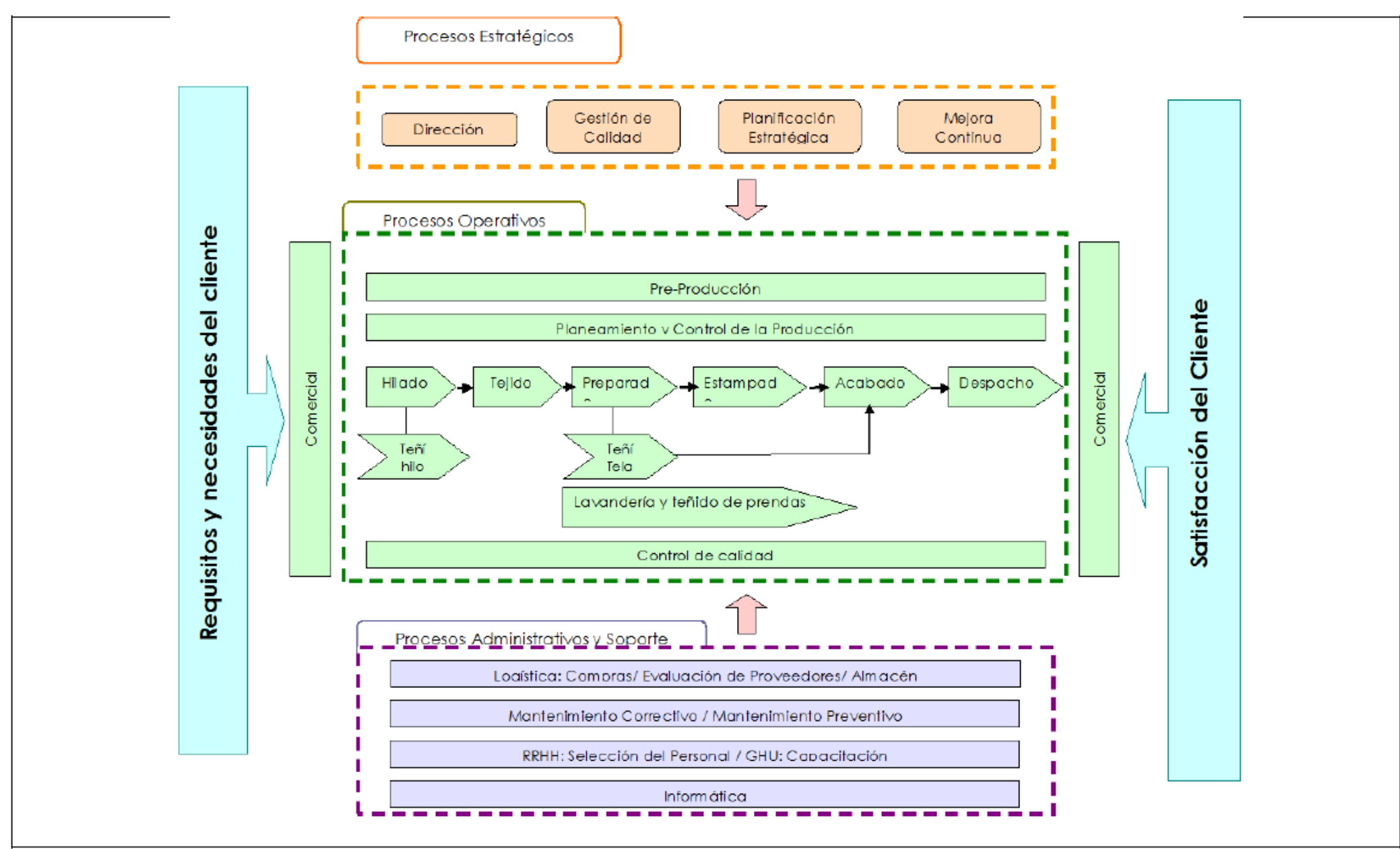

Fuente: La empresa 


\subsubsection{Perfil Organizacional}

\section{Misión}

Somos una empresa textil con líneas de negocio diversificadas y verticalmente integrada. Trabajamos para satisfacer los estándares de calidad de nuestros clientes, basados en capacidad innovadora, flexibilidad y vocación de servicio, a través de productos diferenciados. Contamos con un equipo humano especializado, identificado, y comprometido con la empresa, promoviendo el desarrollo de sus competencias.

Orientamos nuestras operaciones a lograr una rentabilidad que permita un crecimiento sostenido. Promovemos un accionar con responsabilidad social y ambiental.

\section{Visión}

Ser referente mundial en productos textiles diversificados de calidad, cuyas operaciones permitan una alta rentabilidad. Accionar basado en la investigación y desarrollo para otorgar satisfacción y rápida respuesta a los clientes, actuando acorde a las normas de buen gobierno corporativo.

\section{Filosofía y cultura empresarial}

- Valoramos la identificación del personal con la empresa, el comportamiento ético y responsable, fomentando su capacitación y desarrollo.

- Practicamos una cultura de orden, disciplina, puntualidad y limpieza.

- Promovemos una actitud de cambio e innovación, orientando su accionar a las

- necesidades del mercado, manteniendo una organización ágil, flexible y de permanente

- optimización tecnológica.

\section{Política de calidad}

Interpretar las necesidades y requerimientos de nuestros clientes, estableciendo especificaciones y parámetros de procesos, que nos permitan proveerlos de productos que satisfagan e incluso excedan sus expectativas. Esto se logra gracias a un personal altamente calificado, al uso de materia prima y accesorios selectos, a la innovación de productos y procesos, al empleo de tecnología de punta, que permitan adaptarnos rápidamente a las nuevas necesidades del mercado, respetando el medio ambiente y siendo socialmente responsables. 


\section{Organigrama}

La estructura organizacional se encuentra encabezada por el Directorio y seguidamente por la Gerencia General. La organización cuenta con tres departamentos: Ingeniería Industrial, Auditoria Interna y Pre Producción. El primer departamento está conformado por Planeamiento y Control de la Producción (PCP), Control de la calidad, Organización y Métodos $(\mathrm{O}$ y M) y Proyectos especiales. Asimismo, existen cuatro gerencias las cuales son Administración y finanzas, Gerencia Técnica, Gerencia Comercial Hilandería y Gerencia Comercial Tejidos. Por su parte, la Gerencia de administración y finanzas está compuesta por seis jefaturas, las cuales son Administración, Contabilidad, Finanzas, Logística, Recursos Humanos e informática. Igualmente, la Gerencia técnica tiene a su cargo dos superintendencias las cuales son Superintendencia de Hilandería y Superintendencia de Tejeduría. La primera superintendencia solo cuenta con una jefatura la cual es de Hilandería; en cambio la Superintendencia de planta tiene a su cargo cinco jefaturas, las cuales son Muestras, Tejeduría, Tintorería, Estampado y Mantenimiento. Finalmente existen dos áreas que reportan directamente a Gerencia General, estas son Administración de desmontadoras y Jefatura Retail. (Véase Figura 5) 
Figura 5: Organigrama de la empresa

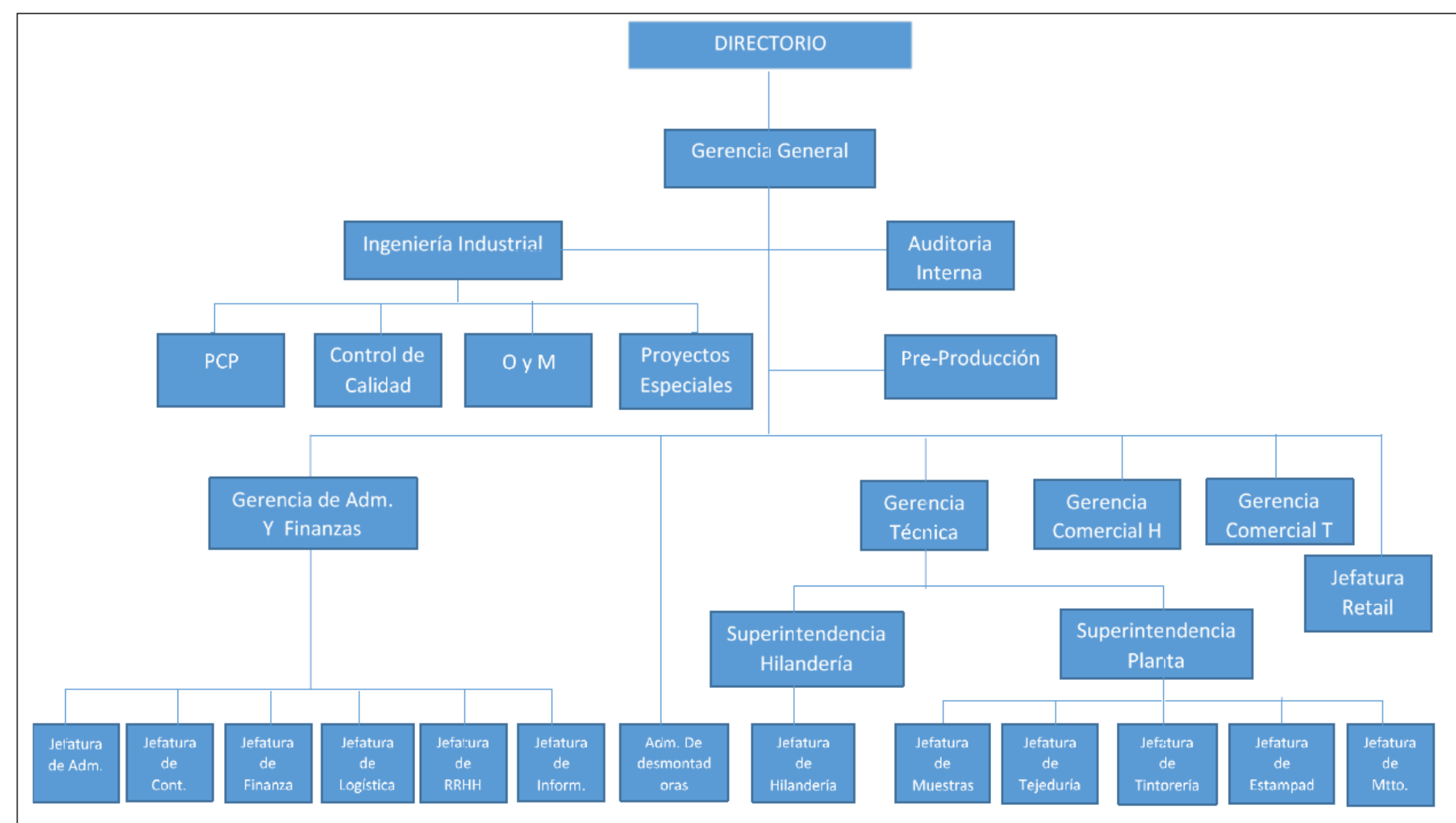

Fuente: La empresa 


\subsubsection{Participación en el modelo de negocio}

Dentro del modelo de negocio de la empresa, se encuentra la participación de las siguientes entidades.

\subsubsection{Clientes}

La empresa bajo estudio comercializa sus productos de hilo, tela y prendas en el mercado local y en el extranjero siendo sus mercados Sudamérica, Europa, Asia, Estados unidos y Centroamérica. Por tanto, sus principales clientes son los siguientes:

Tabla 5: Principales Clientes (Por productos)

\begin{tabular}{|c|c|c|c|c|}
\hline \multicolumn{2}{|c|}{ Hilados } & Tejidos & \multicolumn{2}{|c|}{ Confecciones } \\
\hline Industrias Cavalier & $\begin{array}{l}\text { Devanlay } \\
\text { (Lacoste } \\
\text { Perú) }\end{array}$ & $\begin{array}{l}\text { Braemore } \\
\text { Textiles }\end{array}$ & $\begin{array}{l}\text { Tommy } \\
\text { Bahamas }\end{array}$ & Cabelas \\
\hline Cotton Knit & Paramount & Folia Fabrics & $\begin{array}{l}\text { Devanlay } \\
\text { USA }\end{array}$ & $\begin{array}{l}\text { Robert } \\
\text { Graham }\end{array}$ \\
\hline Textil Camones & $\begin{array}{l}\text { Industrias } \\
\text { Cataguages }\end{array}$ & Swavelle & L.L Bean & Charly Dog \\
\hline Textil Del Valle & Vesuvio & Mill Creek & Broder Bros & $\begin{array}{l}\text { Clifton } \\
\text { Charles }\end{array}$ \\
\hline Precotex & Mey GMBG & Waverley & $\begin{array}{l}\text { Cutter \& } \\
\text { Buck }\end{array}$ & Life is good \\
\hline Textil Océano & $\begin{array}{l}\text { Industrias } \\
\text { Nettalco }\end{array}$ & Kaufmann & $\begin{array}{l}\text { Island } \\
\text { Company }\end{array}$ & $\begin{array}{l}\text { Industrias } \\
\text { Cavalier }\end{array}$ \\
\hline Universal Textil & IAFIL & Ferrioni & $\begin{array}{l}\text { Psycho } \\
\text { Bunny }\end{array}$ & $\begin{array}{l}\text { Cueros } \\
\text { Velez }\end{array}$ \\
\hline Textil Amazonas & INTIFIL & Nataly Group & $\begin{array}{l}\text { University } \\
\text { Club }\end{array}$ & Bassil \\
\hline
\end{tabular}


Principales Clientes (Por productos)

\begin{tabular}{|l|l|l|l|}
\hline \multicolumn{1}{|c|}{ Hilados } & \multicolumn{1}{|c|}{ Tejidos } & \multicolumn{2}{c|}{ Confecciones } \\
\hline Mitsubishi & La Martina & Paula & / Pengüin \\
\hline & Marimekko & / La martina & $/$ Gola / \\
\hline & Anne Fontaine & Basement & Uomo Venetto \\
\hline & Nakayama & Cristian Lacroix & Crawford \\
\hline & Macclem & Pacco Rabanne & Malwee \\
\hline & & Etiqueta Negra & Damyleer \\
\hline & & Baumgarten & Martina Di trento \\
\hline & & Wrangle-UFO & / Brooksfield \\
\hline
\end{tabular}

Principales Clientes (Por Región)

\begin{tabular}{|c|c|c|c|c|c|}
\hline \multicolumn{4}{|c|}{ Norte América } & Europa & Asia \\
\hline $\begin{array}{c}\text { Braemore } \\
\text { Textiles - } \\
\text { USA }\end{array}$ & $\begin{array}{c}\text { Broder } \\
\text { Bros- USA }\end{array}$ & $\begin{array}{l}\text { L.L Bean - } \\
\text { USA }\end{array}$ & $\begin{array}{c}\text { Island } \\
\text { Company- } \\
\text { USA }\end{array}$ & $\begin{array}{l}\text { Marimekko } \\
\text { - Filandia }\end{array}$ & $\begin{array}{c}\text { Mitsubishi - } \\
\text { Japón }\end{array}$ \\
\hline $\begin{array}{c}\text { Folia } \\
\text { Fabrics - } \\
\text { USA }\end{array}$ & $\begin{array}{c}\text { Devanlay - } \\
\text { USA }\end{array}$ & $\begin{array}{c}\text { Tommy } \\
\text { Bahamas- } \\
\text { USA }\end{array}$ & $\begin{array}{c}\text { Robert } \\
\text { Graham - } \\
\text { USA }\end{array}$ & $\begin{array}{c}\text { Mey } \\
\text { GMBG- } \\
\text { Alemania }\end{array}$ & $\begin{array}{c}\text { Nakayama - } \\
\text { Japón }\end{array}$ \\
\hline $\begin{array}{c}\text { Swavelle - } \\
\text { USA }\end{array}$ & $\begin{array}{c}\text { Cutter \& } \\
\text { Buck - USA }\end{array}$ & $\begin{array}{l}\text { Cabelas- } \\
\text { USA }\end{array}$ & $\begin{array}{c}\text { Life is } \\
\text { good- USA }\end{array}$ & $\begin{array}{l}\text { INTIFIL - } \\
\text { Suiza }\end{array}$ & \\
\hline $\begin{array}{c}\text { Mill Creek - } \\
\text { USA }\end{array}$ & $\begin{array}{c}\text { Psycho } \\
\text { Bunny - } \\
\text { USA }\end{array}$ & $\begin{array}{c}\text { Charly } \\
\text { Dog- USA }\end{array}$ & $\begin{array}{l}\text { Industrias } \\
\text { Cavalier- } \\
\text { Mexico }\end{array}$ & $\begin{array}{l}\text { IAFIL - } \\
\text { Italia }\end{array}$ & \\
\hline $\begin{array}{c}\text { Waverly - } \\
\text { USA }\end{array}$ & $\begin{array}{c}\text { Clifton } \\
\text { Charles- } \\
\text { USA }\end{array}$ & $\begin{array}{c}\text { Kaufmann- } \\
\text { USA }\end{array}$ & $\begin{array}{l}\text { Ferrioni - } \\
\text { Mexico }\end{array}$ & $\begin{array}{c}\text { Anne } \\
\text { Fontaine - } \\
\text { Francia }\end{array}$ & \\
\hline
\end{tabular}


Principales Clientes (Por Región)

\begin{tabular}{|c|c|c|c|}
\hline \multicolumn{4}{|c|}{ Sudamérica } \\
\hline Cotton Knit - Perú & $\begin{array}{c}\text { Universal Textil- } \\
\text { Perú }\end{array}$ & $\begin{array}{c}\text { University Club - } \\
\text { Perú }\end{array}$ & Precotex - Perú \\
\hline $\begin{array}{c}\text { Textil Camones - } \\
\text { Perú }\end{array}$ & $\begin{array}{c}\text { Textil Amazonas- } \\
\text { Perú }\end{array}$ & Basement- Perú & $\begin{array}{c}\text { Devanlay (Lacoste } \\
\text { Perú) }\end{array}$ \\
\hline $\begin{array}{c}\text { Textil Del Valle - } \\
\text { Perú }\end{array}$ & $\begin{array}{c}\text { Industrias Nettalco } \\
\text { - Perú }\end{array}$ & $\begin{array}{c}\text { Cristian Lacroix- } \\
\text { Perú }\end{array}$ & $\begin{array}{c}\text { Pacco Rabanne - } \\
\text { Perú }\end{array}$ \\
\hline $\begin{array}{l}\text { Textil Océano - } \\
\text { Perú }\end{array}$ & $\begin{array}{c}\text { Coast Cadena - } \\
\text { Colombia }\end{array}$ & $\begin{array}{l}\text { Crystal SAS- } \\
\text { Colombia }\end{array}$ & $\begin{array}{c}\text { Cueros Velez- } \\
\text { Colombia }\end{array}$ \\
\hline Bassil - Ecuador & $\begin{array}{l}\text { / Uomo Venetto - } \\
\text { Ecuador }\end{array}$ & Paramount - Brasil & $\begin{array}{c}\text { Industrias } \\
\text { Cataguages - Brasil }\end{array}$ \\
\hline $\begin{array}{l}\text { Vesuvio - } \\
\text { Argentina }\end{array}$ & $\begin{array}{l}\text { La Martina- } \\
\text { Argentina }\end{array}$ & $\begin{array}{c}\text { Nataly Group - } \\
\text { Brasil }\end{array}$ & Macclem- Brasil \\
\hline $\begin{array}{c}\text { Wrangle-UFO - } \\
\text { Argentina }\end{array}$ & $\begin{array}{c}\text { Martina Di trento - } \\
\text { Argentina }\end{array}$ & $\begin{array}{c}\text { Etiqueta Negra - } \\
\text { Brasil- Chile- } \\
\text { Argentina }\end{array}$ & Crawford -Brasil \\
\hline $\begin{array}{c}\text { / Brooksfield - } \\
\text { Argentina }\end{array}$ & Paula - Argentina & Malwee - Brasil & Damyleer - Brasil \\
\hline $\begin{array}{l}\text { Pengüin - } \\
\text { Argentina }\end{array}$ & Gola - Argentina & $\begin{array}{c}\text { Baumgarten - } \\
\text { Brasil }\end{array}$ & \\
\hline
\end{tabular}

Fuente: La empresa

Asimismo, cuenta con marcas propias en prendas de vestir las cuales son Norman \& Taylor, Marc Boehler y M.bö

\subsubsection{Colaboradores}

La fuerza laboral de la empresa bajo estudio se encuentra conformada por funcionarios, empleados yobreros. A continuación, se muestra dicha clasificación desde el año 2014 hasta el 2016. 
Tabla 6: Número de colaboradores de la empresa textil bajo estudio 2014- 2016

\begin{tabular}{|l|r|r|r|r|r|r|r|r|r|r|r|}
\cline { 2 - 13 } \multicolumn{1}{c|}{} & \multicolumn{3}{c|}{ Año 2016 } & \multicolumn{3}{c|}{ Año 2015 } & \multicolumn{3}{c|}{ Año 2014 } & \multicolumn{2}{c|}{ Variación (\%) } \\
\hline $\mathbf{N}^{\circ}$ Trabaj. & Perman & Event. & Total & Perman & Event & Total & Perman & Eventu & Total & $\begin{array}{c}\mathbf{2 0 1 6}- \\
\mathbf{2 0 1 5}\end{array}$ & $\begin{array}{c}\mathbf{2 0 1 5}- \\
\mathbf{2 0 1 4}\end{array}$ \\
\hline Funcionarios & 5 & 0 & 5 & 5 & 0 & 5 & $\mathbf{5}$ & 0 & 5 & $\mathbf{0} \%$ & $\mathbf{0} \%$ \\
\hline Empleados & 115 & 445 & 560 & 113 & 458 & 571 & 123 & 456 & 579 & $\mathbf{- 1 , 9 3 \%}$ & $\mathbf{1 , 3 8 \%}$ \\
\hline Obreros & 74 & 793 & 867 & 76 & 814 & 890 & 76 & 930 & 1006 & $\mathbf{- 2 , 5 8 \%}$ & $\mathbf{- 1 1 , 5 3 \%}$ \\
\hline
\end{tabular}

Fuente: La empresa

\subsubsection{Proveedores}

La empresa Textil para garantizar productos de calidad debe tener proveedores que cumplan con las exigencias que garanticen que nuestros productos cumplan con los requisitos del

cliente.

Tabla 7: Principales proveedores por tipo de insumo o recurso

\begin{tabular}{|c|l|l|}
\hline$N^{\circ}$ & \multicolumn{1}{|c|}{ Tipo de recurso } & \multicolumn{1}{|c|}{ Proveedor } \\
\hline 1 & Químicos y colorantes & Química suiza \\
\hline 2 & Algodón & Avery Dennison Worldwide Ticke \\
\hline 3 & Maquinarias & $\begin{array}{l}\text { Trutzschler industria e comercio de } \\
\text { máquinas Itda. }\end{array}$ \\
\hline 4 & Maquinarias & Picanol \\
\hline 5 & Maquinarias & Schlafhorst \\
\hline 6 & Maquinarias & Marzoli machines textile srl \\
\hline 7 & Maquinarias & Rieter machine works Itd. \\
\hline 8 & Avíos & Gustavo sanchez s.a.c. \\
\hline 9 & Avíos & Label peru sac \\
\hline 10 & Equipos & Datatex ag \\
\hline
\end{tabular}

Fuente: La empresa

\subsubsection{Objetivos estratégicos de la empresa}

Los objetivos estratégicos de la empresa son definidos en base a las decisiones estratégicas propuestas por el directorio y la gerencia general. Los objetivos estratégicos son plasmados en una matriz de control, en la cual se concibe los objetivos por cada 
perspectiva con sus respectivos indicadores de control. A continuación, se lista las decisiones estratégicas formuladas para el ejercicio 2017

- Desarrollar un sistema de gestión integral que permita tener información de gestión y financiera para la toma de decisiones estratégicas adecuadas.

- Elaborar un plan estratégico a mediano y largo plazo el cual permita cumplir con la misión, visión, objetivos y metas de la empresa.

- Crear un sistema de capacitación para los colaboradores claves de la organización con la finalidad de que estos adquieran nuevas habilidades y competencias.

- Despachar los pedidos de acuerdo a los parámetros solicitados por el cliente (Cantidad, tiempo y calidad)

\subsubsection{Mapa estratégico}

El mapa estratégico de la empresa textil cuenta con un total de once objetivos de los cuales dos objetivos corresponden a la perspectiva financiera, dos objetivos pertenecen a la perspectiva clientes, cuatro objetivos pertenecen a la perspectiva procesos y finalmente tres objetivos pertenecen a la perspectiva clientes. Asimismo, se puede observar que el alcance de un logro determinado está directamente relacionado o depende del cumplimiento de otros objetivos. Por ejemplo, para incrementar la satisfacción de los clientes será necesario alcanzar los objetivos de cumplimiento de despacho y tiempos programados de entrega de muestras hacia los clientes. El mapa estratégico también muestra que los objetivos de cumplimiento de tiempo de despacho se encuentran en un estado crítico (Rojo), todos los objetivos referentes a las perspectivas financieras y de clientes se encuentran en un estado de peligro o alerta (amarillo) y finalmente algunos de los objetivos de las perspectivas de procesos y aprendizaje se encuentran en un estado de control (verde). 
Figura 6: Mapa estratégico de la empresa textil 2016

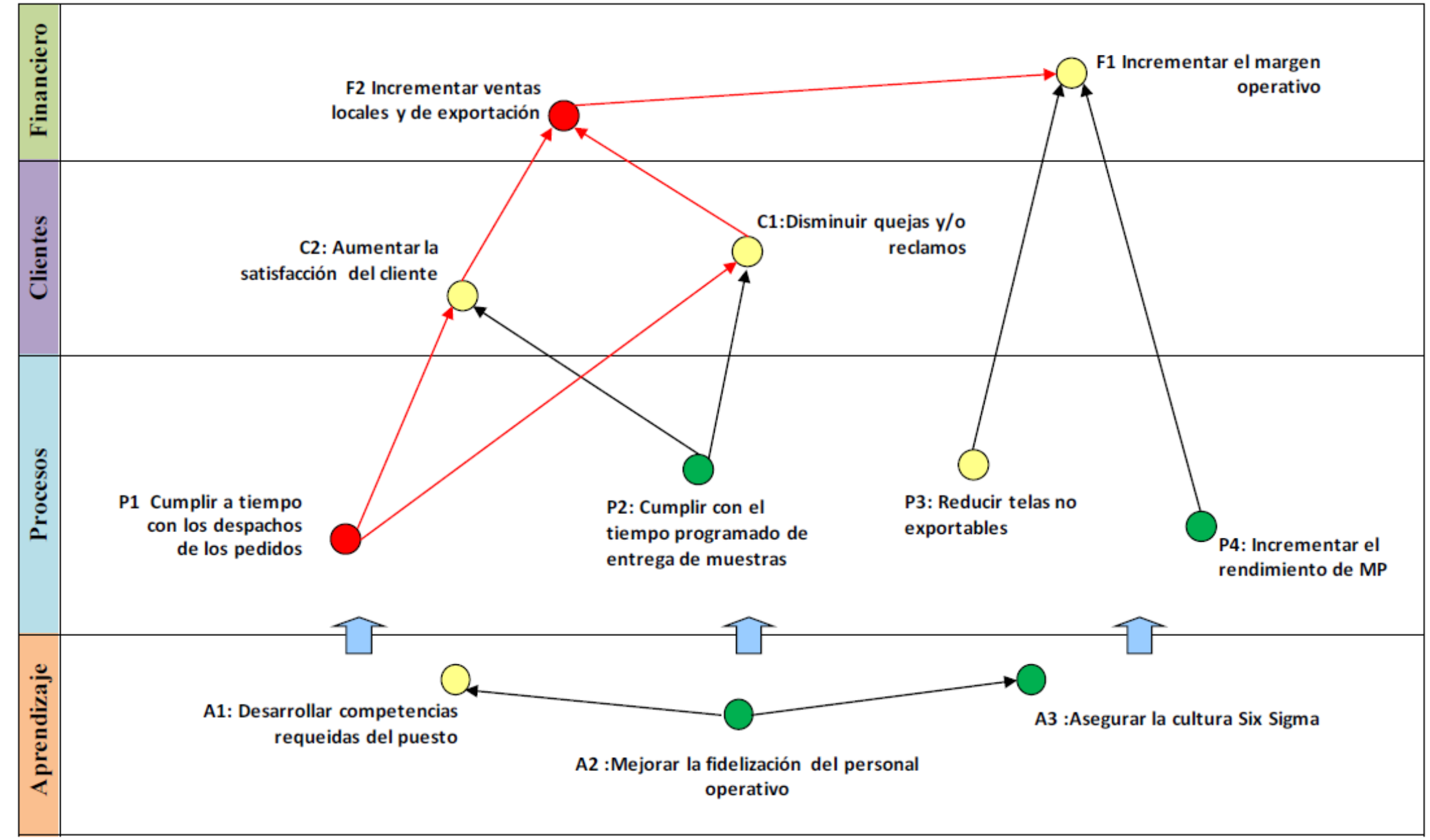

Fuente: La empresa 


\subsubsection{Matriz estratégica}

La matriz estratégica que se muestra a continuación muestra en un mayor nivel de detalle los objetivos de cada perspectiva, mediante el empleo de indicadores. Asimismo, se muestra el nombramiento de los responsables, así como la unidad de medida de cada uno de los indicadores definidos para el cumplimiento de los indicadores. Del mismo modo que los objetivos se encuentran en un estado los indicadores también tienen un estado definido que se visualiza en la siguiente matriz.

Tabla 8: Matriz estratégica 2016

\begin{tabular}{|c|c|c|c|c|c|}
\hline Perspectiva & Obje tivo & Resp & Titulo & Und & $\begin{array}{l}\text { Frecuencia de } \\
\text { Seguimiento }\end{array}$ \\
\hline \multirow{3}{*}{ Financiera } & $\begin{array}{l}\text { F1: Incrementar el margen } \\
\text { operativo }\end{array}$ & GG & Fl.a Crecimiento en el MO & $\%$ & Anual \\
\hline & \multirow{2}{*}{$\begin{array}{l}\text { F2: Incrementar ventas bcales } \\
\text { y de exportación }\end{array}$} & \multirow{2}{*}{ GG } & $\begin{array}{l}\text { F2.a Ingresos generados por h venta } \\
\text { cartera de productos }\end{array}$ & $\%$ & Anual \\
\hline & & & F2.b Incrementar de mevos chentes & $\%$ & Anual \\
\hline \multirow{2}{*}{ Cliente } & $\begin{array}{l}\mathrm{Cl} \text { :Dismimir quejas y/o } \\
\text { rechamos }\end{array}$ & GC & Cl.a Reclamos de bs chentes & Cant & Semestral \\
\hline & $\begin{array}{l}\text { C2: Aumentar h satisfacción } \\
\text { del cliente }\end{array}$ & GC & (1) C2.a Nivel de satisfacción del chente & $\%$ & Semestral \\
\hline \multirow{5}{*}{ Procesos } & \multirow{2}{*}{$\begin{array}{l}\text { Pl: Cumplir a tiempo con bs } \\
\text { despachos de bs pedidos }\end{array}$} & \multirow{2}{*}{ GT } & $\begin{array}{l}\text { Pl.a Índice de pedidos que se entregan } \\
\text { a tiempo }\end{array}$ & $\%$ & Mensual \\
\hline & & & $\begin{array}{l}\text { Pl.b Cumplimiento de programas de } \\
\text { producción }\end{array}$ & $\%$ & Mensual \\
\hline & $\begin{array}{l}\text { P2: Cumplir con el tiempo } \\
\text { programado de entrega de } \\
\text { nmestras }\end{array}$ & PP & $\begin{array}{l}\text { P2.a Entrega de mmestras en el tiempo } \\
\text { establecido }\end{array}$ & $\%$ & Mensual \\
\hline & $\begin{array}{l}\text { P3: Reducir telas no } \\
\text { exportables }\end{array}$ & SP & P3.a Tela no exportable & Cant & Mensual \\
\hline & $\begin{array}{l}\text { P4: Incrementar el rendimiento } \\
\text { de materia prima }\end{array}$ & $\mathrm{SH}$ & P4.a Eficiencia del algodón & $\%$ & Mensual \\
\hline \multirow{3}{*}{ Aprendizaje } & $\begin{array}{l}\text { Al: Desarrollar competencias } \\
\text { requeridas del puesto }\end{array}$ & RRHH & Al.a Índice de desempeño & $\%$ & Semestral \\
\hline & $\begin{array}{l}\text { A2: Mejorar la fidelización del } \\
\text { personal operativo }\end{array}$ & RRHH & $\begin{array}{l}\text { A2.a Tasa de rotación del personal } \\
\text { operativo }\end{array}$ & $\%$ & Semestral \\
\hline & $\begin{array}{l}\text { A3: Asegurar h cultura Six } \\
\text { Sigma }\end{array}$ & PE & A3.a Proyectos Six SIgma & Cant & Anual \\
\hline
\end{tabular}

Fuente: La empresa

\subsection{Descripción del proceso de producción}

El proceso de producción textil en la empresa bajo investigación involucra nueve subprocesos. El inicio de la producción se realiza en las plantas desmontadoras que se 
encargan de acopiar el algodón entregado por agricultores locales de Piura y Lambayeque. Posteriormente, el subproceso de Hilandería se encarga de transformar la materia prima en hilos de diferentes tipos.

Seguido a ello, el hilo podrá ser despachado a un cliente externo o ser la materia prima de los subprocesos de tintorería de Hilos o Tejeduría. El subproceso de tintorería de hilos, tal como su nombre lo indica se encarga de brindar color al hilo crudo. Este producto también puede ser despachado a un cliente externo o ser la materia prima del subproceso de tejeduría. Por su parte, el subproceso de Tejeduría se encarga de entrelazar perpendicularmente dos o más hilos estirados con el objetivo de transformar las fibras o hilos en telas. Dependiendo del tipo de tela que se desee se desarrollará el diseño, la proporción de la fibra y la estructura de la tela. Cabe mencionar que la empresa solo cuenta con el subproceso de tejido plano más no de tejido de punto. El producto final de tejeduría es el tejido crudo. Este producto será la materia prima del siguiente subproceso, el cual es el preparado. El preparado tiene el objetivo dar un tratamiento previo a la tela y de esa forma eliminar del tejido el $15 \%$ o hasta el $25 \%$ de sustancias extrañas. Luego del preparado, la tela puede seguir por diferentes subprocesos: teñido de tela, estampado o acabado. El subproceso de teñido de tela se lleva a cabo utilizando medios mecánicos (humectación por impregnado y exprimido).

El baño de teñido se distribuye homogéneamente sobre la tela. Por otra parte, el subproceso de estampado se encarga de la aplicación local del colorante que resulta en diseños por composición de la forma y el color, A diferencia del subproceso de teñido de tela, en el estampado se emplea soluciones o dispersiones espesadas, de tal forma se evita que la partícula de colorante migre, reteniendo el color en la superficie de estampación Posteriormente las tela preparada, la tela estampada y la tela teñida pasarán al subproceso de acabado, la cual tiene como fin modificar su tacto, apariencia o comportamiento, ya que durante los subprocesos anteriores se perdieron ceras y grasas naturales de la materia prima. El acabado de telas brinda un valor agregado a las telas, además de diferenciarse por crear acabados únicos.

Cabe mencionar que el tipo de acabado dependerá del tipo de prenda y en qué segmento de precio se va a vender. Como se puede apreciar en el subproceso de acabado se generan cuatro tipos de telas las cuales podrán ser comercializadas a los clientes finales o seguir con el subproceso de confección. En este último subproceso la tela se transformara en piezas y pasará por diferentes actividades hasta conseguir una prenda final. Cabe mencionar que el proceso de confección lo realiza una subsidiaria de la empresa. 
Asimismo, es importante mencionar pre producción, control de calidad y planeamiento y control de la producción son procesos de apoyo fundamentales para que se llegue con el objetivo de la empresa. A continuación, se muestra una representación gráfica de los subprocesos de producción detallados líneas anteriores. Asimismo, se muestra los tipos de productos que se venden y los procesos por los que deben de pasar para ser fabricados. 
Figura 7: Proceso de producción y productos finales

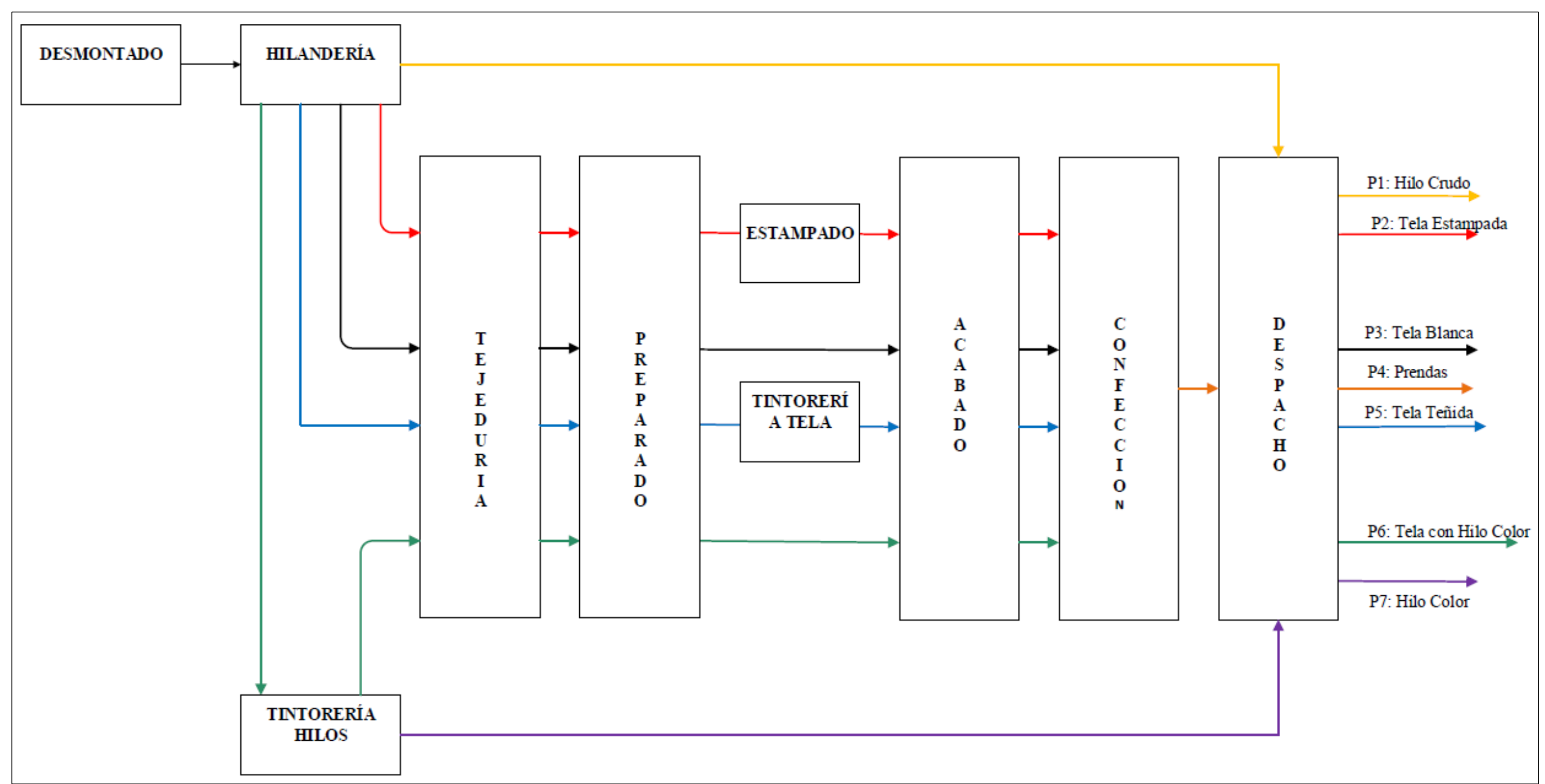

Fuente: Elaboración propia 


\subsection{Identificación del problema actual: Oportunidad de mejora}

La empresa al ser una empresa de gran escala mantiene oportunidades de mejora en cada uno de sus Macroprocesos; sin embargo, para identificar la problemática a solucionar se empleará el análisis de los resultados 2016 de la matriz estratégica.

\subsubsection{Análisis de la matriz estratégica: Objetivos de ventas}

De acuerdo con lo presentado en el punto 2.1.5.1 y 2.1.5.2 se puede observar que el objetivo de incrementar las ventas no ha sido logrado. Según información proporcionada por la empresa se pronosticaba un incremento del $5 \%$ de las ventas nacionales y extranjeras; respecto al año precedente; sin embargo, el indicador financiero arrojo resultados no favores.

Los ingresos por ventas de la empresa al 31 de diciembre del año 2016 alcanzaron la cifra de S/ 244299 546. Siendo este monto un 5\% menor al de año 2015. Asimismo, se puede identificar que desde el 2014 existe una tendencia a la baja en el nivel de ventas. Además, analizando los resultados de ventas por tipo de producto se observa que respecto al año 2015, los ingresos referentes a la venta de tejido y sub productos tuvieron incrementos del 15\% y más del $100 \%$ respectivamente; en cambio, los otros tipos de productos han sufrido una disminución considerable en sus ventas.

Tabla 9: Ventas de la empresa en los tres últimos años

\begin{tabular}{|l|r|r|r|}
\hline \multicolumn{1}{|c|}{ Ventas } & \multicolumn{1}{c|}{$\mathbf{2 0 1 4}$} & \multicolumn{1}{c|}{$\mathbf{2 0 1 5}$} & \multicolumn{1}{c|}{$\mathbf{2 0 1 6}$} \\
\hline Hilado & \multicolumn{1}{c|}{ S/. } & \multicolumn{1}{c|}{ S/. } & \multicolumn{1}{c|}{ S/. } \\
\hline Tejido & 138136314 & 143023598 & 131099362 \\
\hline Prendas & 61615659 & 44707334 & 51614534 \\
\hline Accesorios y otros & 55611665 & 59166835 & 52747802 \\
\hline Algodón & 883677 & 1088536 & 1038680 \\
\hline Otros & 4060543 & 2526439 & 24988 \\
\hline Sub-productos & 0 & 0 & 49555 \\
\hline Pepa de algodón & 4664013 & 1307030 & 3400659 \\
\hline Servicios en mercado local & 1849950 & 2477848 & 1453303 \\
\hline Servicios en mercado del exterior & 3377357 & 4033388 & 2870663 \\
\hline Total & $\mathbf{2 7 0 1 9 9 1 7 8}$ & $\mathbf{2 5 8 3 3 1 0 0 8}$ & $\mathbf{2 4 4 2 9 9 5 4 6}$ \\
\hline
\end{tabular}

Fuente: La empresa 
La oportunidad de mejora será enfocada en aquellos productos que proporcionan a la empresa mayores ingresos; es decir Hilado, tejido y prendas. De estos tres productos la selección de tipo de producto a mejorar se basa en la cantidad de productos que quedan en inventario y el análisis de la rentabilidad que genera los productos a la empresa.

De acuerdo con la información presentada en la memoria 2016, la empresa produjo la cantidad de 7779774 kilos en hilado, asimismo se produjo 4745076 metros de tejidos y finalmente la producción de prendas de vestir sumo un total de 777643 unidades. Por otra parte, en lo que se refiere a ventas en el 2016 se vendió 6834705 kilos de hilo, 3 424928 metros de tejido de algodón y 874957 prendas de vestir. Al tener la información de producción y ventas se pudo realizar el cálculo del inventario por tipo de producto, es así como de acuerdo a la tabla 10 se observa que la mayor diferencia de producción que permaneció sin ser vendida fue la categoría de tejidos de algodón.

Tabla 10: Inventario de productos 2016

\begin{tabular}{|l|c|c|c|}
\hline Tipo de producto & Producción & Venta & Diferencia \\
\hline Hilado de algodón $(\mathrm{Kg})$ & $7,779,774$ & $6,834,705$ & 945,069 \\
\hline Tejidos de algodón $(\mathrm{m})$ & $4,745,076$ & $3,424,928$ & $1,320,148$ \\
\hline Prendas (Und) & 777,643 & 874,957 & $-97,314$ \\
\hline
\end{tabular}

Fuente: La empresa

Asimismo, para analizar la rentabilidad de los productos seleccionados se utilizó la información proporcionada por la empresa, así como también la contenida en su Estado de Ganancias y Pérdidas. De esa forma se identificó que el producto Hilos aporta un margen de ganancia de $12 \%$, el producto telas un $25 \%$ y las prendas un $13 \%$. Por tanto, se concluye que las telas representan al producto de mayor rentabilidad para la empresa.

Tabla 11: Rentabilidad por productos 2016

\begin{tabular}{|l|c|c|c|}
\hline \multicolumn{1}{|c|}{ Tipo de producto } & $\begin{array}{c}\text { Venta Anual en } \\
\text { S/. }\end{array}$ & $\begin{array}{c}\text { Margen } \\
\text { Ganancia S/. }\end{array}$ & $\begin{array}{c}\text { \% Margen de Ganancia } \\
\text { por producto }\end{array}$ \\
\hline Hilado de Algodón & 131.009 .362 & 15.721 .123 & $12 \%$ \\
\hline Tejido de Algodòn & 51.614 .534 & 12.903 .634 & $25 \%$ \\
\hline Prendas & 52.747 .802 & 6.857 .214 & $13 \%$ \\
\hline
\end{tabular}


Finalmente, analizando la rentabilidad por tipo de tela comercializada se puede observar el menor margen de ganancia aportado hace referencia al producto tela Hilo color a pesar de que en el 2016 fue el producto con más ventas. En contraparte la tela teñida genera un margen de ganancia de 25\%; no obstante, fue uno de los productos con menor venta del año anterior al actual. Los otros tipos de productos mantienen un margen de ganancia de $25 \%$ y $28 \%$

\subsubsection{Análisis del cumplimiento de despacho a tiempo del producto tela}

Una vez identificado la importancia monetaria del producto tela se procede a analizar el cumplimiento de despachos a tiempo del producto en mención. Durante el 2016 hubo un total de 4898 pedidos de diferentes tipos de tela. A continuación, se mostrará el total de pedidos por mes y la cantidad de despachos entregados fuera de tiempo.

Figura 8: Telas Despachos con demoras de entrega vs. Despachos programados a tiempo.

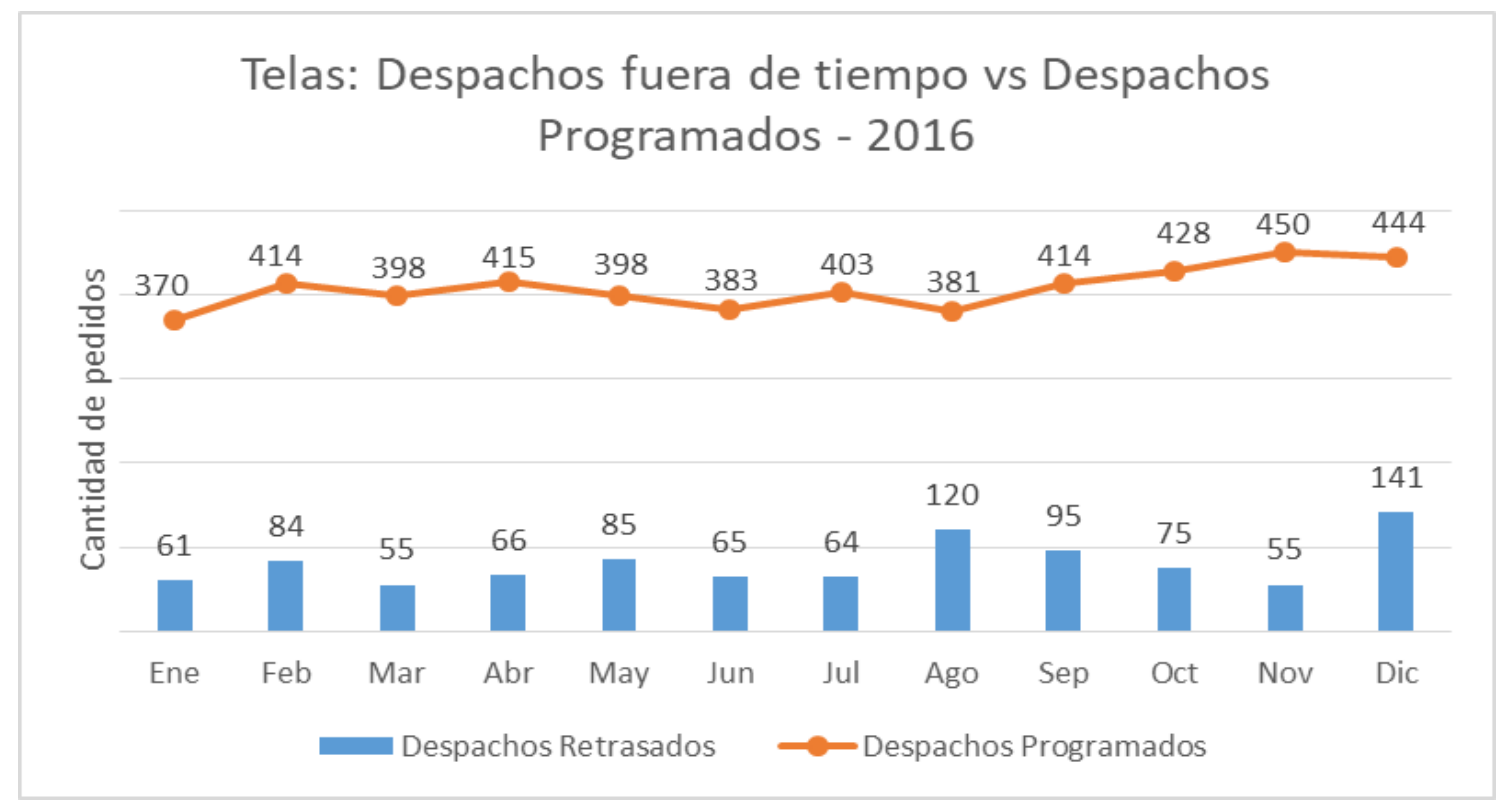

Elaboración propia. Fuente: La empresa

Al año la cantidad de despachos fuera de tiempo suman un total de 1201 pedidos; es decir casi el $25 \%$ del total de pedidos. Asimismo, de acuerdo con la información proporcionada por la empresa en ninguno de los meses del año 2016 el indicador de nivel de cumplimiento del tiempo de despacho alcanzó el porcentaje óptimo de 95\% ni tampoco alcanzó el resultado de alerta (amarillo) $(>90 \%,<95 \%)$. Como se muestra a continuación: 
Figura 9: Nivel de cumplimiento de despacho de tela

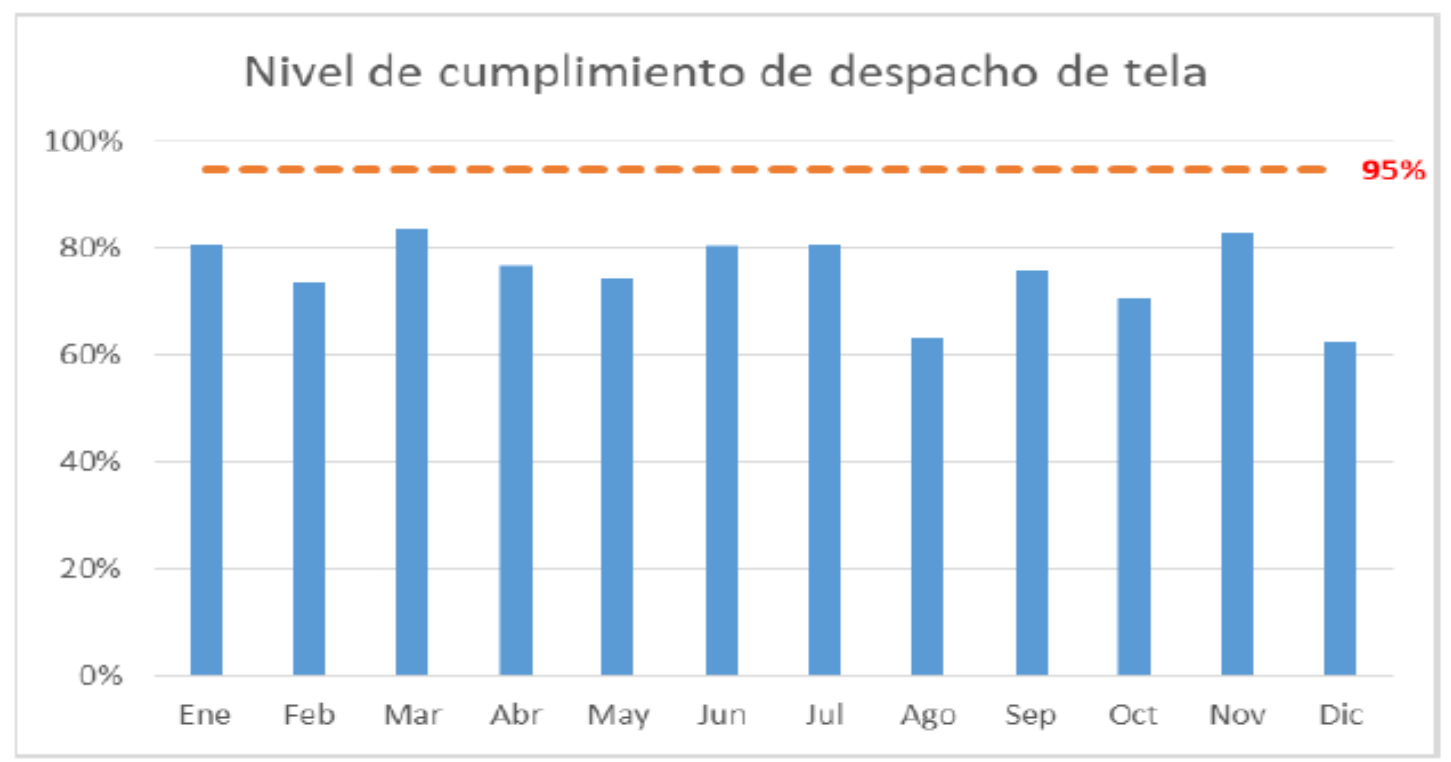

Elaboración propia. Fuente: La empresa

Por lo mostrado anteriormente fue necesario identificar la cantidad de pedidos entregados fuera de tiempo y el nivel de cumplimiento de despacho a tiempo por tipo de tela.

Con respecto al subproducto tela con Hilo de color se observa en la figura 10 que durante el 2016 se tuvo un total de 2061 pedidos de los cuales 193 se entregaron fuera de tiempo, equivalente al $9 \%$ del total de pedidos. Asimismo, analizando el nivel de cumplimiento óptimo durante seis meses se llegó a la meta de pasar del 95\% y los otros meses se encontraron dentro de un rango mayor del $85 \%$, como se muestra a continuación: 
Figura 10: Tela con Hilo de Color: Despachos con demoras vs. Despachos programados a tiempo

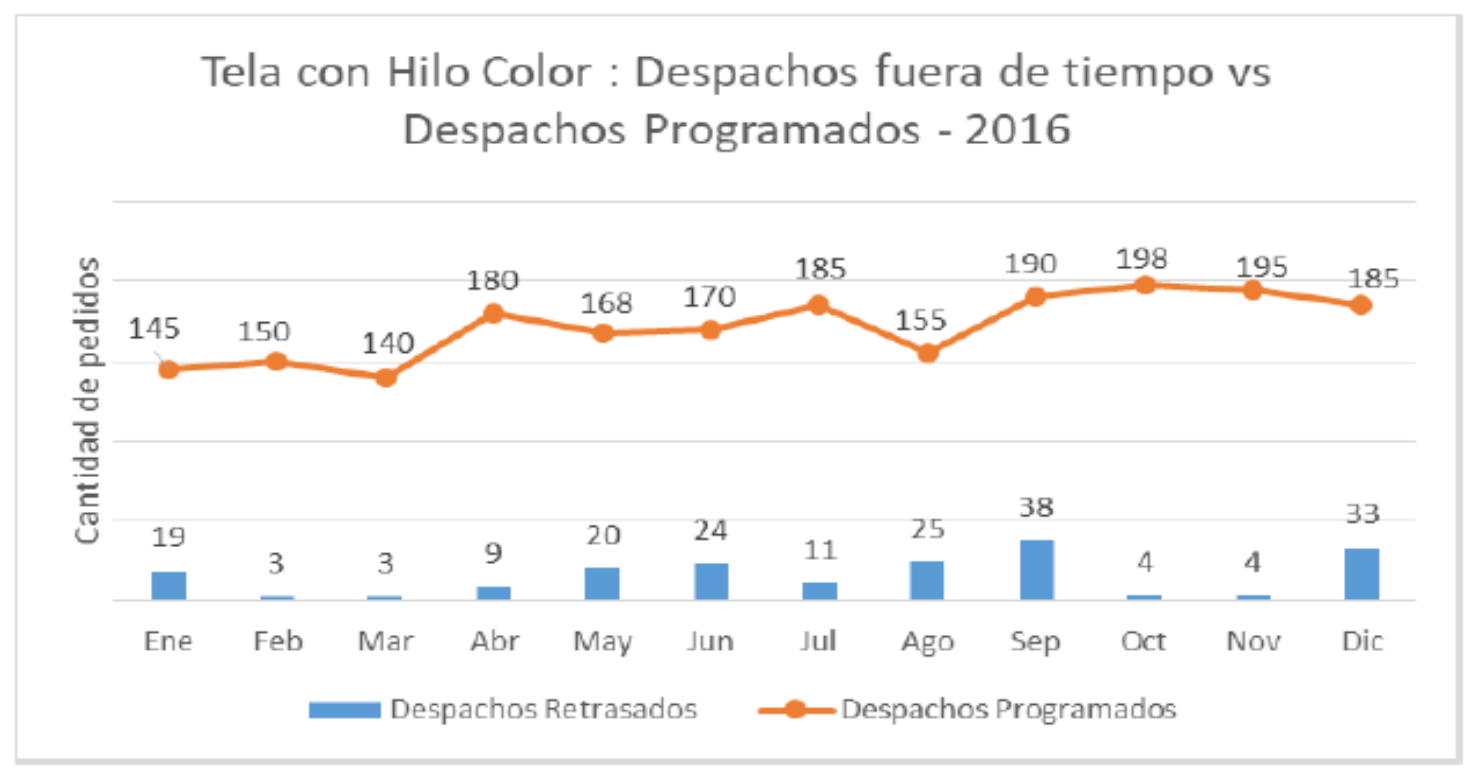

Elaboración propia. Fuente: La empresa

Figura 11: Nivel de cumplimiento de despacho de tela con hilo de color

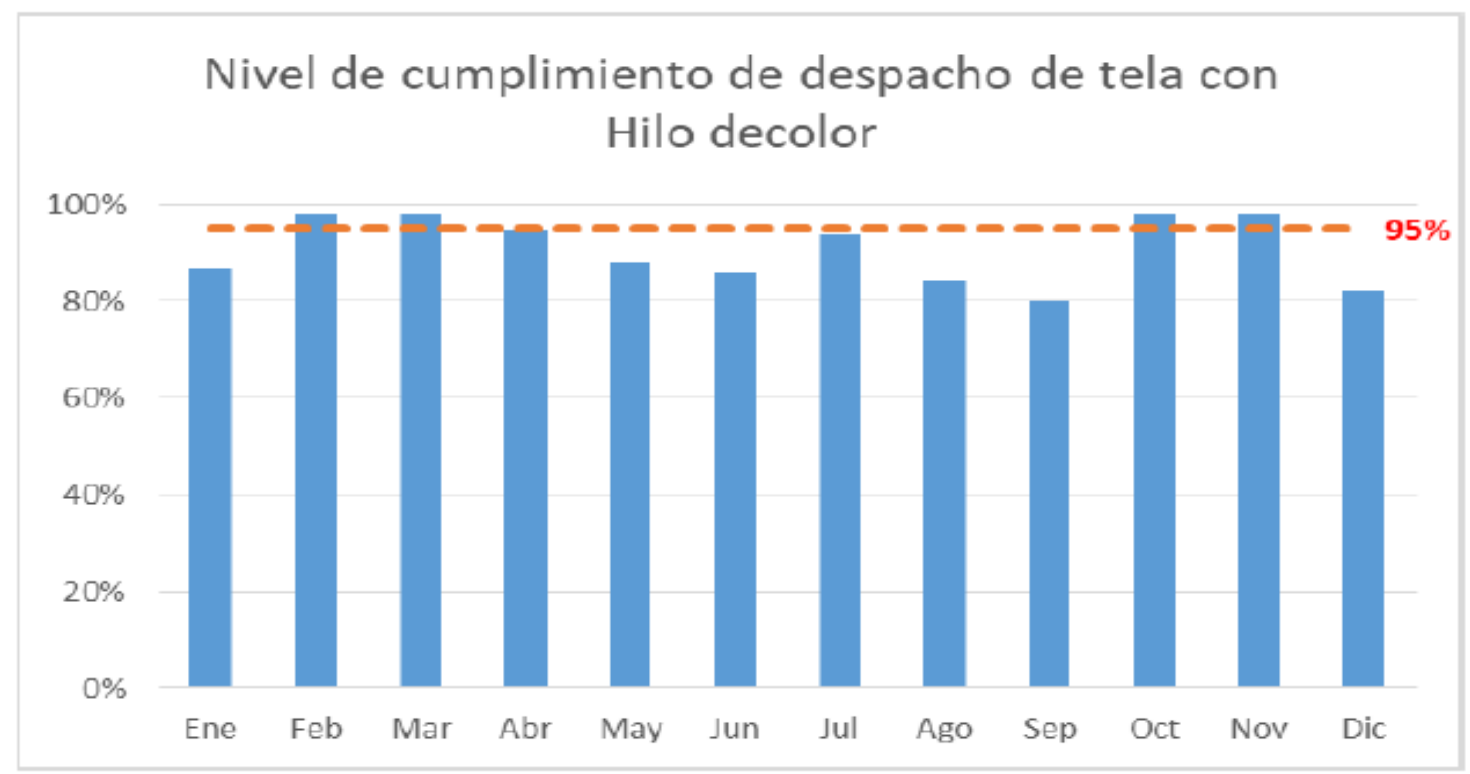

Elaboración propia. Fuente: La empresa

Por otro lado, en el subproducto tela cruda los resultados durante el 2016 muestran un total de 1128 pedidos de los cuales 150 se entregaron fuera de tiempo. Equivalentes al $13 \%$ del total de pedidos. Asimismo, analizando el nivel de cumplimiento óptimo durante seis meses se llegó a pasar la meta del 95\%, sin embargo, los meses de julio, agosto y 
setiembre el nivel de cumplimiento de despacho a tiempo fue menor a $80 \%$.

Figura 12: Tela cruda: Despachos con demora vs. Despachos programados a tiempo

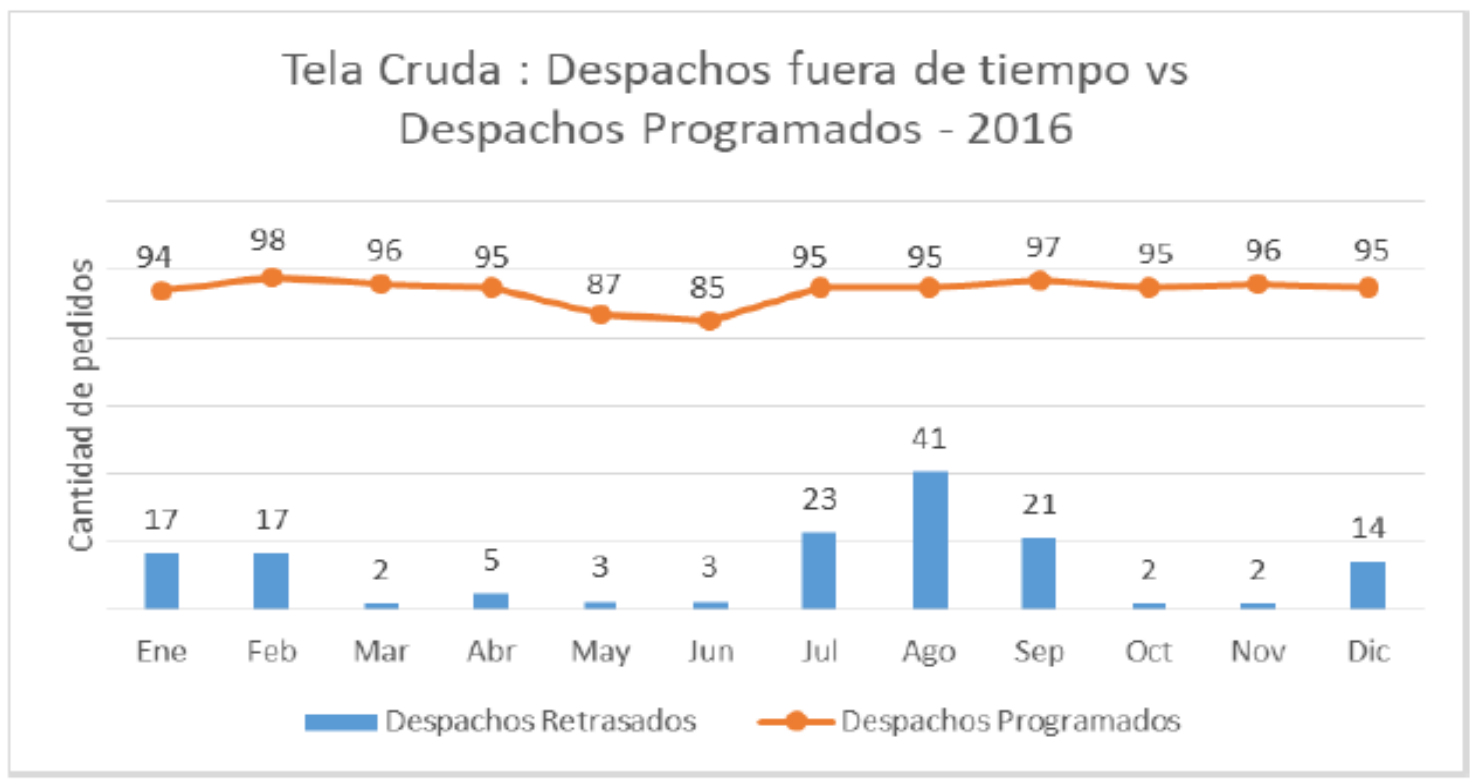

Elaboración propia. Fuente: La empresa

Figura 13: Nivel de cumplimiento de despacho de tela cruda

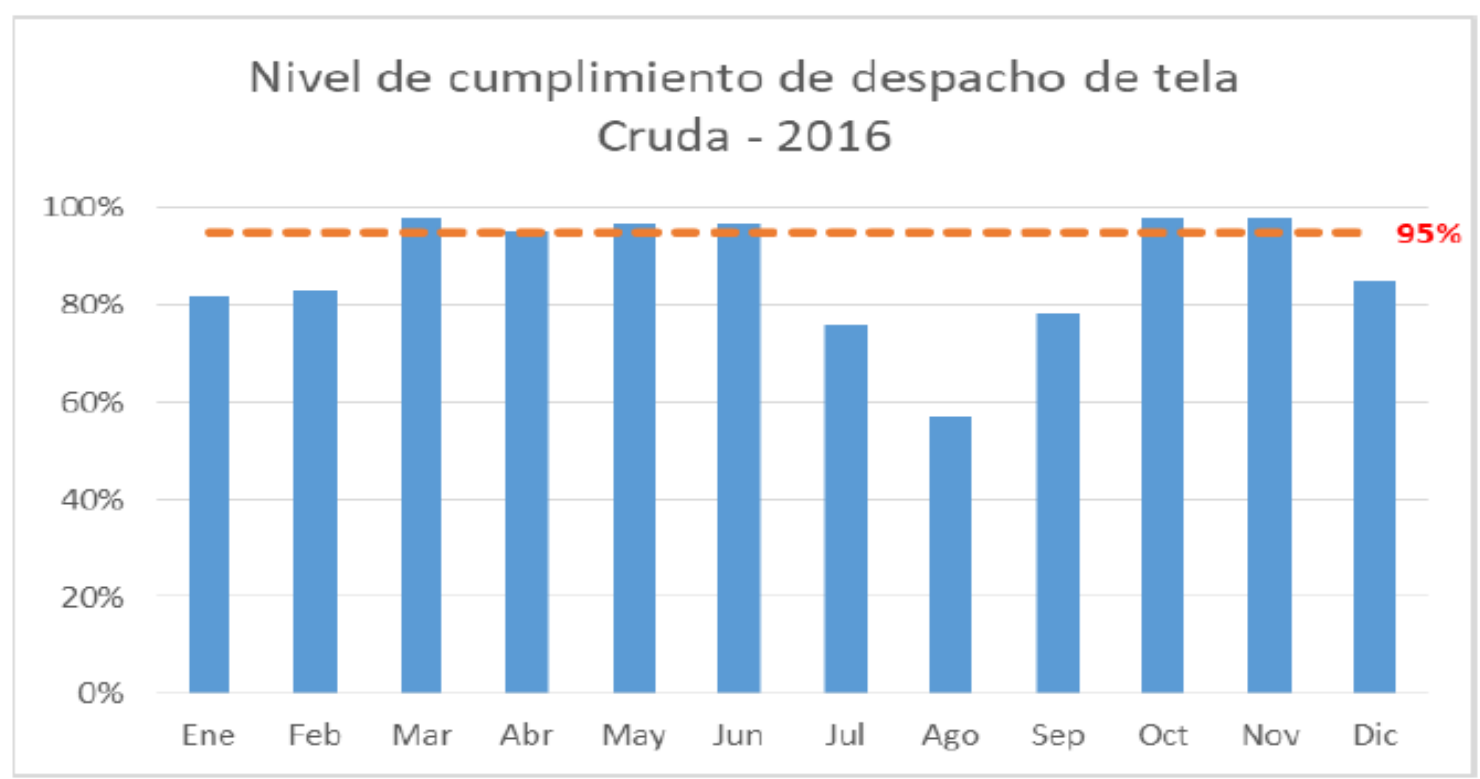

Elaboración propia. Fuente: La empresa

En referencia al subproducto tela estampada los resultados no fueron tan favorables como los anteriores, ya que en el 2016 de un total de 1022 pedidos 281 se entregaron fuera de tiempo; $27 \%$ de pedidos. Ocasionando, un nivel de cumplimiento por debajo de la meta 
en los meses del año 2016, como se muestra en las siguientes figuras 14 y 15

Figura 14: Tela estampada: Despachos con demoras y despachos programados a tiempo

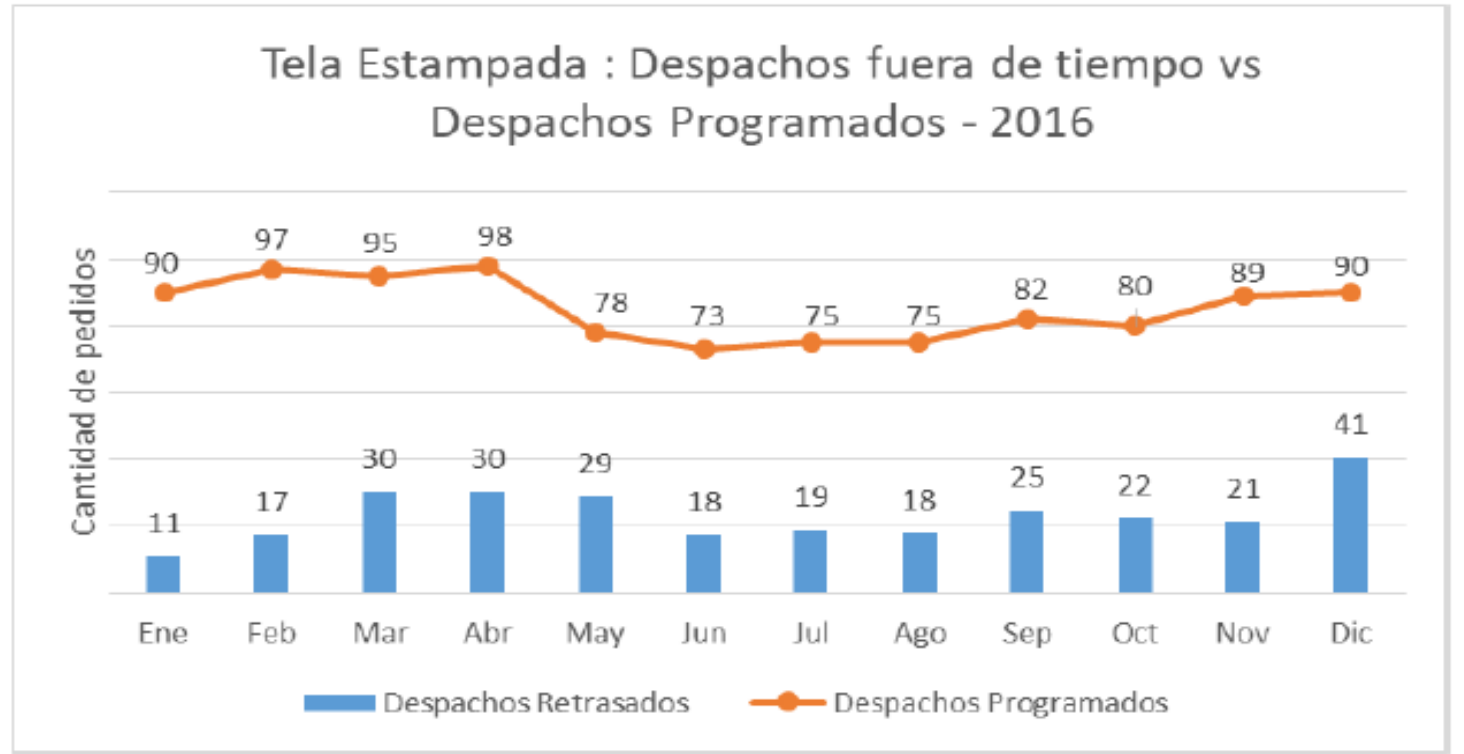

Elaboración propia. Fuente: La empresa

Figura 15: Nivel de cumplimiento de despacho de tela estampada

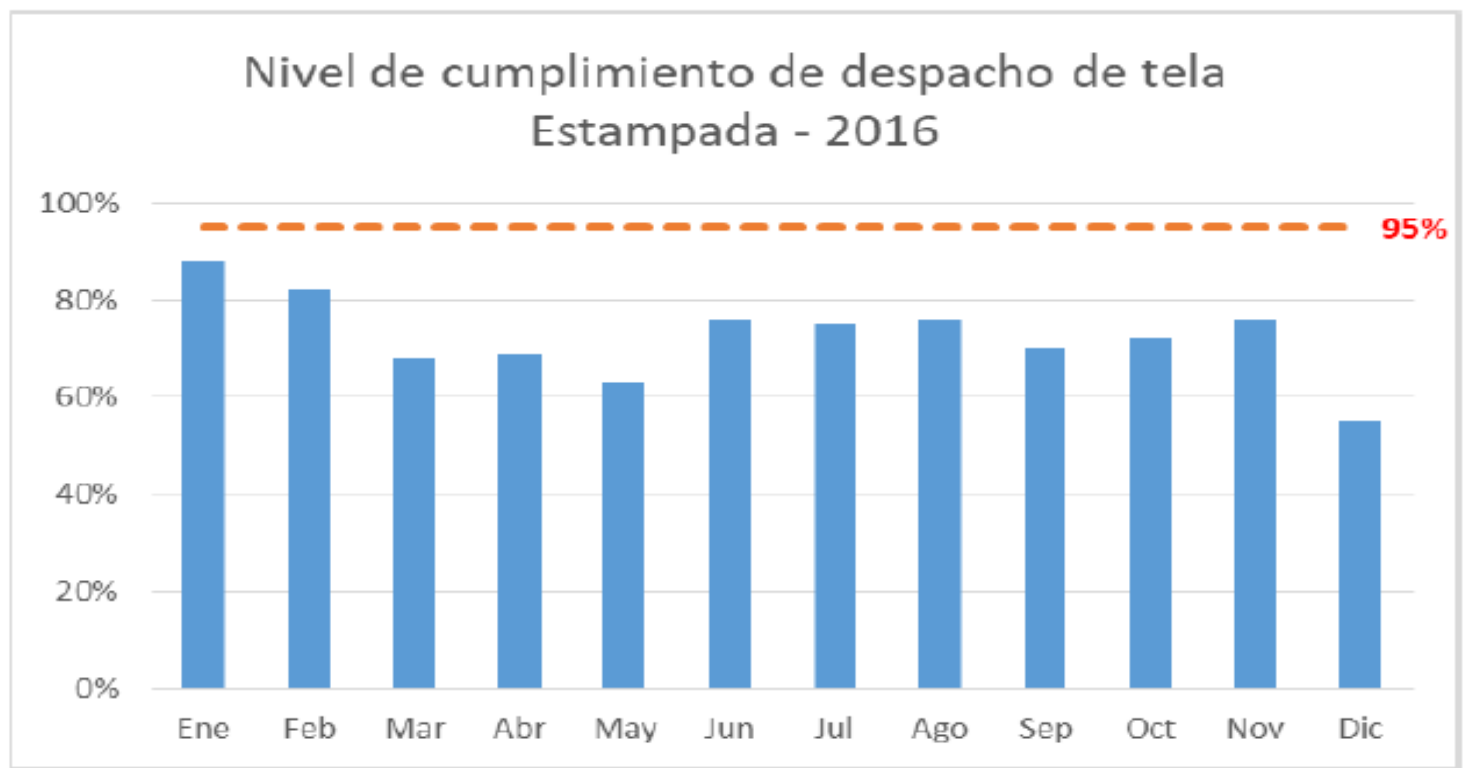

Elaboración propia. Fuente: La empresa

Finalmente, el subproducto tela teñida tuvo mayor cantidad de pedidos entregados fuera de tiempo, de un total de 687 pedidos 342 se entregaron fuera de la fecha, equivalentes a un 49\%. El nivel de cumplimiento se encontró por debajo de la meta porcentual, y por 
debajo del rango crítico en todos los meses del 2016, véase las figuras 16 y 17

Figura 16: Tela Teñida: Despachos con demoras vs. Despachos programados a tiempo

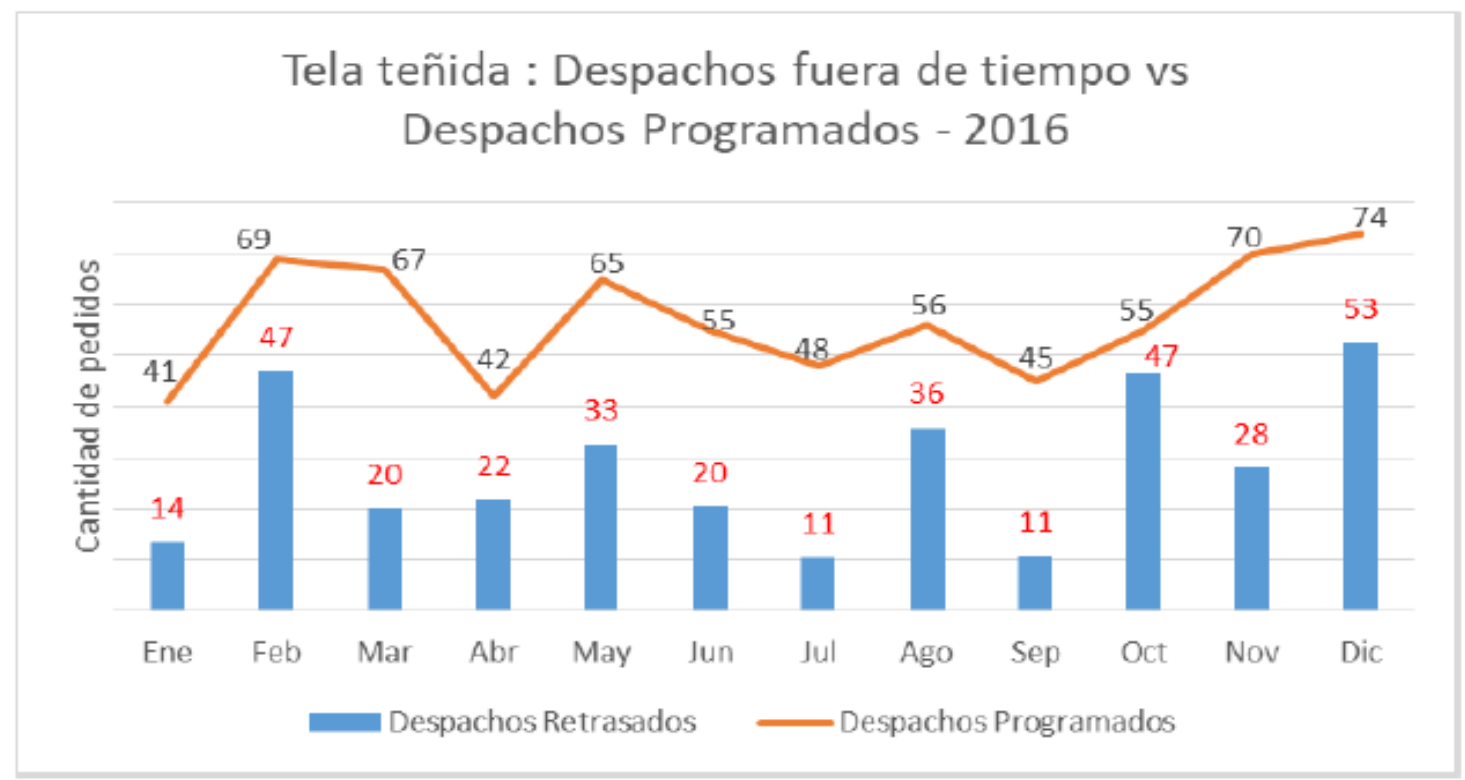

Elaboración propia. Fuente: La empresa

Figura 17: Nivel de cumplimiento de despacho de tela teñida

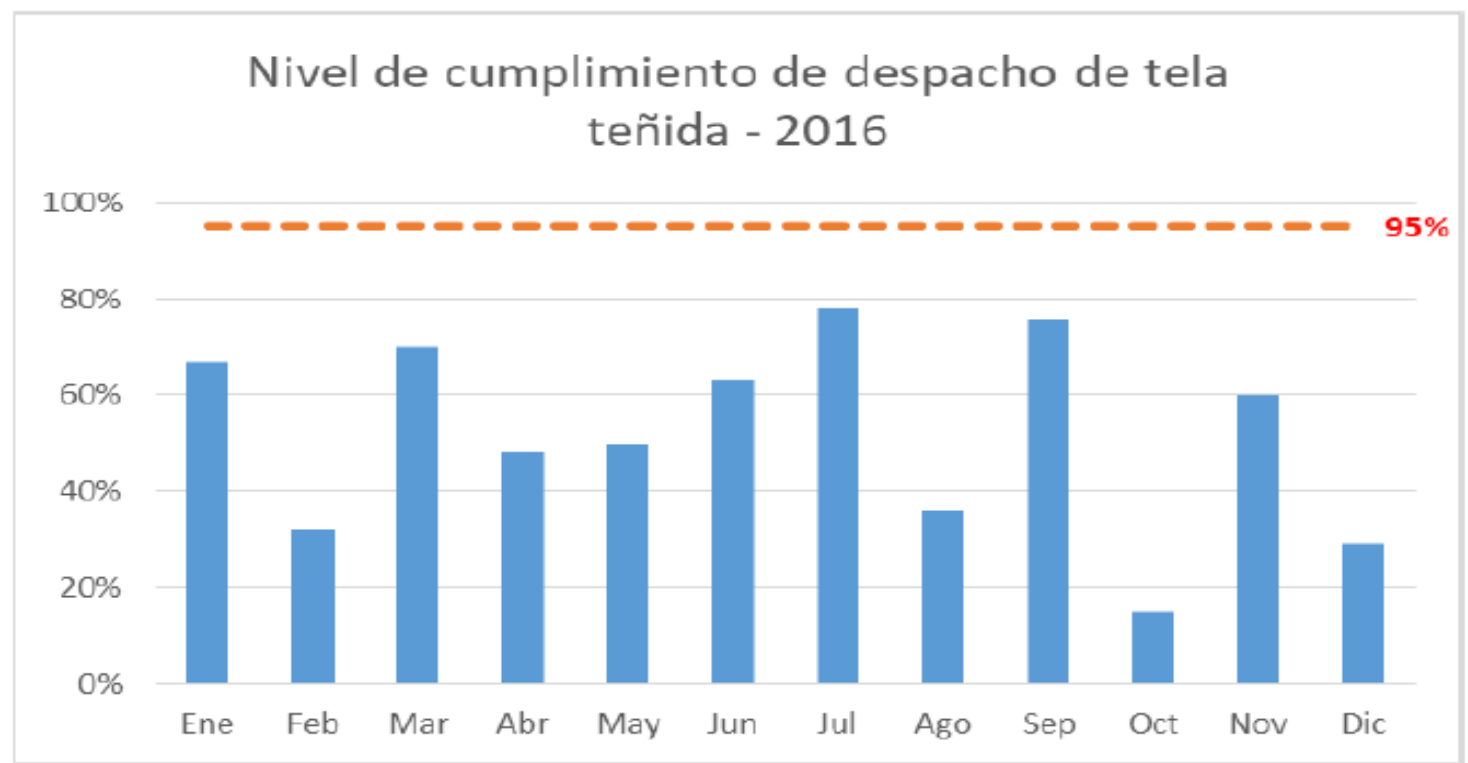

Elaboración propia. Fuente: La empresa

Según los resultados presentados anteriormente, sé determina que el despacho de tela teñida es aquel producto crítico y con mayor variabilidad respecto al cumplimiento de despacho a tiempo. Por lo tanto, será necesario identificar las causas por las cuales se 
origina este problema.

Tabla 11: Comparación Tipo de Producto de acuerdo con su nivel de cumplimiento

\begin{tabular}{|l|c|c|c|}
\hline \multicolumn{1}{|c|}{ Tipo de producto } & $\begin{array}{c}\text { Nivel de } \\
\text { cumplimiento a } \\
\text { tiempo }\end{array}$ & $\begin{array}{c}\text { Nivel de } \\
\text { cumplimiento } \\
\text { fuera de fecha }\end{array}$ & $\begin{array}{c}\text { Nivel de } \\
\text { cumplimiento } \\
\text { esperado }\end{array}$ \\
\hline Tela Cruda (Blanco) & $87 \%$ & $13 \%$ & $95 \%$ \\
\hline Tela Estampada & $73 \%$ & $27 \%$ & $95 \%$ \\
\hline Tela Hilo Color & $91 \%$ & $86 \%$ & $95 \%$ \\
\hline Tela Teñida & $52 \%$ & $49 \%$ & $95 \%$ \\
\hline
\end{tabular}

Elaboración propia, fuente: La empresa

Por lo tanto, en la siguiente tabla 13 se han ingresado todos los resultados del análisis precedente, en donde, se muestra que el subproducto de tela teñida es el que menor nivel de cumplimiento (NC) de entregas de 33\%, cuando, el subproducto de tela con hilo de color tiene un nivel de cumplimiento fuera de tiempo de $9 \%$, la tela cruda de $12 \%$ y la tela estampada de $22 \%$. Al compararse al $100 \%$ de la producción el tiempo de entrega fuera de tiempo del subproducto de tela teñida es de $6 \%$ 
Tabla 12: Resultados del Análisis de entregas tardías

\begin{tabular}{|c|c|c|c|c|c|c|c|c|c|c|c|c|c|c|c|c|c|c|}
\hline \multirow[b]{2}{*}{ Mes - 2016} & \multicolumn{4}{|c|}{ TELA CON HILO COLOR } & \multicolumn{4}{|c|}{ TELA CRUDA } & \multicolumn{4}{|c|}{ TELA ESTAMPADA } & \multicolumn{4}{|c|}{ TELA TEÑIDA } & \multicolumn{2}{|c|}{ TOTAL } \\
\hline & \begin{tabular}{|c|} 
Programado \\
$\mathrm{s}$
\end{tabular} & $\begin{array}{c}\text { Fuera de } \\
\text { tiempo }\end{array}$ & NC & NNC & $\begin{array}{c}\text { Programado } \\
\mathrm{s}\end{array}$ & $\begin{array}{c}\text { Fuera de } \\
\text { tiempo }\end{array}$ & NC & NNC & \begin{tabular}{|c|} 
Progra mado \\
$\mathrm{s}$
\end{tabular} & $\begin{array}{c}\text { Fuera de } \\
\text { tiempo }\end{array}$ & NC & NNC & $\begin{array}{c}\text { Progra ma do } \\
\mathrm{s}\end{array}$ & $\begin{array}{c}\text { Fuera de } \\
\text { tiempo }\end{array}$ & $\mathrm{NC}$ & NNC & \begin{tabular}{|c|}
$\begin{array}{c}\text { Programa } \\
\text { dos }\end{array}$ \\
\end{tabular} & \begin{tabular}{|c|} 
Fuera de \\
tiempo
\end{tabular} \\
\hline Enero & 145 & 19 & $88 \%$ & $12 \%$ & 94 & 17 & $85 \%$ & $15 \%$ & 90 & 11 & $89 \%$ & $11 \%$ & 41 & $\begin{array}{r}14 \\
\end{array}$ & $75 \%$ & $25 \%$ & 370 & 61 \\
\hline Febrero & 150 & 3 & $98 \%$ & $2 \%$ & 98 & 17 & $85 \%$ & $15 \%$ & 97 & 17 & $85 \%$ & $15 \%$ & 69 & 47 & $59 \%$ & $41 \%$ & 414 & 84 \\
\hline Marzo & 140 & 3 & $98 \%$ & $2 \%$ & 96 & 2 & $98 \%$ & $2 \%$ & 95 & 30 & $76 \%$ & $24 \%$ & 67 & 20 & $77 \%$ & $23 \%$ & 398 & 55 \\
\hline Abril & 180 & 9 & $95 \%$ & $5 \%$ & 95 & 5 & $95 \%$ & $5 \%$ & 98 & 30 & $77 \%$ & $23 \%$ & 42 & 22 & $66 \%$ & $34 \%$ & 415 & 66 \\
\hline Mayo & 168 & 20 & $89 \%$ & $11 \%$ & 87 & 3 & $97 \%$ & $3 \%$ & 78 & 29 & $73 \%$ & $27 \%$ & 65 & 33 & $66 \%$ & $34 \%$ & 398 & 85 \\
\hline Junio & 170 & 24 & $88 \%$ & $12 \%$ & 85 & 3 & $97 \%$ & $3 \%$ & 73 & 18 & $80 \%$ & $20 \%$ & 55 & 20 & $73 \%$ & $27 \%$ & 383 & 65 \\
\hline Julio & 185 & 11 & $94 \%$ & $6 \%$ & 95 & 23 & $81 \%$ & $19 \%$ & 75 & 19 & $80 \%$ & $20 \%$ & 48 & 11 & $81 \%$ & $19 \%$ & 403 & 64 \\
\hline Agosto & 155 & 25 & $86 \%$ & $14 \%$ & 95 & 41 & $70 \%$ & $30 \%$ & 75 & 18 & $81 \%$ & $19 \%$ & 56 & 36 & $61 \%$ & $39 \%$ & 381 & 120 \\
\hline \begin{tabular}{|l} 
Setiembre \\
\end{tabular} & 190 & 38 & $83 \%$ & $17 \%$ & 97 & 21 & $82 \%$ & $18 \%$ & 82 & 25 & $77 \%$ & $23 \%$ & 45 & 11 & $80 \%$ & $20 \%$ & 414 & 95 \\
\hline Octubre & 198 & 4 & $98 \%$ & $2 \%$ & 95 & 2 & $98 \%$ & $2 \%$ & 80 & 22 & $78 \%$ & $22 \%$ & 55 & 47 & $54 \%$ & $46 \%$ & 428 & 75 \\
\hline \begin{tabular}{|l|} 
Noviembre \\
\end{tabular} & 195 & 4 & $98 \%$ & $2 \%$ & 96 & 2 & $98 \%$ & $2 \%$ & 89 & 21 & $81 \%$ & $19 \%$ & 70 & 28 & $71 \%$ & $29 \%$ & 450 & 55 \\
\hline Diciembre & 185 & 33 & $85 \%$ & $15 \%$ & \begin{tabular}{|c|}
95 \\
\end{tabular} & 14 & $87 \%$ & $13 \%$ & 90 & 41 & $69 \%$ & $31 \%$ & 74 & 53 & $58 \%$ & $42 \%$ & 444 & 141 \\
\hline & 2061 & 193 & & & 1128 & 150 & & & 1022 & 281 & & & 687 & 342 & & & 4898 & 966 \\
\hline \begin{tabular}{|l|} 
Nivel de \\
cumplimiento/incumplimie \\
nto por categoría
\end{tabular} & $91 \%$ & $9 \%$ & & & $88 \%$ & $12 \%$ & & & $78 \%$ & $22 \%$ & & & $67 \%$ & $33 \%$ & & & $84 \%$ & $16 \%$ \\
\hline $\begin{array}{l}\begin{array}{l}\text { Nivel de } \\
\text { cumplimiento/incumplimie } \\
\text { nto total }\end{array} \\
\end{array}$ & $35 \%$ & $3 \%$ & & & $19 \%$ & $3 \%$ & & & $17 \%$ & $5 \%$ & & & $12 \%$ & $6 \%$ & & & & \\
\hline
\end{tabular}

Fuente: Elaboración Propia

Leyenda

$\mathrm{NC}=$ Nivel de cumplimiento

$\mathrm{NNC}=$ Nivel de no cumplimiento 
Por lo que se concluye que, el subproducto de tela teñida es la que lleva mayor nivel de incumplimiento de entregas con un 33\% de los pedidos de teñido, y el $6 \%$ del total.

\subsection{Diagnóstico de las posibles causas que originan el problema}

Para poder identificar las causas raíz del problema de bajo nivel de cumplimiento de entregas por los subproductos de telas teñidas, se han determinado las siguientes causas:

1. Tiempo de espera

2. Reprocesos

3. Paradas Programadas

\subsubsection{Tiempo de Espera}

En el diagrama de análisis del proceso (DAP) que se muestra en la tabla 14, indica las esperas de los tres procesos, Preparado, Teñido y Acabado de 2.75, 4.75 y 2.17 días respectivamente: 
Tabla 13: Diagrama de análisis del proceso teñido de telas

\begin{tabular}{|c|c|c|c|c|c|c|c|c|c|c|c|}
\hline DAP & & & PROCESO DE & EÑIDO & & & & & & & \\
\hline Diagrama: $\quad N^{\circ} 1$ & Hoja $N^{\circ} 1$ de 1 & & & & & ESUME & & & & & \\
\hline Objeto: & & & Activ & idad & Pasos & & $\%$ & Días & $\%$ & & \\
\hline Bobina de tela & & & Demora & $\mathrm{D}$ & 11 & & $5 \%$ & 9.9 & $57 \%$ & & \\
\hline $\begin{array}{l}\text { Actividad: } \\
\text { Preparar (P), teñir (T) y acabar }\end{array}$ & Rutas: & & Operación & $\mathrm{O}$ & 15 & & $4 \%$ & 6.6 & $38 \%$ & & \\
\hline tela $(A)$ & $P:, T:$, A: & & Almacenaje & $\nabla$ & 0 & & $0 \%$ & 0.0 & $0 \%$ & & \\
\hline Método: Actual & & & Transporte & $\Rightarrow$ & 16 & & $6 \%$ & 0.7 & $4 \%$ & & \\
\hline Lugar: Planta de teñido de hilos & telas & & Inspección & $\square$ & 2 & & $5 \%$ & 0.2 & $1 \%$ & & \\
\hline Compuesto por : Elena Arce & & & Distancia to & $\mathrm{al}(\mathrm{m})$ & & & & & & & \\
\hline Descri & & Cantidad & Distancia & $\begin{array}{l}\text { Tiempo } \\
\text { Estándar }\end{array}$ & & & IMBOLOG & & OBS. & & \\
\hline & & & & $\begin{array}{l}\text { (Dias) } \\
\end{array}$ & $\mathrm{O}$ & $\Rightarrow$ & D & $\square$ & $\nabla$ & & \\
\hline Bobina de tela en espera de Char & uscado/desenconlado & 1 & - & 0.55 & & & $x$ & & (1) & & \\
\hline Chamusc/Desencolado & & 1 & - & 0.54 & $x$ & & & & & & \\
\hline traslado de bobina para reposo & & 1 & 9 & 0.00 & & $x$ & & & & & \\
\hline Reposo & & 1 & - & 1.25 & $x<1$ & & & & & & \\
\hline Bobina de tela en espera de blan & ueo químico & 1 & - & 0.80 & & & $z^{*}$ & & (2) & 2.75 & \\
\hline traslado de bobina para blanqueo & químico & 1 & 9 & 0.00 & & $x$ & & & & días & \\
\hline Blanqueo químico & & 1 & & 0.54 & $\times$ & & & & & & \\
\hline traslado de bobina para reposo & & 1 & 6 & 0.00 & & $2 x$ & & & & 7.5 & \\
\hline Reposo & & 1 & & 1.25 & $x$ & & & & & dias & reparado, \\
\hline Traslado de bobina para lavado se & miblanco & 1 & 9 & 0.00 & & $x$ & & & & & romedio tiempos \\
\hline Lavado semiblanco & & 1 & & 0.56 & $x$ & & & & & & le espera: 2.75 días \\
\hline traslado de bobina para merceriz & & 1 & 25 & 0.01 & & $x$ & & & & & \\
\hline Bobina de tela en espera de merc & erizado & 1 & & 0.45 & & & $P x$ & & (3) & & \\
\hline Mercerizado & & 1 & & 0.47 & $x$ & & & & & & \\
\hline Traslado de bobina para secado & & 1 & 24 & 0.01 & & $x$ & & & & & \\
\hline Bobina de tela en espera de seca & & 1 & & 0.95 & & & $x$ & & (4) & & \\
\hline Secado & & 1 & & 0.14 & $x$ & & & & & & \\
\hline Traslado de bobina para ser teñid & & 1 & 12 & 0.00 & & $x$ & & & & & \\
\hline Bobina de tela en espera de teñic & & 1 & & 2.00 & & & 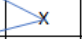 & & (5) & & \\
\hline Teñido & & 1 & & 0.06 & $x$ & & & & & & \\
\hline traslado de bobina para reposo & & 1 & 20 & 0.01 & & $x$ & & & & & \\
\hline Reposo & & 1 & & 1.12 & $x<$ & & & & & & \\
\hline Rollo de tela en espera de lavado & eñido & & & 0.25 & & & $x$ & & & & \\
\hline Traslado de rollo de tela para lav & do teñido & 1 & 18 & 0.01 & & $x$ & & & (6) & 4.75 & \\
\hline Lavado teñido & & 1 & & 0.09 & $x$ & & & & & días & \\
\hline Traslado de rollo de tela para sec & & 1 & 18 & 0.01 & & $x$ & & & & & \\
\hline Rollo de tela en espera de de sec & & 1 & & 0.50 & & & $x$ & & & $6.21 \mathrm{~T}$ & \\
\hline Secado & & 1 & & 0.09 & $x$ & & & & & días & leniao, promedio \\
\hline Traslado de bobina para su revisic & & 1 & 22 & 0.01 & & $x$ & & & & & 1empos de espera: \\
\hline Bobina en espera para su revisiór & & 1 & & 2.00 & & & $x$ & & (7) & & ..75 días \\
\hline Revisión de tela teñida & & 1 & & 0.07 & & & & 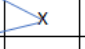 & & & \\
\hline Traslado de bobina para impregna & & 1 & 36 & 0.01 & & $x$ & & & & & \\
\hline Bobina de tela en espera de impr & gnado & 1 & & 1.00 & & & $P x$ & & (8) & & \\
\hline Impregnado & & 1 & & 0.07 & $x$ & & & & & & \\
\hline Traslado de bobina para calandra & & 1 & 10 & 0.00 & & $x$ & & & & & \\
\hline Calandrado & & 1 & & 0.10 & $x<$ & & & & & & \\
\hline Traslado de bobina para sanforiza & & 1 & 4 & 0.00 & & $>x$ & & & & & \\
\hline Sanforizado & & 1 & & 0.08 & $x$ & & & & & 2.17 & \\
\hline Traslado de bobina para revisión & & 1 & 26 & 0.01 & & $x$ & & & 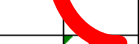 & días & \\
\hline Bobina en espera para su revisiór & & 1 & & 2.00 & & & $x$ & & 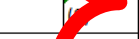 & & \\
\hline Revisión de tela acabada & & 1 & & 0.13 & & & & $x$ & & 3.90 & \\
\hline traslado de bobina para enrollado & doblado & 1 & 5 & 0.00 & & $x<$ & & & & dia Ac & cabado, promedio \\
\hline Bobina en espera de enrollado/do & lado & 1 & & 0.17 & & $\angle$ & $P x$ & & $(10)$ & & empos de espera: \\
\hline Enrollado/Doblado & & 1 & & 0.33 & $x$ & & & & & & días \\
\hline TOT & & & 252 & 17.64 & 15 & 16 & 11 & 2 & 0 & & \\
\hline
\end{tabular}

Elaboración propia. Fuente: La empresa 
Por lo tanto, de la tabla 14, se tomará como línea piloto el proceso de teñido, ya que el tiempo promedio de espera para las 252 observaciones es de 4.75 días por bobina.

Tabla 14: Comparación de Promedio de tiempos entre los 3 procesos

\begin{tabular}{l|r|r|r|}
\multicolumn{3}{c}{$\begin{array}{l}\text { Promedio } \\
\text { días }\end{array}$} & \\
Proceso & Espera & $\%$ & \multicolumn{2}{c}{$\%$ acum } \\
\hline Teñido & 4.75 & $49 \%$ & $49 \%$ \\
\hline Preparado & 2.75 & $28 \%$ & $78 \%$ \\
\hline Acabado & 2.17 & $22 \%$ & $100 \%$ \\
\hline & 9.67 & & \\
\hline
\end{tabular}

Elaboración propia

De la tabla se observa que el $49 \%$ del tiempo de espera se genera en el proceso de teñido con un promedio de 4.75días, creando el cuello de botella, y por ende el mayor retraso en las entregas de este producto. A continuación, se muestra de manera gráfica:

Figura 18: Comparación de Promedio de tiempos entre los 3 procesos

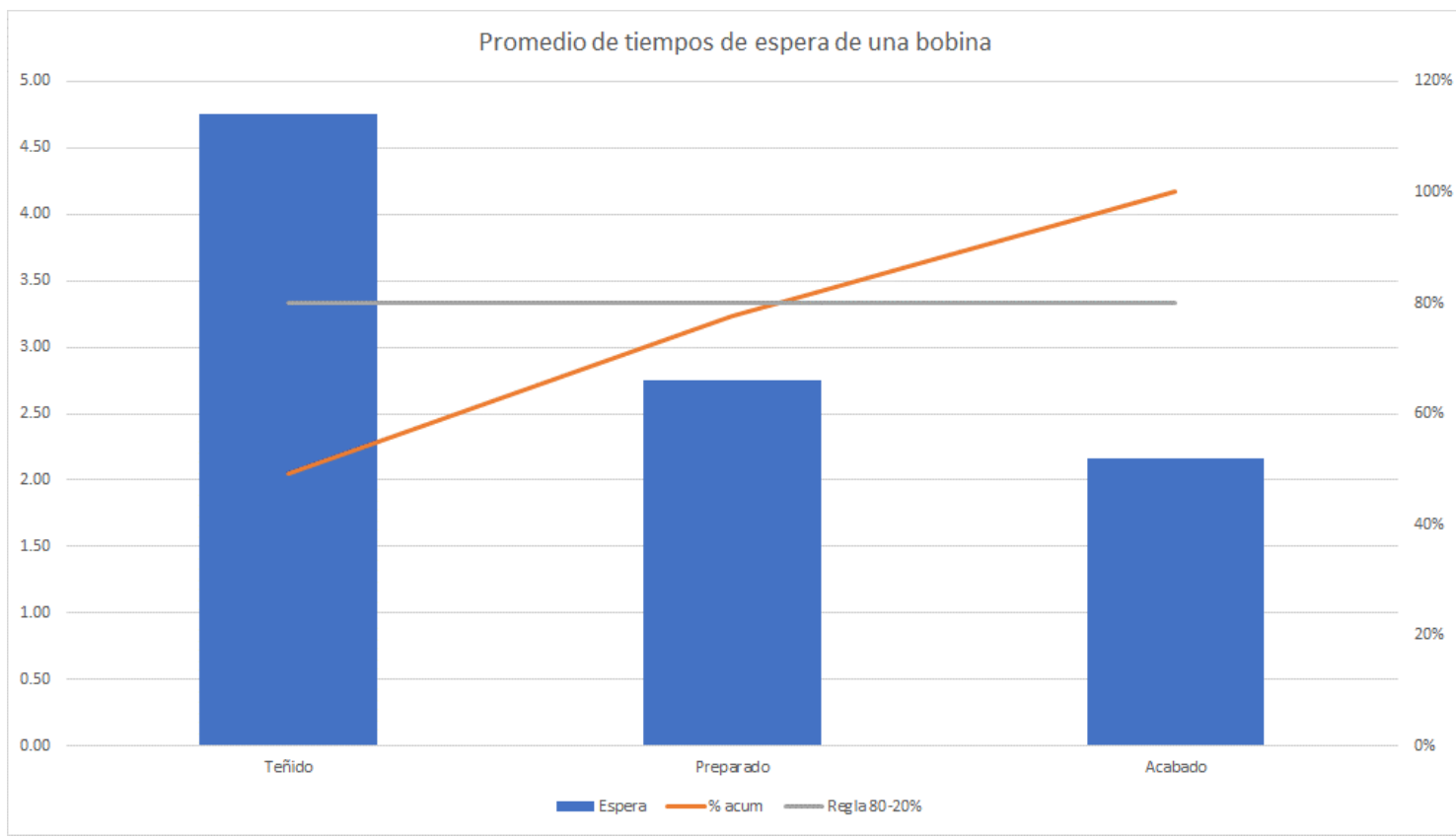

Elaboración propia

Estos tiempos de espera se generan por la cola en una máquina, se quiere dar entender que existen órdenes que están en espera de ser atendidas. La empresa trabaja bajo un sistema make to order, existe la posibilidad de que se genere una sobreproducción de tela. 
Asimismo, una vez que se relacionan el tiempo del proceso sin tiempo de espera, el proceso de teñido muestra que en sí el proceso por bobina es de un promedio de 1.46 días, mientas que para los procesos de preparado y acabado son de 4.78 y 1.73 días respectivamente, como se muestra a continuación:

Tabla 15: Relación de tiempos de proceso y tiempo de espera

\begin{tabular}{|l|r|r|r|r|} 
& \multicolumn{3}{|c|}{ Proceso } & Tiempo de espera \\
\hline Fase & Días & $\%$ & Días & $\%$ \\
\hline Preparado & 4.78 & $27 \%$ & 2.75 & $16 \%$ \\
\hline Teñido & 1.46 & $8 \%$ & 4.75 & $27 \%$ \\
\hline Acabado & 1.73 & $10 \%$ & 2.17 & $12 \%$ \\
\hline Porcentaje & & $45 \%$ & & $55 \%$ \\
\hline
\end{tabular}

Elaboración propia

En la tabla 16 se muestra la relación de los tiempos de cada uno de los procesos y sus respectivos tiempos de espera, en donde para el proceso de teñido se observa que por cada 1.46 días por proceso de una bobina se generan 4.75 días de espera por proceso. Para ello se debe identificar el equipo o maquinaria que genera mayor tiempo de espera o de cola. En la siguiente tabla, se muestra que los totales de paros programados del equipo Jigger (teñido) son de 96.7 horas por año, sin embargo, generan 563.23 horas de tiempo de espera, equivalente a un índice de $17 \%$ de horas de tiempo de espera vs. paros programados, lo cual indica que la relación por 1 hora programada de paro son 6 horas de tiempo de espera o de cola. (Véase tabla 17).

Tabla 16: Relación horas programadas vs horas colas (tiempo de espera)

\begin{tabular}{|c|c|c|c|c|c|}
\hline & \multicolumn{2}{|c|}{ Horas } & \multirow[b]{2}{*}{ Índice } & \multirow{2}{*}{$\begin{array}{l}\text { Relación } \\
\text { Hora } \\
\text { prgramada }\end{array}$} & \multirow[b]{2}{*}{ Cola hora } \\
\hline Máquina & $\begin{array}{l}\text { Paros } \\
\text { programados }\end{array}$ & Cola & & & \\
\hline Blanqueadora & 863.0 & 3519.87 & $25 \%$ & 1 & 4 \\
\hline Gasead/Desenco & 781.2 & 3950.75 & $20 \%$ & 1 & 5 \\
\hline Jigger & 96.7 & 563.23 & $17 \%$ & 1 & 6 \\
\hline Lavadora & 567.5 & 2964.50 & $19 \%$ & 1 & 5 \\
\hline Merceriz/secad & 3258.1 & 13188.55 & $25 \%$ & 1 & 4 \\
\hline Pad Steam & 55.4 & 253.32 & $22 \%$ & 1 & 5 \\
\hline Rama Babcock & 2139.8 & 9514.40 & $22 \%$ & 1 & 4 \\
\hline Rama Monforts & 1554.0 & 5831.50 & $27 \%$ & 1 & 4 \\
\hline
\end{tabular}

Elaboración propia

En la tabla 17 se observa que los equipos a excepción del Jigger, la relación de horas programadas contra las horas de tiempo de espera (colas), es de 1:4 y 1:5, demostrando 
que la Jigger es la que genera mayores tiempos de espera que cualquier otro equipo en el proceso de teñido.

Para descartar las posibles causas de sobreproducción o cuello de botella por capacidad de maquinaria se procedió identificar las capacidades. Cabe indicar que las unidades de medición se encuentran en minutos (min) y metros (m)

Tabla 17: Capacidades de Máquinas

\begin{tabular}{|l|c|c|c|c|c|c|}
\hline \multicolumn{1}{|c|}{ Maquina } & $\begin{array}{c}\text { Tiempo de } \\
\text { procesamiento } \\
(\mathbf{m i n} / \mathbf{m})\end{array}$ & $\begin{array}{c}\text { Capacidad } \\
\text { diaria } \mathbf{( m )}\end{array}$ & $\begin{array}{c}\text { Capacidad } \\
\text { semanal (m) }\end{array}$ & $\begin{array}{c}\text { Capacidad } \\
\text { mensual (m) }\end{array}$ & $\begin{array}{c}\text { Requerimientos } \\
\text { mensual } \\
\text { (programados + no } \\
\text { programados) (m) }\end{array}$ & $\begin{array}{c}\text { Capacidad } \\
\text { Anual (m) }\end{array}$ \\
\hline Gaseadora & 0.020 & 73,495 & 514,467 & $2,204,860$ & 395,423 & $26,458,320$ \\
\hline Blanqueadora & 0.028 & 51,605 & 361,235 & $1,548,149$ & 415,194 & $18,577,790$ \\
\hline Lavadora & 0.032 & 44,813 & 313,690 & $1,344,386$ & 541,730 & $16,132,630$ \\
\hline Mercerizadora & 0.023 & 62,459 & 437,210 & $1,873,757$ & 395,423 & $22,485,079$ \\
\hline Jigger & 0.020 & 71,190 & 498,327 & $2,135,686$ & 431,358 & $25,628,237$ \\
\hline Rama Morfort (Secadora) & 0.032 & 45,161 & 316,130 & $1,354,843$ & 281,146 & $16,258,112$ \\
\hline Rama Babcock (Secadora) & 0.038 & 37,464 & 262,248 & $1,123,919$ & 374,861 & $13,487,028$ \\
\hline Foulard (Teñir) & 0.034 & 42,380 & 296,659 & $1,271,397$ & 114,673 & $15,256,769$ \\
\hline Lavadora & 0.042 & 34,462 & 241,235 & $1,033,866$ & & $12,406,388$ \\
\hline Lavadora & 0.041 & 35,495 & 248,463 & $1,064,841$ & 650,669 & $12,778,090$ \\
\hline Calandra & 0.045 & 31,789 & 222,523 & 953,672 & 395,423 & $11,444,059$ \\
\hline Sanforizadora & 0.037 & 39,205 & 274,437 & $1,176,157$ & 395,423 & $14,113,889$ \\
\hline
\end{tabular}

Elaboración propia

La tabla precedente muestra que el nivel de requerimientos de producción es menor a la capacidad de máquina. Por tanto, se afirma que la sobreproducción no es una causa de los tiempos de espera. Por otra parte, se puede verificar que los tiempos de procesamiento por maquina son similares entre ellos. Los únicos tiempos de mayor procesamiento hacen referencia a la máquina Lavadora y las máquinas Blanqueadora y Jigger.

\subsubsection{Reprocesos}

Los reprocesos se generan una vez que la inspección o revisión no aprueba, cierta actividad de cada uno de los procesos. A continuación, se muestra que el proceso de teñido genera el $11 \%$ de los reprocesos con un promedio de 2.24 días por reprocesos por bobina generando colas en las máquinas. 
Tabla 18: Tiempos de reproceso

\begin{tabular}{|l|r|r|r|r|r|r|r|} 
& \multicolumn{3}{|c|}{ Proceso } & \multicolumn{3}{|l|}{ Tiempo de espera } & \multicolumn{2}{l|}{ Tiempo de Reproceso } \\
\hline Fase & Días & $\%$ & Dias & $\%$ & Días & \multicolumn{1}{l|}{$\%$} \\
\hline Preparado & 4.78 & $27 \%$ & 2.75 & $16 \%$ & 0.78 & $4 \%$ \\
\hline Teñido & 1.46 & $8 \%$ & 4.75 & $27 \%$ & 2.24 & $11 \%$ \\
\hline Acabado & 1.73 & $10 \%$ & 2.17 & $12 \%$ & 0.03 & $0 \%$ \\
\hline Porcentaje & & $45 \%$ & & $55 \%$ & &
\end{tabular}

Elaboración propia

En la tabla 19 se observa que, el proceso de teñido genera un $27 \%$ de tiempos de espera y un $11 \%$ de tiempos por reproceso al tener el menor tiempo del proceso en sí de 1.46 días, comparándose con los otros procesos de preparado y acabado.

\subsubsection{Paradas programadas}

Las paradas programadas por mantenimiento preventivo y otros, sólo equivale al $0.22 \%$ anual de las horas disponibles de todos los equipos de los diferentes procesos de producción, como se muestra a continuación:

Tabla 19: Horas programadas vs. Horas disponibles

\begin{tabular}{|l|r|r|}
\hline \multicolumn{1}{|c|}{ Descripción } & \multicolumn{1}{c|}{ Horas } & \multicolumn{1}{c|}{$\%$} \\
\hline $\begin{array}{l}\text { Total paros programados por mantenimientos y limpieza } \\
\text { de máquinas por año }\end{array}$ & 9315.64 & $13.29 \%$ \\
\hline Total horas por año disponibles & 70080.00 & $100.00 \%$ \\
\hline
\end{tabular}

Elaboración propia

En la tabla 20, se toma en consideración todos los equipos en producción para calcular las horas disponibles y por mantenimiento y limpieza de máquinas, se para por un $13.29 \%$ equivalente a 9315.64 horas de 70080 horas disponibles de 8 equipos (véase tabla 20)

\subsection{Diagnóstico de Causas raíz Cuantitativas}

Para poder dar solución al problema identificado se procedió con el primer paso, el cual fue realizar el análisis de causa raíz mediante el uso de un diagrama de Árbol.

El diagrama de árbol que se muestra posteriormente posee tres posibles causas primarias, las cuales tienen diferentes porcentajes de ocurrencia sobre el problema identificado y por último las causas raíz determinada cuantitativamente. 
Figura 19: Diagrama de árbol de las posibles causas raíces

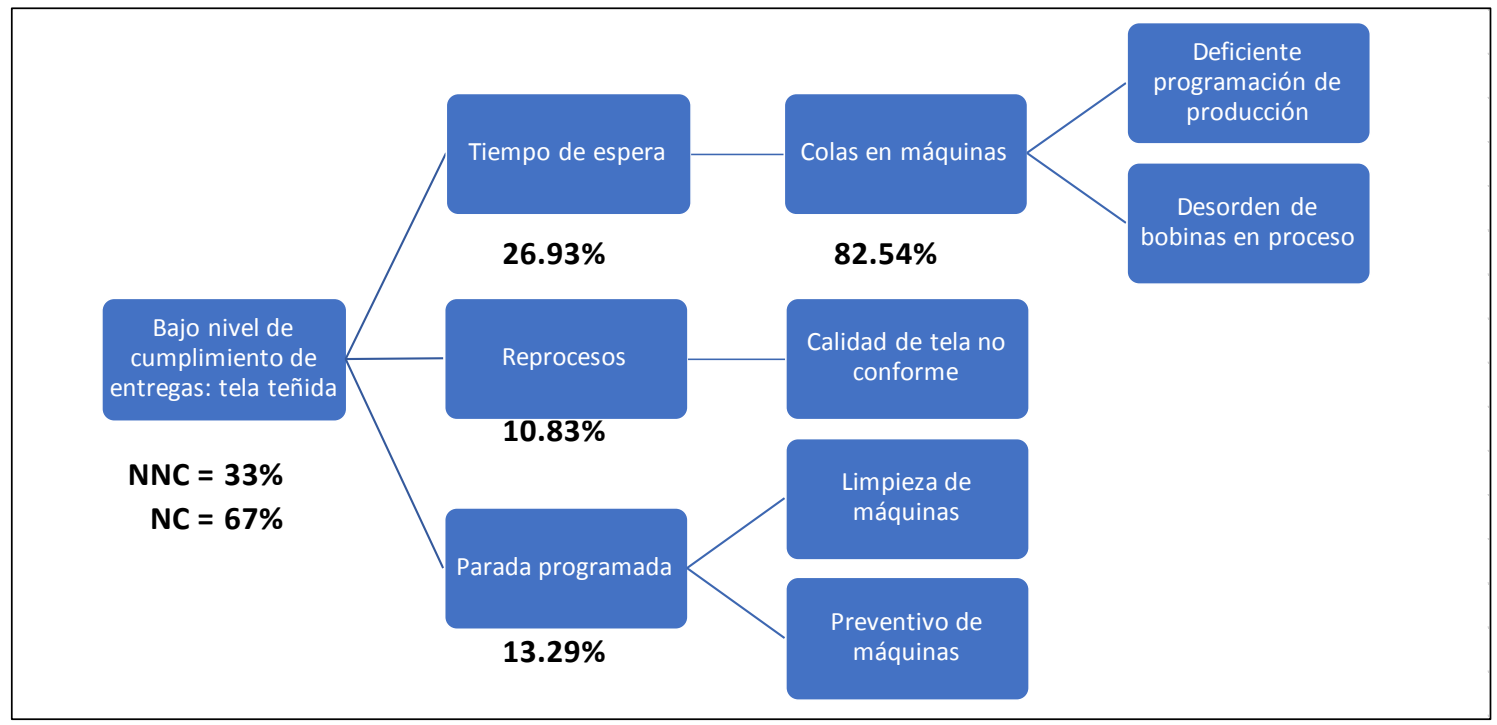

Elaboración propia

En la figura 19 se observa que por el nivel de no cumplimiento de entregas a tiempo del $33 \%$, al buscar los porqués, se determinó que son tiempo de espera $26.93 \%$, reprocesos $10.83 \%$ y paradas programadas por $13.2 \%$. Al seleccionar los tiempos de espera, se pregunta una segunda vez porqué, y se da la respuesta cuantitativa de colas en máquinas con el $82.54 \%$ que las bobinas permanecen en cola en el sistema. Las colas en máquinas se generan por la deficiente programación de producción y el desorden de las bobinas en el proceso, mientras se encuentran en espera para continuar su proceso.

A continuación, se analizarán las dos causas raíz determinadas en la figura 19.

\subsubsection{Deficiente programación de producción}

Para determinar la deficiente programación de producción que generan las colas o tiempos de espera en las actividades en el proceso de teñido, se ha calculado una muestra representativa de la población de 1518 bobinas para el año 2016, teniendo como resultado una muestra de la población de 252 bobinas, como se muestra a continuación: 
Tabla 20: Cálculo del Tamaño de Muestra

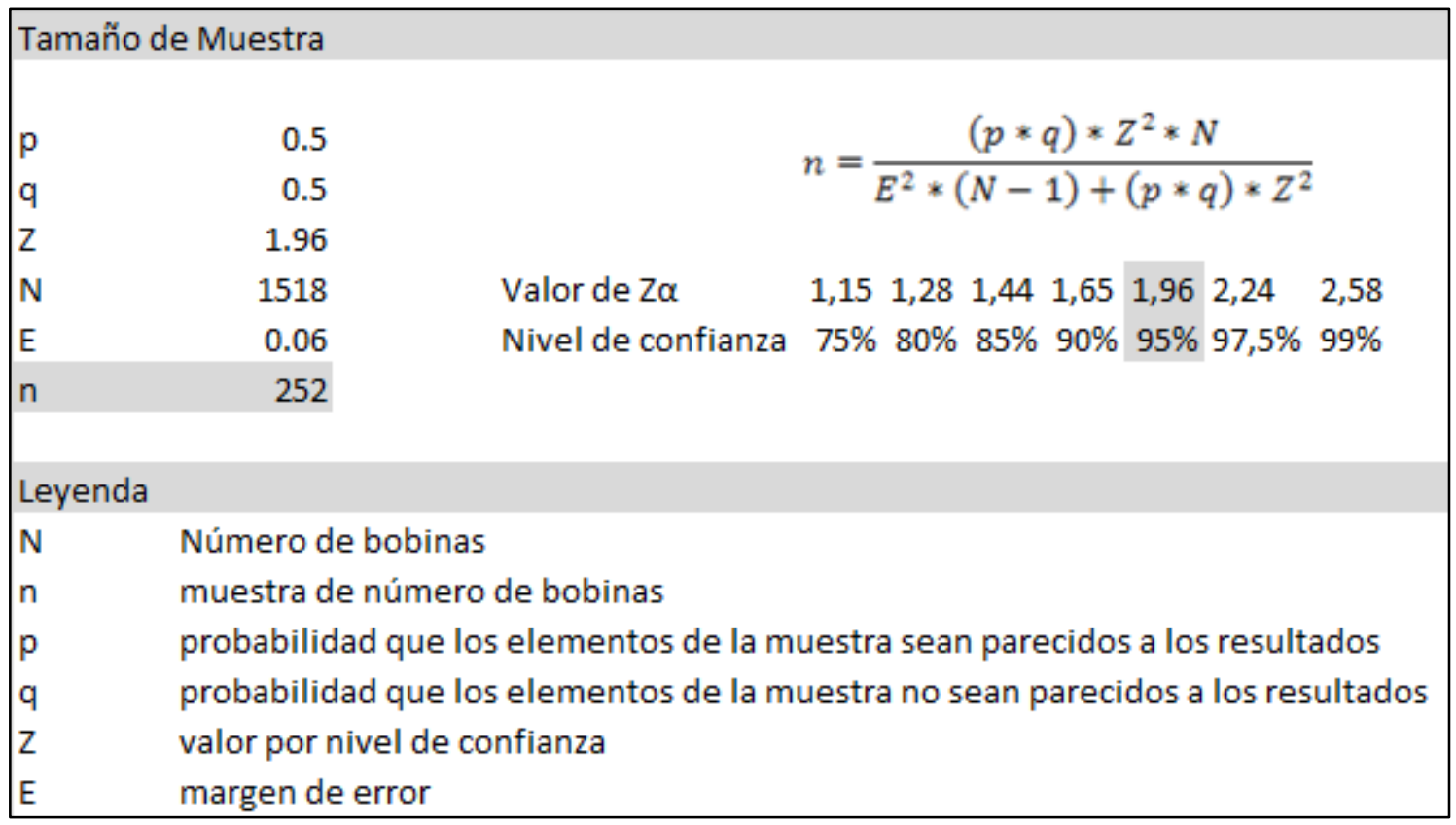

Elaboración propia

Después de haber obtenido la muestra representativa, se recolectaron los tiempos de los 252 procesos de cada una de las bobinas. Véase Anexo 1, en donde se indica cada uno de los 179 pedidos representan 252 procesos. Cada proceso equivale al empleo de una bobina.

Tabla 21: Procesos y pedidos del tamaño de la muestra

\begin{tabular}{|c|c|c|c|c|c|c|c|c|c|c|c|}
\hline Mes & \begin{tabular}{|l} 
REAL \\
Retrasado
\end{tabular} & mpo & Total & Bobinas & \begin{tabular}{|l} 
MUESTRA \\
Retrasados
\end{tabular} & A tiempo & Total & Metros & En proceso & En cola & Bobinas \\
\hline Enero & 14 & 41 & 55 & 87 & 2 & 5 & 7 & 21500 & 8078 & 13422 & 11 \\
\hline Febrero & 47 & 69 & 116 & 174 & 2 & 2 & 4 & 13127 & 4932 & 8195 & 6 \\
\hline Marzo & 20 & 67 & 87 & 119 & 3 & 11 & 14 & 34500 & 12962 & 21538 & 19 \\
\hline Abril & 22 & 42 & 64 & 98 & 6 & 11 & 17 & 40751 & 15311 & 25440 & 26 \\
\hline Mayo & 33 & 65 & 98 & 98 & 4 & 9 & 13 & 16000 & 6011 & 9989 & 13 \\
\hline Junio & 20 & 55 & 75 & 84 & 5 & 12 & 17 & 23800 & 8942 & 14858 & 19 \\
\hline Julio & 11 & 48 & 59 & 69 & 4 & 15 & 19 & 31872 & 11975 & 19897 & 22 \\
\hline Agosto & 36 & 56 & 92 & 121 & 6 & 10 & 16 & 28732 & 10795 & 17937 & 21 \\
\hline Setiembre & 11 & 45 & 56 & 56 & 5 & 18 & 23 & 40814 & 15335 & 25479 & 23 \\
\hline Octubre & 47 & 55 & 102 & 179 & 6 & 6 & 12 & 35222 & 13234 & 21988 & 21 \\
\hline Noviembre & 28 & 70 & 98 & 172 & 5 & 11 & 16 & 59770 & 22457 & 37313 & 28 \\
\hline \multirow[t]{2}{*}{ Diciembre } & 53 & 74 & 127 & 261 & 9 & 12 & 21 & 85270 & 32037 & 53233 & 43 \\
\hline & 342 & 687 & 1029 & 1518 & 57 & 122 & 179 & 431358 & & & 252 \\
\hline
\end{tabular}

Elaboración propia

Los 179 pedidos es la suma de los despachos con demora y a tiempo, representan 252 bobinas. La máquina que se utiliza para el teñido se llama Jigger (véase tabla 17) y tiene una capacidad de 2850 metros por bobina, como se muestra a continuación: 
Figura 20: Capacidad de Jigger para la muestra

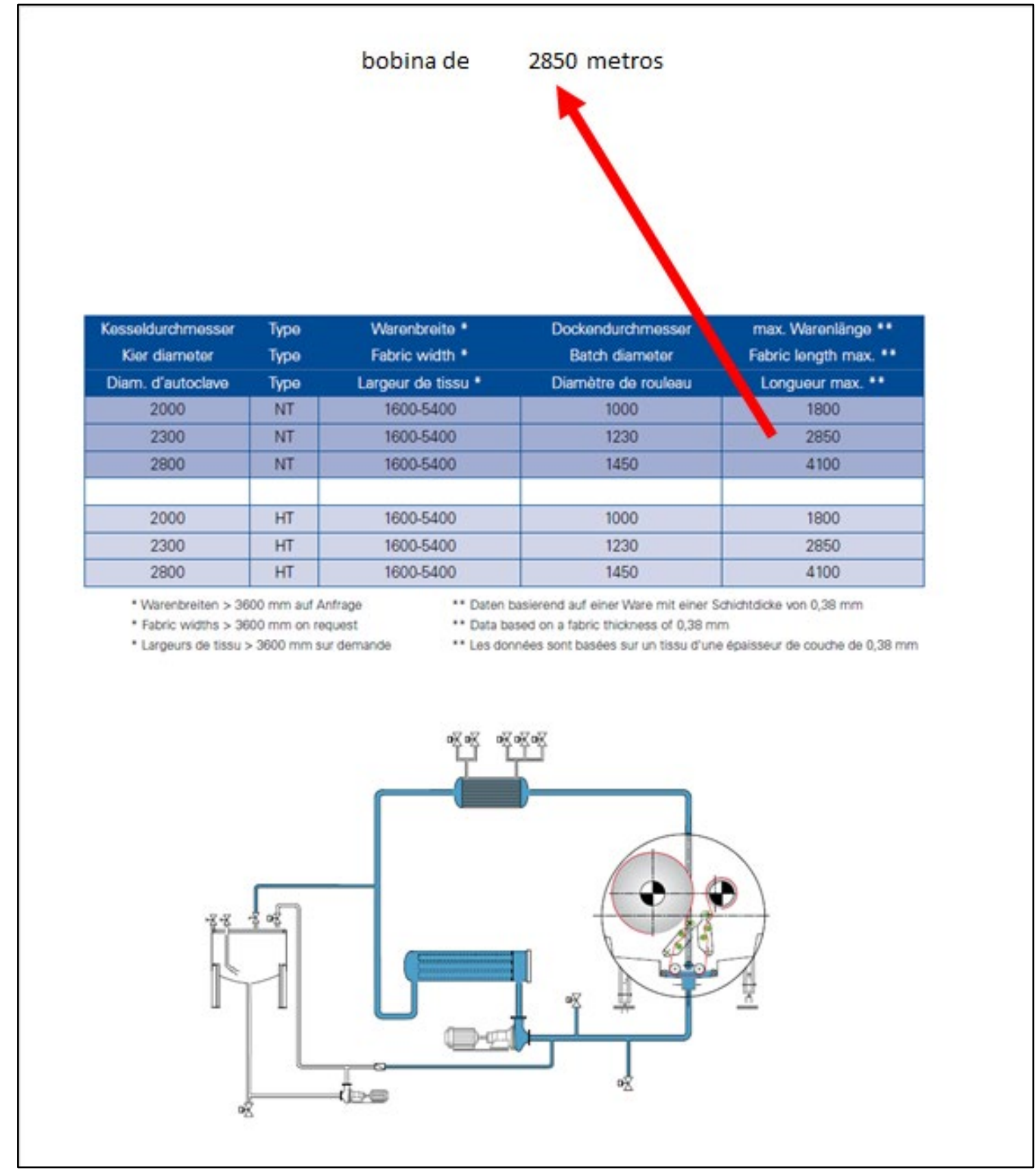

Fuente: El proveedor

Los tiempos de las 252 observaciones de la muestra se encuentran en el anexo 1. Estos datos, indican que el proceso se encuentra fuera de control estadístico ya que se han calculado 48 observaciones que se encuentran por encima del LCS y 45 por debajo del LCI, al haberse calculado la desviación estándar de 0.90295 días, el promedio de 5.83 días, el Límite control superior es 6.93 días y el límite de control inferior es 4.92 días para el proceso por completo, como se muestra a continuación: 
Figura 21: Diagrama de control del proceso de teñido

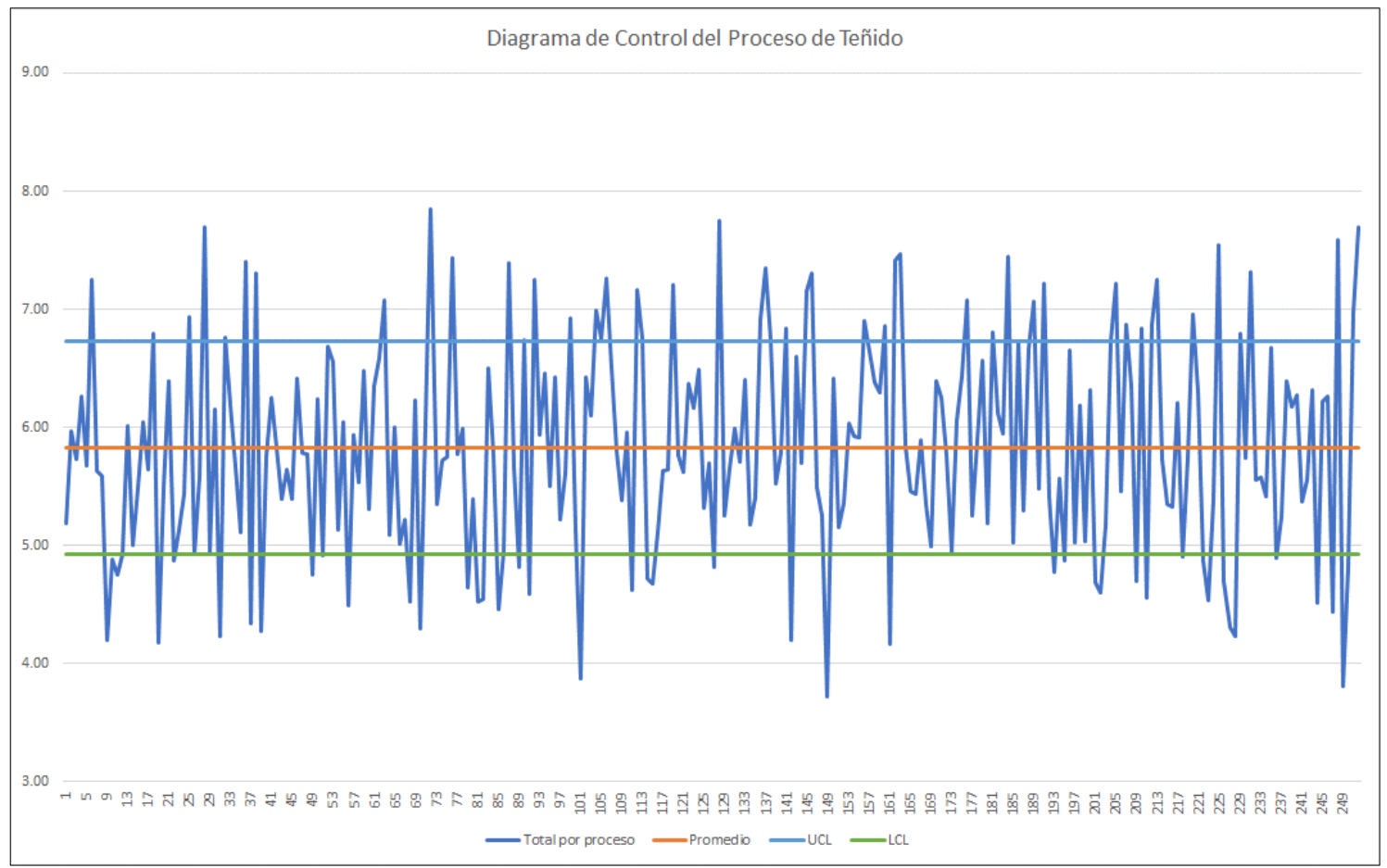

\section{Elaboración propia}

Como se ha establecido que el proceso de teñido se encuentra fuera de control estadístico, se debe determinar el sistema del cual es parte la máquina de teñido. El sistema comprende que esta máquina Jigger ( 1 servidor) recibe bobinas de 9 diferentes procesos de preparado llamado rutas por la empresa (clientes), los cuales pueden ir a teñido, estampado o dirigirse directamente a acabado, como se muestra a continuación. Los clientes proveen los metros para el proceso de teñido de 431,538 metros, para luego proseguir con el proceso de acabado: 
Figura 22: Sistema del proceso de teñido

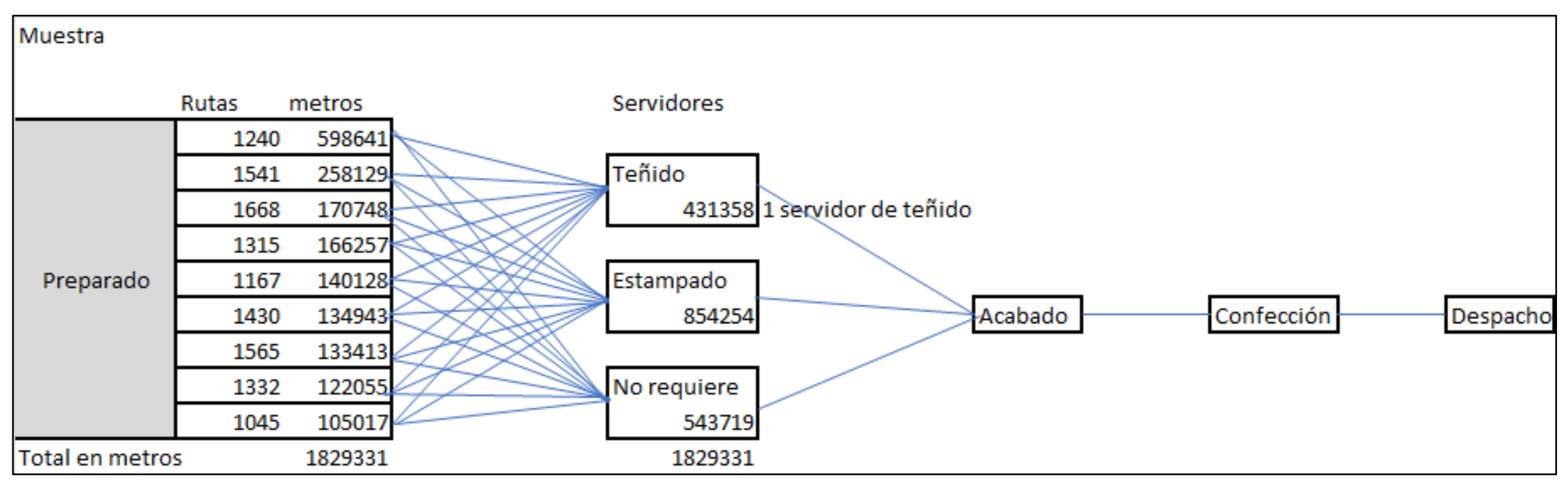

Elaboración propia 
Una vez que se ha determinado que el proceso de teñido genera los cuellos de botella y por ende la demora en entrega de los productos, se debe determinar la actividad dentro del proceso de teñido, que genera los cuellos de botella, al determinarse el tiempo de arribo de una bobina, debe esperar dos días para ingresar a la actividad propia de teñido y dos días para la actividad de revisión.

Para determinar los cuellos de botella en el proceso completo de teñido, se ha elaborado un VSM, véase figura 23. Se ha ingresado la cantidad del tamaño de muestra de 252 bobinas, calculándose el pedido diario de 0.69 bobinas/día y el pedido mensual de un promedio de 21 bobinas/mes. El tiempo takt es la división del tiempo disponible de la máquina Jigger entre la demanda de bobinas/día siendo un total de 1.0712 días por bobina. Este valor significa que se procesa 1 bobina cada 1.0712 días. Luego se calcula el tiempo de ciclo o CT de cada actividad y de espera, de acuerdo con el Diagrama de análisis del proceso (DAP), véase tabla 12 de la presente investigación. Si el valor CT de cada actividad es mayor que el Takt, se generan cuellos de botella en la espera para teñido, la actividad de reposo y la espera para revisión 
Figura 23: VSM Proceso Actual de Teñido

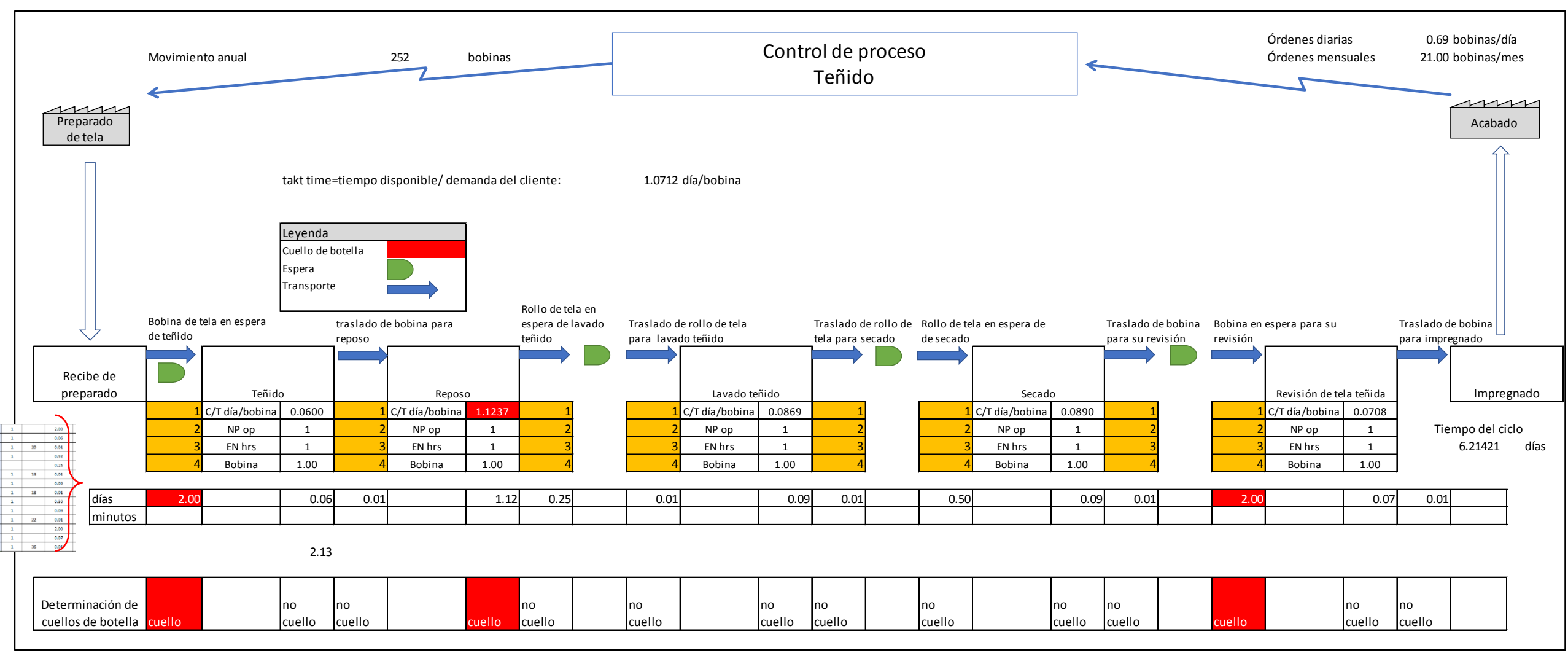

Elaboración propia 
Por lo tanto, al determinarse que, existen tres actividades en el proceso de teñido que generan los cuellos de botella en el proceso mayores a 1.1237 días que acumulándose es mayor que 5.1237 días de tiempo de espera (cuello o cola), se debe analizar la cola del proceso real científicamente por medio del análisis de la teoría de Colas. Para ello se debe obtener la distribución de los metros de los pedidos siendo equivalente al número de las bobinas (Véase Anexo 1), los datos se ingresaron en el componente del programa de Arena (Rockwell Automation) 1lamado Input Analyzer para determinar que es una distribución exponencial, como se muestra a continuación:

Figura 24: Distribución de pedidos en metros

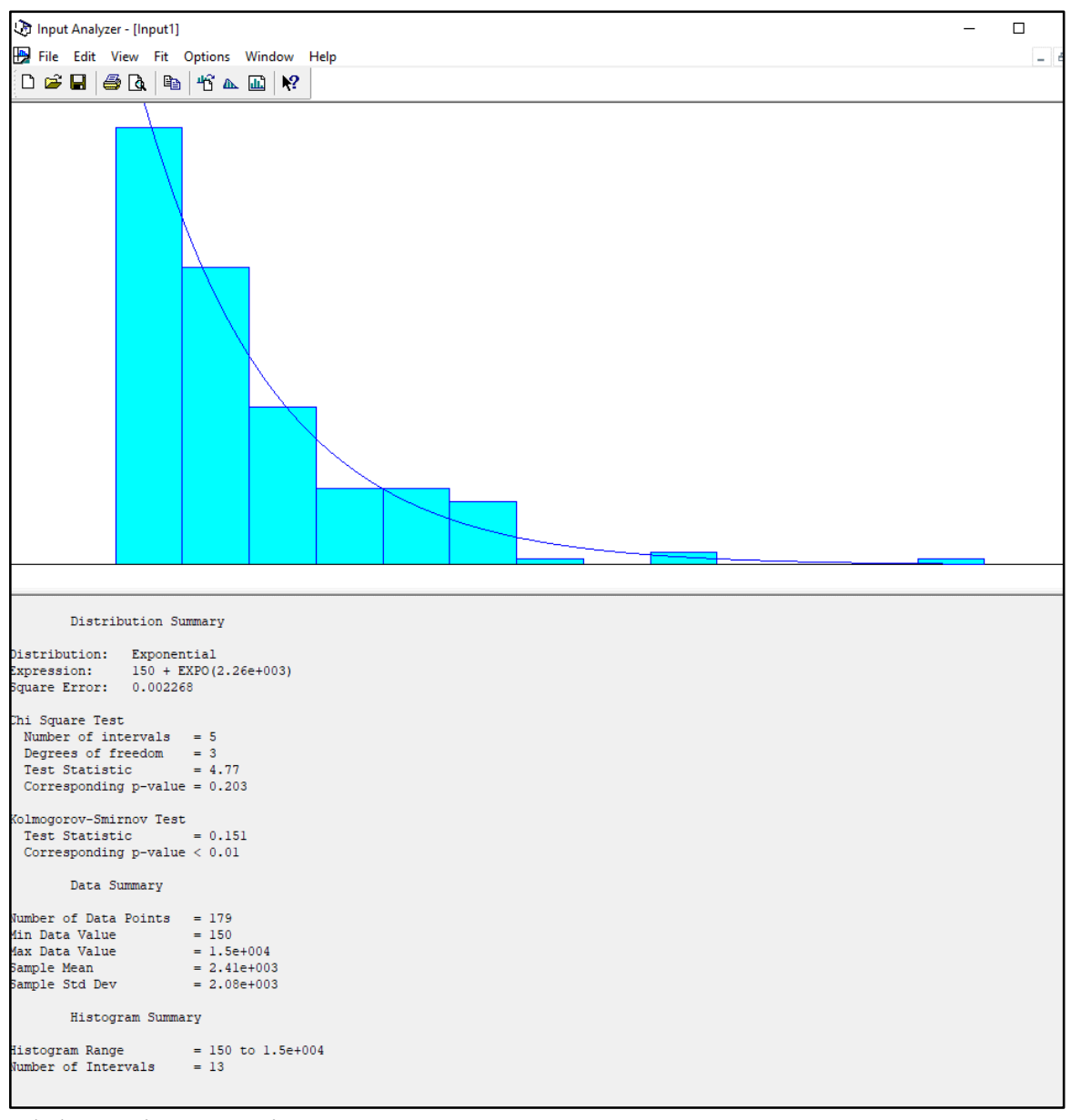

Elaboración propia

Por lo que para analizar las colas del proceso se ha identificado el modelo $\mathrm{M} / \mathrm{M} / 1$ de la teoría de colas, en donde debe utilizarse el proceso de Poisson para analizar las colas, y un servidor comprendido por el proceso completo de teñido que incluye el equipo Jigger, para la muestra. 
Se ha calculado que cada 7.53 días se demora una bobina en llegar del proceso de preparado al sistema de teñido, y el promedio del servicio para dicha bobina es de 6.21 días, generándose colas o tiempos de espera en el proceso de teñido. Calculándose el ratio de llegada de 0.133 bobinas por día, y ratio de servicio de teñido es de 0.161 bobinas por día, llegan menor cantidad de bobinas por día que las bobinas que son atendidas, por lo que la generación del tiempo de espera se identifica en el proceso de teñido. Al utilizarse los datos de llegada $(\lambda)$ y salida $(\mu)$ se calculan la intensidad de tráfico de 0.825 bobinas/día. Por lo que el número esperado de las bobinas en el sistema es de 4.728 bobinas, y en cola es de 3.903 bobinas y el tiempo de espera esperado en el sistema es de 35.597 días, y los días en cola de 29.383 días. La utilización del servidor de teñido $(\lambda / \mu)$, al $82.5 \%$ lo que indica que las bobinas que llegan al sistema esperan en cola y el $17.5 \%$ de bobinas no esperan en cola. Si la relación de utilización del servidor es mayor que 1 , significa que las bobinas llegan más rápido de lo que se les puede atender, por lo que la línea crecerá sin límite. Si el porcentaje es inferior a 1, la línea alcanzará un cierto estado estacionario en promedio. A continuación, se muestra el análisis de colas del equipo Jigger:

Tabla 23: M/M/1- Modelo de colas del proceso de teñido para el proceso de teñido 


\begin{tabular}{|c|c|c|}
\hline \multicolumn{3}{|l|}{ Datos } \\
\hline Por proceso & \multicolumn{2}{|c|}{1 bobina } \\
\hline Cada & 7.53 & días \\
\hline Servicio & 6.21 & días \\
\hline \multicolumn{3}{|l|}{$\mathrm{M} / \mathrm{M} / 1$ queue } \\
\hline \multicolumn{3}{|l|}{ Ingreso } \\
\hline \multicolumn{3}{|l|}{ Unidad tiempo } \\
\hline Ratio de llegada $(\lambda)$ & \multirow{2}{*}{$\begin{array}{l}0.133 \\
0.161 \\
\end{array}$} & \multirow{2}{*}{$\begin{array}{l}\text { bobinas/día } \\
\text { bobinas/día }\end{array}$} \\
\hline Ratio de servicio de teñido $(\mu)$ & & \\
\hline \multicolumn{3}{|l|}{ Salida } \\
\hline \multicolumn{3}{|l|}{ Salidas directas de las entradas } \\
\hline Tiempo medio entre llegadas & 7.528 & días \\
\hline Tiempo medio por servicio & 6.214 & días \\
\hline Intensidad de tráfico $(\lambda / \mu)$ & 0.825 & \\
\hline \multicolumn{3}{|l|}{ Resumen de resultados } \\
\hline Número esperado de bobinas en el sistema & 4.728 & bobinas \\
\hline Número esperado de bobinas en cola & 3.903 & bobinas \\
\hline Tiempo de espera esperado en el sistema & 35.597 & días \\
\hline Tiempo de espera esperado en cola & 29.383 & días \\
\hline Uso del servidor (teñido) & $82.5 \%$ & \\
\hline
\end{tabular}

Cliente $=$ bobina $($ entrada $)$
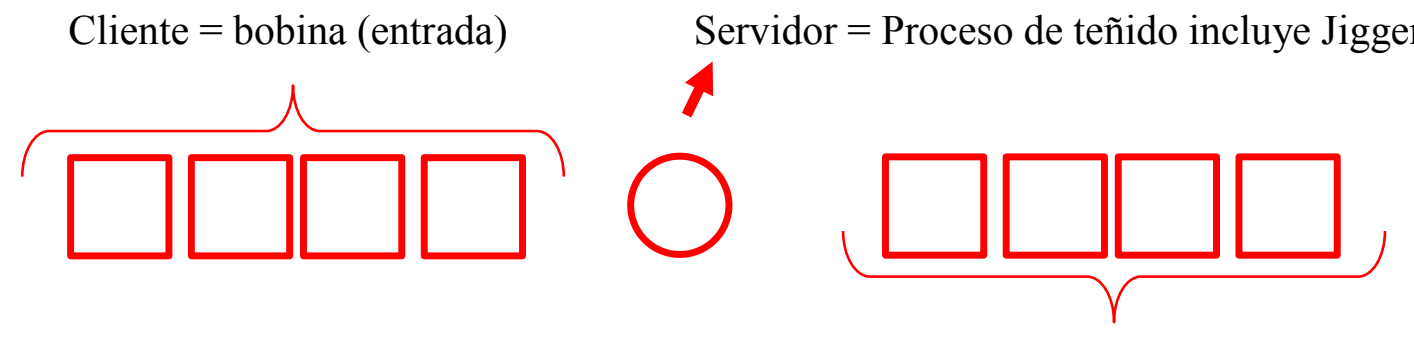

Cliente $=$ bobina $($ salida $)$

Elaboración propia

A continuación, se muestra primero que la probabilidad de la distribución de un número determinado de bobinas se encuentra en el sistema, por ejemplo, que la probabilidad de tener exactamente 4 bobinas en el sistema es de 0.081 , equivalente a decir que el $8.1 \%$ del tiempo hay 4 bobinas en el sistema. Por otro lado, $78 \%$ de las bobinas permanece más de 2 días en cola, como se muestra a continuación:

Tabla 22: Distribuciones en el sistema y tiempo en cola 


\begin{tabular}{|c|c|c|c|}
\hline \multicolumn{2}{|c|}{ Distribución del número en el sistema } & \multicolumn{2}{|c|}{ Distribución del tiempo en cola } \\
\hline $\mathrm{n}$ (bobinas) & $\mathrm{P}(\mathrm{n}$ en el sistema $)$ & $\mathrm{t}$ (en días) & $\mathrm{P}($ espera $>\mathrm{t})$ \\
\hline 0 & 0.175 & 2.000 & 0.780 \\
\hline 1 & 0.144 & & \\
\hline 2 & 0.119 & & \\
\hline 3 & 0.098 & & \\
\hline 4 & 0.081 & & \\
\hline 5 & 0.067 & & \\
\hline 6 & 0.055 & & \\
\hline 7 & 0.046 & & \\
\hline 8 & 0.038 & & \\
\hline 9 & 0.031 & & \\
\hline 10 & 0.026 & & \\
\hline 11 & 0.021 & & \\
\hline 12 & 0.017 & & \\
\hline 13 & 0.014 & & \\
\hline 14 & 0.012 & & \\
\hline 15 & 0.010 & & \\
\hline 16 & 0.008 & & \\
\hline 17 & 0.007 & & \\
\hline 18 & 0.006 & & \\
\hline 19 & 0.005 & & \\
\hline 20 & 0.004 & & \\
\hline 21 & 0.003 & & \\
\hline 22 & 0.003 & & \\
\hline
\end{tabular}

Elaboración propia

Si el valor de $\mathrm{t}$ (en días) es igual a 1 día, indica que el $80.3 \%$ de las bobinas permanece más de 1 día en cola, como se muestra a continuación:

Tabla 23: Distribución del tiempo en cola para $\mathrm{t}($ en días $)>=1$ día

\section{Distribución del tiempo en cola}

$\mathrm{t}$ (en días) $\mathrm{P}$ (espera $>\mathrm{t}$ )

$1.000 \quad 0.803$

Elaboración propia

Si el valor de $\mathrm{t}$ (en días) es igual a 10 días, indica que el $62.3 \%$ de las bobinas permanece más de 10 días en cola, como se muestra a continuación:

Tabla 24: Distribución del tiempo en cola para t(en días) >=10 días

\section{Distribución del tiempo en cola}

$\mathrm{t}$ (en días) $\mathrm{P}$ (espera $>\mathrm{t}$ )

$10.000 \quad 0.623$

Elaboración propia 
Por lo tanto, el proceso se encuentra desbalanceado, ya que como se ha demostrado, el $82.5 \%$ espera en cola de las bobinas que ingresan, del proceso de preparado al de teñido.

\subsubsection{Desorden de bobinas en el proceso}

En la figura 25 se observa que en el área de espera en el ingreso a teñido, hay porta bobinas que pertenecen a otros procesos y otras actividades de los otros dos procesos que no pertenecen al proceso de teñido, así como el inventario en proceso. Cabe indicar que este último se encuentra representado mediante barras de diferentes colores, debido a que las bobinas de tela son transportadas en una estructura metálica llamada porta bobinas.

Figura 25: Desorden de bobinas en el proceso

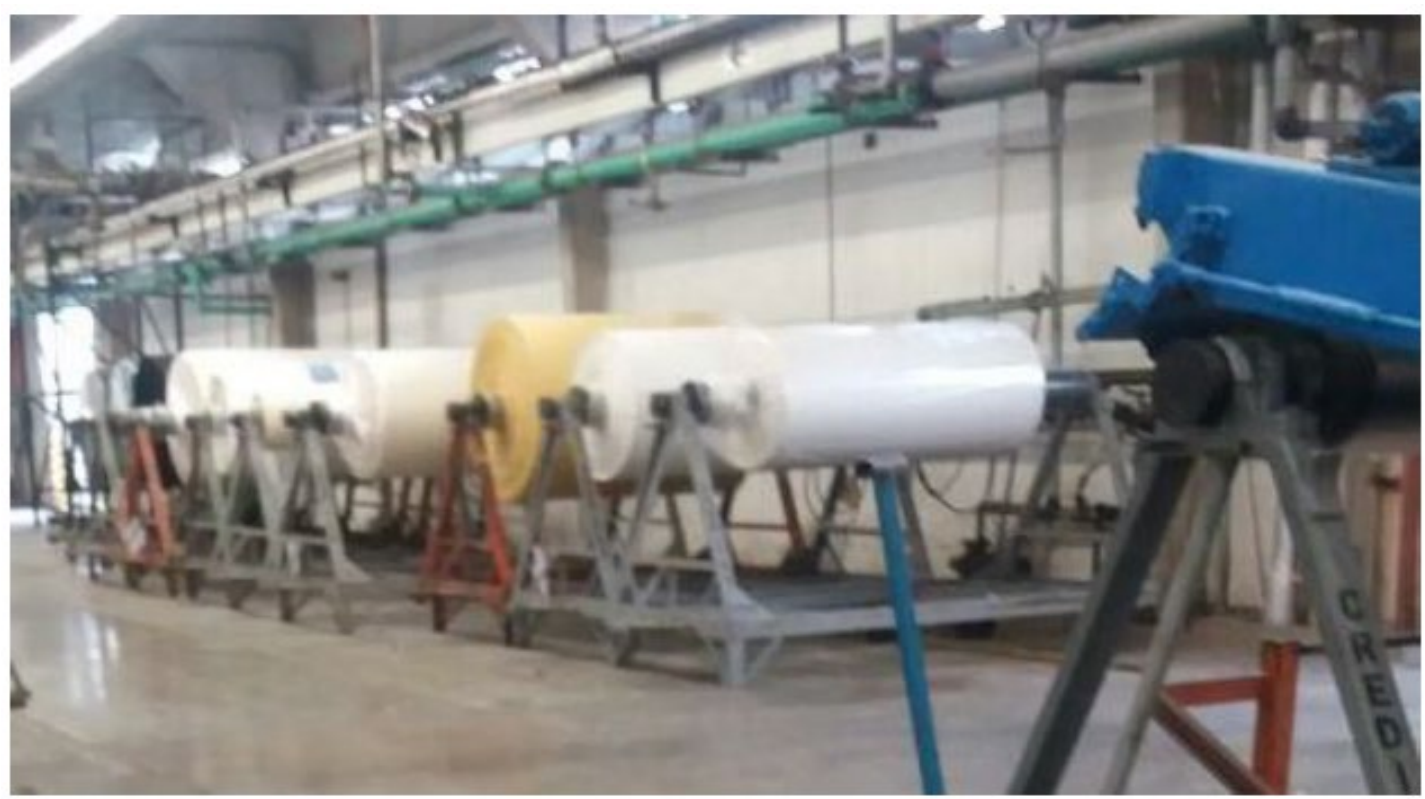

Fuente: La empresa 
Actualmente, se cuenta con 170 porta bobinas clasificadas por colores. A continuación, se muestra en la tabla 27 la cantidad de porta bobinas clasificadas de acuerdo con un color. 
Tabla 25: Clasificación de porta bobinas de tela

\begin{tabular}{|c|c|c|}
\hline Cantidad & Color & Utilidad \\
\hline 4 & & Recibe la tela hego de que fue revisada por los operarios de Calidad \\
\hline 30 & & $\begin{array}{l}\text { Transpotan las bobinas con tela cruda para el ingreso a máquina Gaseadora. } \\
\text { O Reciben la tela luego de que fue procesada en la máquina Sanforizadora }\end{array}$ \\
\hline 4 & & $\begin{array}{l}\text { Reciben la tela hego de que fue procesada en la máquina Gaseadora o } \\
\text { Blanqueadora. }\end{array}$ \\
\hline 13 & & $\begin{array}{l}\text { Reciben la tela hego de que fue procesada en la máquina gaseadora o } \\
\text { blanqueadora. }\end{array}$ \\
\hline 5 & & Reciben la tela huego de que fue procesada en la máquina Foulard. \\
\hline 114 & & $\begin{array}{l}\text { Reciben la tela en todas las maquinas salvo a la salida de la maquinas } \\
\text { gaseadora, Blanqueadora, foulard y Sanforizadora. }\end{array}$ \\
\hline
\end{tabular}

Fuente: La empresa

Como se muestra en la tabla precedente las portas bobinas serán los recursos que reciben y transporten la bobina de tela hacia la siguiente operación de acuerdo con lo indicado en la hoja de ruta. Lo correcto es que las porta bobinas trasladen el material cerca o muy próximo a la ubicación donde se encuentra la máquina, estación de reposo o estación de revisado a fin de que el operario visualice la bobina y cargue el material para su operación. Sin embargo, actualmente ello no sucede generando de esa forma que la bobina de tela se encuentre sin movimiento. Por ejemplo, en la figura 26 se observa que las porta bobinas de color verde, luego de la operación reposo deberían de encontrarse cerca de la lavadora; sin embargo, estas se encuentran dispersas por toda la planta. Algunas de las porta bobinas con tela lavada se encuentran cerca de la máquina gaseadora y otras ubicadas entre las máquinas Jigger y sanforizadora. Este desorden en planta no solo causa pérdida de tiempo significativo en el proceso de producción, también genera un peligro, ya que las porta bobinas se colocan en espacios que deberían de estar libres de acuerdo con las normas de seguridad. Finalmente impide el paso normal de los trabajadores y de la mercancía en la planta. 
Figura 26: Gráfico: Layout de la planta de producción de teñido de hilos y telas

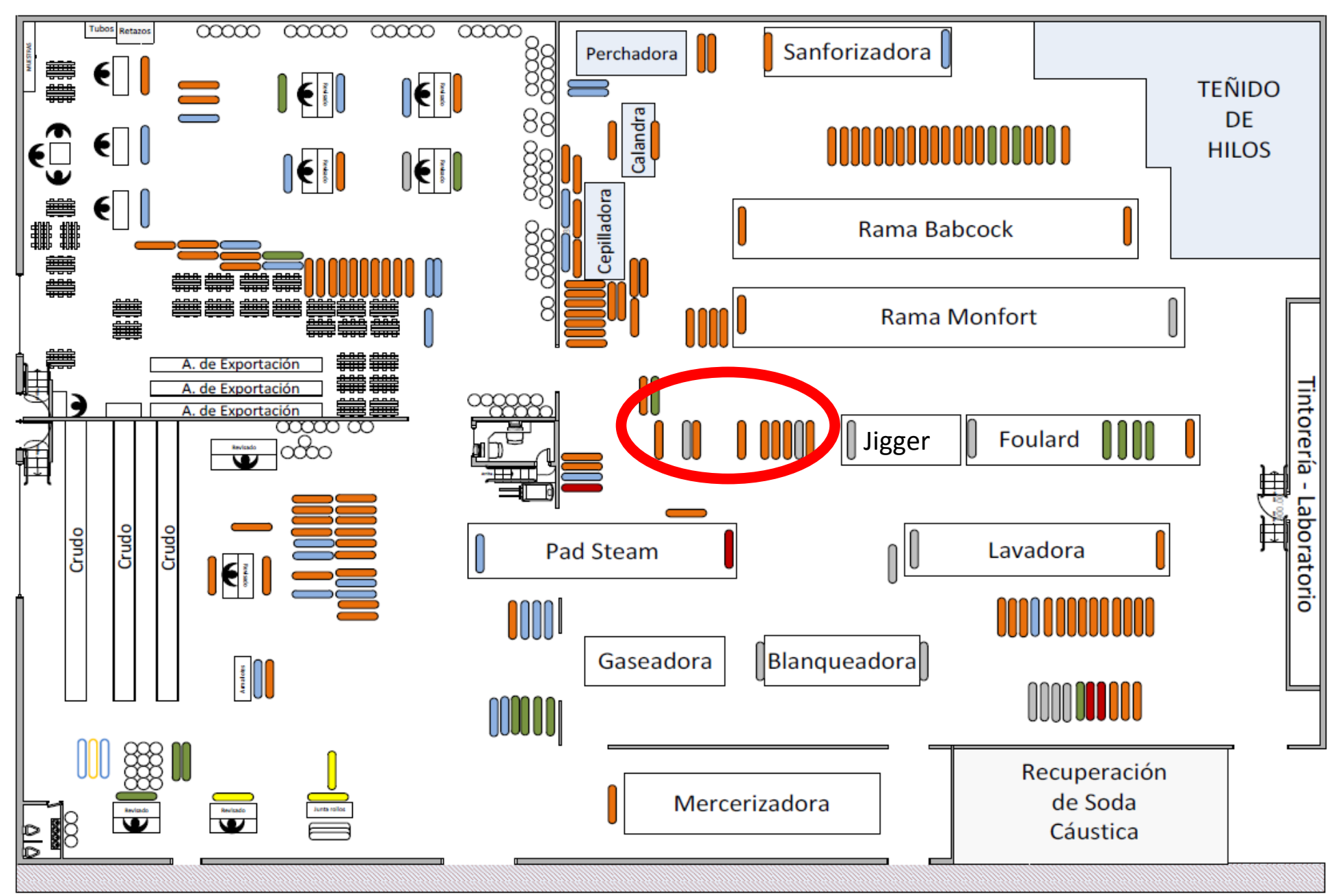

Fuente: La empresa 


\subsection{Impacto Económico}

\subsubsection{Impacto económico de las Penalidades por entregas fuera de tiempo}

El impacto económico se mide por un monto fijo del total de la venta que se entrega fuera de tiempo, de acuerdo con el contrato que se ha firmado con un determinado cliente, asciende a $\mathrm{S} / 205,981.16$ por 85 bobinas que no se entregan a tiempo de la muestra de 252 bobinas en la máquina Jigger, equivalente al $6.06 \%$ de las ventas por teñido de $\mathrm{S} / 3$, 400,659.00 como se muestra a continuación:

Tabla 26: Penalidades por entrega fuera de tiempo del tamaño de la muestra

\begin{tabular}{|c|c|c|c|c|c|c|c|}
\hline \multirow{2}{*}{$\begin{array}{ll} & 2016 \\
\text { Mes }\end{array}$} & \multicolumn{3}{|c|}{ Venta } & \multicolumn{4}{|c|}{ Penalidades por entrega fuera de tiempo } \\
\hline & Metros & Bobinas & Pedidos & Bobinas & Pedidos & \multicolumn{2}{|c|}{ Penalidades } \\
\hline Enero & 21500 & 11 & 7 & 3 & 2 & $\mathrm{~S} /$ & 7,590.96 \\
\hline Febrero & 13127 & 6 & 4 & 3 & 2 & S/ & $7,252.05$ \\
\hline Marzo & 34500 & 19 & 14 & 4 & 3 & S/ & $10,397.00$ \\
\hline Abril & 40751 & 26 & 17 & 9 & 6 & S/ & $22,404.69$ \\
\hline Mayo & 16000 & 13 & 13 & 4 & 4 & S/ & $10,013.56$ \\
\hline Junio & 23800 & 19 & 17 & 6 & 5 & S/ & $14,602.38$ \\
\hline Julio & 31872 & 22 & 19 & 5 & 4 & $\mathrm{~S} /$ & $12,352.25$ \\
\hline Agosto & 28732 & 21 & 16 & 8 & 6 & S/ & $19,836.64$ \\
\hline Setiembre & 40814 & 23 & 23 & 5 & 5 & S/ & $12,380.85$ \\
\hline Octubre & 35222 & 21 & 12 & 11 & 6 & $\mathrm{~S} /$ & $25,260.95$ \\
\hline Noviembre & 59770 & 28 & 16 & 9 & 5 & $\mathrm{~S} /$ & $20,684.25$ \\
\hline Diciembre & 85270 & 43 & 21 & 18 & 9 & $\mathrm{~S} /$ & $43,205.58$ \\
\hline Total & 431358 & 252 & 179 & 85 & & S/ & $205,981.16$ \\
\hline \multicolumn{6}{|c|}{ Equivalente a las ventas en $\%$} & & $6.06 \%$ \\
\hline & & & \multicolumn{3}{|c|}{ Venta Total } & $\mathrm{S} /$ & $3,400,659.00$ \\
\hline
\end{tabular}

Elaboración propia

Las penalidades por la entrega fuera a tiempo del subproducto de teñido son de $\mathrm{S} / 205,981.16$ equivalente al $6.06 \%$ de las ventas de esta sección y del total de las ventas de $\mathrm{S} / 244,299,546$ de la empresa es equivalente al $0.08 \%$. 


\subsubsection{Impacto Económico por Retrasos en el Proceso de Teñido del Equipo Jigger}

El costo de mano de obra por el tiempo de espera en el proceso se calcula al restar el tiempo total de cada uno de los procesos completos de la muestra de 252 observaciones menos el límite de control superior, ya que no existe un límite o indicador o estándar mundial que lo regularice. Se toma el LCS como el objetivo de la empresa, y todos los tiempos mayores a éste se consideran como tiempo de espera lo que genera los retrasos.

De la base de datos, de la cual se muestra un extracto a continuación, se calculan las estadísticas de Promedio, desviación estándar y los límites de control superior (LCL) e inferior (LCI).

Tabla 27: Extracto de Tiempos de la muestra del proceso de teñido del equipo Jigger

\begin{tabular}{|c|c|c|c|c|c|c|c|c|c|c|c|c|c|}
\hline \multicolumn{14}{|l|}{ Tiempos por procesos de bobina } \\
\hline Actividad & 1 & 2 & 3 & 4 & 5 & 6 & 7 & 247 & 248 & 249 & 250 & 251 & 252 \\
\hline Bobina de tela en espera de teñido & 1.60 & 1.27 & 1.43 & 2.67 & 1.98 & 2.79 & 2.78 & 1.01 & 0.73 & 0.86 & 0.82 & 3.41 & 2.09 \\
\hline Teñido & 0.06 & 0.06 & 0.06 & 0.06 & 0.06 & 0.06 & 0.06 & 0.06 & 0.06 & 0.06 & 0.06 & 0.06 & 0.06 \\
\hline traslado de bobina para reposo & 0.01 & 0.01 & 0.00 & 0.00 & 0.00 & 0.01 & 0.00 & 0.01 & 0.01 & 0.01 & 0.00 & 0.01 & 0.01 \\
\hline Reposo & 1.35 & 0.95 & 1.31 & 1.11 & 1.34 & 0.94 & 1.16 & 0.92 & 1.16 & 1.30 & 1.00 & 1.05 & 0.95 \\
\hline Rollo de tela en espera de lavado teñido & 0.30 & 0.29 & 0.27 & 0.32 & 0.25 & 0.26 & 0.36 & 0.30 & 0.24 & 0.23 & 0.27 & 0.20 & 0.22 \\
\hline Traslado de rollo de tela para lavado teñido & 0.01 & 0.01 & 0.01 & 0.01 & 0.01 & 0.01 & 0.01 & 0.01 & 0.01 & 0.01 & 0.01 & 0.01 & 0.01 \\
\hline Lavado teñido & 0.09 & 0.08 & 0.09 & 0.08 & 0.09 & 0.09 & 0.08 & 0.09 & 0.08 & 0.09 & 0.08 & 0.10 & 0.08 \\
\hline Traslado de rollo de tela para secado & 0.01 & 0.01 & 0.01 & 0.01 & 0.01 & 0.01 & 0.01 & 0.00 & 0.01 & 0.00 & 0.00 & 0.01 & 0.01 \\
\hline Rollo de tela en espera de de secado & 0.27 & 0.55 & 0.41 & 0.57 & 0.40 & 0.73 & 0.58 & 0.61 & 0.30 & 0.69 & 0.53 & 0.51 & 0.85 \\
\hline Secado & 0.13 & 0.06 & 0.05 & 0.10 & 0.03 & 0.07 & 0.06 & 0.11 & 0.13 & 0.10 & 0.05 & 0.11 & 0.14 \\
\hline Traslado de bobina para su revisión & 0.01 & 0.01 & 0.01 & 0.01 & 0.01 & 0.01 & 0.01 & 0.01 & 0.01 & 0.01 & 0.01 & 0.01 & 0.01 \\
\hline Bobina en espera para su revisión & 1.63 & 1.25 & 1.74 & 2.03 & 0.58 & 2.37 & 1.42 & 1.23 & 2.61 & 2.27 & 2.17 & 2.66 & 0.46 \\
\hline Revisión de tela teñida & 0.10 & 0.10 & 0.06 & 0.03 & 0.08 & 0.04 & 0.06 & 0.11 & 0.04 & 0.04 & 0.10 & 0.08 & 0.06 \\
\hline Traslado de bobina para impregnado & 0.01 & 0.01 & 0.01 & 0.01 & 0.01 & 0.01 & 0.01 & 0.01 & 0.01 & 0.01 & 0.01 & 0.01 & 0.01 \\
\hline Total por proceso & 5.55 & 4.66 & 5.45 & 7.01 & 4.84 & 7.38 & 6.58 & 4.46 & 5.38 & 5.66 & 5.10 & 8.21 & 4.95 \\
\hline
\end{tabular}

Elaboración propia

De los datos obtenidos de la empresa para la muestra de 252 bobinas equivalentes a 252 procesos completos, se han calculado las estadísticas y el Límite de control superior (LCS o UCL por sus siglas en inglés Upper control limit) el cual es de 7.43 días, lo que indica para la empresa que los procesos que sobrepasen este valor son pérdidas para la empresa en cuanto a mano de obra y hora máquina (Jigger). 
Tabla 28: Cálculo del Límite Superior del Proceso

\begin{tabular}{|l|r|}
\hline Promedio & 6.21 \\
\hline Desv Std & 1.22 \\
\hline UCL & 7.43 \\
\hline LCL & 5.00 \\
\hline
\end{tabular}

Elaboración propia

A continuación, se calcula los tiempos de espera, al programar en Excel la condición:

Sí

$\mathrm{T}_{\text {total }}>\mathrm{UCL}$

Entonces

$\mathrm{T}_{\text {espera }}=\mathrm{T}_{\text {total }}-\mathrm{UCL}$

De lo contrario

$\mathrm{T}_{\text {espera }}=0$

Como se muestra a continuación:

Tabla 29: Cálculo del tiempo de espera en el proceso de teñido del equipo Jigger

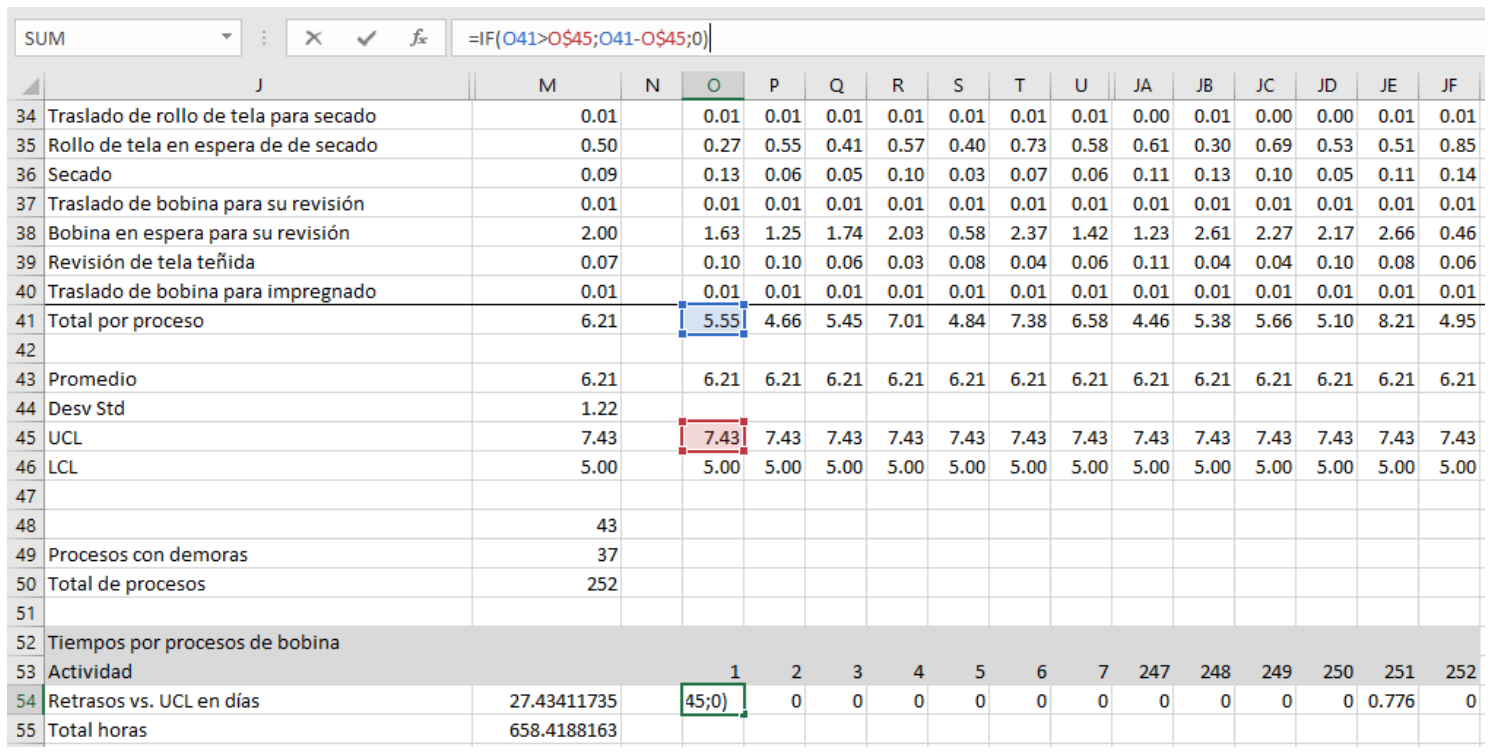

\section{Elaboración propia}

El total de los días de retraso o tiempo de espera es de 27.43 días, equivalente a 658.42

horas, tres turnos por día, con un total de 44 operarios en el equipo de Jigger, dichos operarios tiene un sueldo promedio de $\mathrm{S} / 2,500$ por operario por mes, equivalente a $\mathrm{S} / 12.50$ por hora por operario, y el costo de la hora máquina de acuerdo con la empresa textil es de $\mathrm{S} / 54.00$ por lo que el impacto económico al exceder el tiempo del proceso es de $\mathrm{S} / 397,684.97$ equivalente al $11.69 \%$ del total de las ventas de subproductos 
Tabla 30: Impacto económico por retrasos en el proceso de teñido del equipo Jigger

\begin{tabular}{|c|c|}
\hline $\begin{array}{l}\text { Tiempos por procesos de bobina } \\
\text { Actividad }\end{array}$ & \\
\hline Retrasos vs. UCL en días & 27.43411735 \\
\hline Total horas & 658.4188163 \\
\hline Operarios en proceso de teñido máquina jigger & 44 \\
\hline Promedio sueldo & $2,500.00$ \\
\hline Costo $\mathrm{HH}$ & 12.50 \\
\hline Costo HM (jigger) & 54.00 \\
\hline Impacto económico & S/ $397,684.97$ \\
\hline Equivalente a & $11.69 \%$ \\
\hline Ventas de & S/ 3,400,659.00 \\
\hline
\end{tabular}

Elaboración propia

Este total de impacto económico de S/397,684.97 también equivale al 0.16\% de las ventas totales de la empresa de $\mathrm{S} / 244,299,546.00$.

\subsubsection{Impacto Económico Total}

El impacto total por la demora en las entregas debido a los retrasos en el proceso de teñido del equipo Jigger es de $\mathrm{S} / 603,666.13$

Tabla 31: Impacto económico total

\begin{tabular}{l|l|}
\hline TOTAL Impacto Económico & \\
\hline Penalidades & S/ $205,981.16$ \\
\hline Tiempo de espera & S/ $397,684.97$ \\
\hline & \\
\hline Total & S/ $603,666.13$ \\
\hline
\end{tabular}

Elaboración propia

\subsection{Variables dependientes e independientes}

La función que abarca las variables dependientes e independientes es $f(x)=y$.

En donde y, son las variables independientes y x son las variables dependientes. Se asume que la variable dependiente es la propuesta de mejora del proceso de teñido de telas en una empresa textil y las variables independientes, se muestran como parte de cada uno de los cálculos de las diferentes herramientas que se utilizarán en la propuesta de mejora, como tiempo, identificación de equipo, pérdidas por penalidades. 
Tabla 32: Variables independientes y dependientes

\begin{tabular}{|c|c|c|c|}
\hline Objetivos & Variables $f(X)=Y$ & Medición & Indicadores \\
\hline Objetivo General & Independientes (Y) & Unidades & \\
\hline $\begin{array}{l}\text { Elaborar una propuesta de mejora del proceso de teñido } \\
\text { de telas en una empresa textil }\end{array}$ & \multicolumn{2}{|c|}{ Mejora del proceso de teñido $(\mathrm{Y})$} & \\
\hline Objetivos Específicos & Dependientes (X) & Unidades & \\
\hline Definir el proceso actual y definir tiempos de espera & $\begin{array}{l}\text { Tiempo (X1) } \\
\text { Equipo (X2) }\end{array}$ & $\begin{array}{l}\text { Hora Hombre } \\
\text { Hora máquina }\end{array}$ & $\begin{array}{l}\text { Productividad } \\
\text { Nivel de cumplimiento }\end{array}$ \\
\hline Medir y recolectar los datos requeridos para el estudio & $\begin{array}{l}\text { Tiempo (X1) } \\
\text { Equipo }(\mathrm{X} 2) \\
\end{array}$ & $\begin{array}{l}\text { Hora Hombre } \\
\text { Hora máquina }\end{array}$ & $\begin{array}{l}\text { Productividad } \\
\text { Nivel de cumplimiento }\end{array}$ \\
\hline Analizar proceso actual & $\begin{array}{l}\text { Tiempo (X1) } \\
\text { Equipo (X2) } \\
\text { Penalidades (X3) }\end{array}$ & $\begin{array}{l}\text { Hora Hombre } \\
\text { Hora máquina } \\
\text { Soles }\end{array}$ & \begin{tabular}{|l} 
Productividad \\
Nivel de cumplimiento \\
Costos por depilfarros \\
(penalidades) \\
Ciclo de proceso \\
\end{tabular} \\
\hline $\begin{array}{l}\text { Mejorar el proceso aplicando e implementando las } \\
\text { herramientas para reducir o eliminar las demoras en las } \\
\text { entregas }\end{array}$ & \begin{tabular}{|l} 
Tiempo (X1) \\
Equipo (X2) \\
Penalidades (X3) \\
Inversión (X4) \\
Ahorros (X5) \\
Unidades (X6)
\end{tabular} & $\begin{array}{l}\text { Hora Hombre } \\
\text { Hora máquina } \\
\text { Soles } \\
\text { Soles } \\
\text { Soles } \\
\text { Unidades }\end{array}$ & $\begin{array}{l}\text { Productividad } \\
\text { Nivel de cumplimiento } \\
\text { Costos por depilfarros } \\
\text { (penalidades) } \\
\text { Ciclo de proceso } \\
\text { VAN y TIR } \\
\text { Simulación } \\
\end{array}$ \\
\hline $\begin{array}{l}\text { Controlar la implementación de la propuesta al verificar } \\
\text { su factibilidad de implementación }\end{array}$ & \begin{tabular}{|l} 
Tiempo (X1) \\
Equipo (X2) \\
Penalidades (X3) \\
Inversión (X4) \\
Ahorros (X5) \\
Unidades (X6)
\end{tabular} & $\begin{array}{l}\text { Hora Hombre } \\
\text { Hora máquina } \\
\text { Soles } \\
\text { Soles } \\
\text { Soles } \\
\text { Unidades }\end{array}$ & $\begin{array}{l}\text { Productividad } \\
\text { Nivel de cumplimiento } \\
\text { Costos por depilfarros } \\
\text { (penalidades) } \\
\text { Ciclo de proceso } \\
\text { VAN y TIR } \\
\text { Simulación }\end{array}$ \\
\hline
\end{tabular}

Elaboración propia

\subsection{Objetivos}

\subsubsection{Objetivo General}

Elaborar una propuesta de mejora del proceso de teñido de telas en una empresa textil al utilizar las herramientas de Lean y de Ingeniería para incrementar el nivel de cumplimiento de entregas al reducir o eliminar los cuellos de botellas o tiempos de espera logrando un proceso de mejora continua implementando las herramientas VSM y SMED incluyendo la gestión del proceso con la herramienta MRPII.

\subsubsection{Objetivos Específicos}

- Definir el proceso actual y definir tiempos de espera

- Medir y recolectar los datos requeridos para el estudio

- Analizar proceso actual

- Mejorar el proceso aplicando e implementando las herramientas para reducir o eliminar las demoras en las entregas 
- Controlar la implementación de la propuesta al verificar su factibilidad de implementación

\subsection{Hipótesis}

La mejora del proceso de teñido de telas en una empresa textil se mejora al utilizar las herramientas de Lean y de Ingeniería para incrementar el nivel de cumplimiento de entregas al reducir o eliminar los cuellos de botellas o tiempos de espera logrando un proceso de mejora continua implementando las herramientas VSM y SMED incluyendo la gestión del proceso con la herramienta MRPII.

\subsection{Indicadores}

Los indicadores que se han calculado en el análisis de la situación actual se recopilan en la siguiente tabla:

Tabla 33: Indicadores

\begin{tabular}{|l|r|r|l|l|}
\hline \multirow{2}{*}{\multicolumn{1}{|c|}{ Indicadores }} & \multicolumn{1}{|c|}{ Actual } & \multicolumn{2}{c|}{ Objetivo } \\
\cline { 2 - 5 } & \multicolumn{2}{c|}{ unidades } & \multicolumn{2}{c|}{ unidades } \\
\hline Takt Time & 1.07 & día/bobina & incrementar & día/bobina \\
\hline Máx Tiempo registrado del proceso & 9.17 & días & 4.42 & días \\
\hline Promedio de tiempo del proceso & 6.21 & días & 1.46 & días \\
\hline Nivel de cumplimiento & $66.76 \%$ & porcentaje & $95.00 \%$ & porcentaje \\
\hline Tiempo de esperas & 4.75 & días & 0.24 & días \\
\hline Tiempo de proceso sin esperas & 1.46 & días & disminuir & días \\
\hline Porcentaje de la distribución de las bobinas en cola & $82.5 \%$ & porcentaje & reducir & porcentaje \\
\hline
\end{tabular}

Elaboración propia

El tiempo Takt es de 1.07 días/bobina, sin embargo, este valor debe regularizarse de acuerdo con las paradas programadas, debe incrementar al dato que la empresa toma como paradas de horas por día. Otro indicador es el máximo del tiempo que se utiliza para el servicio de una bobina de 9.17días y de acuerdo con la empresa debe ser 4.42 días y el promedio es de 6.21 días lo que debería ser 1.46 días de acuerdo con las políticas de la empresa, el nivel de cumplimiento debe lograrse al 95\% por lo que el nivel actual de servicio de $66.76 \%$ que la empresa entrega los pedidos a tiempo debe incrementarse. Se debe eliminar o reducir al mínimo el tiempo de espera de las bobinas antes de la actividad de teñido, en la propia actividad de reposo y antes de la actividad de revisión asumiendo un nivel de cumplimiento de $95 \%$ reduciéndose los tiempos de espera de 4.75 días a 0.24 días, por lo que el tiempo del proceso total también disminuirá si es que se soluciona la 
actividad de reposo así como se reducen los tiempos de espera para ingreso al teñido y de revisión, por lo que se debe lograr la reducción del porcentaje actual de colas de las bobinas en el sistema de teñido de $82.5 \%$ para que se estabilice el proceso y reduzca las bobinas en cola. 


\section{CAPÍTULO III: PROPUESTA DE MEJORA}

En el presente capítulo, se desarrollará la propuesta con el objetivo de reducir tiempos en el propio proceso de teñido para el equipo Jigger, de tal manera que se reduzca la demora en entregas y, por consiguiente, se incremente el nivel de cumplimiento de entregas de bobinas a tiempo. Se supondrá la implementación en el equipo Jigger, y de acuerdo con los resultados de una posible implementación podrá aplicarse a toda la empresa.

\subsection{Diseño de la propuesta}

El diseño de la propuesta comprende de las herramientas de Lean Manufacturing como implementación de la mejora del proceso, al identificar los despilfarros o desperdicios del proceso de teñido como tiempos de espera, los cuales producen la demora en la entrega de las bobinas a tiempo. Así como se utilizarán herramientas de ingeniería que ayudarán analizar el nuevo proceso estándar y confirmar que se logra el objetivo de reducir tiempos y despilfarros en el proceso logrando incrementar el valor en el proceso, de acuerdo con las diferentes definiciones propias de la Filosofía Lean, como teoría de colas. Todas estas herramientas se enmarcan bajo la herramienta MRPII como gestión del proceso. El diseño de la propuesta se basará en los siguientes trabajos e indicados en el marco teórico.

Tabla 34: Herramientas propuestas

\begin{tabular}{|l|l|}
\hline Herramientas & Fuente \\
\hline Relación de las herramientas Lean (VSM y & Ocampo, J. R., Hernández-Matías, J. \\
$\begin{array}{l}\text { SMED) como mejora del proceso y MRP II } \\
\text { como gestión del proceso }\end{array}$ & C., \& Vizán, A. (2017) \\
\cline { 2 - 2 } Implementación de Lean Manufacturing & Goyal, A., \& Agrawal, R. (2017) \\
\hline
\end{tabular}

Elaboración propia

En la tabla se muestra exactamente que para solucionar el problema de la demora en las entregas debido al proceso de teñido de la máquina Jigger se requiere utilizar las herramientas VSM para identificar los cuellos de botella como tiempos de espera tanto para las actividades de teñido como para revisión y en la propia actividad de reposo, para tal motivo se debe mejorar el proceso al utiliza la herramienta SMED, herramienta que al implementarse correctamente, reducirá significativamente el proceso y por ende los 
tiempos de espera identificados con la herramienta VSM. Por último, se aplicará la teoría de colas para calcular la reducción de colas en el sistema y poder elaborar el VSM de estado futuro o de la propuesta de mejora. Al implementar nuevamente el VSM se demuestra la reducción de los despilfarros y por ende la reducción de los tiempos del proceso, logrando un Diagrama de Análisis de Procesos que demuestra la mejora del proceso al implementar las herramientas.

\subsubsection{Objetivo e impacto económico}

Para iniciar el desarrollo de la propuesta, se resumirá el análisis de la situación actual en modo de que se introduzca el problema, el objetivo y el impacto económico que genera directamente dicho problema identificado.

Tabla 35: Relación del problema, objetivo e impacto económico

\begin{tabular}{|c|c|c|}
\hline Problema & Objetivo & Impacto Económico \\
\hline $\begin{array}{l}\text { La mala programación de la producción y } \\
\text { desorden de las porta bobinas son las } \\
\text { causas raíz del bajo nivel de } \\
\text { cumplimiento de los productos del } \\
\text { proceso de teńido del equipo Jigger }\end{array}$ & $\begin{array}{l}\text { Solucionar los problemas con } \\
\text { herramientas de ingeniería para } \\
\text { establecer los tiempos y así establecer } \\
\text { los procedimientos estandarizados con } \\
\text { herramientas de Lean que aseguren la } \\
\text { reducción o eliminación de los tiempos } \\
\text { de espera en el sistema y así los costos } \\
\text { generados por ellos como las } \\
\text { penalidades por el retraso en la entrega } \\
\text { y el costo del tiempo de espera }\end{array}$ & $\begin{array}{l}\text { Reducir los tiempos de espera por la } \\
\text { mala programación de producción del } \\
\text { equipo Jigger y las penalidades que } \\
\text { estas generan, generando un impacto } \\
\text { económico de } S / 603,666.13 \text { en el } \\
\text { proceso de teñido debido al equipo } \\
\text { Jigger }\end{array}$ \\
\hline
\end{tabular}

Elaboración propia

El problema es el bajo nivel de cumplimiento de entregas a tiempo de las bobinas que se producen del equipo Jigger, generado por la mala programación de producción y el desorden de las porta bobinas, ubicadas en diferentes lugares de la planta. El objetivo de implementar herramientas Lean es la de mejorar los procesos, VSM para identificar los despilfarros y SMED para la mejora del proceso de teñido del equipo Jigger, implementándose el MRPII para la gestión del proceso. Estos despilfarros, generan un impacto económico total por $\mathrm{S} / 603,666.13$ por penalidades al entregar los productos terminados después del tiempo de entrega establecido y por la carga de mano de obra que se generan por los retrasos en el proceso. La mano de obra no necesariamente son horas extras, sino la extensión del trabajo del proceso que toma a los operarios en realizar el mismo proceso por más tiempo. 


\subsubsection{Propuesta}

En la tabla 38 se muestra, el diseño de la propuesta relacionándose con el problema y sus causas: 
Tabla 36: Propuesta

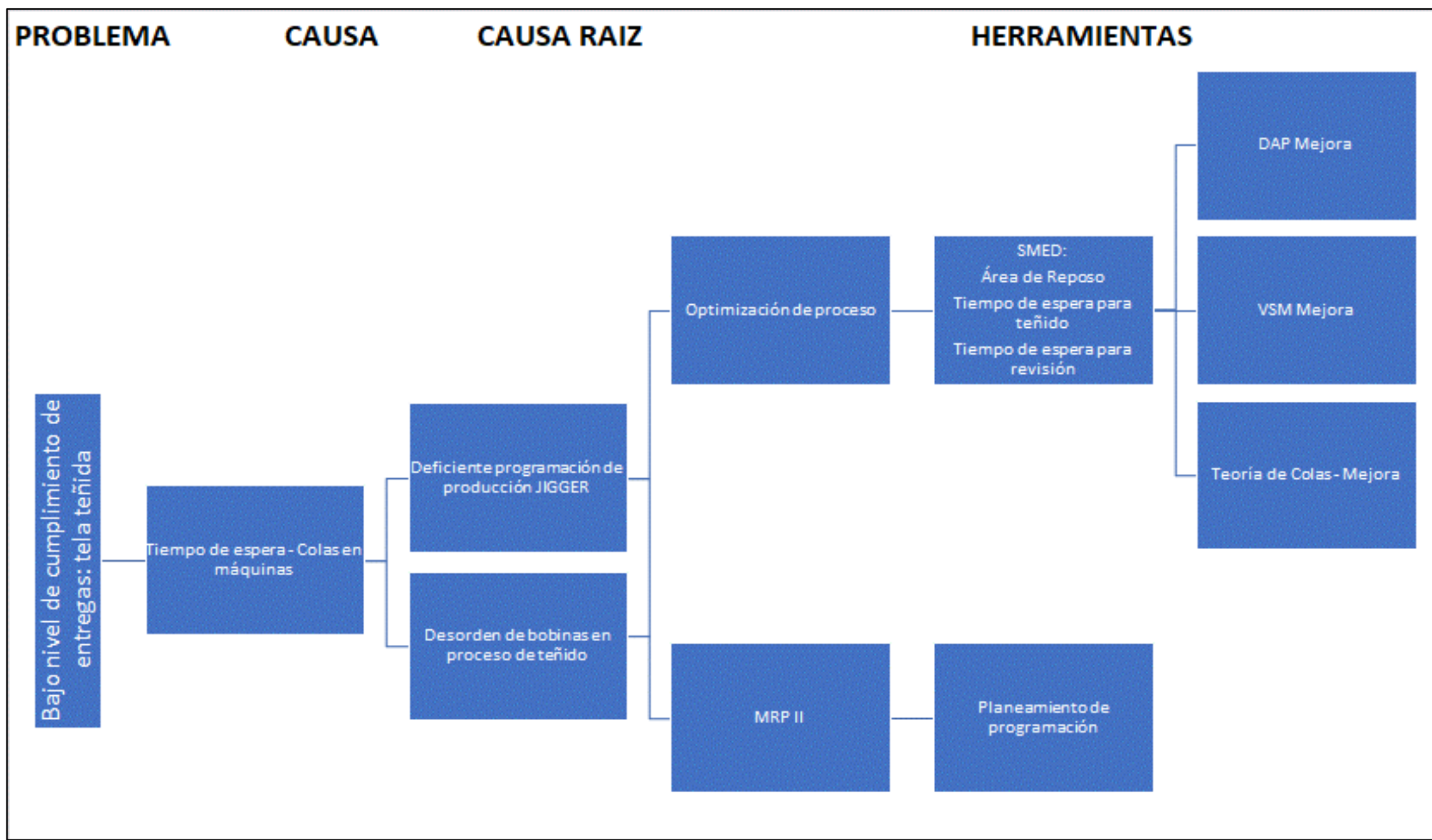

Elaboración propia 
Al solucionar la causas raíz en la deficiencia de la programación de producción se solucionará el desorden de las bobinas por medio de la optimización del proceso de teñido para el equipo Jigger al utilizar la herramienta SMED, estandarizando el nuevo proceso y se manifiestan los resultados en la elaboración de un DAP del proceso de mejora, un VSM del proceso de mejora y como validación la teoría de Colas para la propuesta de mejora al demostrar que el porcentaje de colas en el sistema se reduce y mayor cantidad de bobinas pasan sin detenerse por tiempos de espera. Por último, se elabora la herramienta MRPII, cuyo objetivo es el planeamiento de la producción de acuerdo con los resultados hallados al implementar la mejora, comparándose entre la situación actual de un posible MRPII sin implementar las herramientas y la propuesta de mejora.

\subsection{Desarrollo de la propuesta}

La empresa textil bajo estudio requiere la mejora continua del proceso de teñido en la máquina Jigger, de tal forma que se reduzcan o eliminen los tiempos de espera lo que origina la demora en la entrega a tiempo de las bobinas a sus clientes llevando a un nivel de cumplimiento de $67 \%$. En la siguiente tabla, se muestra que el proceso de teñido es el proceso que más genera tiempos de espera y cada bobina llega cada 7.53 días aproximadamente del proceso de preparado.

Tabla 37: Días de procesos

\begin{tabular}{|c|c|c|c|c|c|}
\hline Proceso & $\begin{array}{l}\text { Promedio } \\
\text { días } \\
\text { total }\end{array}$ & $\begin{array}{l}\text { Promedio } \\
\text { días } \\
\text { acividades }\end{array}$ & $\begin{array}{l}\text { Promedio } \\
\text { días } \\
\text { Espera }\end{array}$ & $\%$ & $\%$ acum \\
\hline Teñido & 6.21 & 1.46 & 4.75 & $49 \%$ & $49 \%$ \\
\hline Preparado & 7.53 & 4.78 & 2.75 & $28 \%$ & $78 \%$ \\
\hline Acabado & 3.90 & 1.73 & 2.17 & $22 \%$ & $100 \%$ \\
\hline & & & 9.67 & & \\
\hline
\end{tabular}

Elaboración propia

En la tabla 39, se observa que el proceso de teñido es de 6.21 días, lo que genera los tiempos de espera cuando las bobinas llegan del proceso de preparado, ya que el tiempo de esta actividad es de 7.53 días y el proceso de acabado se encuentre en espera de las bobinas que salen del sistema de teñido del equipo Jigger para la muestra de 252 bobinas exclusivamente del equipo Jigger. El proceso de teñido genera 4.75 horas de tiempo de espera mientras que las actividades propias de trabajo son sólo de 1.46 horas, la relación 
de tiempo de trabajo productivo versus el tiempo de espera es de 1:3, es decir que por cada hora de trabajo en el proceso de teñido genera 3 horas de tiempo de espera.

Para lograr la reducción de las actividades que generan tiempos de espera de acuerdo con el VSM actual se han identificado desperdicios en el área de reposo, el cual es el que genera también el tiempo de espera antes del teñido y revisión, el proceso en sí del teñido de una bobina es de 0.06 días equivalente a 1.44 horas, y una bobina espera para ingresar a este subproceso por 2 días, sin embargo, en el subproceso de reposo, se produce en un tiempo de 1.1237 días (26.97 horas), lo que de acuerdo con las instrucciones de las cámaras de reposo, este procedimiento sólo debe durar de 12 a 18 horas por bobina. Identificándose despilfarros en el proceso, esto origina que la espera para el ingreso de una bobina en el equipo Jigger, espere un aproximado de 2 días. Por último, por la acumulación de la salida del proceso de reposo y el avance rápido de los subprocesos de lavado teñido y secado, originan el tiempo de espera o cola en el subproceso de Revisión. Esto se muestra en el VSM de la situación actual a continuación: 
Figura 27: VSM Actual

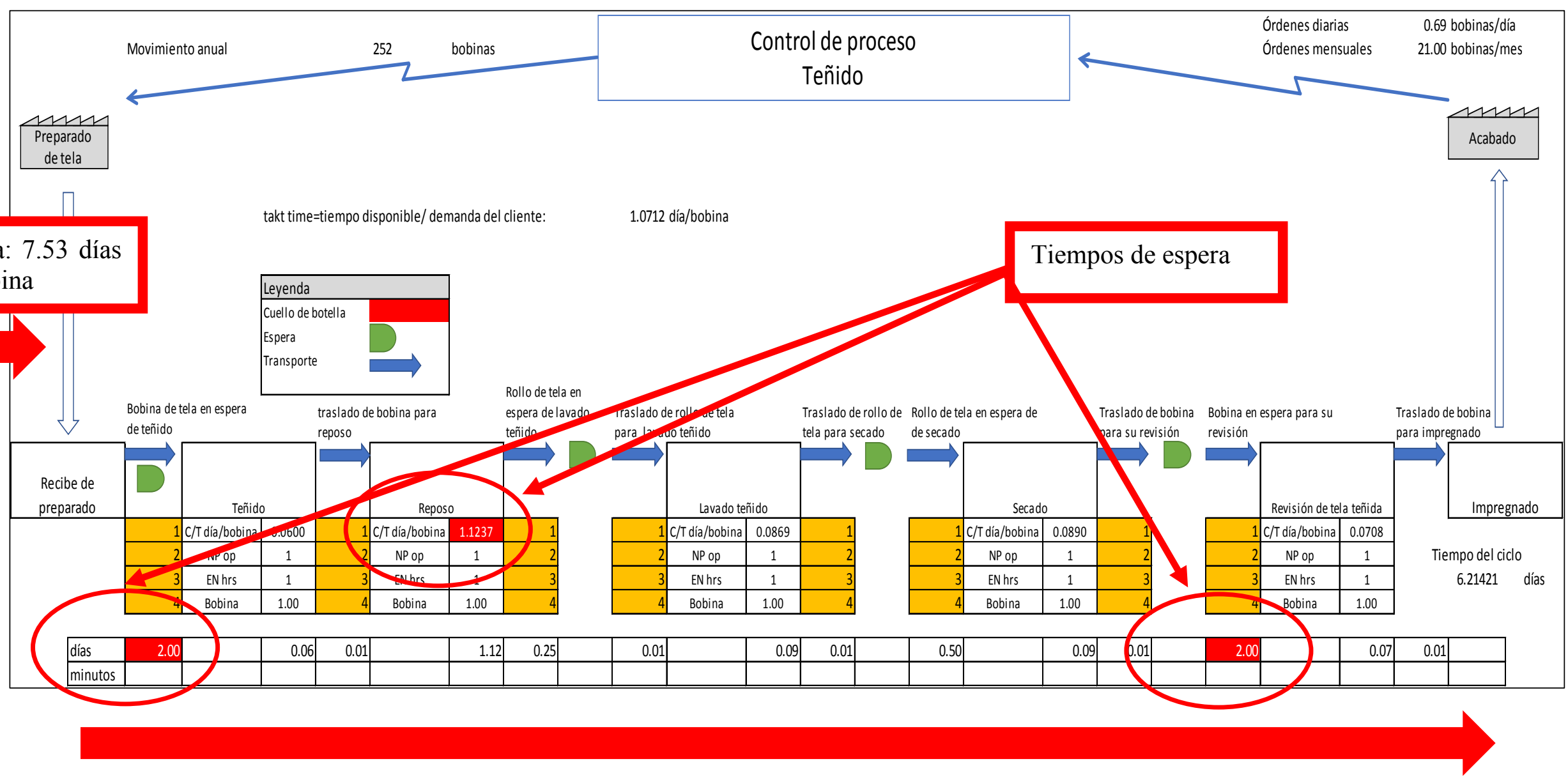

Llegada: 6.21 días

por bobina 
Por lo tanto, primero se analiza el DAP del subproceso Reposo como se muestra a continuación:

Figura 28: DAP - Subproceso Reposo

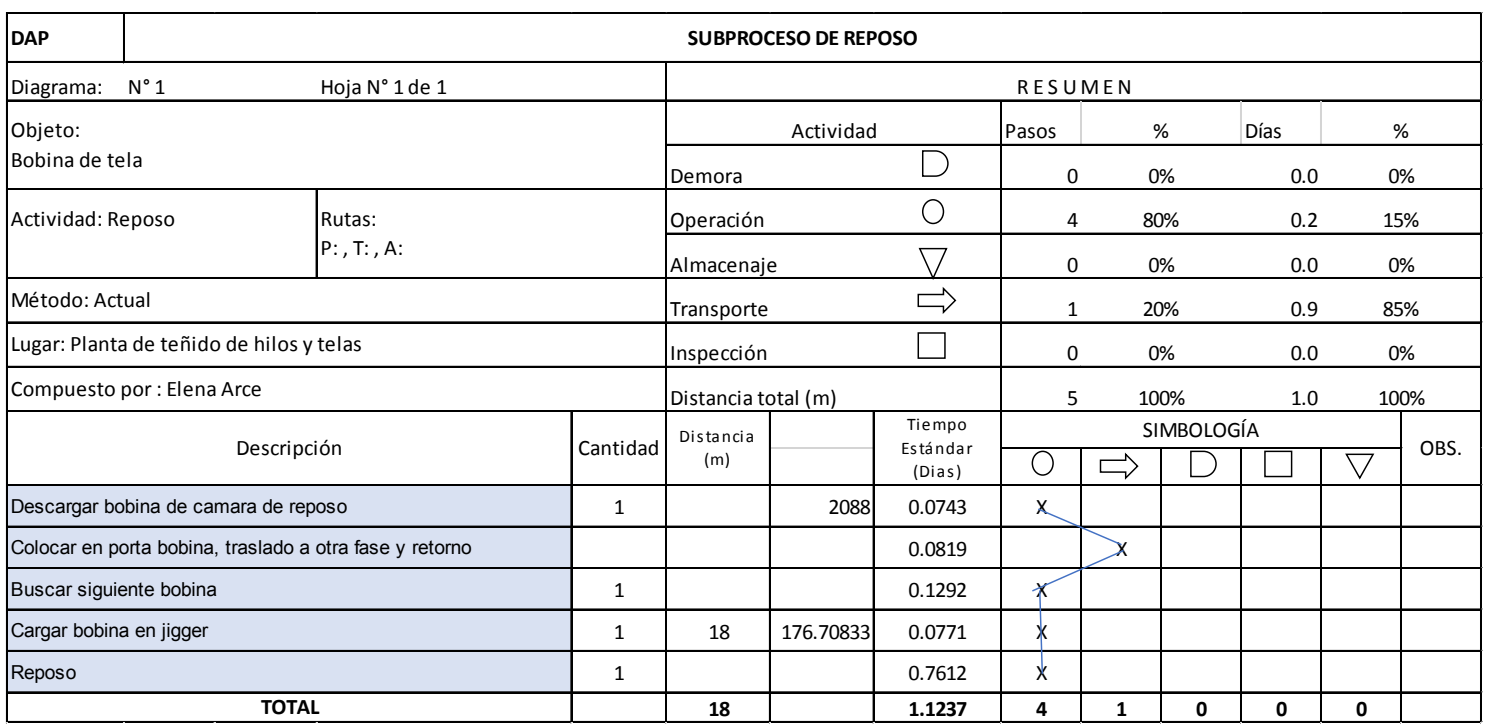

Elaboración propia

Las actividades de carga y descarga de bobinas en el subproceso de Reposo se realizan sólo por dos operarios para cada bobina, es decir, cuando termina el ciclo de reposo para una bobina, los dos operarios descargan (0.0743 días equivalente a 1.7833 horas), el tiempo implica que no existe una forma de alarma que avise a los operarios, ya que llegan sólo cuando se acuerdan o se dan cuenta que el ciclo de reposo terminó. Posteriormente, colocan la bobina en la portabobina para trasladarla a la siguiente fase de lavado de teñido lo cual toma un tiempo de 0.0819 días equivalente a 1.9667 horas, tiempo exorbitante que al analizar este tiempo se detectó que los operarios se encuentran realizando otras actividades, ya que no cuentan con una función definida y rotan por toda la planta realizando labores de apoyon de acuerdo a lo indicado por lossupervisores. La búsqueda de la siguiente bobina en cola, les toma 0.1292 días equivalente a un promedio de 3.1 horas, tiempo que el que la cámara de reposo se encuentra sin actividad, ya que por el desorden de las bobinas, toma tiempo la búsqueda de la siguiente bobina que llega del subproceso de teñido y que se han colocado en espera por otros operarios del subproceso de teñido. Esta actividad se encuentra oculta de los datos de la empresa, ya que consideran la descarga y búsqueda de bobinas como el propio proceso de reposo, por costumbre a un mal proceso. La actividad de Carga de bobina toma 1.85 horas, por la misma causa que los operarios desatienden este proceso por hacer otros trabajos, y dejan el trabajo hasta 
que se acuerdan o alguien les avisa, es decir priorizan otras labores en lugar de terminar con estas acciones.

Por otro lado, la sugerencia de la empresa para el tiempo total del subproceso de reposo debe ser de 15 horas, sin embargo, el propio proceso es de un promedio de 0.761 días equivalente a 18.27 horas, lo cual sugiere que las bobinas también permanecen en la propia actividad de reposo más del tiempo sugerido de 15 horas promedio. En los tiempos tomados para la muestra de 252 bobinas, se detectó que el mínimo tiempo de reposo es de 21.38 horas (0.89 días) y el máximo es de 32.40 horas (1.35 días), incluyendo las actividades de carga y descarga y búsqueda de bobinas:

Tabla 38: Datos de Histograma

\begin{tabular}{|c|c|c|c|c|c|}
\hline Bin & Frecuencia & $\%$ Acum & Bin & Frecuencia & $\%$ Acum \\
\hline 0.891 & 2 & $0.79 \%$ & 0.9522 & 24 & $9.52 \%$ \\
\hline 0.9216 & 18 & $7.94 \%$ & Más & 24 & $19.05 \%$ \\
\hline 0.9522 & 24 & $17.46 \%$ & 1.2888 & 22 & $27.78 \%$ \\
\hline 0.9828 & 15 & $23.41 \%$ & 1.1052 & 20 & $35.71 \%$ \\
\hline 1.0134 & 14 & $28.97 \%$ & 0.9216 & 18 & $42.86 \%$ \\
\hline 1.044 & 13 & $34.13 \%$ & 1.1664 & 18 & $50.00 \%$ \\
\hline 1.0746 & 12 & $38.89 \%$ & 1.2276 & 17 & $56.75 \%$ \\
\hline 1.1052 & 20 & $46.83 \%$ & 1.3194 & 16 & $63.10 \%$ \\
\hline 1.1358 & 14 & $52.38 \%$ & 0.9828 & 15 & $69.05 \%$ \\
\hline 1.1664 & 18 & $59.52 \%$ & 1.0134 & 14 & $74.60 \%$ \\
\hline 1.197 & 11 & $63.89 \%$ & 1.1358 & 14 & $80.16 \%$ \\
\hline 1.2276 & 17 & $70.63 \%$ & 1.044 & 13 & $85.32 \%$ \\
\hline 1.2582 & 12 & $75.40 \%$ & 1.0746 & 12 & $90.08 \%$ \\
\hline 1.2888 & 22 & $84.13 \%$ & 1.2582 & 12 & $94.84 \%$ \\
\hline 1.3194 & 16 & $90.48 \%$ & 1.197 & 11 & $99.21 \%$ \\
\hline \multirow[t]{2}{*}{ More } & 24 & $100.00 \%$ & 0.891 & 2 & $100.00 \%$ \\
\hline & Días & Horas & & & \\
\hline Mínimo & 0.89 & 21.38 & & & \\
\hline Máximo & 1.35 & 32.40 & & & \\
\hline
\end{tabular}

Elaboración propia 
Figura 29: Histograma del subproceso de reposo

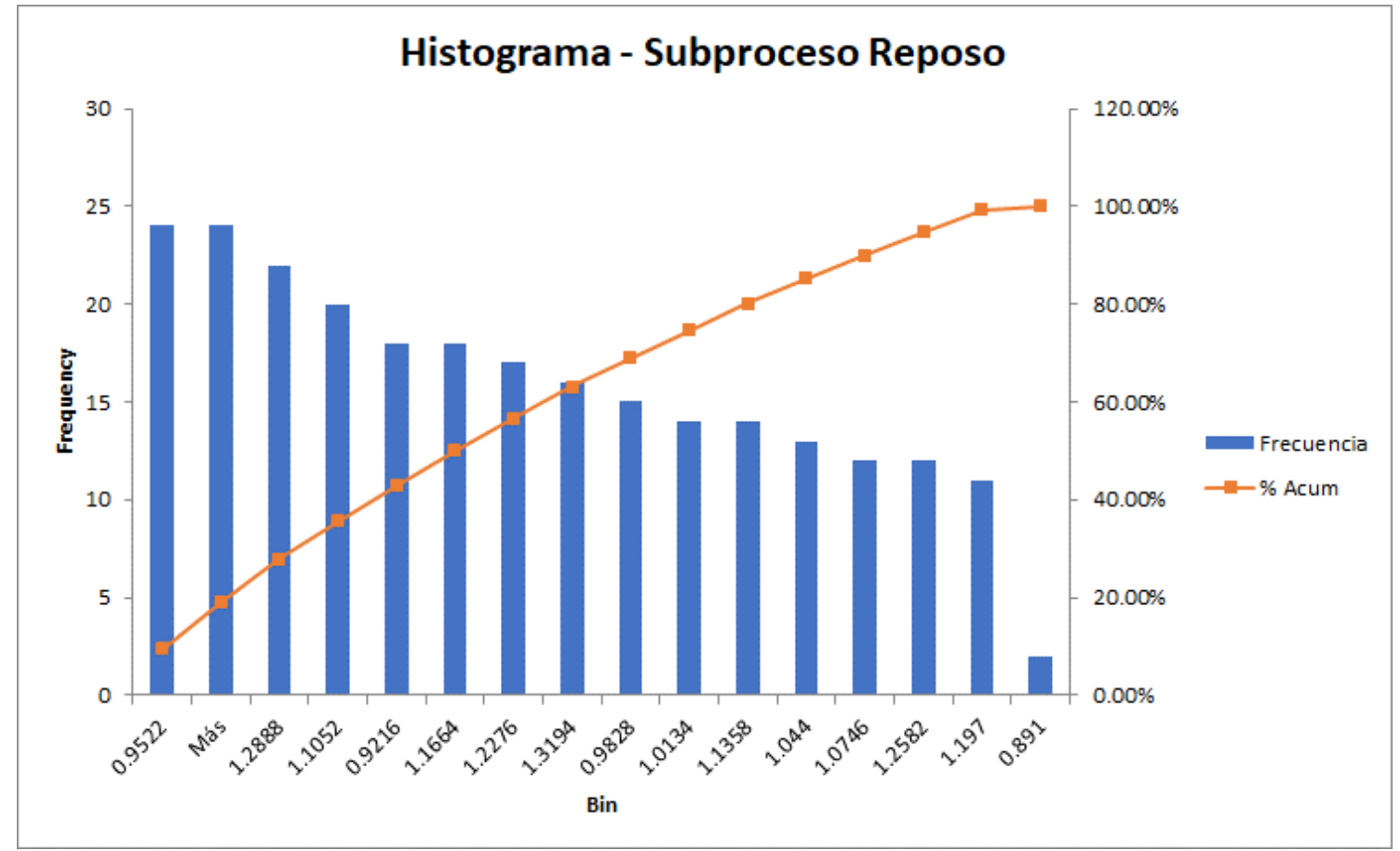

Elaboración propia

El histograma indica que hay 24 procesos en un rango de 0.9522 a 0.9828 días y 24 procesos en un rango de 1.3194 a más días (el máximo de1.35 días).

Por lo tanto, el subproceso de Reposo se muestra a continuación 
Figura 30: Subproceso de Reposo Actual

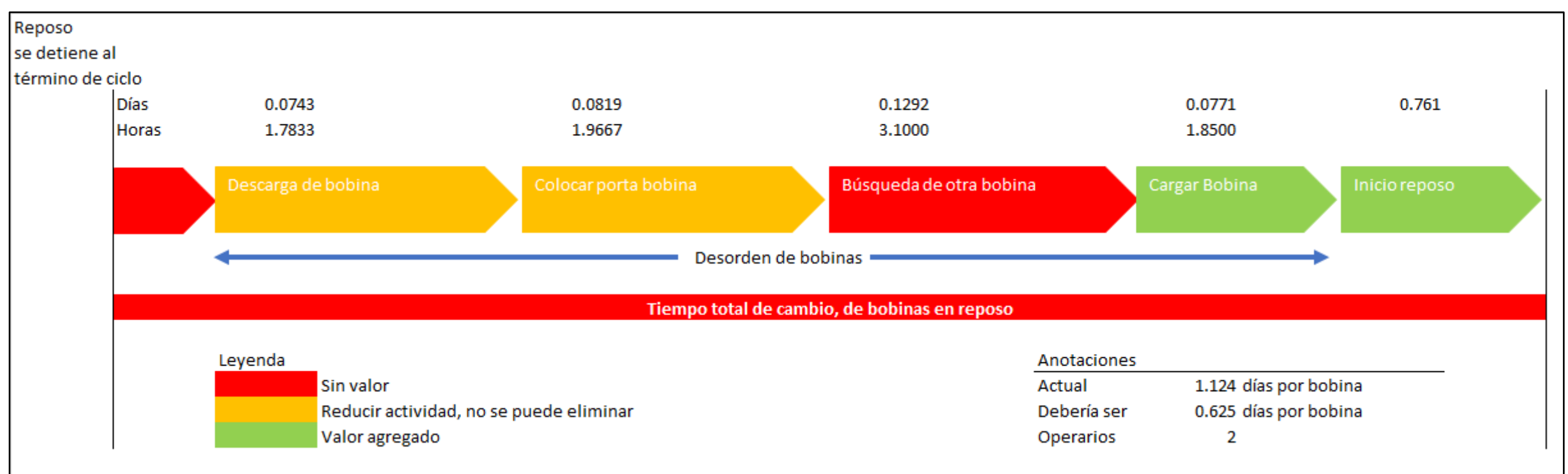

Elaboración propia 
En la figura 30, se observa que la actividad sin valor es la búsqueda de la siguiente bobina en cola y en las actividades de descarga y colocación en porta bobina deben reducirse los tiempos, ya que no pueden eliminarse, pero, sí, reducir tiempos.

\subsubsection{Optimización del subproceso de reposo en el proceso de teñido}

De acuerdo con la herramienta de SMED, el cambio de una herramienta debe ser máximo de 10 minutos por lo que se asumirá que la descarga sea igual a 10 minutos, así como la carga, ya que se debe considerar el peso y la ejecución de estas actividades. Para la implementación de SMED se debe regularizar el proceso de ordenamiento de bobinas en el propio proceso. Una vez organizado el proceso de orden, se implementa SMED.

\subsubsection{Proceso de Orden de Porta bobinas}

La teoría de colas es específicamente el método FIFO (First In - First Out, el primero en ingresar el primero en salir). En la figura, se muestra el ingreso de las porta bobinas de color anaranjado que ingresan al subproceso de teñido e ingresan del proceso de preparado. Se debe capacitar a los operarios que lo posicionen en orden y en el área de espera de las portabobinas cerca de cada máquina, establecer un mecanismo de números para que los operarios, puedan registrar el orden de cada una de las bobinas. 
Figura 31: FIFO, ingreso y salida de portabobinas en el proceso de teñido

\begin{tabular}{|c|c|c|c|c|c|c|c|c|c|c|c|c|c|c|c|c|c|c|}
\hline \multirow[t]{5}{*}{$\begin{array}{l}\text { Recibe de } \\
\text { preparado }\end{array}$} & \multicolumn{3}{|c|}{ Teñido } & \multicolumn{3}{|c|}{ Reposo } & & \multicolumn{3}{|c|}{ Lavado teñido } & & \multicolumn{3}{|c|}{ Secado } & & \multicolumn{3}{|c|}{ Revisión de tela teñida } \\
\hline & & Tdia/bob & 0.0600 & & T día/bobina & 1.1237 & 1 & 1 & c/T día/bobing & 0.0869 & 1 & & C/T día/bobina & 0.0890 & 1 & & c/T día/bobina & \begin{tabular}{|l|l|l|}
0.0708 \\
\end{tabular} \\
\hline & 2 & NP op & 1 & 2 & NP op & 1 & 2 & 2 & NP op & 1 & 2 & 2 & NP op & 1 & 2 & 2 & NP op & 1 \\
\hline & 3 & EN hrs & 1 & 3 & EN hrs & 1 & 3 & 3 & EN hrs & 1 & 3 & 3 & EN hrs & 1 & 3 & 3 & EN hrs & 1 \\
\hline & 4 & Bobina & 1.00 & 4 & Bobina & 1.00 & 4 & 4 & Bobina & 1.00 & 4 & 4 & Bobina & 1.00 & 4 & 4 & Bobina & 1.00 \\
\hline
\end{tabular}

Elaboración propia

Por lo que ocurriría de la siguiente manera:

Figura 32: Orden de Portabobinas en el proceso de Teñido

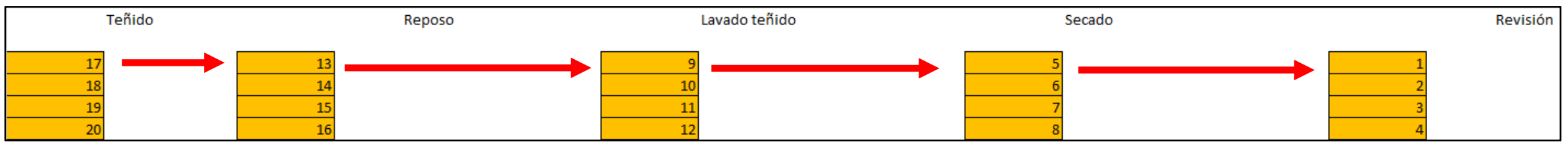

Elaboración propia

En la figura 32, se muestra la forma de colocar las portabobinas en el área correspondiente en orden de acuerdo a su llegada. 
El proceso de control del orden de porta bobinas es:

Tabla 39: Control de Orden de Porta bobinas

\begin{tabular}{|c|c|c|c|c|c|}
\hline \multicolumn{6}{|c|}{ CONTROL ORDEN DE PORTABOBINAS } \\
\hline Diagrama: $\quad \mathrm{N}^{\circ} 1$ & \multicolumn{5}{|l|}{ Hoja N ${ }^{\circ} 1$ de 1} \\
\hline \multicolumn{6}{|c|}{$\begin{array}{l}\text { Objeto: } \\
\text { Orden Bobina de tela }\end{array}$} \\
\hline \multirow[t]{2}{*}{ Actividad: Reposo } & \multirow{2}{*}{$\begin{array}{l}\text { Rutas: } \\
\text { P: , T: , A: }\end{array}$} & & & & \\
\hline & & & & & \\
\hline \multicolumn{6}{|l|}{ Método: Actual } \\
\hline \multicolumn{6}{|c|}{ Lugar: Planta de teñido de hilos y telas } \\
\hline \multicolumn{6}{|c|}{ Compuesto por : Elena Arce } \\
\hline \multirow{2}{*}{\multicolumn{2}{|c|}{ Descripción }} & \multirow{2}{*}{ Fecha } & & & \\
\hline & & & turno 1 & turno 2 & turno 3 \\
\hline \multicolumn{2}{|c|}{ Llegada de portabobina } & $12 / 02 / 2018$ & $x$ & $x$ & $x$ \\
\hline \multicolumn{2}{|c|}{ Operario: Revisar secuencia numérica } & $13 / 02 / 2018$ & $x$ & & $\mathrm{x}$ \\
\hline \multicolumn{2}{|l|}{ Colocar número } & $14 / 02 / 2018$ & $x$ & & \\
\hline \multicolumn{2}{|l|}{ Dejar } & $15 / 02 / 2018$ & $x$ & $x$ & $x$ \\
\hline \multicolumn{2}{|l|}{ Control } & $16 / 02 / 2018$ & $x$ & $x$ & $x$ \\
\hline \multicolumn{2}{|c|}{ TOTAL } & & 5 & 3 & 4 \\
\hline
\end{tabular}

Elaboración propia

Objetivos:

- Lograr el orden para reducir tiempo en la búsqueda de bobinas

- Capacitación a operarios y concientización del nuevo proceso

- Operarios deben asumir su responsabilidad del trabajo realizado en su área de trabajo para reducir tiempos y así servir más bobinas en el proceso de teñido.

\subsubsection{SMED}

Una vez regularizado el orden de las porta bobinas se debe reducir el tiempo de espera por falta de responsabilidad y el que hacer de otras tareas por parte de los operarios para cumplir con los tiempos de SMED.

SMED exige que el cambio de las bobinas debe ser menor a 10 minutos, sin embargo, para este proceso debemos asumir que serán 10 minutos para la descarga y 10 minutos 
para la carga. Estas operaciones fácilmente se realizan en ese tiempo establecido por el mecanismo de la cámara de reposo, que se descarga directamente a la porta bobinas.

\title{
Propuesta de Mejora Parte 1
}

Suposiciones:

SMED

Carga: 10 minutos $=0.007$ días

Descarga: 10 minutos $=0.007$ días

Operarios: 4

Al implementar SMED, se implementa una alarma, la cual empezará a sonar 5 minutos antes de que termine la bobina en el subproceso de reposo.

\section{Procedimiento}

Véase la figura 33 para el procedimiento de manera gráfica.

\begin{abstract}
Alarma
Al sonido de la alarma, los operarios 1 y 2 , buscan la portabobina y se preparan al lado de la cámara de reposo para esperar el término del proceso.

Mientras que los operarios realizan esta tarea, los operarios 3 y 4 buscan la siguiente porta bobina en cola, para colocarse cercanos a los operarios 1 y 2 a la espera del término de la descarga.
\end{abstract}

\section{Descarga}

Al término del proceso de reposo, los operarios 1 y 2 , abren la máquina para descargar la bobina, mientras tanto los operarios 3 y 4 , esperan el mismo tiempo.

\section{Carga}

Una vez que los operarios 1 y 2 se retiran, ingresan los operarios 3 y 4 para la carga de la siguiente bobina en cola.

\section{Inicio de Reposo}

Se inicia el reposo de la bobina por 15 horas. 
Se repite el subproceso para cada una de las bobinas en espera de este subproceso.

Figura 33: Implementación de SMED

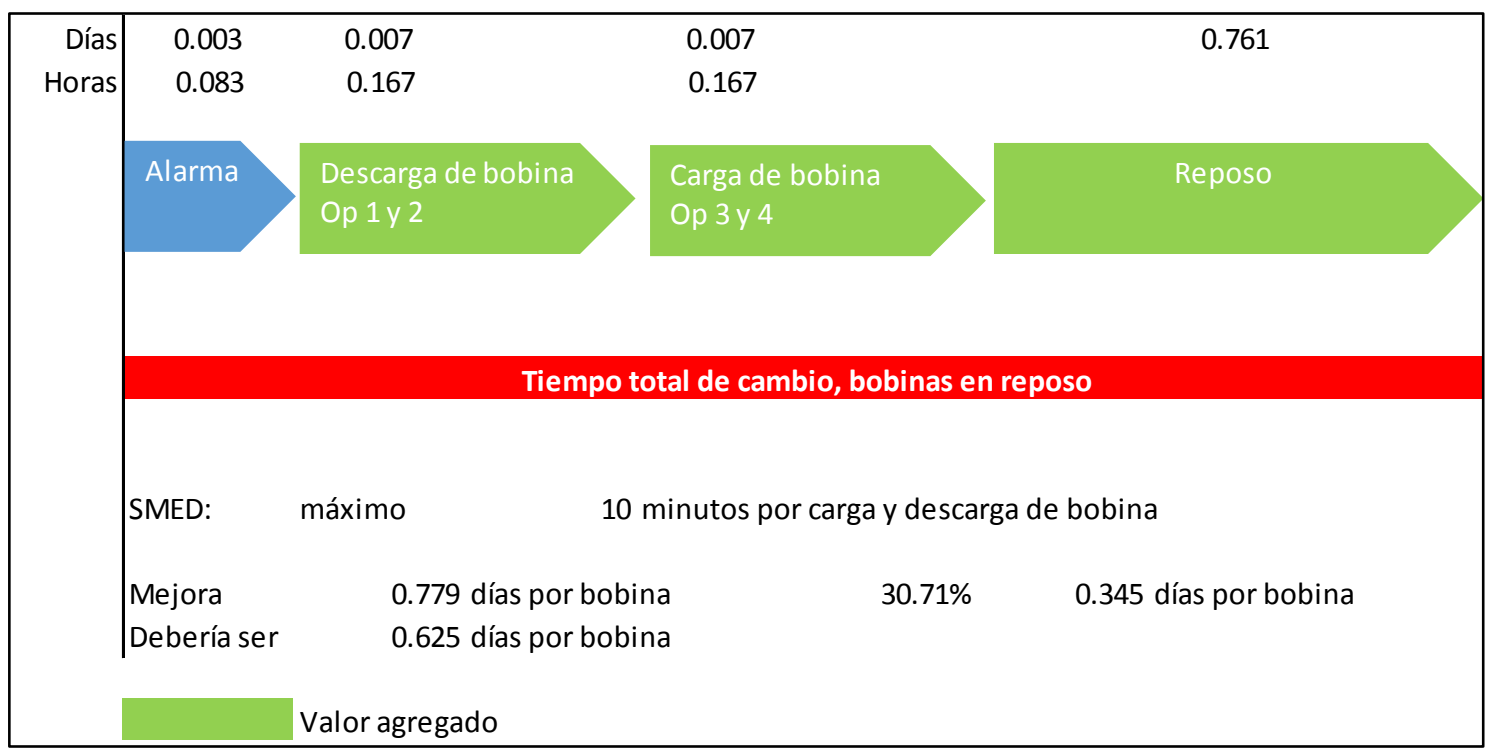

\section{Elaboración propia}

El procedimiento que se ha mejorado al proponer el uso de la herramienta SMED, se coloca en un DAP para conocimiento de los operarios y jefes, además se publica en cada una de las cámaras de reposo. Se ha reducido el subproceso de reposo de 1.124 días a 0.779 , lo que debería ser 0.625 días de acuerdo con el objetivo de la empresa, equivalente a las 15 horas.

\section{Implementación}

Por lo tanto, el nuevo DAP del subproceso de Reposo es: 
Tabla 40: DAP - Subproceso de Reposo - Mejora 1

\begin{tabular}{|c|c|c|c|c|c|c|c|c|c|c|}
\hline DAP & \multicolumn{10}{|c|}{ SUBPROCESO DE REPOSO } \\
\hline Diagrama: $\quad \mathrm{N}^{\circ} 1$ & \multicolumn{2}{|l|}{ Hoja $\mathrm{N}^{\circ} 1$ de 1} & \multicolumn{8}{|c|}{ RESUMEN } \\
\hline \multirow{2}{*}{\multicolumn{3}{|c|}{$\begin{array}{l}\text { Objeto: } \\
\text { Bobina de tela }\end{array}$}} & \multicolumn{2}{|c|}{ Actividad } & Pasos & \multicolumn{2}{|c|}{$\%$} & Días & \multicolumn{2}{|c|}{$\%$} \\
\hline & & & \multicolumn{2}{|l|}{ Demora } & \multicolumn{3}{|c|}{$0 \%$} & \multicolumn{2}{|c|}{0.0} & \\
\hline \multirow[t]{2}{*}{ Actividad: Reposo } & \multirow{2}{*}{$\begin{array}{l}\text { Rutas: } \\
P:, \mathrm{T}: \text {, A: }\end{array}$} & & Operación & O & \multicolumn{2}{|c|}{4} & & \multicolumn{2}{|c|}{0.0} & \\
\hline & & & Almacenaje & $\nabla$ & \multicolumn{2}{|c|}{0} & & \multicolumn{2}{|c|}{0.0} & \\
\hline \multicolumn{2}{|l|}{ Método: Actual } & & Transporte & $\Rightarrow$ & \multicolumn{2}{|c|}{0} & & \multicolumn{2}{|c|}{0.8} & \\
\hline \multicolumn{2}{|c|}{ Lugar: Planta de teñido de hilos y telas } & & Inspección & $\square$ & \multicolumn{2}{|c|}{0} & & \multicolumn{2}{|c|}{0.0} & \\
\hline \multicolumn{2}{|c|}{ Compuesto por : Elena Arce } & & \multicolumn{2}{|c|}{ Distancia total $(\mathrm{m})$} & \multicolumn{2}{|c|}{4} & & \multicolumn{2}{|c|}{0.0} & \\
\hline \multirow{2}{*}{\multicolumn{2}{|c|}{ Descripción }} & Contidad & \multirow{2}{*}{$\begin{array}{c}\text { Distancia } \\
(\mathrm{m})\end{array}$} & Tiempo & & & IBOLO & & & ORC \\
\hline & & Cantiaad & & $\begin{array}{l}\text { Estandar } \\
\text { (Dias) }\end{array}$ & $\mathrm{O}$ & $\Rightarrow$ & $\mathrm{D}$ & $\square$ & $\nabla$ & UBS. \\
\hline Alarma de preparaci & & 1 & & 0.0035 & $x$ & & & & & \\
\hline Descarga de boboni & p 1 y 2) & 1 & & 0.0069 & $x$ & & & & & \\
\hline Cargar bobina a rep & & 1 & & 0.0069 & $x$ & & & & & \\
\hline Reposo & & 1 & & 0.7612 & $x$ & & & & & \\
\hline & & & 0 & 0.7786 & 4 & 0 & 0 & $\mathbf{0}$ & 0 & \\
\hline
\end{tabular}

Elaboración propia

En el DAP que se muestra en la tabla 42, se muestra la mejora considerando el mismo tiempo de la propia actividad de reposo de 0.7612 días, reduciendo las actividades de los despilfarros que influenciaban en la generación del tiempo de espera por un total de 0.345 días.

Esta disminución es proporcional a los tiempos de espera en el proceso, es decir si se reduce en el subproceso de reposo, se reduce la misma cantidad en todos los tiempos de espera:

Sí,

$\mathrm{T}_{\text {espera actual }}>\mathrm{T}_{\text {reducidoSMED }}$

Entonces,

$\mathrm{T}_{\text {mejoral }}=\mathrm{T}_{\text {actual }}-\mathrm{T}_{\text {reducidoSMED }}$

De lo contrario,

$\mathrm{T}_{\text {mejoral }}=0$

Lo que indica que, si el tiempo de espera actual del proceso de teñido es mayor que el tiempo que se ha reducido al implementar SMED en el subproceso de reposo, entonces el tiempo de espera de mejora 1 es la resta de los últimos valores, de lo contrario si el tiempo de espera actual es menor o igual que el tiempo que se ha reducido por SMED, el tiempo de espera de mejora 1 es cero. Estas fórmulas se han traducido en Excel, como se muestra a continuación: 
Figura 34: Cálculo de reducción de tiempos de espera en el proceso de teñido por implementar SMED

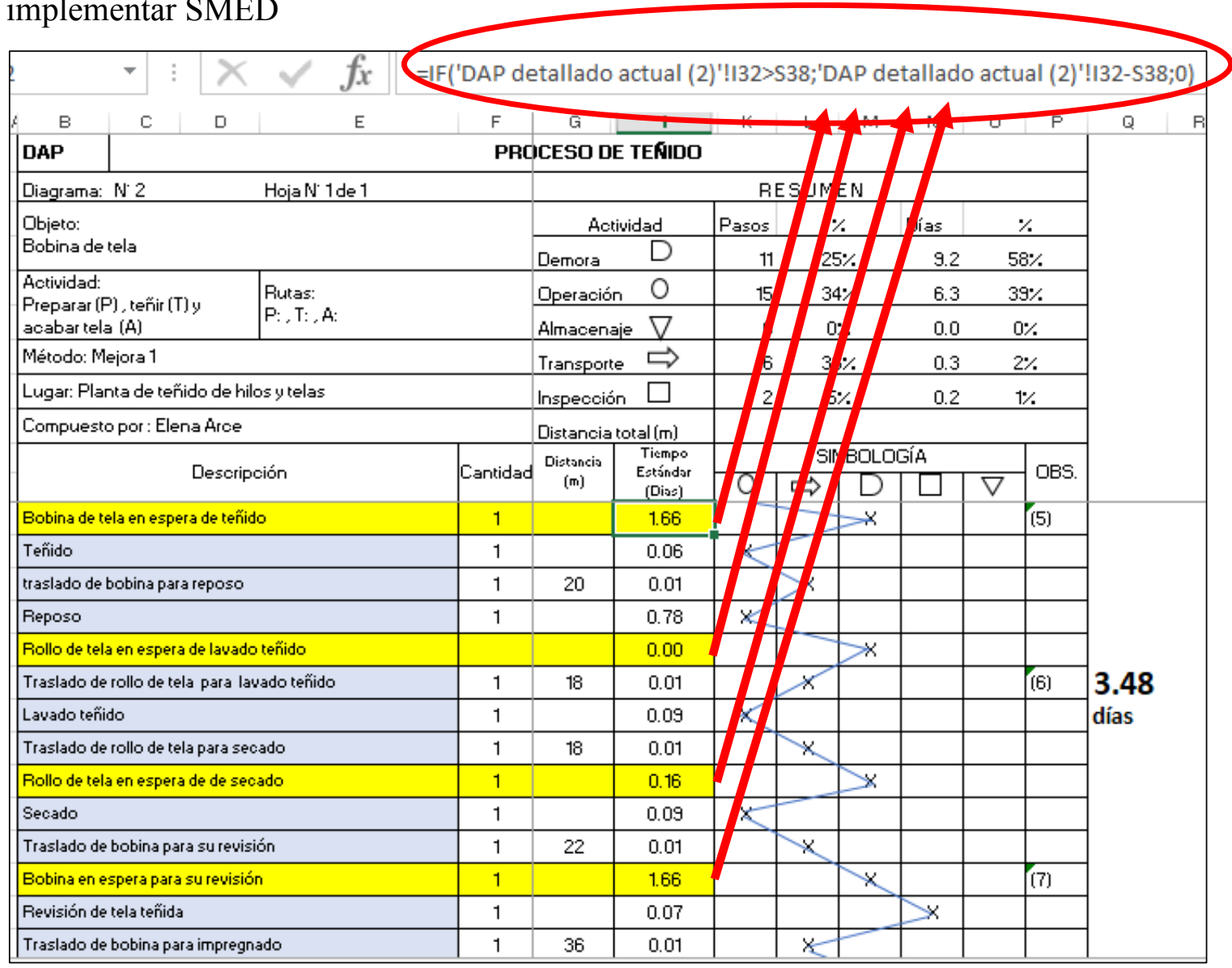

Elaboración propia

Por lo que al aplicar las fórmulas en la actividad de bobina de tela en espera de teñido Sí,

$\mathrm{T}_{\text {actual }}>\mathrm{T}_{\text {reducidoSMED }} \rightarrow 2.00>0.342$ días $\rightarrow$ Verdadero

Entonces,

$\mathrm{T}_{\text {mejoral }}=2.00-0.342$ días $=1.6$ días

Para la actividad de Rollo de tela en espera de lavado teñido

Sí,

$\mathrm{T}_{\text {actual }}>\mathrm{T}_{\text {reducidoSMED }} \rightarrow 0.25>0.342$ días $\rightarrow$ Falso

Entonces,

$\mathrm{T}_{\text {mejoral }}=0$ días

Eliminándose esta actividad en el proceso de mejora de teñido. 
Por consiguiente, se colocarán los nuevos procesos en la cámara de reposo, para el conocimiento y concientización del proceso de los operarios, por lo que es extremadamente importante las capacitaciones a los operarios:

Figura 35: Cámaras de Reposo

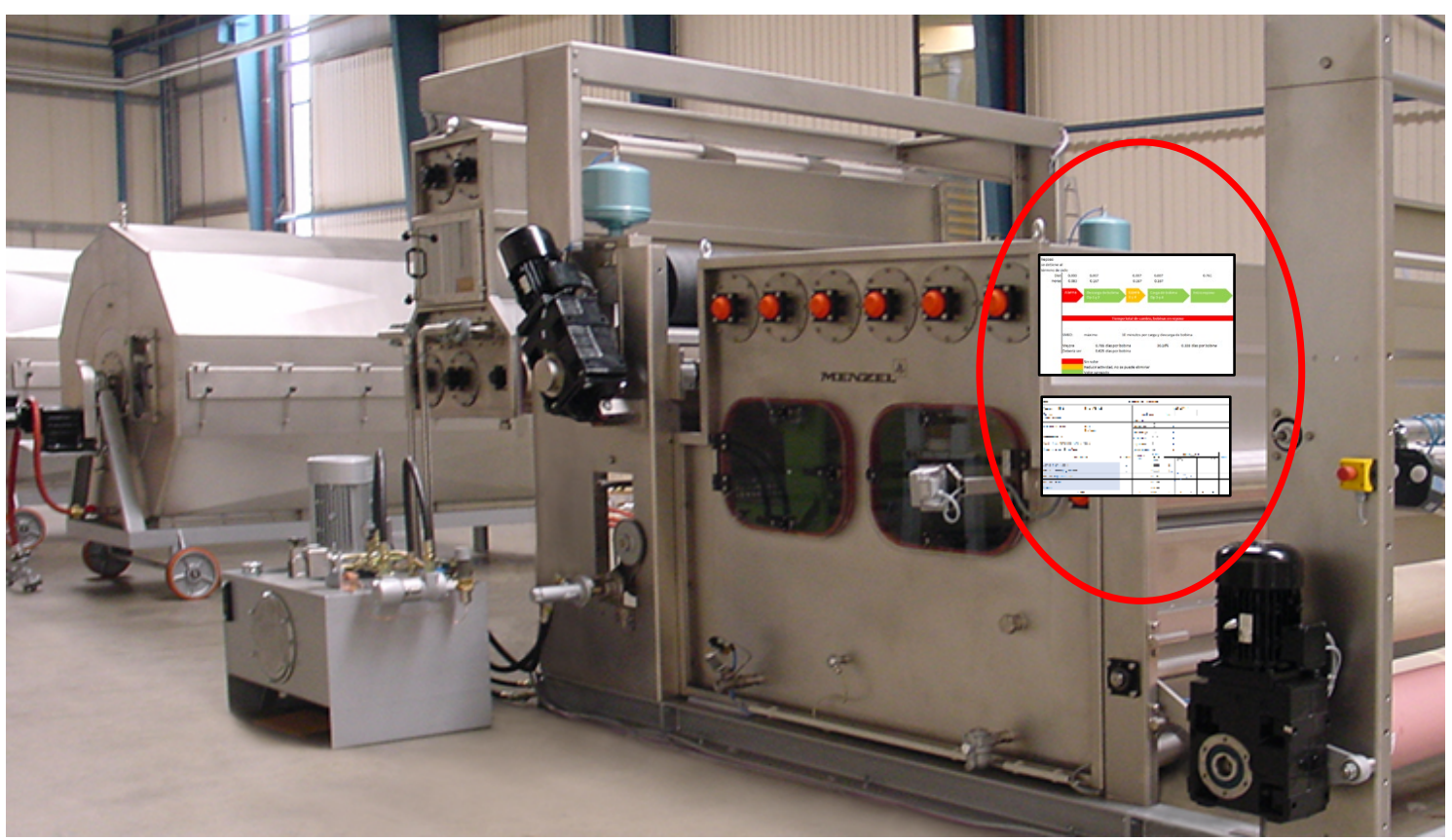

Elaboración propia. Fuente: La empresa

Al implementar SMED en el subproceso de Reposo, el tiempo de espera se ha reducido de 4.75 días de tiempo de espera a 3.49 días, reduciendo el tiempo del proceso de teñido de 6.21 días a 4.61 días, reduciéndose 1.27 días equivalentes a $26.62 \%$ de variación. Por lo tanto, el nuevo DAP general es como se muestra a continuación: 
Tabla 41: DAP - Proceso General de Teñido - Mejora Parte 1

\begin{tabular}{|c|c|c|c|c|c|c|c|c|c|c|c|}
\hline DAP & & & PROCESO DE & TEÑIDO & & & & & & & \\
\hline Diagrama: $\quad \mathrm{N}^{\circ} 2$ & Hoja $N^{\circ} 1$ de 1 & & & & & ESUM & & & & & \\
\hline Objeto: & & & Acti & jidad & Pasos & & $\%$ & Días & & $\%$ & \\
\hline Bobina de tela & & & Demora & $\mathrm{D}$ & 11 & 25 & $5 \%$ & 9.2 & & $58 \%$ & \\
\hline Actividad: & Rutas: & & Operación & 0 & 15 & 3 & $4 \%$ & 6.3 & & $39 \%$ & \\
\hline tela $(\mathrm{A})$ & $P:, T:, A:$ & & Almacenaje & $\nabla$ & 0 & & $\%$ & 0.0 & & $0 \%$ & \\
\hline Método: Mejora 1 & & & Transporte & $\Rightarrow$ & 16 & & $6 \%$ & 0.3 & & $2 \%$ & \\
\hline Lugar: Planta de teñido de hilos & telas & & Inspección & $\square$ & 2 & & $\%$ & 0.2 & & $1 \%$ & \\
\hline Compuesto por : Elena Arce & & & Distancia to & $\mathrm{tal}(\mathrm{m})$ & & & & & & & \\
\hline Descrin & & Cantidad & Distancia & $\begin{array}{l}\text { Tiempo } \\
\text { Estándar }\end{array}$ & & & IMBOLO & & & & \\
\hline Descrip & & Cantidad & (m) & $\begin{array}{c}\text { Estandar } \\
\text { (Dias) }\end{array}$ & $\mathrm{O}$ & $\Rightarrow$ & $D$ & $\square$ & $\nabla$ & OBS. & \\
\hline Bobina de tela en espera de Chan & uscado/desenconlado & 1 & - & 0.55 & & & $x$ & & & (1) & \\
\hline Chamusc/Desencolado & & 1 & - & 0.54 & $x$ & & & & & & \\
\hline traslado de bobina para reposo & & 1 & 9 & 0.00 & & $x$ & & & & & \\
\hline Reposo & & 1 & - & 1.25 & $x<$ & & & & & & \\
\hline Bobina de tela en espera de blana & leo químico & 1 & - & 0.80 & & & 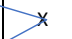 & & & (2) & 2.75 \\
\hline traslado de bobina para blanqueo & uimico & 1 & 9 & 0.00 & & $x$ & & & & & días \\
\hline Blanqueo químico & & 1 & & 0.54 & 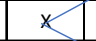 & & & & & & \\
\hline traslado de bobina para reposo & & 1 & 6 & 0.00 & & $\sum x$ & & & & & \\
\hline Reposo & & 1 & & 1.25 & $x$ & & & & & & 7.53 \\
\hline Traslado de bobina para lavado se & niblanco & 1 & 9 & 0.00 & & $x$ & & & & & \\
\hline Lavado semiblanco & & 1 & & 0.56 & $x$ & & & & & & \\
\hline traslado de bobina para merceriza & & 1 & 25 & 0.01 & & $x$ & & & & & \\
\hline Bobina de tela en espera de merc & rizado & 1 & & 0.45 & & & $D x$ & & & (3) & \\
\hline Mercerizado & & 1 & & 0.47 & $x$ & & & & & & \\
\hline Traslado de bobina para secado & & 1 & 24 & 0.01 & & * & & & & & \\
\hline Bobina de tela en espera de seca & & 1 & & 0.95 & & & $x_{x}$ & & & (4) & \\
\hline Secado & & 1 & & 0.14 & $x$ & & & & & & \\
\hline Traslado de bobina para ser teñid & & 1 & 12 & 0.00 & & $x$ & & & & & \\
\hline Bobina de tela en espera de teñid & & 1 & & 1.66 & & & $x$ & & & (5) & \\
\hline Teñido & & 1 & & 0.06 & $\times$ & & & & & & \\
\hline traslado de bobina para reposo & & 1 & 20 & 0.01 & & $\mathrm{x}$ & & & & & \\
\hline Reposo & & 1 & & 0.78 & $x$ & & & & & & \\
\hline Rollo de tela en espera de lavado & eñido & & & 0.00 & & & $D^{x}$ & & & & \\
\hline Traslado de rollo de tela para lav & do teñido & 1 & 18 & 0.01 & & $x$ & & & & (6) & 3.48 \\
\hline Lavado teñido & & 1 & & 0.09 & 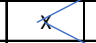 & & & & & & días \\
\hline Traslado de rollo de tela para sece & & 1 & 18 & 0.01 & & $x$ & & & & & \\
\hline Rollo de tela en espera de de sec & & 1 & & 0.16 & & & $x$ & & & & \\
\hline Secado & & 1 & & 0.09 & $x$ & & & & & - & \\
\hline Traslado de bobina para su revisió & & 1 & 22 & 0.01 & & $x$ & & & & 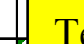 & ñido nromedio \\
\hline Bobina en espera para su revisión & & 1 & & 1.66 & & & $x$ & & & 4 & Hive, \\
\hline Revisión de tela teñida & & 1 & & 0.07 & & & & & & & empos de espera: \\
\hline Traslado de bobina para impregna & & 1 & 36 & 0.01 & & $x$ & & & & & redujo de 4.75 \\
\hline Bobina de tela en espera de impre & nado & 1 & & 1.00 & & & $D x$ & & & d1 & as a 3.48 días, un \\
\hline Impregnado & & 1 & & 0.07 & $x$ & & & & & to & tal de 1.2 días $=$ \\
\hline Traslado de bobina para calandrar & & 1 & 10 & 0.00 & & $2 *$ & & & & 26 & \\
\hline Calandrado & & 1 & & 0.10 & $x<$ & & & & & & \\
\hline Traslado de bobina para sanforiza & & 1 & 4 & 0.00 & & $>x$ & & & & & \\
\hline Sanforizado & & 1 & & 0.08 & $x<$ & & & & & & 2.17 \\
\hline Traslado de bobina para revisión & & 1 & 26 & 0.01 & & $x$ & & & & & días \\
\hline Bobina en espera para su revisión & & 1 & & 2.00 & & & $x$ & & & (9) & \\
\hline Revisión de tela acabada & & 1 & & 0.13 & & & & 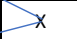 & & & \\
\hline traslado de bobina para enrollado/ & oblado & 1 & 5 & 0.00 & & $x$ & & & & & 3.90 \\
\hline Bobina en espera de enrollado/dot & ado & 1 & & 0.17 & & & $B x$ & & & (10) & \\
\hline Enrollado/Doblado & & 1 & & 0.33 & $x$ & & & & & & \\
\hline TOT & & & 252 & 16.03 & 15 & 16 & 11 & 2 & 0 & & \\
\hline
\end{tabular}

Elaboración propia 
La relación de 1 día operativo por días de retraso es de: 1:3.

Para elaborar el VSM de la propuesta de mejora 1, se debe considerar los paros programados de las bases de datos entregadas por la empresa y no del supuesto que maneja la empresa de los paros programados, ya que se diferencian. El equipo Jigger, muestra un total de paros programados 96.7 horas anuales equivalente a 4.03 días por todo un año, considerándose así para el proceso de teñido completo, ya que los demás equipos se utilizan en un mismo ratio y para las demás máquinas en planta, incluye mantenimientos preventivos y correctivos, limpieza entre otros, como se muestra a continuación:

Tabla 42: Paros programados del equipo Jigger

\begin{tabular}{|c|c|c|c|}
\hline \multirow[b]{2}{*}{ Máquina } & \multicolumn{2}{|c|}{ Horas } & \multirow[b]{2}{*}{ Índice } \\
\hline & $\begin{array}{l}\text { Paros } \\
\text { programados }\end{array}$ & Cola & \\
\hline Blanqueadora & 863.0 & 3519.87 & $25 \%$ \\
\hline Gasead/Desenco & 781.2 & 3950.75 & $20 \%$ \\
\hline Jigger & 96.7 & 563.23 & $17 \%$ \\
\hline Lavadora & 567.5 & 2964.50 & $19 \%$ \\
\hline Merceriz/secad & 3258.1 & 13188.55 & $25 \%$ \\
\hline Pad Steam & 55.4 & 253.32 & $22 \%$ \\
\hline Rama Babcock & 2139.8 & 9514.40 & $22 \%$ \\
\hline Rama Monforts & 1554.0 & 5831.50 & $27 \%$ \\
\hline
\end{tabular}

Elaboración propia

Por lo que, al convertir, 1 día menos los mantenimientos por día de 0.01104 días de parada por mantenimiento en un día. Por lo que el takt time es 0.9 días / 0.69 bobinas $=1.4477$ días por bobina

Estos resultados, se trasladan al Mapa de Valor - VSM Mejora 1, como se muestra a continuación: 
Figura 36: VSM Proceso de Teñido - Mejora Parte 1

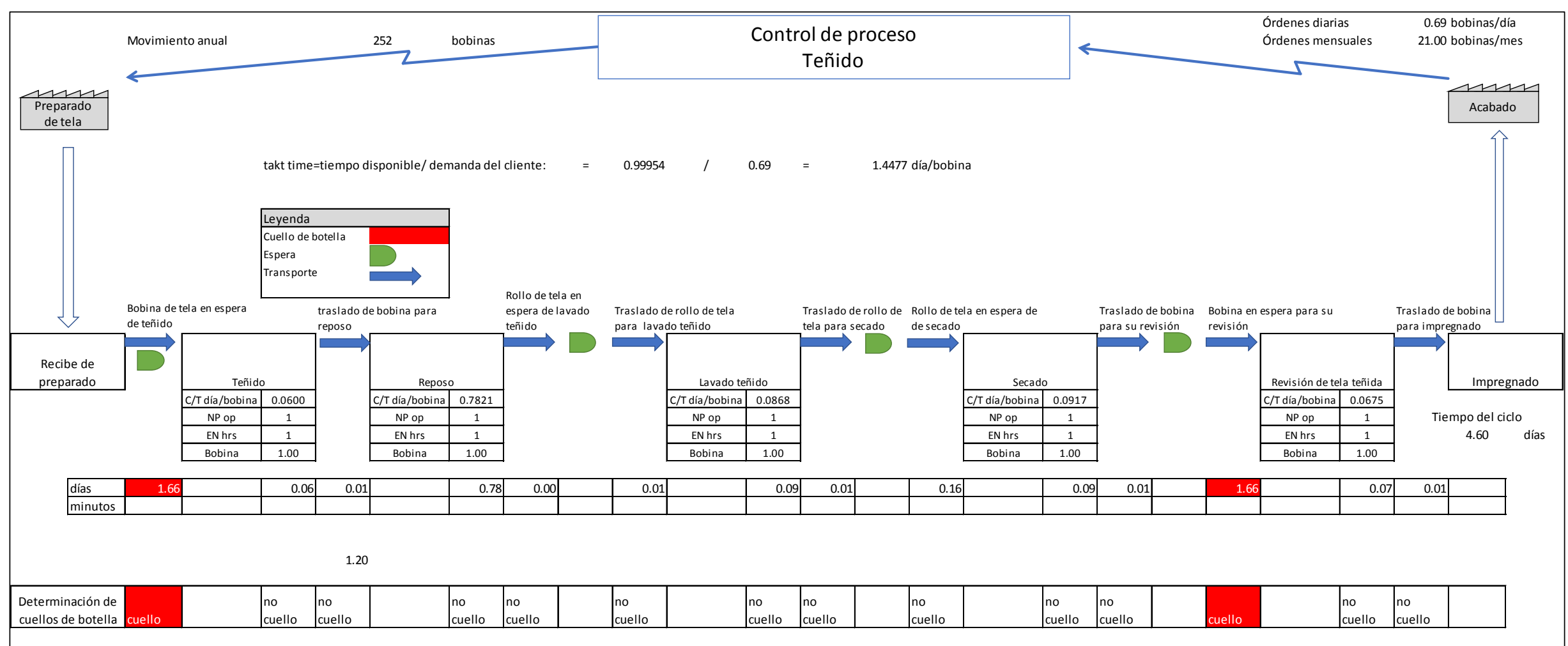

Elaboración propia 
Al implementar SMED, la actividad de reposo ya no presenta cuello de botella, ya que el valor CT es de 0.7855 días por bobina, menor al tiempo Takt. Sin embargo, a pesar de haber reducido lo que se ha ahorrado en esta actividad, los tiempos de espera antes de las actividades de teñido y revisión, con 1.66 días/bobina, son mayores al valor del tiempo Takt de 1.4324 días por bobina. En la propuesta de Mejora 2, se solucionará este cuello de botella, mientras tanto, simularemos los tiempos nuevos con valores aleatorios en un rango que sea el promedio de los días calculados para determinar el ahorro en esta primera fase, como se muestra a continuación:

Figura 37: Cálculo de tiempos para la propuesta de mejora 1

\begin{tabular}{|c|c|c|c|c|c|c|c|c|c|c|c|c|c|c|}
\hline \multirow{3}{*}{\multicolumn{3}{|c|}{$\frac{\mathrm{A}_{\mathrm{A}} f x}{\text { Tiempos estimados para la muestra }}$}} & \multicolumn{12}{|c|}{$=$ RANDBETWEEN $\left(\$ D \$ 3^{*} 1000 ; \$ E \$ 3^{*} 1000\right) / 1000$} \\
\hline & & & & & & & $\mathrm{E}$ & $\mathbf{F}$ & G & $\mathrm{H}$ & & J & K & L \\
\hline & & & & \\
\hline Actividad & & & & Días & & Min & Máx & 1. & & 3 & 4 & 5 & 6 & 7 \\
\hline \multicolumn{4}{|c|}{ Bobina de tela en espera de teñido } & 1.66 & & 0.553 & 2.764 & 2.654 & 1.087 & 1.245 & 0.671 & 0.753 & 2.246 & 2.615 \\
\hline \multicolumn{4}{|l|}{ Teñido } & 0.06 & & 0.057 & 0.063 & 0.062 & 0.061 & 0.058 & 0.059 & 0.057 & 0.059 & 0.062 \\
\hline \multicolumn{4}{|c|}{ traslado de bobina para reposo } & 0.01 & & 0.002 & 0.01 & 0.008 & 0.003 & 0.002 & 0.006 & 0.006 & 0.006 & 0.007 \\
\hline \multicolumn{4}{|l|}{ Reposo } & 0.78 & & 0.59 & 0.974 & 0.925 & 0.95 & 0.675 & 0.705 & 0.677 & 0.627 & 0.592 \\
\hline \multicolumn{4}{|c|}{ Rollo de tela en espera de lavado ten̂́ido } & 0.00 & & & & 0 & 0 & 0 & 0 & 0 & 0 & 0 \\
\hline \multicolumn{4}{|c|}{ Traslado de rollo de tela para lavado teńido } & 0.01 & & 0.005 & 0.006 & 0.006 & 0.006 & 0.006 & 0.006 & 0.006 & 0.006 & 0.006 \\
\hline \multicolumn{4}{|l|}{ Lavado teñido } & 0.09 & & 0.076 & 0.098 & 0.09 & 0.082 & 0.088 & 0.078 & 0.095 & 0.077 & 0.084 \\
\hline \multicolumn{4}{|c|}{ Traslado de rollo de tela para secado } & 0.01 & & 0.003 & 0.008 & 0.007 & 0.007 & 0.003 & 0.005 & 0.004 & 0.006 & 0.005 \\
\hline \multicolumn{4}{|c|}{ Rollo de tela en espera de de secado } & 0.16 & & 0.11 & 0.207 & 0.19 & 0.142 & 0.15 & 0.134 & 0.136 & 0.122 & 0.154 \\
\hline \multicolumn{4}{|l|}{ Secado } & 0.09 & & 0.034 & 0.149 & 0.11 & 0.137 & 0.076 & 0.041 & 0.088 & 0.118 & 0.105 \\
\hline \multicolumn{4}{|c|}{ Traslado de bobina para su revisión } & 0.01 & & 0.006 & 0.008 & 0.006 & 0.007 & 0.007 & 0.007 & 0.007 & 0.006 & 0.007 \\
\hline \multicolumn{4}{|c|}{ Bobina en espera para su revisión } & 1.66 & & 0.452 & 2.865 & 2.626 & 1.686 & 2.157 & 1.583 & 0.551 & 2.793 & 0.768 \\
\hline \multicolumn{4}{|c|}{ Revisión de tela teñida } & 0.07 & & 0.02 & 0.115 & 0.043 & 0.079 & 0.112 & 0.067 & 0.048 & 0.092 & 0.111 \\
\hline \multirow{2}{*}{\multicolumn{4}{|c|}{ Traslado de bobina para impregnado }} & 0.01 & & 0.007 & 0.014 & 0.012 & 0.01 & 0.007 & 0.012 & 0.009 & 0.011 & 0.008 \\
\hline & & & & 4.60 & & & & & & & & & & \\
\hline
\end{tabular}

Elaboración propia

1. Se han colocado los tiempos calculados al implementar SMED del DAP de la tabla 43

2. Los valores mínimos y máximo de cada una de las actividades dan como resultado valor de (1). Por ejemplo:

$$
\text { Promedio act } 1=\frac{0.553+2.764}{2}=1.66
$$

3. Se utiliza la función de Excel para generar los números aleatorios RANDBETWEEN(min, máx), esta función selecciona un valor dentro del rango del mínimo y máximo establecidos. Cada valor del rango se multiplicó por 1000 y luego el número aleatorio se divide entre 1000, para obtener dicho aleatorio con decimales, de lo contrario la función provee aleatorios de números enteros, a pesar que, los valores mínimos y máximos sean con decimales.

4. Estos valores aleatorios, se fijan al copiarlos sólo como valores, como se muestra a continuación (Véase anexo 3, para los valores que se han supuesto para los 252 procesos de bobinas y véase la tabla sobre el extracto de dichos cálculos). 
Tabla 43: Extracto de los tiempos de la propuesta de mejora 1

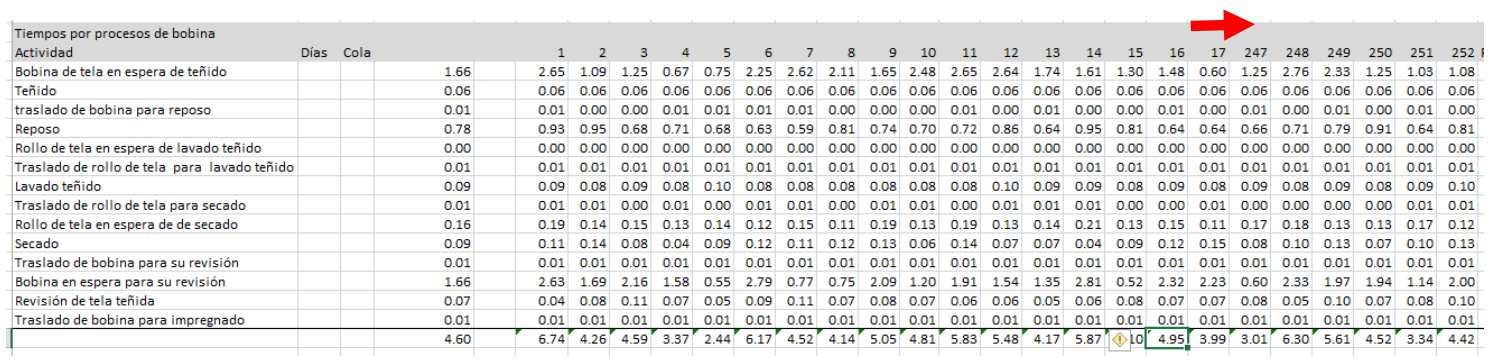

Elaboración propia

Por lo tanto, de acuerdo con los tiempos que se han estimado, el mínimo es de 0.59 días y el máximo de 0.97 días equivalentes a 14.2 y 23.2 horas respectivamente. De lo cual, se demuestra que el rango con mayor frecuencia es de 0.717 y 0.792 con una frecuencia de 21 veces, seguido por el rango de 0.667 con una frecuencia de 19 veces, como se muestra a continuación (véase tabla 46 y figura 38 ): 
Tabla 44: Rangos del Histograma del Subproceso de Reposo - Mejora 1

\begin{tabular}{|c|c|c|c|c|c|}
\hline Bin & Frecuencia & $\%$ Acum & Bin & Frecuencia & $\%$ Acum \\
\hline 0.592 & 2 & $0.79 \%$ & 0.717 & 21 & $8.33 \%$ \\
\hline 0.617 & 18 & $7.94 \%$ & 0.792 & 21 & $16.67 \%$ \\
\hline 0.642 & 12 & $12.70 \%$ & 0.667 & 19 & $24.21 \%$ \\
\hline 0.667 & 19 & $20.24 \%$ & 0.867 & 19 & $31.75 \%$ \\
\hline 0.692 & 13 & $25.40 \%$ & 0.892 & 19 & $39.29 \%$ \\
\hline 0.717 & 21 & $33.73 \%$ & 0.617 & 18 & $46.43 \%$ \\
\hline 0.742 & 16 & $40.08 \%$ & 0.917 & 18 & $53.57 \%$ \\
\hline 0.767 & 15 & $46.03 \%$ & y mayor... & 18 & $60.71 \%$ \\
\hline 0.792 & 21 & $54.37 \%$ & 0.742 & 16 & $67.06 \%$ \\
\hline 0.817 & 15 & $60.32 \%$ & 0.767 & 15 & $73.02 \%$ \\
\hline 0.842 & 11 & $64.68 \%$ & 0.817 & 15 & $78.97 \%$ \\
\hline 0.867 & 19 & $72.22 \%$ & 0.942 & 15 & $84.92 \%$ \\
\hline 0.892 & 19 & $79.76 \%$ & 0.692 & 13 & $90.08 \%$ \\
\hline 0.917 & 18 & $86.90 \%$ & 0.642 & 12 & $94.84 \%$ \\
\hline 0.942 & 15 & $92.86 \%$ & 0.842 & 11 & $99.21 \%$ \\
\hline y mayor... & 18 & $100.00 \%$ & 0.592 & 2 & $100.00 \%$ \\
\hline & Días & Horas & & & \\
\hline Mínimo & 0.59 & 14.2 & & & \\
\hline Máximo & 0.97 & 23.2 & & & \\
\hline
\end{tabular}

Elaboración propia

Figura 38: Histograma - Subproceso de Reposo - Mejora 1

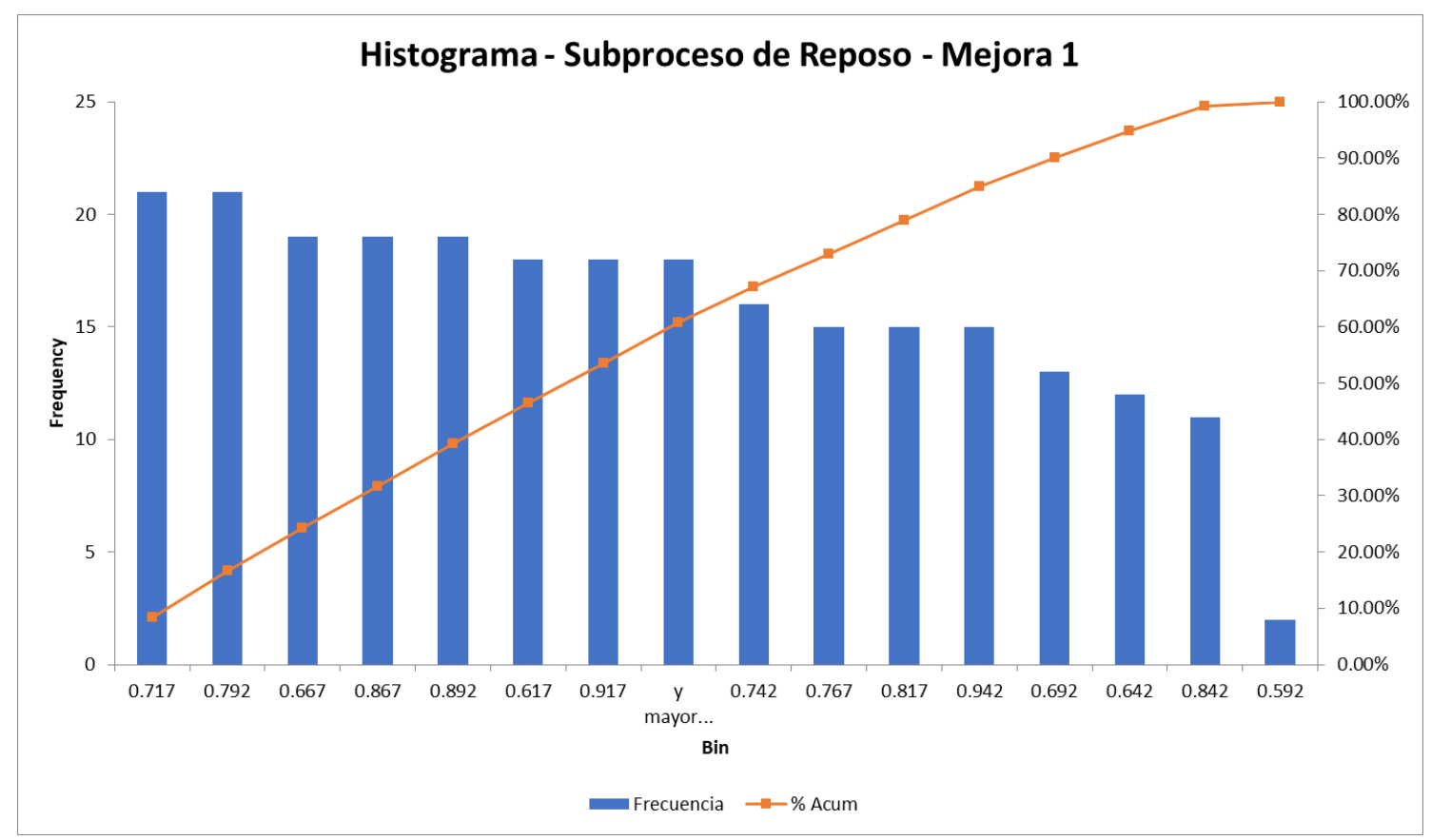

Elaboración propia 
El histograma muestra la frecuencia del subproceso de Reposo todavía sobrepasa las 15 horas, sin embargo, se considera dentro del 95\% de confiabilidad, ya que el $5 \%$ de los 4.60 días es de 4.375 y 4.836 días como mínimo y máximo, en el rango aceptable.

\section{$\underline{\text { Ahorros }}$}

Para poder calcular los ahorros se establece el Límite de control superior (UCL) como el objetivo de la empresa que no exceda este proceso total de teñido de 5.5 días, para calcular este valor se ha calculado el promedio de los tiempos de la propuesta de mejora 1 y la desviación estándar o 1 sigma, este valor UCL $=5.5$ días representa el $81 \%$ de confiabilidad y $19 \%$ de error:

Tabla 45: Estadísticas para los tiempos de la propuesta de mejora 1

\begin{tabular}{|l|r|}
\hline Promedio & 4.60 \\
\hline Desv Std & 0.96 \\
\hline UCL & 5.55 \\
\hline LCL & 3.64 \\
\hline
\end{tabular}

Elaboración propia.

Por lo tanto, se calcula el exceso de cada uno de los totales, si es que es superior el UCL, se toma la resta como el exceso al tiempo objetivo, de lo contrario es cero, ya que no excede el objetivo establecido.

Sí:

$\mathrm{T}_{\text {total } / \text { bobina }}>\mathrm{T}_{\mathrm{UCL}}$, entonces

$\mathrm{T}_{\text {exceso }}=\mathrm{T}_{\text {total } / \text { bobina }}-\mathrm{T}_{\mathrm{UCL}}$

De lo contrario

$\mathrm{T}_{\text {exceso }}=0$

Como se muestra a continuación: 
Figura 39: Cálculo de tiempos de la mejora 1 del subproceso de reposo en exceso al objetivo

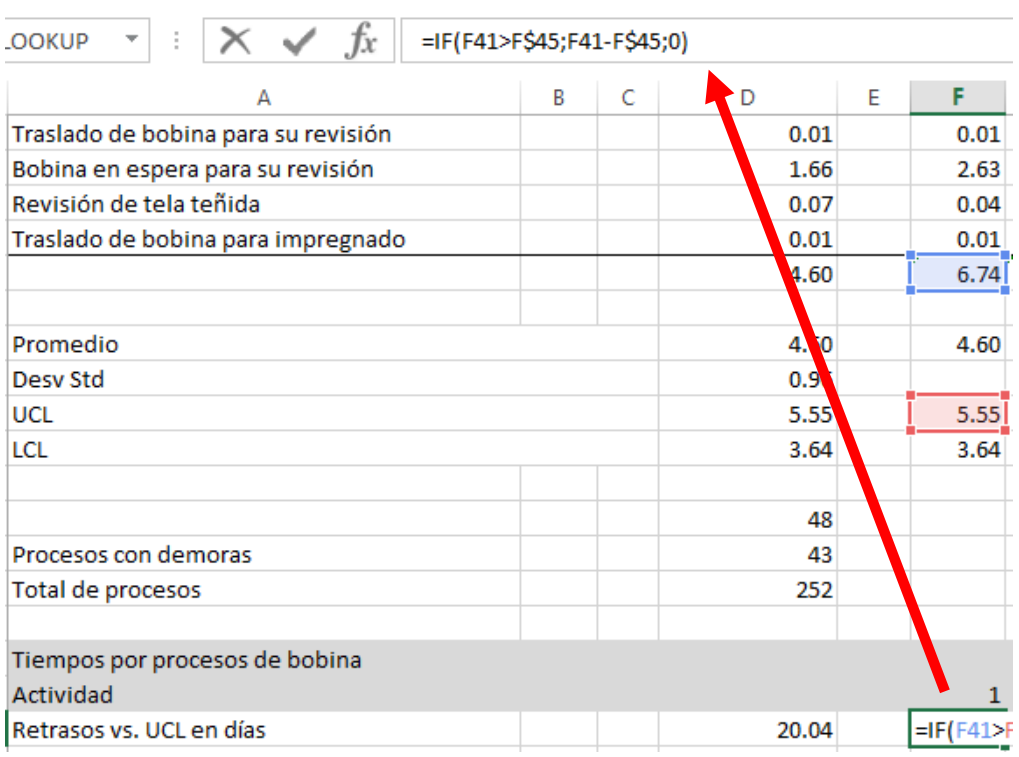

\section{Elaboración propia}

Por ejemplo, para el primer proceso:

$\mathrm{T}_{\text {total/bobina }}>\mathrm{T}_{\mathrm{UCL}} \rightarrow \mathbf{\rightarrow} 6.74>5.55$, verdadero, entonces

$\mathrm{T}_{\text {exceso }}=6.74-5.55=1.19$

Para el segundo proceso:

$\mathrm{T}_{\text {total } / \text { bobina }}>\mathrm{T}_{\mathrm{UCL}}, \rightarrow 4.26>5.55$, falso, entonces

$\mathrm{T}_{\text {exceso }}=0$

Como se muestra a continuación, un extracto de los tiempos en exceso del objetivo establecido como 5.5 horas, siendo el total de 20.04 días equivalentes a un total de 481.029 horas:

Tabla 46: Cálculo de horas en exceso del objetivo por proceso - Mejora 1

\begin{tabular}{|c|c|c|c|c|c|c|c|c|c|c|c|c|c|}
\hline \multicolumn{14}{|c|}{ Tiempos por procesos de bobina } \\
\hline Actividad & 1 & 2 & 3 & 4 & 5 & 6 & 7 & 247 & 248 & 249 & 250 & 251 & 252 \\
\hline Retrasos vs. UCL en días & 1.19 & 0.00 & 0.00 & 0.00 & 0.00 & 0.62 & 0.00 & 0.00 & 0.75 & 0.06 & 0.00 & 0.00 & 0.00 \\
\hline \multicolumn{14}{|c|}{ Tiempos por procesos de bobina } \\
\hline \multicolumn{14}{|l|}{ Actividad } \\
\hline Retrasos vs. UCL en días & & & 20.04 & & & & & & & & & & \\
\hline Total horas & & 481.0 & 292039 & & & & & & & & & & \\
\hline
\end{tabular}

Elaboración propia 
El costo de cada hora de mano de obra es de 44 operarios que comprenden el proceso de teñido, por lo que el promedio de sueldos es de $\mathrm{S} / 2500$ y el costo de mano de obra por operario es de $\mathrm{S} / 12.50$ el total por hora es la multiplicación de $44 \times \mathrm{S} / 12.50=\mathrm{S} / 550$ por hora por mano de obra.

El costo de hora máquina de Jigger, cámara de reposo, lavado y secado es de S/54 para todas las máquinas y sólo considerando el proceso de teñido. Por lo tanto, el total del Ahorro es de S/107,143.33 generando un impacto económico (pérdidas) de S/441,027.85.

Referente a los ahorros la reducción del costo de horas en exceso del proceso actual y de la propuesta de mejora 1 es igual a S/.397,684.97-290,541.64 $=\mathrm{S} / 107,143.33$. En cuanto a mano de obra, pero en total incluyendo las penalidades el ahorro es la resta del impacto económico actual menos el impacto económico de la mejora $1=\mathrm{S} / 603,666.13$ $441,0271.85=/ \mathrm{S} / 162,638.27$, se ha reducido el tiempo de espera de 658 a 481 horas. Como se muestra a continuación:

Tabla 47: Cálculo de ahorros de la propuesta Mejora Parte 1

\begin{tabular}{|c|c|c|}
\hline Descripción & Mejora 1 & Actual \\
\hline Horas en exceso de objetivo & 481 & 658 \\
\hline Operarios en proceso de teñido máquina jigger & 44 & 44 \\
\hline Promedio sueldo & $2,500.00$ & $2,500.00$ \\
\hline Costo $\mathrm{HH}$ & 12.50 & 12.50 \\
\hline Costo HM (jigger) & 54.00 & 54.00 \\
\hline Impacto económico & S/ $290,541.64$ & S/ $397,684.97$ \\
\hline Equivalente a & $8.54 \%$ & $12 \%$ \\
\hline Ventas de & S/ $3,400,659$ & S/ $3,400,659$ \\
\hline & $0.12 \%$ & $0.16 \%$ \\
\hline Ahorro (Versus Proceso Actual) & S/ $107,143.33$ & \\
\hline \multicolumn{3}{|l|}{ TOTAL Impacto Económico } \\
\hline Penalidades & S/ $150,486.21$ & S/ $205,981.16$ \\
\hline Tiempo de espera & S/ $290,541.64$ & S/ $397,684.97$ \\
\hline Total & S/ $441,027.85$ & S/ $603,666.13$ \\
\hline Ahorro Total & S/ $162,638.27$ & \\
\hline
\end{tabular}

Elaboración propia 


\section{Cálculo de Colas}

Con los valores que se han calculado, se debe calcular el porcentaje de utilización del servidor en cuanto a colas y tiempo esperado de las bobinas en el sistema y en cola. El tiempo de llegada es el mismo que el tiempo de llegada en el proceso actual, ya que el proceso de preparación no se estudia en esta investigación, siendo de 7.53 días por bobina.

El servicio de cada bobina se redujo de $82.5 \%$ a $61.1 \%$, lo que indica que se ha reducido en un $21.5 \%$, como se muestra a continuación:

Tabla 48: Cálculo de colas - Propuesta de Mejora 1

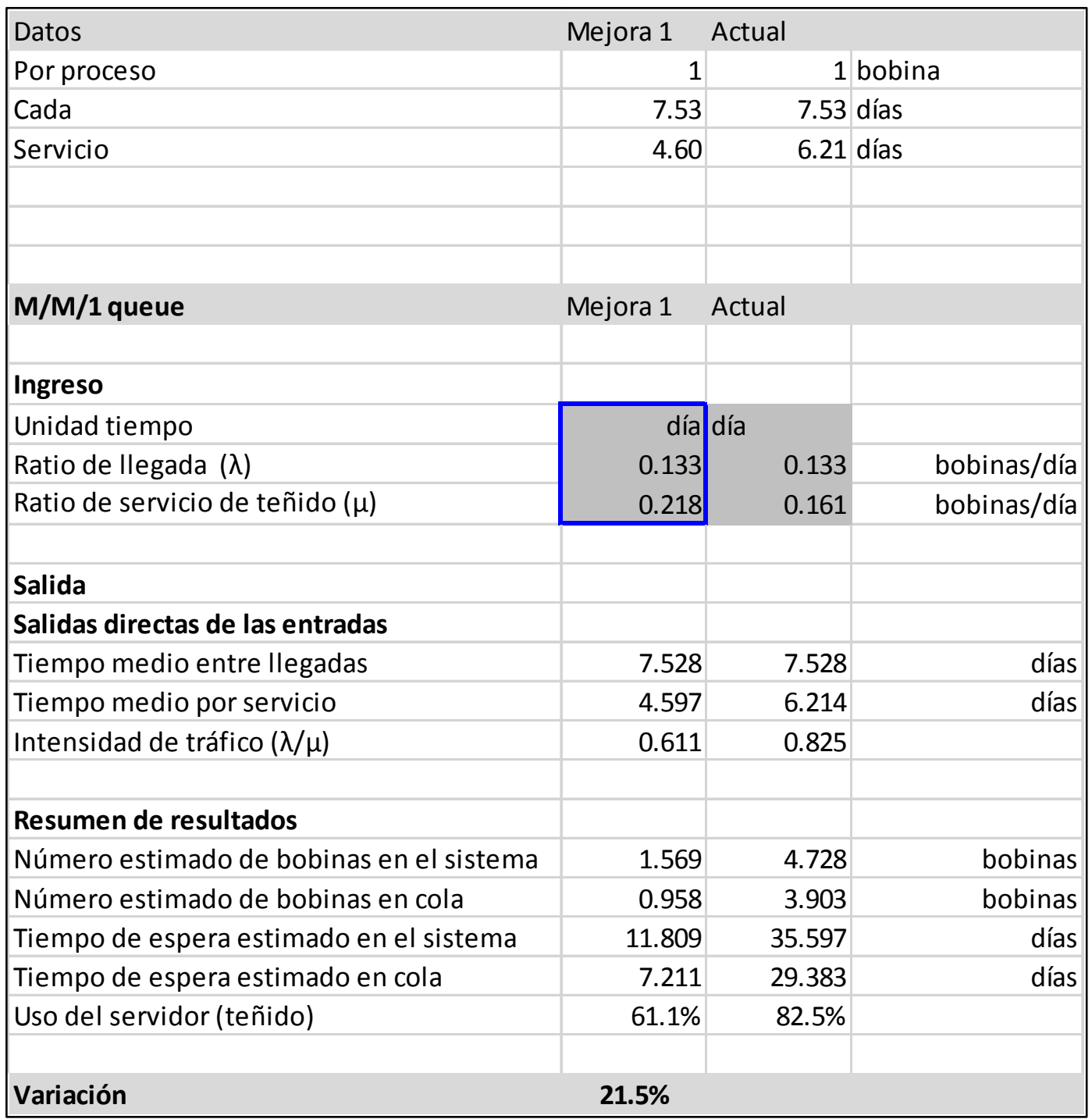

Elaboración propia 
En la tabla 50, se observa que con la propuesta de mejora 1, al implementar SMED en el subproceso de reposo se ha incrementado el ratio de servicio de teñido de 0.161 bobinas/día a 0.218 bobinas/día, reduciendo la intensidad del tráfico de 0.825 a 0.611 . El número espera de bobinas en el sistema se ha reducido del proceso actual de 4.728 bobinas a 1.569 bobinas y por ende, se redujo el número esperado de bobinas en cola de 3.903 a 0.958 bobinas. El uso del servidor indica que el $61.1 \%$ de las bobinas todavía ingresará al proceso de teñido con tiempo de espera o cola, lo que se demuestra en el VSM de la figura 36.

Tabla 49: Distribución del número en el sistema y del tiempo en cola de la propuesta de mejora 1

\begin{tabular}{|c|c|c|c|}
\hline \multicolumn{2}{|c|}{ Distribución del número en el sistema } & \multicolumn{2}{|c|}{ Distribución del tiempo en cola } \\
\hline $\mathrm{n}$ (bobinas) & $\mathrm{P}(\mathrm{n}$ en el sistema $)$ & t (en días) & $\mathrm{P}($ espera $>\mathrm{t})$ \\
\hline 0 & 0.389 & 2.000 & 0.516 \\
\hline 1 & 0.238 & & \\
\hline 2 & 0.145 & & \\
\hline 3 & 0.089 & & \\
\hline 4 & 0.054 & & \\
\hline 5 & 0.033 & & \\
\hline 6 & 0.020 & & \\
\hline 7 & 0.012 & & \\
\hline 8 & 0.008 & & \\
\hline 9 & 0.005 & & \\
\hline 10 & 0.003 & & \\
\hline 11 & 0.002 & & \\
\hline 12 & 0.001 & & \\
\hline 13 & 0.001 & & \\
\hline 14 & 0.000 & & \\
\hline 15 & 0.000 & & \\
\hline 16 & 0.000 & & \\
\hline 17 & 0.000 & & \\
\hline 18 & 0.000 & & \\
\hline 19 & 0.000 & & \\
\hline 20 & 0.000 & & \\
\hline 21 & 0.000 & & \\
\hline 22 & 0.000 & & \\
\hline
\end{tabular}

Elaboración propia

De la tabla 51, se observa que por ejemplo la probabilidad de tener exactamente 4 bobinas en el sistema es de 0.054. Equivalente a decir que el 5.5\% del tiempo hay exactamente 4 bobinas en el sistema. Por otro lado, bajo el título de Distribución del tiempo en cola, si el valor de $\mathrm{t}$ (en días) es igual a 2 días, indica que el $51.6 \%$ de las bobinas permanece más de 2 días en cola. 
Si el valor de $\mathrm{t}$ (en días) es igual a 1 día, indica que el 56.1\% de las bobinas permanece más de 1 día en cola, como se muestra a continuación:

Tabla 50: Distribución del tiempo en cola para t(en días $)>=1$ días

\section{Distribución del tiempo en cola}

\begin{tabular}{rr|}
\hline$t$ (en días) & $P($ espera $>t)$ \\
\hline 1.000 & 0.561 \\
\hline
\end{tabular}

Elaboración propia

Si el valor de $\mathrm{t}$ (en días) es igual a 10 días, indica que el $26.2 \%$ de las bobinas permanece más de 10 días en cola, como se muestra a continuación:

Tabla 51: Distribución del tiempo en cola para $\mathrm{t}$ (en días) >=10 días

\section{Distribución del tiempo en cola

$$
\mathrm{t} \text { (en días) } \mathrm{P}(\text { espera }>\mathrm{t})
$$

$10.000 \quad 0.262$

Elaboración propia

Al comparar las distribuciones del proceso actual y el proceso de mejora 1, en cuanto a las distribuciones del número de bobinas en el sistema, se muestra que, hay menor cantidad de bobinas en el sistema, por la reducción de los tiempos de espera, es decir que el $8.1 \%$ del tiempo hay 4 bobinas en el sistema en el proceso actual, sin embargo en el proceso de la propuesta de mejora 1 es de $5.4 \%$, como se muestra a continuación: 
Tabla 52: Comparación de bobinas en el sistema Actual vs. Mejora 1

\begin{tabular}{|c|c|c|}
\hline \multicolumn{3}{|c|}{$\begin{array}{cc}\text { Mejora } 1 & \text { Actual } \\
\text { Distribución del número en el sistema }\end{array}$} \\
\hline $\mathrm{n}$ (bobinas) & $\mathrm{P}(\mathrm{n}$ en el sistema) & $\mathrm{P}(\mathrm{n}$ en el sistema) \\
\hline 0 & 0.389 & 0.175 \\
\hline 1 & 0.238 & 0.144 \\
\hline 2 & 0.145 & 0.119 \\
\hline 3 & 0.089 & 0.098 \\
\hline 4 & 0.054 & 0.081 \\
\hline 5 & 0.033 & 0.067 \\
\hline 6 & 0.020 & 0.055 \\
\hline 7 & 0.012 & 0.046 \\
\hline 8 & 0.008 & 0.038 \\
\hline 9 & 0.005 & 0.031 \\
\hline 10 & 0.003 & 0.026 \\
\hline 11 & 0.002 & 0.021 \\
\hline 12 & 0.001 & 0.017 \\
\hline 13 & 0.001 & 0.014 \\
\hline 14 & 0.000 & 0.012 \\
\hline 15 & 0.000 & 0.010 \\
\hline 16 & 0.000 & 0.008 \\
\hline 17 & 0.000 & 0.007 \\
\hline 18 & 0.000 & 0.006 \\
\hline 19 & 0.000 & 0.005 \\
\hline 20 & 0.000 & 0.004 \\
\hline 21 & 0.000 & 0.003 \\
\hline 22 & 0.000 & 0.003 \\
\hline
\end{tabular}

Elaboración propia

Por lo tanto, el porcentaje de espera disminuye en el tiempo, para el proceso actual, el $78 \%$ de las bobinas permanece en cola más de 2 días, pero en el proceso de mejora es del $51.8 \%$, como se muestra a continuación:

Tabla 53: Comparación de distribución del tiempo en cola Actual Vs. Mejora 1

\begin{tabular}{|r|r|r|}
\hline \multicolumn{2}{|c|}{ Mejora 1 } & \multicolumn{2}{c|}{ Actual } \\
\multicolumn{2}{|c|}{ Distribución del tiempo en cola } \\
$\mathrm{t}$ (en días) & $\mathrm{P}($ espera $>\mathrm{t}$ ) & $\mathrm{P}($ espera $>\mathrm{t}$ ) \\
\hline 2.00 & 0.516 & 0.780 \\
\hline & & \\
\hline 1.00 & 0.561 & 0.803 \\
\hline 10.00 & 0.262 & 0.623 \\
\hline
\end{tabular}

Elaboración propia

También en la tabla 55 se muestra que la permanencia mayor que 10 días en cola se reduce significativamente de $62.3 \%$ a $26.2 \%$ de las bobinas que ingresan al sistema. 


\section{Propuesta de Mejora Parte 2}

En la primera parte, se redujo el tiempo del subproceso de reposo al implementar SMED, de 6.21 a 4.60 días. Sin embargo, en el VSM se muestra que existen dos cuellos de botella, antes de ingresar el subproceso de teñido y el subproceso de revisión, siendo sus valores de 1.66 días/bobina mayor que el tiempo Takt de 1.4477 días (Véase figura 36).

Para reducir los tiempos de espera de la bobina antes de los subprocesos de teñido y de revisión se debe considerar que una bobina no puede esperar más del tiempo que le sigue, es decir, para el tiempo de espera de la bobina para el subproceso de teñido es de 1.66 días, del DAP de la propuesta de mejora parte 1, sin embargo, la suma de los tiempos de las actividades siguientes desde la actividad de teñido hasta el traslado de la bobina para su revisión es de 1.21 días, por lo que se supone que, la espera de una bobina es imposible que sea 1.66 días si es que se ha implementado SMED y ordenamiento de portabobinas en todo el proceso, por lo que se asumirá que el tiempo de espera será de 1.20días para el tiempo de espera de una bobina que ingrese al subproceso de teñido.

Para el tiempo de espera de la bobina al subproceso de revisión, también se indica un tiempo de espera de 1.66 días, sin embargo, las actividades siguientes es de un total de 1.08 días, antes de que ingrese al subproceso de impregnado bajo el proceso de acabado. Debido a que el proceso de acabado no se encuentra bajo estudio, se debe suponer que este valor también sea de 1.20 días por el tiempo que le toma las actividades precedentes. 


\begin{tabular}{|c|c|c|c|c|}
\hline Bobina de tela en espera de teñido & 1 & & 1.66 & \\
\hline Teñido & 1 & & 0.06 & \\
\hline traslado de bobina para reposo & 1 & 20 & 0.01 & \\
\hline Reposo & 1 & & 0.78 & \\
\hline Rollo de tela en espera de lavado teñido & & & 0.00 & \\
\hline Traslado de rollo de tela para lavado teñido & 1 & 18 & 0.01 & \\
\hline Lavado teñido & 1 & & 0.09 & \\
\hline Traslado de rollo de tela para secado & 1 & 18 & 0.01 & \\
\hline Rollo de tela en espera de de secado & 1 & & 0.16 & \\
\hline Secado & 1 & & 0.09 & \\
\hline Traslado de bobina para su revisión & 1 & 22 & 0.01 & \\
\hline Bobina en espera para su revisión & 1 & & 1.66 & \\
\hline Revisión de tela teñida & 1 & & 0.07 & \\
\hline Traslado de bobina para impregnado & 1 & 36 & 0.01 & 1.08 días \\
\hline Bobina de tela en espera de impregnado & 1 & & 1.00 & \\
\hline
\end{tabular}

Por lo tanto, el algoritmo matemático es como sigue:

Sí,

Sí,

$\mathrm{T}_{\text {actual }}>\mathrm{T}_{\text {reducidoSMED }}$

Entonces,

$\mathrm{T}_{\text {mejora2 }}=\mathrm{T}_{\text {actual }}-\mathrm{T}_{\text {reducidoSMED }}$

De lo contrario,

$\mathrm{T}_{\text {mejora2 }}=0$

$\mathrm{T}_{\text {mejora2 }}>\sum \mathrm{act}_{1}, \mathrm{act}_{2}, \ldots$ act $\mathrm{n}_{\mathrm{n}}$, en donde $\mathrm{n}=$ el número de las actividades siguientes (precedentes)

Entonces,

$\mathrm{T}_{\text {mejora2 }}=\sum \mathrm{act}_{1}, \mathrm{act}_{2}, \ldots$ act $\mathrm{n}_{\mathrm{n}}$, en donde $\mathrm{n}=$ el número de las actividades siguientes (precedentes)

De lo contrario,

$\mathrm{T}_{\text {mejora2 }}=0$

Lo que indica que, si el tiempo de espera actual del subproceso de teñido es mayor que el tiempo que se ha reducido al implementar SMED en el subproceso de reposo, entonces el tiempo de espera de mejora 2 es la resta de los últimos valores, de lo contrario si el tiempo de espera actual es menor o igual que el tiempo que se ha reducido por SMED, el tiempo de espera de mejora 2 es cero, sí el valor que resulta de la primera condición, es mayor a la suma de las actividades siguientes (precedentes en el caso del tiempo de espera 
de las bobinas al subproceso de revisión), el tiempo de mejora 2 es la suma de ellos, de lo contrario, es cero. Estas fórmulas se han traducido en Excel, como se muestra a continuación:

Figura 40: Cálculo de los tiempos de espera para los subprocesos de teñido y revisión

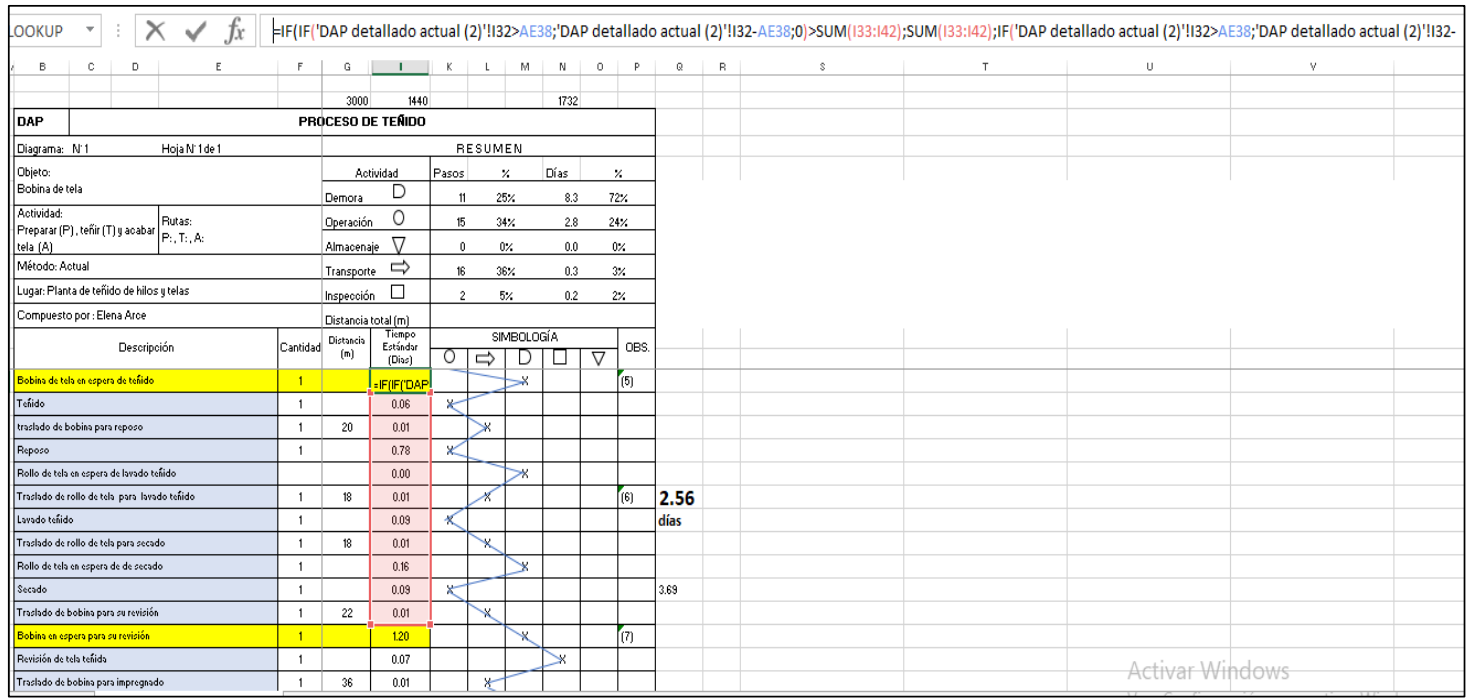

Elaboración propia

\section{$\underline{\text { Implementación }}$}

Por lo tanto, el tiempo del proceso de teñido total se redujo de 4.60 días a 3.69 días de la propuesta de mejora parte 1 a parte 2, respectivamente, y los tiempos de retraso de 3.48 días a 2.56 días, respectivamente. Como se muestra en el siguiente DAP: 
Tabla 54: DAP - Proceso General de Teñido - Mejora Parte 2

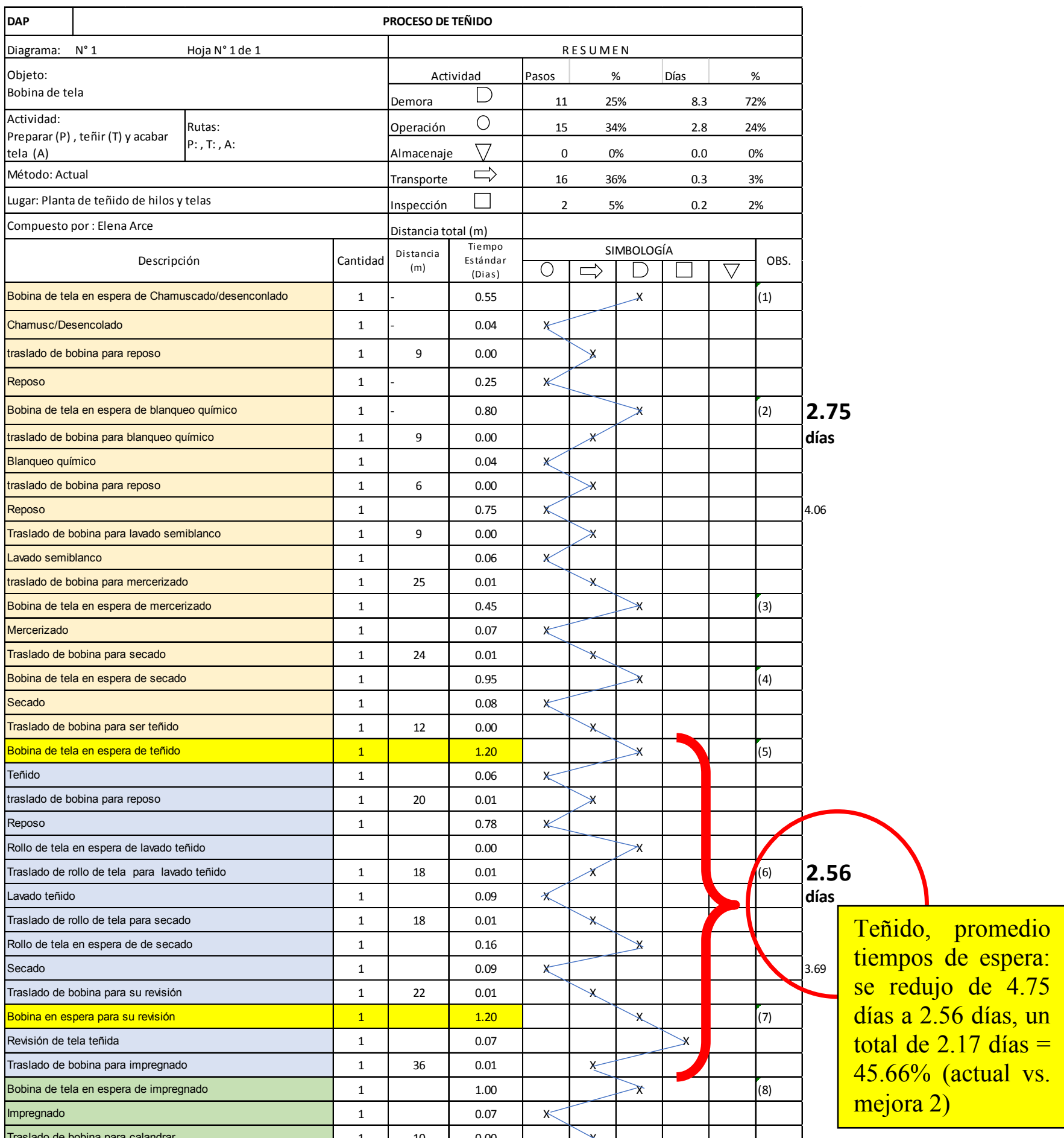

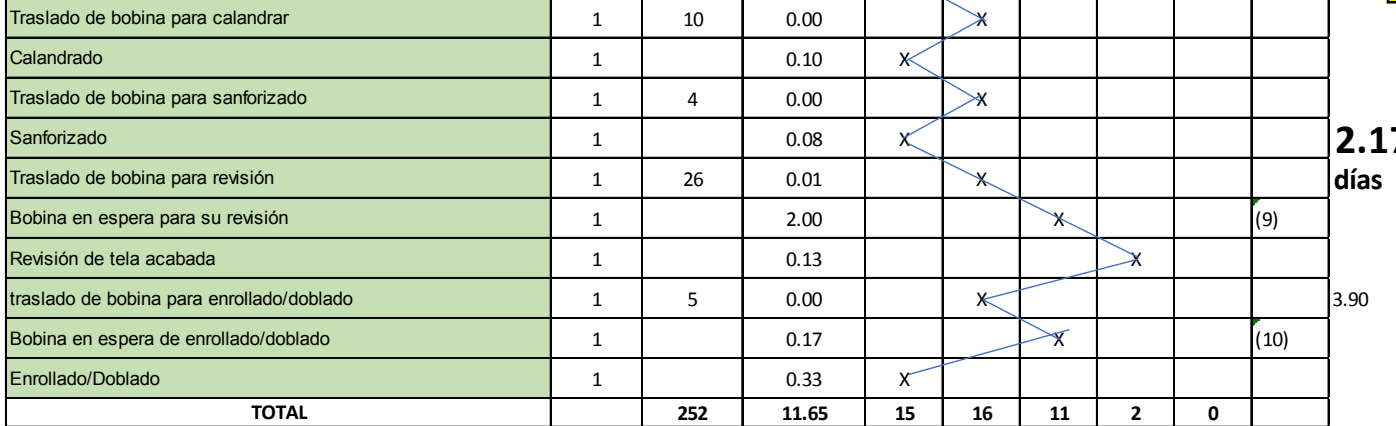

Elaboración propia 
En la tabla 56, se muestra también que del proceso actual se ha reducido el tiempo de espera de 4.75 días del proceso actual a 2.56 días del proceso de mejora parte 2, por un total de 2.17 días, equivalente a la reducción de $45.66 \%$.

Estos valores, se transfieren a un nuevo VSM (figura 41), en donde se observa que ninguno de los valores a lo largo del proceso de teñido es mayor que el tiempo Takt de 1.4324 días, por lo que se comprueba que no hay cuellos de botella, lo que no indica que hay colas o tiempo de espera. 
Figura 41: VSM Proceso de Teñido - Mejora Parte 2

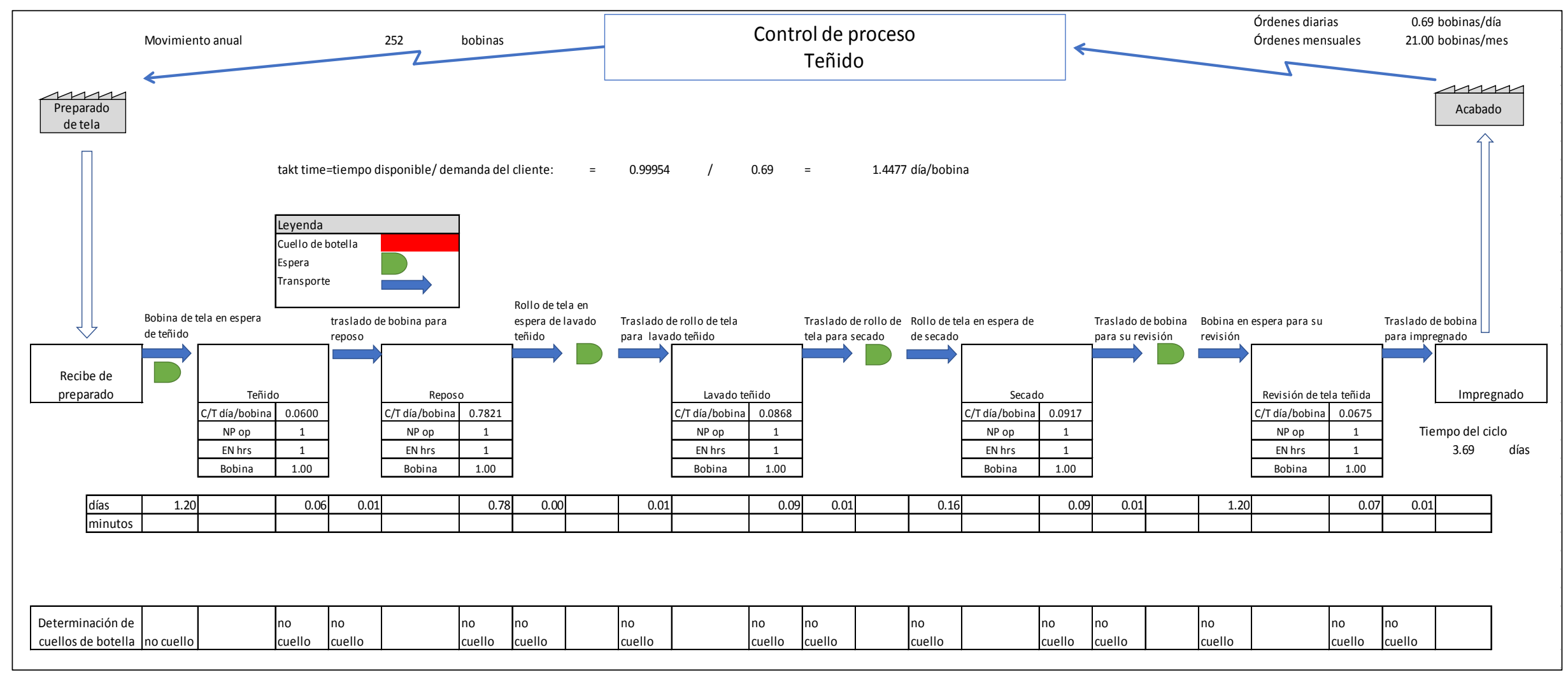

Elaboración propia 
Por lo tanto, se simulan los tiempos nuevos con valores aleatorios en un rango que sea el promedio de los días calculados para determinar el ahorro en esta primera fase, como se muestra a continuación:

Figura 42: Cálculo de tiempos para la propuesta de mejora 2

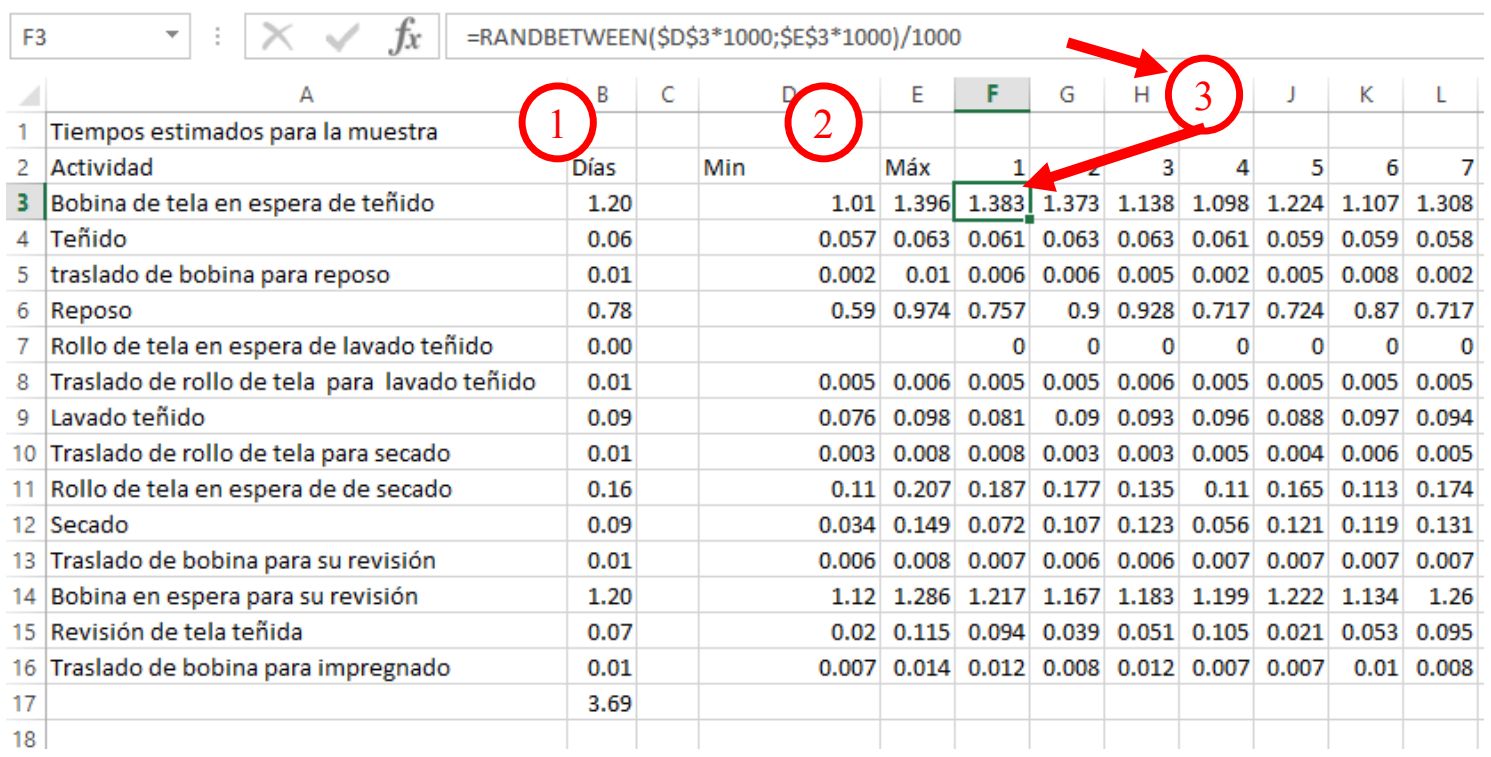

Elaboración propia

1. Se han colocado los tiempos de espera calculados del DAP de la tabla 56

2. Los valores mínimos y máximo de cada una de las actividades dan como resultado valor de (1). Por ejemplo:

$$
\text { Promedio act } 1=\frac{1.01+1.396}{2}=1.20
$$

3. Se utiliza la función de Excel para generar los números aleatorios RANDBETWEEN(min, máx), esta función selecciona un valor dentro del rango del mínimo y máximo establecidos. Cada valor del rango se multiplicó por 1000 y luego el número aleatorio se divide entre 1000, para obtener dicho aleatorio con decimales, de lo contrario la función provee aleatorios de números enteros, a pesar de que, los valores mínimos y máximos sean con decimales.

4. Estos valores aleatorios, se fijan al copiarlos sólo como valores, como se muestra a continuación (Véase anexo 4, para los valores que se han supuesto para los 252 procesos de bobinas y véase la tabla sobre el extracto de dichos cálculos). 
Tabla 55: Extracto de los tiempos de la propuesta de mejora parte2

\begin{tabular}{|c|c|c|c|c|c|c|c|c|c|c|c|c|c|c|}
\hline \multicolumn{15}{|l|}{ Tiempos por procesos de bobina } \\
\hline Actividad & & 1 & 2 & 3 & 4 & 5 & 6 & 7 & 247 & 248 & 249 & 250 & 251 & 252 \\
\hline Bobina de tela en espera de teñido & 1.20 & 1.38 & 1.37 & 1.14 & 1.10 & 1.22 & 1.11 & 1.31 & 1.14 & 1.21 & 1.17 & 1.08 & 1.05 & 1.26 \\
\hline Teñido & 0.06 & 0.06 & 0.06 & 0.06 & 0.06 & 0.06 & 0.06 & 0.06 & 0.06 & 0.06 & 0.06 & 0.06 & 0.06 & 0.06 \\
\hline traslado de bobina para reposo & 0.01 & 0.01 & 0.01 & 0.01 & 0.00 & 0.01 & 0.01 & 0.00 & 0.00 & 0.00 & 0.00 & 0.00 & 0.01 & 0.01 \\
\hline Reposo & 0.78 & 0.76 & 0.90 & 0.93 & 0.72 & 0.72 & 0.87 & 0.72 & 0.65 & 0.75 & 0.88 & 0.65 & 0.64 & 0.84 \\
\hline Rollo de tela en espera de lavado teñido & 0.00 & 0.00 & 0.00 & 0.00 & 0.00 & 0.00 & 0.00 & 0.00 & 0.00 & 0.00 & 0.00 & 0.00 & 0.00 & 0.00 \\
\hline Traslado de rollo de tela para lavado teñido & 0.01 & 0.01 & 0.01 & 0.01 & 0.01 & 0.01 & 0.01 & 0.01 & 0.01 & 0.01 & 0.01 & 0.01 & 0.01 & 0.01 \\
\hline Lavado teñido & 0.09 & 0.08 & 0.09 & 0.09 & 0.10 & 0.09 & 0.10 & 0.09 & 0.10 & 0.10 & 0.10 & 0.09 & 0.08 & 0.09 \\
\hline Traslado de rollo de tela para secado & 0.01 & 0.01 & 0.00 & 0.00 & 0.01 & 0.00 & 0.01 & 0.01 & 0.00 & 0.00 & 0.01 & 0.00 & 0.00 & 0.01 \\
\hline Rollo de tela en espera de de secado & 0.16 & 0.19 & 0.18 & 0.14 & 0.11 & 0.17 & 0.11 & 0.17 & 0.18 & 0.18 & 0.19 & 0.12 & 0.16 & 0.12 \\
\hline Secado & 0.09 & 0.07 & 0.11 & 0.12 & 0.06 & 0.12 & 0.12 & 0.13 & 0.07 & 0.11 & 0.06 & 0.10 & 0.05 & 0.07 \\
\hline Traslado de bobina para su revisión & 0.01 & 0.01 & 0.01 & 0.01 & 0.01 & 0.01 & 0.01 & 0.01 & 0.01 & 0.01 & 0.01 & 0.01 & 0.01 & 0.01 \\
\hline Bobina en espera para su revisión & 1.20 & 1.22 & 1.17 & 1.18 & 1.20 & 1.22 & 1.13 & 1.26 & 1.28 & 1.25 & 1.27 & 1.25 & 1.19 & 1.27 \\
\hline Revisión de tela teñida & 0.07 & 0.09 & 0.04 & 0.05 & 0.11 & 0.02 & 0.05 & 0.10 & 0.10 & 0.02 & 0.03 & 0.05 & 0.11 & 0.10 \\
\hline Traslado de bobina para impregnado & 0.01 & 0.01 & 0.01 & 0.01 & 0.01 & 0.01 & 0.01 & 0.01 & 0.01 & 0.01 & 0.01 & 0.01 & 0.01 & 0.01 \\
\hline Total por proceso & 3.69 & 3.89 & 3.94 & 3.75 & 3.47 & 3.65 & 3.59 & 3.86 & 3.60 & 3.70 & 3.78 & 3.42 & 3.38 & 3.83 \\
\hline
\end{tabular}

Elaboración propia

\section{$\underline{\text { Ahorros }}$}

Para poder calcular los ahorros se establece el Límite de control superior (UCL) como el objetivo de la empresa que no exceda este proceso total de teñido de 3.85 días, para calcular este valor se ha calculado el promedio de los tiempos de la propuesta de mejora 1 y la desviación estándar o 1 sigma, este valor $\mathrm{UCL}=3.85$ días representa el $95 \%$ de confiabilidad y $5 \%$ de error, con respecto al promedio de 3.68 días del proceso total:

Tabla 56: Estadísticas para los tiempos de la propuesta de mejora 2

\begin{tabular}{|l|r|}
\hline Promedio & 3.68 \\
\hline Desv Std & 0.17 \\
\hline UCL & 3.85 \\
\hline LCL & 3.52 \\
\hline
\end{tabular}

Elaboración propia.

Por lo tanto, se calcula el exceso de cada uno de los totales, si es que es superior el UCL, se toma la resta como el exceso al tiempo objetivo, de lo contrario es cero, ya que no excede el objetivo establecido.

Sí:

$\mathrm{T}_{\text {total/bobina }}>\mathrm{T}_{\mathrm{UCL}}$, entonces

$\mathrm{T}_{\text {exceso }}=\mathrm{T}_{\text {total } / \text { bobina }}-\mathrm{T}_{\mathrm{UCL}}$

De lo contrario

$\mathrm{T}_{\text {exceso }}=0$ 
Como se muestra a continuación:

Figura 43: Cálculo de tiempos de la mejora 2 del subproceso de reposo en exceso al objetivo

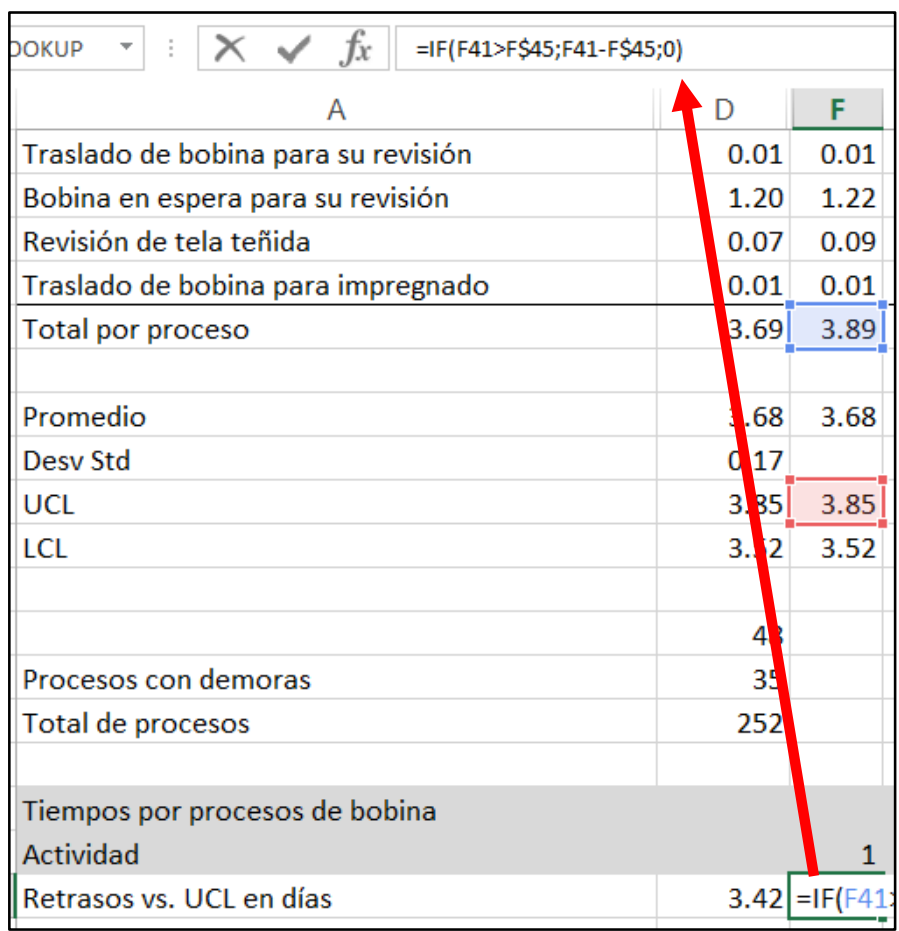

Elaboración propia

Por ejemplo, para el primer proceso:

$\mathrm{T}_{\text {total } / \text { bobina }}>\mathrm{T}_{\mathrm{UCL}}, \rightarrow 3.89>3.85$, verdadero, entonces

$\mathrm{T}_{\text {exceso }}=3.89-3.85=0.04$

Para el tercer proceso:

$\mathrm{T}_{\text {total } / \text { bobina }}>\mathrm{T}_{\mathrm{UCL}}, \rightarrow 3.75>3.85$, falso, entonces

$\mathrm{T}_{\text {exceso }}==0$

Como se muestra a continuación, un extracto de los tiempos en exceso del objetivo establecido como 3.85 horas, siendo el total de 3.42 días equivalentes a un total de 82.07 horas de tiempo de espera: 
Tabla 57: Cálculo de horas en exceso del objetivo por proceso - Mejora 2

\begin{tabular}{|c|c|c|c|c|c|c|c|c|c|c|c|c|c|}
\hline \multicolumn{14}{|c|}{ Tiempos por procesos de bobina } \\
\hline Actividad & 1 & 2 & 3 & 4 & 5 & 6 & 7 & 247 & 248 & 249 & 250 & 251 & 252 \\
\hline Retrasos vs. UCL en días & 0.04 & 0.09 & 0.00 & 0.00 & 0.00 & 0.00 & 0.01 & 0.00 & 0.00 & 0.00 & 0.00 & 0.00 & 0.00 \\
\hline Retrasos vs. UCL en días & 3.4 & & & & & & & & & & & & \\
\hline Total horas & 82.0761 & & & & & & & & & & & & \\
\hline
\end{tabular}

\section{Elaboración propia}

El costo de cada hora de mano de obra es de 44 operarios que comprenden el proceso de teñido, por lo que el promedio de sueldos es de $\mathrm{S} / 2500$ y el costo de mano de obra por operario es de $\mathrm{S} / 12.50$ el total por hora es la multiplicación de $44 \times \mathrm{S} / 12.50=\mathrm{S} / 550$ por hora por mano de obra.

El costo de hora máquina de Jigger, cámara de reposo, lavado y secado es de S/54 para todas las máquinas y sólo considerando el proceso de teñido. Por lo tanto, el total del Ahorro es de S/348,110.95 generando un impacto económico (pérdidas) de S/75,250.91.

Los ahorros es equivalente a la reducción del costo del tiempo de espera del proceso actual y de la propuesta de mejora $2=\mathrm{S} / .397,684.97-49,574.02=\mathrm{S} / 348,110.95$ en cuanto a mano de obra, pero en total incluyendo las penalidades el ahorro es la resta del impacto económico actual menos el impacto económico de la mejora $1=\mathrm{S} / 603,666.13-$ $75,250.91=\mathrm{S} / 528,415.22$, se ha reducido el tiempo de espera de 658 a 82 horas. Como se muestra a continuación: 
Tabla 58: Cálculo de ahorros de la propuesta Mejora Parte 2

\begin{tabular}{|c|c|c|c|c|c|c|}
\hline Descripción & \multicolumn{2}{|c|}{ Mejora 2} & \multicolumn{2}{|c|}{ Mejora 1} & \multicolumn{2}{|c|}{ Actual } \\
\hline Horas de exceso (tiempos de espera) & & 82 & & 481 & & 658 \\
\hline Operarios en proceso de teñido máquina jigger & & 44 & & 44 & & 44 \\
\hline Promedio sueldo & S/ & $2,500.00$ & S/ & $2,500.00$ & S/ & $2,500.00$ \\
\hline Costo HH & S/ & 12.50 & S/ & 12.50 & S/ & 12.50 \\
\hline Costo HM (jigger) & S/ & 54.00 & S/ & 54.00 & S/ & 54.00 \\
\hline Impacto económico & S/ & $49,574.02$ & S/ & $290,541.64$ & S/ & $397,684.97$ \\
\hline Equivalente a & & $1.46 \%$ & & $8.54 \%$ & & $12 \%$ \\
\hline \multirow[t]{2}{*}{ Ventas de } & \multicolumn{2}{|c|}{ S/ $3,400,659.00$} & \multicolumn{2}{|c|}{ S/ $3,400,659.00$} & \multicolumn{2}{|c|}{ S/ $3,400,659.00$} \\
\hline & & $0.02 \%$ & & $0.12 \%$ & & $0.16 \%$ \\
\hline Ahorro mano de obra (Proceso actual - Mejora) & S/ & $348,110.95$ & S/ & $107,143.33$ & S/ & - \\
\hline \multicolumn{7}{|l|}{ TOTAL Impacto Económico } \\
\hline Penalidades & S/ & $25,676.89$ & S/ & $150,486.21$ & S/ & $205,981.16$ \\
\hline Tiempo de espera & S/ & $49,574.02$ & S/ & $290,541.64$ & S/ & $397,684.97$ \\
\hline Total & S/ & $75,250.91$ & S/ & $441,027.85$ & S/ & $603,666.13$ \\
\hline Total de ahorros & S/ & $528,415.22$ & S/ & $162,638.27$ & S/ & - \\
\hline
\end{tabular}

Elaboración propia

\section{Cálculo de Colas}

Con los valores que se han calculado, se debe calcular el porcentaje de utilización del servidor en cuanto a colas y tiempo esperado de las bobinas en el sistema y en cola. El tiempo de llegada es el mismo que el tiempo de llegada en el proceso actual, ya que el proceso de preparación no se estudia en esta investigación, siendo de 7.53 días por bobina. El tiempo de servicio se ha reducido de 6.21 a 3.69 días para los procesos actual y proceso de mejora parte 2 , respectivamente.

El servicio de cada bobina se redujo de $82.5 \%$ a $49.0 \%$, lo que indica que se ha reducido en un 33.5, como se muestra a continuación: 
Tabla 59: Cálculo de colas - Propuesta de Mejora 2

\begin{tabular}{|c|c|c|c|c|}
\hline Datos & Mejora 2 & Mejora 1 & Actual & \\
\hline Por proceso & 1 & 1 & \multicolumn{2}{|c|}{1 bobina } \\
\hline Cada & 7.53 & 7.53 & \multicolumn{2}{|c|}{7.53 días } \\
\hline Servicio & 3.69 & 4.60 & \multicolumn{2}{|c|}{6.21 días } \\
\hline $\mathrm{M} / \mathrm{M} / 1$ queue & Mejora 2 & Mejora 1 & Actual & \\
\hline \multicolumn{5}{|l|}{ Ingreso } \\
\hline Unidad tiempo & día & día & día & \\
\hline Ratio de llegada $(\lambda)$ & 0.133 & 0.133 & 0.133 & bobinas/día \\
\hline Ratio de servicio de teñido $(\mu)$ & 0.271 & 0.218 & 0.161 & bobinas/día \\
\hline \multicolumn{5}{|l|}{ Salida } \\
\hline \multicolumn{5}{|l|}{ Salidas directas de las entradas } \\
\hline Tiempo medio entre llegadas & 7.528 & 7.528 & 7.528 & días \\
\hline Tiempo medio por servicio & 3.686 & 4.597 & 6.214 & días \\
\hline Intensidad de tráfico $(\lambda / \mu)$ & 0.490 & 0.611 & 0.825 & \\
\hline \multicolumn{5}{|l|}{ Resumen de resultados } \\
\hline Número estimado de bobinas en el sistema & 0.959 & 1.569 & 4.728 & bobinas \\
\hline Número estimado de bobinas en cola & 0.470 & 0.958 & 3.903 & bobinas \\
\hline Tiempo de espera estimado en el sistema & 7.223 & 11.809 & 35.597 & días \\
\hline Tiempo de espera estimado en cola & 3.537 & 7.211 & 29.383 & días \\
\hline Uso del servidor (teñido) & $49.0 \%$ & $61.1 \%$ & $82.5 \%$ & \\
\hline \multicolumn{5}{|l|}{ Variación } \\
\hline
\end{tabular}

Elaboración propia

En la tabla 61, se observa que con la propuesta de mejora 2, al implementar los tiempos siguientes de espera por actividades se incrementará el ratio de servicio de teñido de 0.161 bobinas/día a 0.271 bobinas/día, reduciendo la intensidad del tráfico de 0.825 a 0.490 . El número espera de bobinas en el sistema se ha reducido del proceso actual de 4.728 bobinas a 0.959 bobinas $\mathrm{y}$, por ende, se redujo el número esperado de bobinas en cola de 3.903 a 0.478 bobinas. El uso del servidor indica que el $49.0 \%$ de las bobinas todavía ingresará al proceso de teñido con tiempo de espera o cola, pero sin originar cuellos de botella, lo que se demuestra en el VSM de la figura 41. 
Tabla 60: Distribución del número en el sistema y del tiempo en cola de la propuesta de mejora 1

\begin{tabular}{|c|c|c|c|}
\hline \multicolumn{2}{|c|}{ Distribución del número en el sistema } & \multicolumn{2}{|c|}{ Distribución del tiempo en cola } \\
\hline $\mathrm{n}$ (bobinas) & $\mathrm{P}(\mathrm{n}$ en el sistema $)$ & t (en días) & $\mathrm{P}($ espera $>\mathrm{t})$ \\
\hline 0 & 0.510 & 2.000 & 0.371 \\
\hline 1 & 0.250 & & \\
\hline 2 & 0.122 & & \\
\hline 3 & 0.060 & & \\
\hline 4 & 0.029 & & \\
\hline 5 & 0.014 & & \\
\hline 6 & 0.007 & & \\
\hline 7 & 0.003 & & \\
\hline 8 & 0.002 & & \\
\hline 9 & 0.001 & & \\
\hline 10 & 0.000 & & \\
\hline 11 & 0.000 & & \\
\hline 12 & 0.000 & & \\
\hline 13 & 0.000 & & \\
\hline 14 & 0.000 & & \\
\hline 15 & 0.000 & & \\
\hline 16 & 0.000 & & \\
\hline 17 & 0.000 & & \\
\hline 18 & 0.000 & & \\
\hline 19 & 0.000 & & \\
\hline 20 & 0.000 & & \\
\hline 21 & 0.000 & & \\
\hline 22 & 0.000 & & \\
\hline
\end{tabular}

Elaboración propia

De la tabla 62, se observa que por ejemplo la probabilidad de tener exactamente 4 bobinas en el sistema es de 0.029. Equivalente a decir que el 3.3\% del tiempo hay exactamente 4 bobinas en el sistema. Por otro lado, bajo el título de Distribución del tiempo en cola, si el valor de $\mathrm{t}$ (en días) es igual a 2 días, indica que el 37.1\% de las bobinas permanece más de 2 días en cola.

Si el valor de $\mathrm{t}$ (en días) es igual a 1 día, indica que el 42.6\% de las bobinas permanece más de 1 día en cola, como se muestra a continuación:

Tabla 61: distribución del tiempo en cola para t (en días) $>=1$ días

\begin{tabular}{|r|r|}
\hline Distribución del tiempo en cola \\
\hline $\mathrm{t}($ en $\mathrm{s})$ & $\mathrm{P}($ espera $>\mathrm{t})$ \\
1.000 & 0.426 \\
\hline
\end{tabular}

Elaboración propia

Si el valor de $\mathrm{t}$ (en días) es igual a 10 días, indica que el $12.3 \%$ de las bobinas permanece más de 10 días en cola, como se muestra a continuación: 
Tabla 62: distribución del tiempo en cola para t(en días) >=10 días

\begin{tabular}{|r|r|}
\hline Distribución del tiempo en cola \\
\hline $\mathrm{t}(\mathrm{en} \mathrm{s})$ & $\mathrm{P}($ espera $>\mathrm{t})$ \\
10.000 & 0.123 \\
\hline
\end{tabular}

Elaboración propia

Al comparar las distribuciones del proceso actual y el proceso de mejora 2, en cuanto a las distribuciones del número de bobinas en el sistema, se muestra que, hay menor cantidad de bobinas en el sistema, por la reducción de los tiempos de espera, es decir que el $8.1 \%$ del tiempo hay 4 bobinas en el sistema en el proceso actual, sin embargo, en el proceso de la propuesta de mejora 2 es de $2.9 \%$, como se muestra a continuación:

Tabla 63: Comparación de bobinas en el sistema Actual vs. Mejora 2

\begin{tabular}{|r|r|r|r|}
\hline & $\begin{array}{c}\text { Mejora 2 } \\
\text { Distribución del número en el sistema }\end{array}$ \\
\hline $\mathrm{n}$ (bobinas) & $\mathrm{P}$ (n en el sistema) & $\mathrm{P}(\mathrm{n}$ en el sistema) & $\mathrm{P}(\mathrm{n}$ en el sistema) \\
\hline 0 & 0.510 & 0.389 & 0.175 \\
\hline 1 & 0.250 & 0.238 & 0.144 \\
\hline 2 & 0.122 & 0.145 & 0.119 \\
\hline 3 & 0.060 & 0.089 & 0.098 \\
\hline 4 & 0.029 & 0.054 & 0.081 \\
\hline 5 & 0.014 & 0.033 & 0.067 \\
\hline 6 & 0.007 & 0.020 & 0.055 \\
\hline 7 & 0.003 & 0.012 & 0.046 \\
\hline 8 & 0.002 & 0.008 & 0.038 \\
\hline 9 & 0.001 & 0.005 & 0.031 \\
\hline 10 & 0.000 & 0.003 & 0.026 \\
\hline 11 & 0.000 & 0.002 & 0.021 \\
\hline 12 & 0.000 & 0.001 & 0.017 \\
\hline 13 & 0.000 & 0.001 & 0.014 \\
\hline 14 & 0.000 & 0.000 & 0.012 \\
\hline 15 & 0.000 & 0.000 & 0.010 \\
\hline 16 & 0.000 & 0.000 & 0.008 \\
\hline 17 & 0.000 & 0.000 & 0.007 \\
\hline 18 & 0.000 & 0.000 & 0.006 \\
\hline 19 & 0.000 & 0.000 & 0.005 \\
\hline 20 & 0.000 & 0.000 & 0.004 \\
\hline 21 & 0.000 & 0.000 & 0.003 \\
\hline 22 & 0.000 & 0.000 & 0.003 \\
\hline
\end{tabular}

Elaboración propia

Por lo tanto, el porcentaje de espera disminuye en el tiempo, para el proceso actual, el $78 \%$ de las bobinas permanece en cola más de 2 días, pero en el proceso de mejora 2 es del $37.1 \%$, como se muestra a continuación: 
Tabla 64: Comparación de distribución del tiempo en cola Actual Vs. Mejora 2

\begin{tabular}{|c|c|c|c|}
\hline & Mejora 2 & Mejora 1 & Actual \\
\hline \multicolumn{4}{|c|}{ Distribución del tiempo en cola } \\
\hline $\mathrm{t}$ (en días) & $\mathrm{P}($ espera $>\mathrm{t})$ & $\mathrm{P}($ espera $>\mathrm{t})$ & $\mathrm{P}($ espera $>\mathrm{t})$ \\
\hline 2.000 & 0.371 & 0.516 & 0.780 \\
\hline 1.000 & 0.426 & 0.561 & 0.803 \\
\hline 10.000 & 0.123 & 0.262 & 0.623 \\
\hline
\end{tabular}

Elaboración propia

También en la tabla 66 se muestra que la permanencia mayor que 10 días en cola se reduce significativamente de $62.3 \%$ a $12.3 \%$ de las bobinas que ingresan al sistema.

Por lo tanto, para presentar un panorama completo, se ha compilado los resultados en una sola tabla para poder observar la reducción de tiempos al implementar SMED en un solo subproceso de Reposo, así como el ordenamiento de las porta bobinas y el balance de los tiempos de espera, los cuales no pueden ser mayores a las actividades siguientes, como se muestra a continuación:

Tabla 65: Resultados finales

\begin{tabular}{|c|c|c|c|}
\hline Resultados & Actual & Mejora 1 & Mejora 2 \\
\hline \multicolumn{4}{|l|}{ Tiempos } \\
\hline Bobina de tela en espera de teñido & 2.00 & 1.66 & 1.20 \\
\hline Teñido & 0.06 & 0.06 & 0.06 \\
\hline traslado de bobina para reposo & 0.01 & 0.01 & 0.01 \\
\hline Reposo & 1.12 & 0.78 & 0.78 \\
\hline Rollo de tela en espera de lavado teñido & 0.25 & 0.00 & 0.00 \\
\hline Traslado de rollo de tela para lavado teñido & 0.01 & 0.01 & 0.01 \\
\hline Lavado teñido & 0.09 & 0.09 & 0.09 \\
\hline Traslado de rollo de tela para secado & 0.01 & 0.01 & 0.01 \\
\hline Rollo de tela en espera de de secado & 0.50 & 0.16 & 0.16 \\
\hline Secado & 0.09 & 0.09 & 0.09 \\
\hline Traslado de bobina para su revisión & 0.01 & 0.01 & 0.01 \\
\hline Bobina en espera para su revisión & 2.00 & 1.66 & 1.20 \\
\hline Revisión de tela teñida & 0.07 & 0.07 & 0.07 \\
\hline Traslado de bobina para impregnado & 0.01 & 0.01 & 0.01 \\
\hline Total & 6.21 & 4.60 & 3.69 \\
\hline tiempo de Espera & 4.75 & 3.48 & 2.56 \\
\hline Tiempo de actividades & 1.46 & 1.12 & 1.12 \\
\hline \multicolumn{4}{|l|}{ COLAS } \\
\hline Número de bobinas en el sistema & 4.73 & 1.57 & 0.96 \\
\hline Número de bobinas en cola & 3.90 & 0.96 & 0.47 \\
\hline Tiempo de espera en el sistema & 35.60 & 11.81 & 7.22 \\
\hline Tiempo de espera en cola & 29.38 & 7.21 & 3.54 \\
\hline Uso del servidor (teñido) & $82.54 \%$ & $61.07 \%$ & $48.97 \%$ \\
\hline \multicolumn{4}{|l|}{ Ahorros } \\
\hline Mano de obra & S/ & S/ $107,143.33$ & S/348,110.95 \\
\hline Penalidades & S/ & S/ $55,494.95$ & S/ 180,304.27 \\
\hline \multicolumn{4}{|l|}{ Impacto Económico } \\
\hline Pérdidas & $S / 603,666.13$ & S/ 441,027.85 & S/ $75,250.91$ \\
\hline
\end{tabular}

Elaboración propia 


\section{Indicadores de la Propuesta de Mejora}

Lo que el estudio concluye con los siguientes indicadores, cumpliéndose en todos menos la reducción de tiempos de espera, el objetivo de la empresa es de 0.24 días, sin embargo, se redujo a 2.56 días y el nivel de cumplimiento se incrementó de $66.76 \%$ a $94.05 \%$ y no al $95 \%$ que la empresa sugiere.

Tabla 66: Indicadores de la Propuesta de Mejora

\begin{tabular}{|c|c|c|c|c|c|c|}
\hline \multirow[b]{2}{*}{ Indicadores } & \multicolumn{2}{|c|}{ Actual } & \multicolumn{2}{|c|}{ Objetivo } & \multicolumn{2}{|c|}{ Mejora } \\
\hline & \multicolumn{2}{|c|}{ unidades } & \multicolumn{2}{|c|}{ unidades } & \multicolumn{2}{|c|}{ unidades } \\
\hline Takt Time & 1.07 & día/bobina & ن & día/bobina & 1.45 & día/bobina \\
\hline Máx Tiempo registrado del proceso & 9.17 & días & 4.42 & días & 4.07 & días \\
\hline Promedio de tiempo del proceso & 6.21 & días & 1.46 & días & 3.69 & días \\
\hline Nivel de cumplimiento & $66.76 \%$ & porcentaje & $95.00 \%$ & porcentaje & $94.84 \%$ & porcentaje \\
\hline Tiempo de esperas & 4.75 & días & 0.24 & días & 2.56 & días \\
\hline Tiempo de proceso sin esperas & 1.46 & días & ת & días & 1.12 & días \\
\hline Porcentaje de bobinas en el sistema en cola & $82.54 \%$ & porcentaje & 乙 & porcentaje & $48.97 \%$ & porcentaje \\
\hline
\end{tabular}

Elaboración propia

Al concluir, la parte de la propuesta de mejora y los cálculos de ahorros y demostración de reducción de colas por las mejoras propuestas, se engloba en el planeamiento de producción, con la metodología MRPII.

\subsubsection{MRP II}

Para construir el planeamiento de producción, se debe tomar en cuenta los cálculos que se realizaron en el acápite anterior. A continuación, se explicará paso a paso de ello. Para analizar el MRP II de la mejora debe confeccionarse primero, el MRPII de los datos del proceso actual:

1. Primero se coloca, los días de cada mes y el mes además de la demanda mensual, la cual se asume del año 2017, como la que se proseguirá con la misma demanda. 
Figura 44: Elaboración de MRPII Proceso actual - Paso 1

\begin{tabular}{|c|c|c|c|c|c|}
\hline 4 & A & B & C & D & $\mathrm{E}$ \\
\hline 1 & \multicolumn{5}{|r|}{ Planea } \\
\hline 2 & \multicolumn{2}{|c|}{2017} & \multicolumn{2}{|c|}{$\begin{array}{c}\text { Programación de } \\
\text { producción mensual }\end{array}$} & Demanda mer \\
\hline 3 & & & & & \\
\hline 4 & Días & Mes & Bobinas & Días & Bobinas \\
\hline 5 & 31 & Ene & & & 11 \\
\hline 6 & 28 & Feb & & & 6 \\
\hline 7 & 31 & Mar & & & 19 \\
\hline 8 & 30 & Abr & & & 26 \\
\hline 9 & 31 & May & & & 13 \\
\hline 10 & 30 & Jun & & & 19 \\
\hline 11 & 31 & Jul & & & 22 \\
\hline 12 & 31 & Ago & & & 21 \\
\hline 13 & 30 & Sept & & & 23 \\
\hline 14 & 31 & Oct & & & 21 \\
\hline 15 & 30 & Nov & & & 28 \\
\hline 16 & 31 & Dic & & & 43 \\
\hline 17 & & TOTAL & & & \\
\hline
\end{tabular}

Elaboración propia

2. Luego se calcula los días de producción para la demanda, es decir para el mes de enero la demanda es de 11 bobinas x 6.21 días/bobina $=68$ días y la capacidad diaria de bobinas en la máquina Jigger $=4$ procesos/día y la capacidad mensual al multiplicar la capacidad mensual por los días de cada mes.

Figura 45: Elaboración de MRPII Proceso actual - Paso 2

\begin{tabular}{|c|c|c|c|c|c|c|c|c|}
\hline$\Delta$ & A & B & C & D & E & $\mathrm{F}$ & G & $\mathrm{H}$ \\
\hline 1 & \multicolumn{8}{|c|}{ Planeación de Recursos de Producción } \\
\hline 2 & \multicolumn{2}{|c|}{2017} & \multicolumn{2}{|c|}{$\begin{array}{c}\text { Programación de } \\
\text { producción mensual }\end{array}$} & \multicolumn{2}{|c|}{ Demanda mensual } & & \\
\hline 4 & Días & Mes & Bobinas & Días & Bobinas & Días & $\begin{array}{c}\text { Capacidad } \\
\text { diario } \\
(n=252)\end{array}$ & $\begin{array}{c}\text { Capacidad } \\
\text { mensual } \\
(n=252)\end{array}$ \\
\hline 5 & 31 & Ene & & & 11 & 68 & 4 & 124 \\
\hline 6 & 28 & Feb & & & 6 & 37 & 4 & 112 \\
\hline 7 & 31 & Mar & & & 19 & 118 & 4 & 124 \\
\hline 8 & 30 & Abr & & & 26 & 161 & 4 & 120 \\
\hline 9 & 31 & May & & & 13 & 81 & 4 & 124 \\
\hline 10 & 30 & Jun & & & 19 & 118 & 4 & 120 \\
\hline 11 & 31 & Jul & & & 22 & 137 & 4 & 124 \\
\hline 12. & 31 & Ago & & & 21 & 130 & 4 & 124 \\
\hline 13 & 30 & Sept & & & 23 & 143 & 4 & 120 \\
\hline 14. & 31 & Oct & & & 21 & 130 & 4 & 124 \\
\hline 15 & 30 & Nov & & & 28 & 174 & 4 & 120 \\
\hline 16 & 31 & Dic & & & 43 & 267 & 4 & 124 \\
\hline
\end{tabular}

Elaboración propia

3. Se supone que el sistema ya se encuentra ocupado por el cálculo de colas en el proceso actual de $82.5 \%$ de utilización del servidor (proceso de teñido completo), por lo que del total de 124 bobinas que puede servir el proceso de teñido del equipo Jigger, el $82.5 \%$ de ellas es 102 bobinas ya se encuentran en el sistema para el mes de enero y existe la disponibilidad para teñir 22 bobinas. Por lo que existe las horas disponibles 
es de 22 bobinas por 6.21 horas del proceso actual de teñido completo $=137$ horas, como se muestra a continuación:

Figura 46: Elaboración de MRPII Proceso actual - Paso 3

\begin{tabular}{|c|c|c|c|c|c|c|c|c|c|c|c|c|}
\hline \multicolumn{3}{|c|}{ SUM } & $\checkmark$ & $x$ & $\checkmark$ & \multicolumn{7}{|c|}{$=$ ROUND $\left(\mathrm{H}^{*}{ }^{* 1}\right.$ Modelo MM1 actual'!\$B\$26;0) } \\
\hline$\Delta$ & A & B & & $\mathrm{C}$ & D & $\mathrm{E}$ & $\mathrm{F}$ & G & $\mathrm{H}$ & I & J & K \\
\hline 1 & \multicolumn{12}{|c|}{ Planeación de Recursos de Producción del Proceso de Teñido para el equipo } \\
\hline & \multirow{2}{*}{\multicolumn{2}{|c|}{2017}} & \multirow{2}{*}{\multicolumn{3}{|c|}{$\begin{array}{c}\text { Programación de } \\
\text { producción mensual }\end{array}$}} & \multirow{2}{*}{\multicolumn{2}{|c|}{ Demanda mensual }} & & & & & \\
\hline 2 & & & & & & & & & & \multicolumn{2}{|c|}{ Bobinas } & \multirow{3}{*}{$\begin{array}{l}\text { Horas } \\
\begin{array}{c}\text { Sistema } \\
\text { Disponible }\end{array} \\
\end{array}$} \\
\hline 3 & & & & & & & & Capacidad & Capacidad & & & \\
\hline 4 & Días & Mes & & Bobinas & Días & Bobinas & Días & $\begin{array}{c}\text { diario } \\
(n=252)\end{array}$ & $\begin{array}{c}\text { mensual } \\
(n=252)\end{array}$ & $\begin{array}{l}\text { Sistema } \\
\text { ocupado }\end{array}$ & $\begin{array}{c}\text { Sistema } \\
\text { Disponible }\end{array}$ & \\
\hline 5 & 31 & Ene & & & & 11 & 68 & 4 & 124 & $=\mathrm{ROUND}(\mathrm{H}$ & 22 & 137 \\
\hline 6 & 28 & Feb & & & & 6 & 37 & 4 & 112 & 92 & 20 & 124 \\
\hline 7 & 31 & Mar & & & & 19 & 118 & 4 & 124 & 102 & 22 & 137 \\
\hline 8 & 30 & Abr & & & & 26 & 161 & 4 & 120 & 99 & 21 & 130 \\
\hline 9 & 31 & May & & & & 13 & 81 & 4 & 124 & 102 & 22 & 137 \\
\hline 10 & 30 & Jun & & & & 19 & 118 & 4 & 120 & 99 & 21 & 130 \\
\hline 11 & 31 & Jul & & & & 22 & 137 & 4 & 124 & 102 & 22 & 137 \\
\hline 12 & 31 & Ago & & & & 21 & 130 & 4 & 124 & 102 & 22 & 137 \\
\hline 13 & 30 & Sept & & & & 23 & 143 & 4 & 120 & 99 & 21 & 130 \\
\hline 14 & 31 & Oct & & & & 21 & 130 & 4 & 124 & 102 & 22 & 137 \\
\hline 15 & 30 & Nov & & & & 28 & 174 & 4 & 120 & 99 & 21 & 130 \\
\hline 16 & 31 & Dic & & & & 43 & 267 & 4 & 124 & 102 & 22 & 137 \\
\hline
\end{tabular}

Elaboración propia

4. Se calcula las bobinas en espera, al ingresar la programación de producción designada para ese mes, si es que excede o no la capacidad del equipo Jigger, y se condiciona a lo siguiente:

Sí

Producción inicial $>$ Producción disponible

Entonces

Bobinas $_{\text {espera }}=$ Producción inicial - Producción disponible

De lo contrario

Bobinas $_{\text {espera }}=0$

Para el mes de enero, la demanda adicional a la producción ya programada no excede la capacidad del equipo por lo que las bobinas en espera son igual a cero, como se muestra a continuación: 
Figura 47: Elaboración de MRPII Proceso actual - Paso 4

\begin{tabular}{|c|c|c|c|c|c|c|c|c|c|c|c|c|c|}
\hline \multicolumn{3}{|c|}{ SuM } & 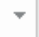 & $x$ & $\checkmark$ & \multicolumn{8}{|c|}{$=\mid \mathrm{F}(\mathrm{C} 5>\mathrm{J} 5 ; \mathrm{C} 5-\mathrm{J} 5 ; 0)$} \\
\hline$\Delta$ & A & B & & $\mathrm{C}$ & $\mathrm{D}$ & $\mathrm{E}$ & $\mathrm{F}$ & G & $\mathrm{H}$ & I & J & $\mathrm{K}$ & $\mathrm{L}$ \\
\hline 1 & \multicolumn{13}{|c|}{ Planeación de Recursos de Producción del Proceso de Teñido para el equipo Jigger - Actua } \\
\hline 2 & \multicolumn{2}{|c|}{2017} & \multicolumn{3}{|c|}{$\begin{array}{c}\text { Programación de } \\
\text { producción mensual }\end{array}$} & \multicolumn{2}{|c|}{ Demanda mensual } & & & \multicolumn{2}{|c|}{ Bobinas } & Horas & \\
\hline 4 & Días & Mes & & Bobinas & Días & Bobinas & Días & $\begin{array}{c}\text { Capacidad } \\
\text { diario } \\
(n=252) \\
\end{array}$ & $\begin{array}{c}\text { Capacidad } \\
\text { mensual } \\
(n=252)\end{array}$ & $\begin{array}{l}\text { Sistema } \\
\text { ocupado }\end{array}$ & \begin{tabular}{|c} 
Sistema \\
Disponible
\end{tabular} & $\begin{array}{c}\text { Sistema } \\
\text { Disponible }\end{array}$ & $\begin{array}{c}\text { Bobinas en } \\
\text { espera }\end{array}$ \\
\hline 5 & 31 & Ene & & 11 & 68 & 11 & 68 & 4 & 124 & 102 & 22 & 137 & $=\mathrm{IF}(\mathrm{C} 5>\mathrm{J} 5 ; \mathrm{C} 5$ \\
\hline 6 & 28 & Feb & & & & 6 & 37 & 4 & 112 & 92 & 20 & 124 & \\
\hline 7 & 31 & Mar & & & & 19 & 118 & 4 & 124 & 102 & 22 & 137 & \\
\hline 8 & 30 & $A b r$ & & & & 26 & 161 & 4 & 120 & 99 & 21 & 130 & \\
\hline 9 & 31 & May & & & & 13 & 81 & 4 & 124 & 102 & 22 & 137 & \\
\hline 10 & 30 & Jun & & & & 19 & 118 & 4 & 120 & 99 & 21 & 130 & \\
\hline 11 & 31 & Jul & & & & 22 & 137 & 4 & 124 & 102 & 22 & 137 & \\
\hline 12 & 31 & Ago & & & & 21 & 130 & 4 & 124 & 102 & 22 & 137 & \\
\hline 13 & 30 & Sept & & & & 23 & 143 & 4 & 120 & 99 & 21 & 130 & \\
\hline 14 & 31 & Oct & & & & 21 & 130 & 4 & 124 & 102 & 22 & 137 & \\
\hline 15 & 30 & Nov & & & & 28 & 174 & 4 & 120 & 99 & 21 & 130 & \\
\hline 16 & 31 & Dic & & & & 43 & 267 & 4 & 124 & 102 & 22 & 137 & \\
\hline 17 & & TOTAL & & & & & & & & & & & \\
\hline
\end{tabular}

Elaboración propia

5. Se debe calcular el tiempo de espera, bobinas en espera $\mathrm{x}$ promedio de tiempo del proceso actual $=0 \times 6.21$ días $=0$ días, se programa la alerta que debe programarse para el siguiente mes, ya que excedió la capacidad, de acuerdo con la siguiente condición:

Sí,

Tiempo espera $>0$,

Entonces,

Alerta $=$ Programación de producción para el siguiente mes

De lo contrario,

Alerta $=$ -

Y las bobinas programadas para el siguiente mes son iguales a las bobinas en espera, como se muestra a continuación: 
Figura 48: Elaboración de MRPII Proceso actual - Paso 5

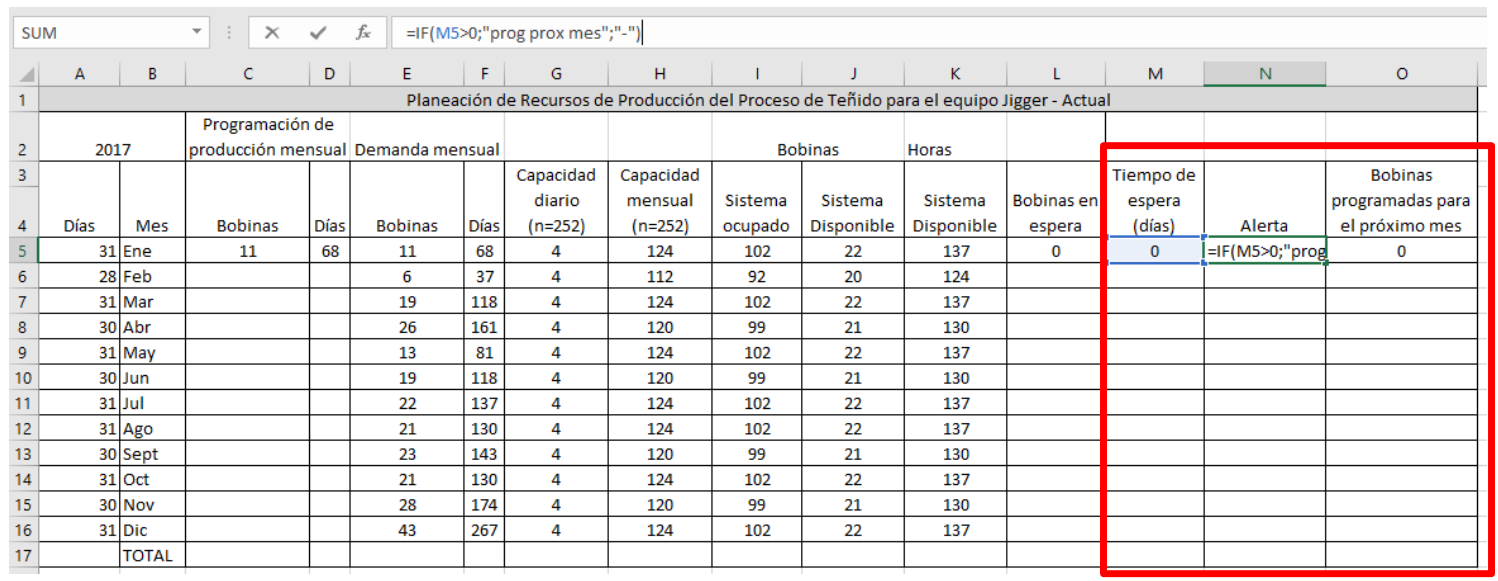

Elaboración propia

6. Para finalizar, la primera columna de programación se suma, la demanda de bobinas más las bobinas que se han dejado para el siguiente mes, para el mes de febrero es 6 $+0=6$

Figura 49: Elaboración de MRPII Proceso actual- Paso 6

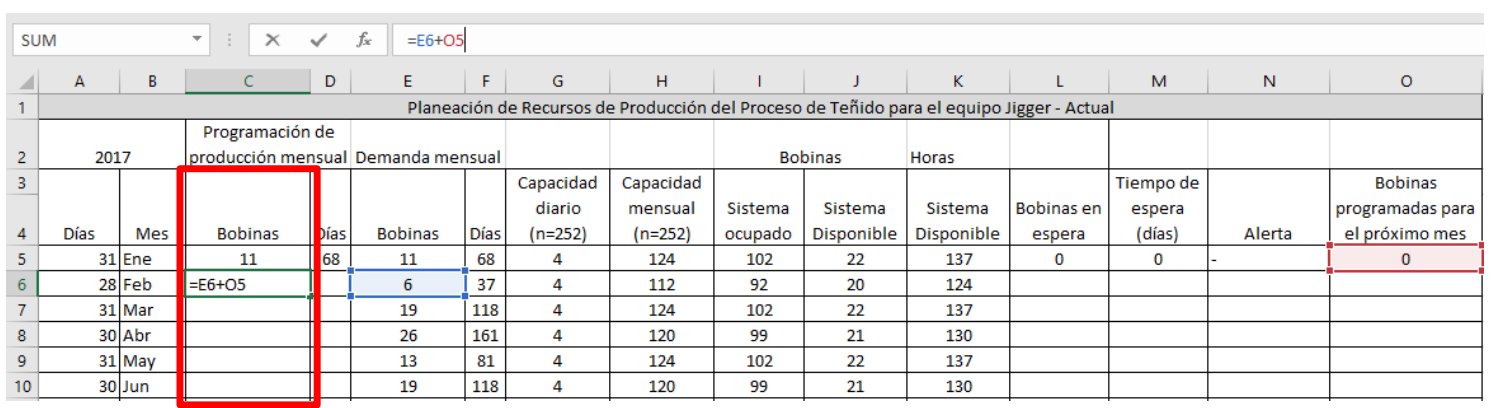

Elaboración propia

7. Por lo tanto, la elaboración de la programación completa del proceso actual es como se muestra a continuación

Figura 50: Elaboración de MRPII Proceso actual - Paso 7

\begin{tabular}{|c|c|c|c|c|c|c|c|c|c|c|c|c|c|c|}
\hline \multicolumn{2}{|c|}{2017} & \multicolumn{2}{|c|}{\begin{tabular}{|} 
Programación de \\
producción mensual
\end{tabular}} & \multicolumn{2}{|c|}{ Demanda mensual } & \multirow[b]{2}{*}{$\begin{array}{c}\text { Capacidad } \\
\text { diario } \\
(\mathrm{n}=252) \\
\end{array}$} & \multirow[b]{2}{*}{$\begin{array}{c}\text { Capacidad } \\
\text { mensual } \\
(\mathrm{n}=252) \\
\end{array}$} & \multicolumn{2}{|c|}{ Bobinas } & \multicolumn{2}{|l|}{ Horas } & \multirow[b]{2}{*}{$\begin{array}{c}\text { Tiempo de } \\
\text { espera } \\
\text { (días) }\end{array}$} & \multirow[b]{2}{*}{ Alerta } & \multirow[b]{2}{*}{\begin{tabular}{|c|} 
Bobinas \\
programadas para \\
el próximo mes
\end{tabular}} \\
\hline Días & Mes & Bobinas & Días & Bobinas & Días & & & $\begin{array}{l}\text { Sistema } \\
\text { ocupado }\end{array}$ & $\begin{array}{c}\text { Sistema } \\
\text { Disponible }\end{array}$ & \begin{tabular}{|c} 
Sistema \\
Disponible
\end{tabular} & $\begin{array}{c}\text { Bobinas en } \\
\text { espera }\end{array}$ & & & \\
\hline 31 & Ene & 11 & 68 & 11 & \begin{tabular}{|c|}
68 \\
\end{tabular} & 4 & 124 & 102 & 22 & 137 & 0 & 0 & - & 0 \\
\hline 28 & Feb & 6 & 37 & 6 & 37 & 4 & 112 & 92 & 20 & 124 & 0 & 0 & - & 0 \\
\hline 31 & Mar & 19 & 118 & 19 & 118 & 4 & 124 & 102 & 22 & 137 & 0 & 0 & - & 0 \\
\hline 30 & Abr & 26 & 161 & 26 & 161 & 4 & 120 & 99 & 21 & 130 & 5 & 31 & prog prox mes & 5 \\
\hline 31 & May & 18 & 112 & 13 & 81 & 4 & 124 & 102 & 22 & 137 & 0 & 0 & - & 0 \\
\hline 30 & Jun & 19 & 118 & 19 & 118 & 4 & 120 & 99 & 21 & 130 & 0 & 0 & - & 0 \\
\hline 31 & Jul & 22 & 137 & 22 & \begin{tabular}{|l|}
137 \\
\end{tabular} & 4 & 124 & 102 & 22 & 137 & 0 & 0 & - & 0 \\
\hline 31 & Ago & 21 & 130 & 21 & 130 & 4 & 124 & 102 & 22 & 137 & 0 & 0 & - & 0 \\
\hline 30 & Sept & 23 & 143 & 23 & 143 & 4 & 120 & 99 & 21 & 130 & 2 & 12 & prog prox mes & 2 \\
\hline 31 & Oct & 23 & 143 & 21 & 130 & 4 & 124 & 102 & 22 & 137 & 1 & 6 & prog prox mes & 1 \\
\hline 30 & Nov & 29 & 180 & 28 & 174 & 4 & 120 & 99 & 21 & 130 & 8 & 50 & prog prox mes & 8 \\
\hline 31 & Dic & 51 & 317 & 43 & 267 & 4 & 124 & 102 & 22 & 137 & 29 & 180 & prog prox mes & 29 \\
\hline & TOTAL & & & & & & & & & & 45 & 279 & & \\
\hline
\end{tabular}

Elaboración propia 
Al elaborar la programación del proceso actual, se calculó que 45 bobinas pasaron para la programación del siguiente mes, durante el año, ya que excedía la capacidad mensual del equipo.

8. Bajo el mismo proceso de (1) a (7), se elabora para el proceso mejorado, al considerar la utilización del servidor que se halló en el cálculo de colas de la propuesta de mejora parte 2 de 48.97\%. Se demuestra que no existe cuellos de botella, ya que no se programa bobinas para el próximo mes, como se observa en la siguiente tabla de comparación entre el MRPII del proceso actual y del proceso de mejora:

Tabla 67: Comparación MRPII - Proceso Actual vs. Mejora

\begin{tabular}{|c|c|c|c|c|c|c|c|c|c|c|c|c|c|c|}
\hline \multicolumn{15}{|c|}{ Planeación de Recursos de Producción del Proceso de Ten̂́ido para el equipo Jigger - Actual } \\
\hline \multicolumn{2}{|c|}{2017} & \multicolumn{2}{|c|}{\begin{tabular}{|c|} 
Programación de \\
producción mensual
\end{tabular}} & \multicolumn{2}{|c|}{ Demanda mensual } & \multirow[b]{2}{*}{$\begin{array}{c}\text { Capacidad } \\
\text { diario } \\
(\mathrm{n}=252)\end{array}$} & \multirow[b]{2}{*}{$\begin{array}{c}\text { Capacidad } \\
\text { mensual } \\
(\mathrm{n}=252)\end{array}$} & \multicolumn{2}{|c|}{ Bobinas } & \multirow{2}{*}{\begin{tabular}{|l} 
Horas \\
Sistema \\
Disponible
\end{tabular}} & \multirow[b]{2}{*}{$\begin{array}{c}\text { Bobinas en } \\
\text { espera }\end{array}$} & \multirow[b]{2}{*}{$\begin{array}{c}\text { Tiempo de } \\
\text { espera } \\
\text { (dias) }\end{array}$} & \multirow[b]{2}{*}{ Alerta } & \multirow[b]{2}{*}{$\begin{array}{c}\text { Bobinas } \\
\text { programadas para } \\
\text { el próximo mes }\end{array}$} \\
\hline Días & Mes & Bobinas & Días & Bobinas & Días & & & $\begin{array}{l}\text { Sistema } \\
\text { ocupado }\end{array}$ & $\begin{array}{c}\text { Sistema } \\
\text { Disponible }\end{array}$ & & & & & \\
\hline 31 & Ene & 11 & 68 & 11 & 68 & 4 & 124 & 102 & 22 & 137 & 0 & 0 & - & 0 \\
\hline 28 & Feb & 6 & 37 & 6 & 37 & 4 & 112 & 92 & 20 & 124 & 0 & 0 & - & 0 \\
\hline 31 & Mar & 19 & 118 & 19 & 118 & 4 & 124 & 102 & 22 & 137 & 0 & 0 & - & 0 \\
\hline 30 & Abr & 26 & 161 & 26 & 161 & 4 & 120 & 99 & 21 & 130 & 5 & 31 & prog prox mes & 5 \\
\hline 31 & May & 18 & 112 & 13 & 81 & 4 & 124 & 102 & 22 & 137 & 0 & 0 & - & 0 \\
\hline 30 & Jun & 19 & 118 & 19 & 118 & 4 & 120 & 99 & 21 & 130 & 0 & 0 & - & 0 \\
\hline 31 & Jul & 22 & 137 & 22 & 137 & 4 & 124 & 102 & 22 & 137 & 0 & 0 & - & 0 \\
\hline 31 & Ago & 21 & 130 & 21 & 130 & 4 & 124 & 102 & 22 & 137 & 0 & 0 & - & 0 \\
\hline 30 & Sept & 23 & 143 & 23 & 143 & 4 & 120 & 99 & 21 & 130 & 2 & 12 & prog prox mes & 2 \\
\hline 31 & oct & 23 & 143 & 21 & 130 & 4 & 124 & 102 & 22 & 137 & 1 & 6 & prog prox mes & 1 \\
\hline 30 & Nov & 29 & 180 & 28 & 174 & 4 & 120 & 99 & 21 & 130 & 8 & 50 & prog prox mes & 8 \\
\hline 31 & Dic & 51 & 317 & 43 & \begin{tabular}{|l|l|}
267 \\
\end{tabular} & 4 & 124 & 102 & 22 & 137 & 29 & 180 & prog prox mes & 29 \\
\hline & TOTAL & & & & & & & & & & 45 & 279 & & \\
\hline & & & & & & & & & & & & & & \\
\hline \multirow{2}{*}{\multicolumn{15}{|c|}{ Planeación de Recursos de Producción del Proceso de Teñido para el equipo Jigger - Mejora }} \\
\hline & & & & & & & & & & & & & & \\
\hline \multicolumn{2}{|c|}{2017} & \multicolumn{2}{|c|}{$\begin{array}{l}\text { Programación de } \\
\text { producción mensual }\end{array}$} & \multicolumn{2}{|c|}{ Demanda mensual } & & & \multicolumn{2}{|c|}{ Bobinas } & Horas & & & & \\
\hline Días & Mes & Bobinas & Días & Bobinas & Días & $\begin{array}{c}\text { Capacidad } \\
\text { diario } \\
(\mathrm{n}=252) \\
\end{array}$ & $\begin{array}{c}\text { Capacidad } \\
\text { mensual } \\
(\mathrm{n}=252) \\
\end{array}$ & $\begin{array}{l}\text { Sistema } \\
\text { ocupado }\end{array}$ & $\begin{array}{c}\text { Sistema } \\
\text { Disponible }\end{array}$ & $\begin{array}{c}\text { Sistema } \\
\text { Disponible }\end{array}$ & $\begin{array}{c}\text { Bobinas en } \\
\text { espera }\end{array}$ & \begin{tabular}{|c|}
$\begin{array}{c}\text { Tiempo de } \\
\text { espera } \\
\text { (dias) }\end{array}$ \\
\end{tabular} & Alerta & \begin{tabular}{|c|} 
Bobinas \\
programadas para \\
el próximo mes \\
\end{tabular} \\
\hline 31 & Ene & 11 & 68 & 11 & \begin{tabular}{|l|l}
68 \\
\end{tabular} & 4 & 124 & 61 & 63 & 391 & 0 & 0 & & 0 \\
\hline 28 & Feb & 6 & 37 & 6 & \begin{tabular}{|l|}
37 \\
\end{tabular} & 4 & 112 & 55 & 57 & 354 & 0 & 0 & & 0 \\
\hline 31 & Mar & 19 & 118 & 19 & \begin{tabular}{|l|}
118 \\
\end{tabular} & 4 & 124 & 61 & 63 & 391 & 0 & 0 & & 0 \\
\hline 30 & Abr & 26 & 161 & 26 & 161 & 4 & 120 & 59 & 61 & 379 & 0 & 0 & & 0 \\
\hline 31 & May & 13 & 81 & 13 & \begin{tabular}{|l|l}
81 \\
\end{tabular} & 4 & 124 & 61 & 63 & 391 & 0 & 0 & & 0 \\
\hline 30 & Jun & 19 & 118 & 19 & 118 & 4 & 120 & 59 & 61 & 379 & 0 & 0 & & 0 \\
\hline 31 & Jul & 22 & 137 & 22 & \begin{tabular}{|l|}
137 \\
\end{tabular} & 4 & 124 & 61 & 63 & 391 & 0 & 0 & - & 0 \\
\hline 31 & Ago & 21 & 130 & 21 & 130 & 4 & 124 & 61 & 63 & 391 & 0 & 0 & - & 0 \\
\hline 30 & Sept & 23 & 143 & 23 & 143 & 4 & 120 & 59 & 61 & 379 & 0 & 0 & - & 0 \\
\hline 31 & Oct & 21 & 130 & 21 & 130 & 4 & 124 & 61 & 63 & 391 & 0 & 0 & - & 0 \\
\hline 30 & Nov & 28 & 174 & 28 & 174 & 4 & 120 & 59 & 61 & 379 & 0 & 0 & - & 0 \\
\hline 31 & Dic & 43 & 267 & 43 & 267 & 4 & 124 & 61 & 63 & 391 & 0 & 0 & - & 0 \\
\hline & TOTAL & & & & & & & & & & 0 & 0 & & \\
\hline
\end{tabular}

Elaboración propia

Por lo tanto, se concluye que la propuesta que se presenta en esta investigación mejorará la programación de producción reduciendo los tiempos de espera y de esta manera incrementa el nivel de cumplimiento de entrega de bobinas a tiempo. 


\subsection{Consideraciones para la implementación}

En esta sección, se presentan las consideraciones de implementación de la propuesta de mejora, como el cronograma de Gantt para la implementación, las capacitaciones e inversión que se requiere y las limitaciones del proyecto.

\subsubsection{Cronograma}

El cronograma de Gantt presenta el tiempo y las actividades de la implementación de 52 semanas de la propuesta de mejora. 


\section{Tabla 68: Cronograma de Gantt}

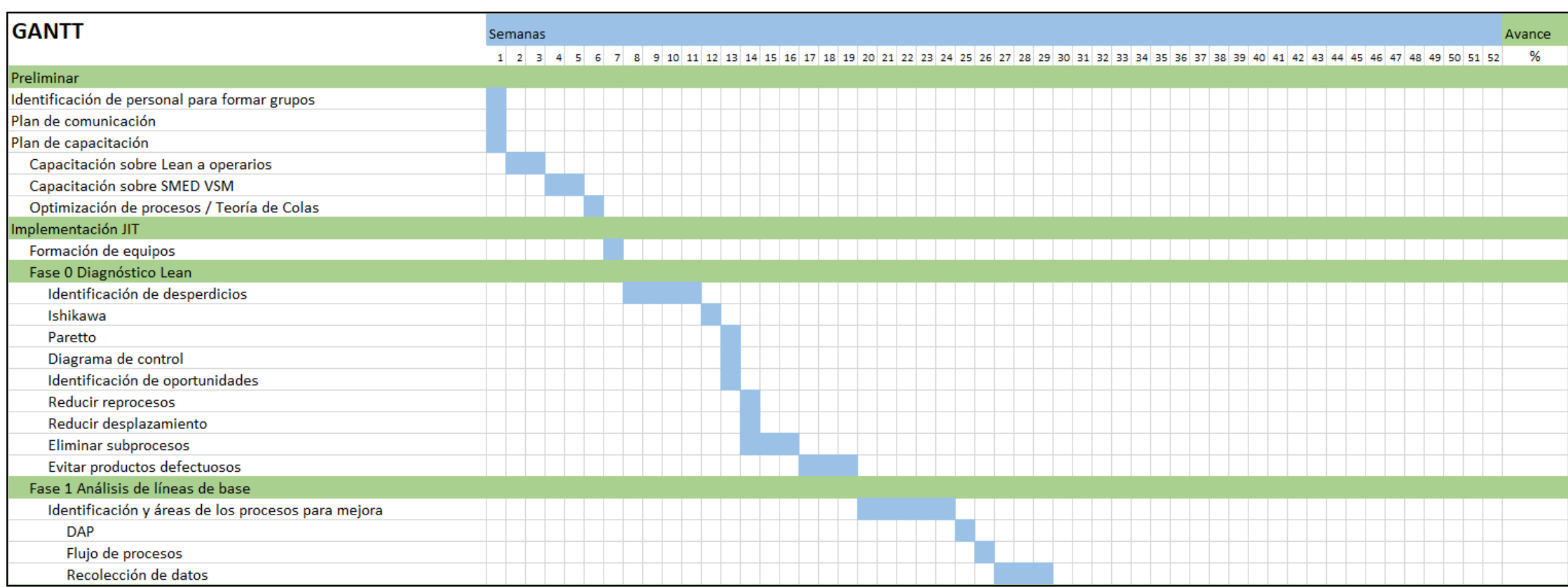




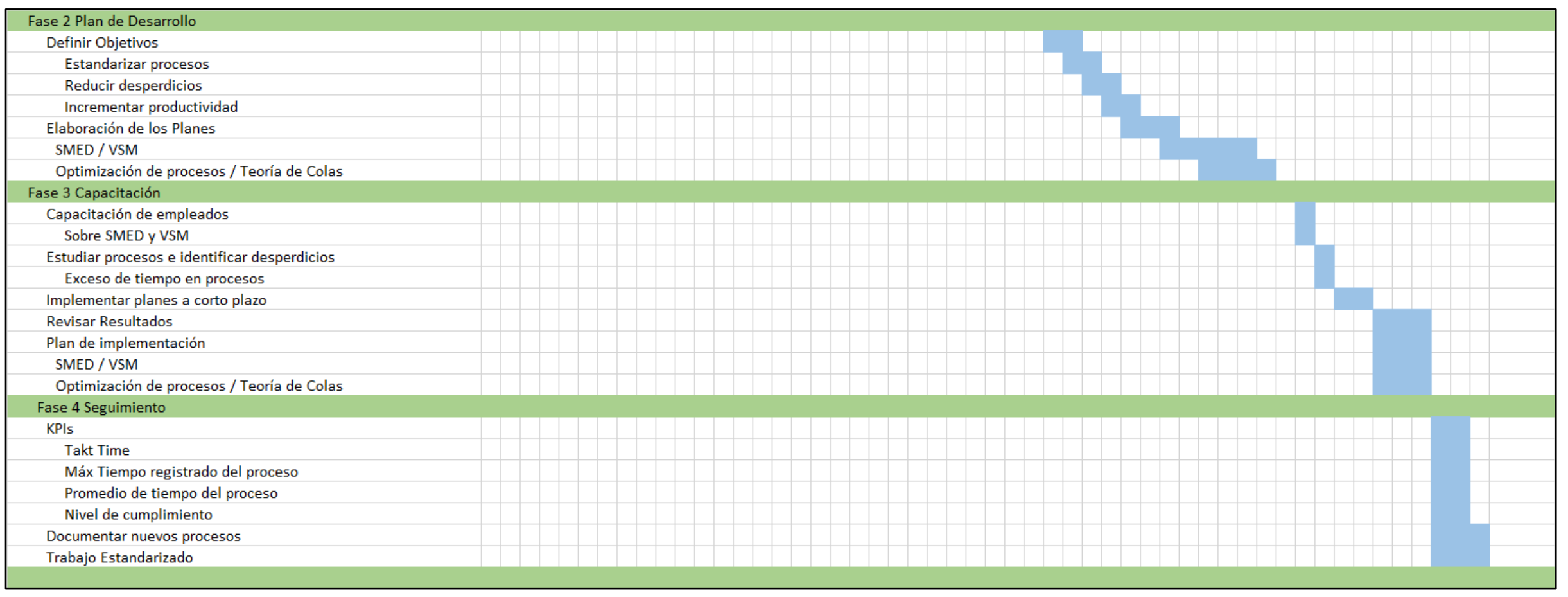

Elaboración propia 


\subsubsection{Capacitaciones}

Para lograr el cumplimiento de la implementación del nuevo proceso de teñido, se debe capacitar y crear el interés requerido a los operarios que operan el proceso, otorgándoles la responsabilidad de sus áreas de trabajo para incrementar el servicio a las bobinas de acuerdo al procedimiento establecido bajo la implementación de la herramienta SMED y VSM, así como el ordenamiento de las porta bobinas en el proceso de teñido. Las capacitaciones se dan por un tercero, una empresa con conocimiento y experiencia en líneas de producción textil y teñido, además de Lean Manufacturing y herramientas de Ingeniería Industrial.

El total de las horas de capacitación por el temario es de 87 horas por operario, son 44 operarios que participan en el proceso de teñido, el costo por hora por participante de las clases es de $\mathrm{S} / 45$. Se debe considerar que las capacitaciones se deben de proveer fuera de las horas de trabajo, por lo que se debe también pagar a los participantes dos horas diarias extras, lo que equivale a la adición del $25 \%$ del costo $\mathrm{HH}$, igual a $15.63 \%$, este pago es de acuerdo con la normativa del Ministerio de Trabajo.

El total de inversión por capacitaciones es de $\mathrm{S} / 232,072.50$, como se muestra a continuación:

Tabla 69: Capacitaciones

\begin{tabular}{|l|r|}
\hline Capacitación & Horas/op \\
\hline Principios de Lean Manufacturing & 12 \\
\hline MRPII & 12 \\
\hline SMED & 20 \\
\hline VSM & 15 \\
\hline Teoría de colas & 20 \\
\hline Optimización de procesos & 8 \\
\hline Total horas & 87 \\
\hline & \\
\hline Costo clase/hora & S/ \\
\hline & 45.00 \\
\hline Operarios & \\
\hline Costo HH & 44 \\
\hline Costo HH extra & S/ \\
\hline & \multicolumn{2}{|c|}{12.50} \\
\hline Inversión por capacitación & 15.63 \\
\hline
\end{tabular}

Elaboración propia 
Por lo tanto, se realiza la capacitación completa de las herramientas SMED, VSM, así como la introducción y principios de Lean Manufacturing, lo cual explica y empodera al operario de la responsabilidad de su área de trabajo para el progreso de la empresa en general y así poder incrementar el nivel de cumplimiento de entregas a tiempo.

\subsubsection{Inversión}

La inversión requiere de tangibles, como la programación de los VSM, conectados a los datos de la empresa, para llevar los resultados en tiempo real de los jefes de producción del proceso de teñido y poder corregir cualquier problema que acurra en la implementación, así como las herramientas SMED y MRPII diario incluyendo el análisis de colas para dar el conocimiento y entendimiento de los progresos de la implementación con una frecuencia diaria, se implementará en 6 estaciones de trabajo bajo una red y conectadas a la base de datos de producción del proceso de teñido, la inversión es de $\mathrm{S} / 41,578$, como se muestra a continuación:

Tabla 70: Inversión de tangibles/Activos

\begin{tabular}{|l|lr|}
\hline Tangible/Activos & & \\
Componente VSM & S/ & $4,500.00$ \\
\hline Componente SMED & S/ & $4,500.00$ \\
\hline Componente MRPII & S/ & $4,500.00$ \\
\hline Componente Teoróa de Colas & S/ & $4,500.00$ \\
\hline Conexión de datos con base de datos principal & S/ & $8,578.00$ \\
\hline Implementación en estaciones de trabajo & S/ & $2,500.00$ \\
\hline Estaciones de trabajo & & 6 \\
\hline Total Tangible/Activos & S/ & $41,578.00$ \\
\hline
\end{tabular}

Elaboración propia

\subsubsection{Limitaciones}

Las limitaciones que se encontraron en el proceso del diseño de la propuesta de mejora son:

- Bases de datos de tiempos son incompletos y algunos datos erróneos y/o faltantes, es por ello la necesidad de calcular una muestra.

- No existen registros de la demanda mensual completos o se han regularizado después de algunos meses después, por lo que hace difícil el análisis real de la demanda y poder tener una proyección confiable de ella. 
- Para los costos de máquina del proceso de teñido, así como los tiempos programados de paradas por mantenimientos, se toma como base la de la máquina Jigger, ya que las otras máquinas también se programan con las otras máquinas de teñido que la empresa tiene.

\subsection{Ahorros e Inversión Total}

A continuación, se muestra el resumen de Inversión de S/273,650.50 y ahorros de $\mathrm{S} / 510,429.50$ que se generan al implementar la propuesta de mejora, como se muestra c continuación:

Tabla 71: Inversión y Ahorros Total de la implementación de mejora

\begin{tabular}{|c|c|}
\hline Inversión & \\
\hline Capacitación & Horas/op \\
\hline Principios de Lean Manufacturing & 12 \\
\hline MRPII & 12 \\
\hline SMED & 20 \\
\hline VSM & 15 \\
\hline Teoría de colas & 20 \\
\hline Optimización de procesos & 8 \\
\hline Total horas & 87 \\
\hline Costo clase/hora & 45.00 \\
\hline Operarios & 44 \\
\hline Costo $\mathrm{HH}$ & 12.50 \\
\hline Costo HH extra & 15.63 \\
\hline Inversión por capacitación & $S / 232,072.50$ \\
\hline Tangible/Activos & \\
\hline Componente VSM & S/ $\quad 4,500.00$ \\
\hline Componente SMED & S/ $4,500.00$ \\
\hline Componente MRPII & S/ $4,500.00$ \\
\hline Componente Teoróa de Colas & S/ $4,500.00$ \\
\hline Conexión de datos con base de datos principal & S/ $8,578.00$ \\
\hline Implementación en estaciones de trabajo & S/ $2,500.00$ \\
\hline Estaciones de trabajo & 6 \\
\hline Total Tangible/Activos & S/ $41,578.00$ \\
\hline Total Inversión & $S / 273,650.50$ \\
\hline
\end{tabular}




\begin{tabular}{|l|l|}
\hline Ahorros & $\mathrm{S} / 348,110.95$ \\
\hline Proceso & $\mathrm{S} / 180,304.27$ \\
\hline Penalidades & \\
\hline & $\mathrm{S} / 528,415.22$ \\
\hline Total ahorros & \\
\hline Elaboración propia &
\end{tabular}

Se debe considerar que para la validación financiera se considera la depreciación al 20\% anual de la inversión tangible/activos. 


\section{CAPÍTULO IV: VALIDACIÓN DE LA PROPUESTA DE MEJORA}

Para la validación de la propuesta de mejora, primero se realiza la simulación de los procesos actual y de la propuesta de mejora, para validar la disminución de los tiempos en el proceso, se utilizan los registros de los tiempos del proceso actual y los asumidos para la propuesta de mejora de las 252 bobinas o procesos de teñido. La validación financiera del proyecto se define de acuerdo con la inversión y ahorros que se generan al implementar la propuesta de mejora, presenta los escenarios de Esperado, con los datos calculados para el proyecto, sin embargo, se debe calcular una suposición de los escenarios pesimista y optimista de acuerdo con los datos calculados de la propuesta de mejora.

\subsection{Validación de los tiempos de los Procesos}

Los datos de los tiempos del proceso actual (anexo 3) y de la propuesta de mejora (anexo 4) se ingresan en el componente del software de simulación Arena de Rockwell Automation, para obtener las distribuciones de cada una de las actividades, como se muestra a continuación: 
Tabla 72: Distribuciones de los tiempos de las actividades del proceso de teñido actual y de la propuesta de mejora

\begin{tabular}{|c|c|c|}
\hline Actividades & Actual & Mejora \\
\hline Bobina de tela en espera de teñido & $0.26+3.47 * \operatorname{BETA}(1.66,1.64)$ & $1+0.45 * \operatorname{BETA}(1.43,1.69)$ \\
\hline Teñido & $0.05+\operatorname{LOGN}(0.00996,0.00213)$ & $0.05+\operatorname{LOGN}(0.00991,0.00203)$ \\
\hline traslado de bobina para reposo & $\operatorname{BETA}(1.98,1.74671)$ & WEIB $(0.00625,2.65)$ \\
\hline Reposo & $0.84+0.56 * \operatorname{BETA}(1.46,1.43)$ & $0.55+0.45 * \operatorname{BETA}(1.53,1.39)$ \\
\hline Rollo de tela en espera de lavado teñido & $0.12+0.26 * \operatorname{BETA}(1.77,1.71)$ & \\
\hline Traslado de rollo de tela para lavado teñido & $\operatorname{LOGN}(0.00548,0.0005)$ & $\operatorname{LOGN}(0.00552,0.000504)$ \\
\hline Lavado teñido & $0.07+0.03 * \operatorname{BETA}(2.93,2.28)$ & $0.07+0.03 * \operatorname{BETA}(2.53,2.12)$ \\
\hline Traslado de rollo de tela para secado & BETA $(4.17,3.34109)$ & BETA(4.1, 3.56654) \\
\hline Rollo de tela en espera de de secado & $0.21+0.7 * \operatorname{BETA}(2.24,3.19)$ & $0.09+0.14 * \operatorname{BETA}(2.38,2.16)$ \\
\hline Secado & $0.02+0.14 * \operatorname{BETA}(1.65,1.7)$ & $0.02+0.15 * \operatorname{BETA}(1.89,2.02)$ \\
\hline Traslado de bobina para su revisión & $\operatorname{BETA}(28.2,15.5777)$ & $\operatorname{BETA}(31.4,17.3787)$ \\
\hline Bobina en espera para su revisión & $0.15+3.7 *$ BETA $(1.65,1.66)$ & $1.1+0.22 * \operatorname{BETA}(1.68,1.76)$ \\
\hline Revisión de tela teñida & $0.01+0.12 * \operatorname{BETA}(1.75,1.7)$ & $0.01+0.12 * \operatorname{BETA}(1.91,2.05)$ \\
\hline Traslado de bobina para impregnado & WEIB $(0.0108,5.77)$ & WEIB $(0.0109,5.78)$ \\
\hline ¿Pasó revisión? & $89.17 \%$ & $89.17 \%$ \\
\hline Réplicas & 24 & 24 \\
\hline
\end{tabular}

Elaboración propia

\subsubsection{Proceso Actual}

Se modela el diagrama de flujo del proceso actual al considerar las operaciones, programando las distribuciones que se obtuvieron, como se muestra a continuación: 
Figura 51: Modelo de simulación del proceso actual de teñido - Operaciones

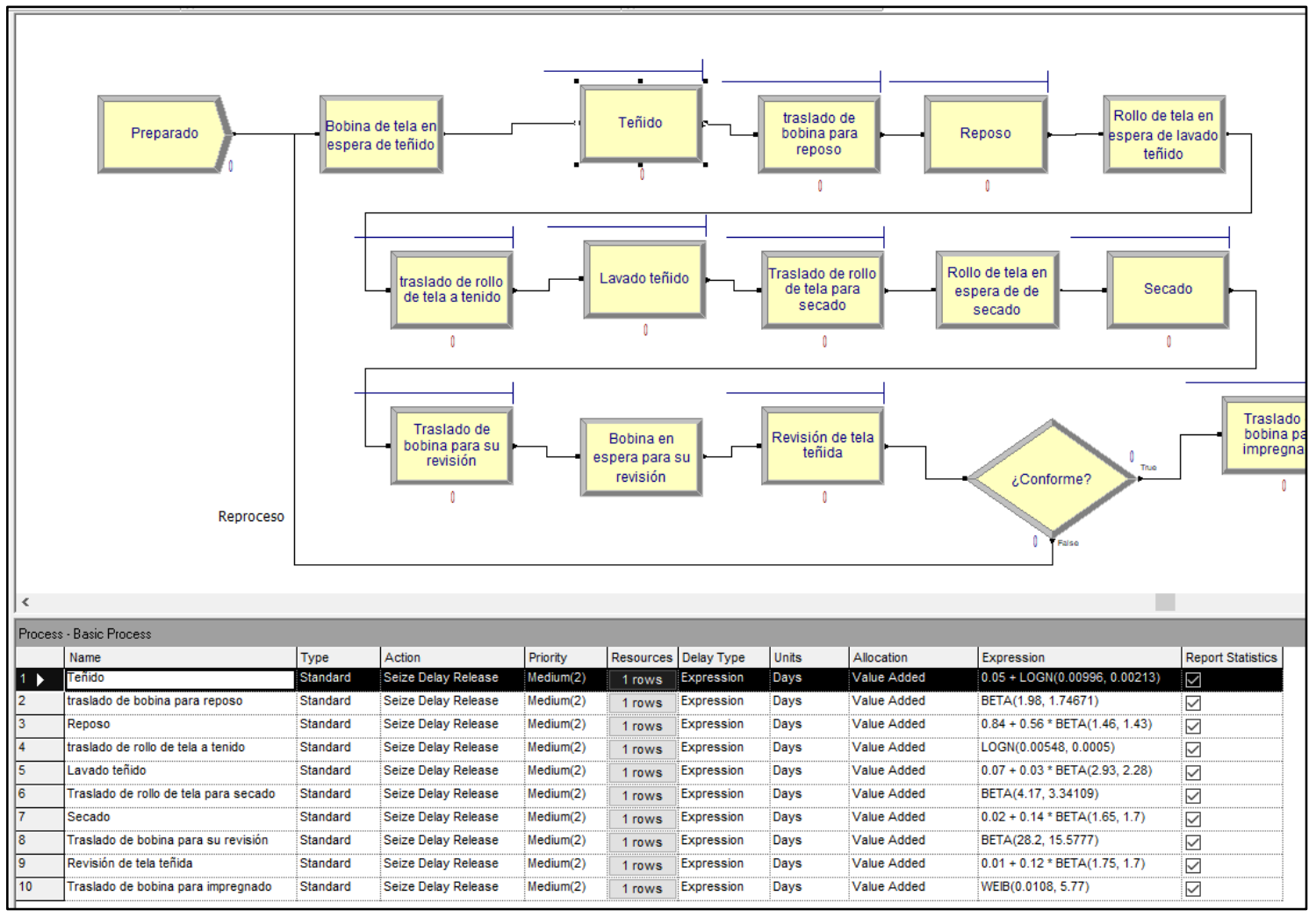

Elaboración propia

Posteriormente se programan los tiempos de espera, con sus distribuciones equivalentes (4) y se coloca en Allocation como WAIT, como se muestra a continuación:

Figura 52: Modelo de simulación del proceso actual de teñido - Tiempos de espera

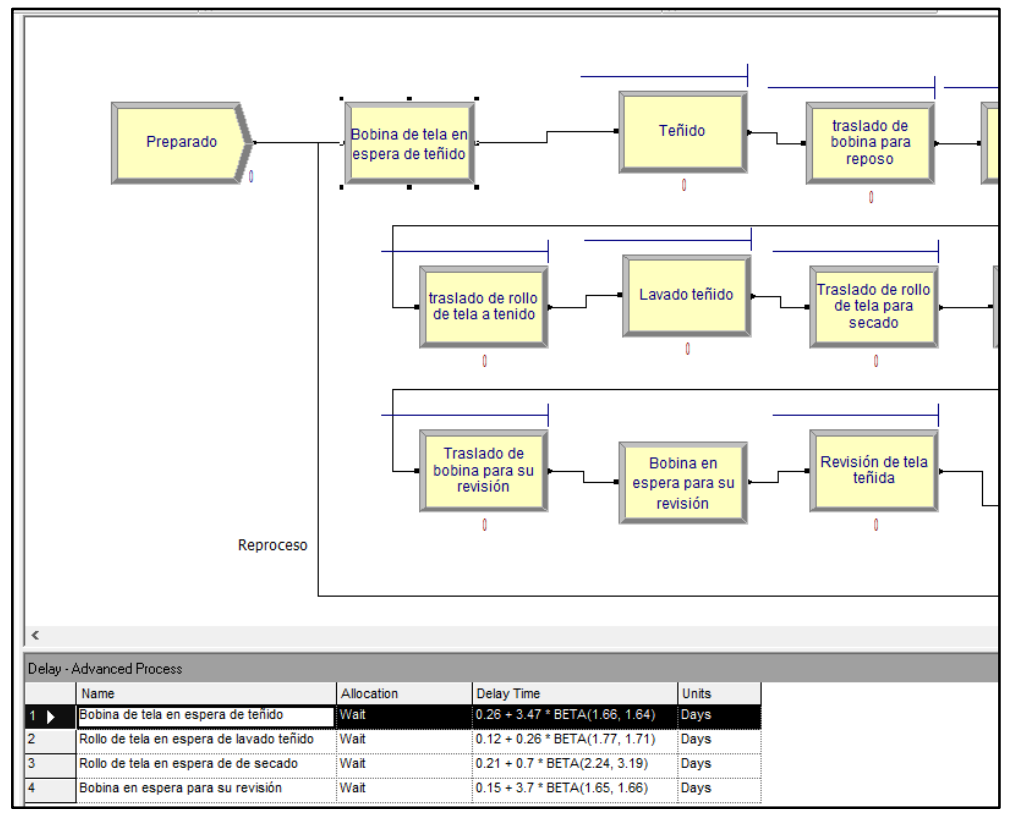

Elaboración propia 
Por lo tanto, el modelo final del proceso actual de teñido se muestra a continuación:

Figura 53: Modelo de simulación del proceso actual de teñido

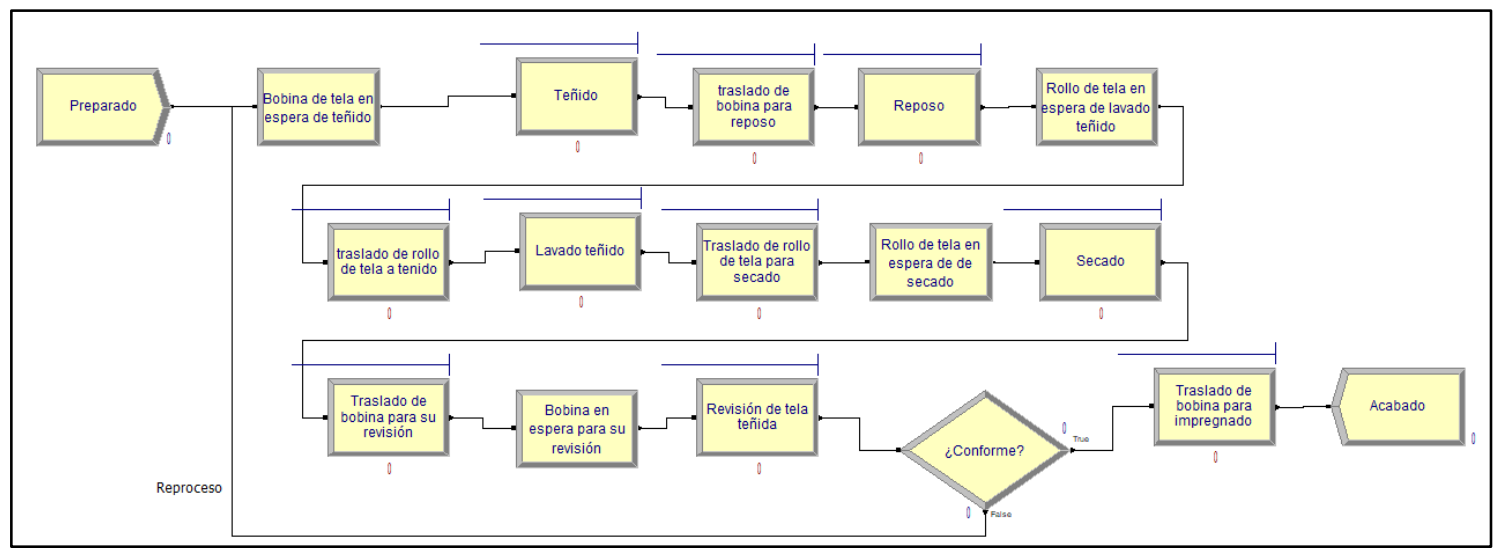

Elaboración propia

\subsubsection{Proceso de la propuesta de Mejora}

Se modela el diagrama de flujo del proceso de mejora al considerar las operaciones, programando las distribuciones que se obtuvieron, como se muestra a continuación:

Figura 54: Modelo de simulación del proceso de mejora de teñido - Operaciones

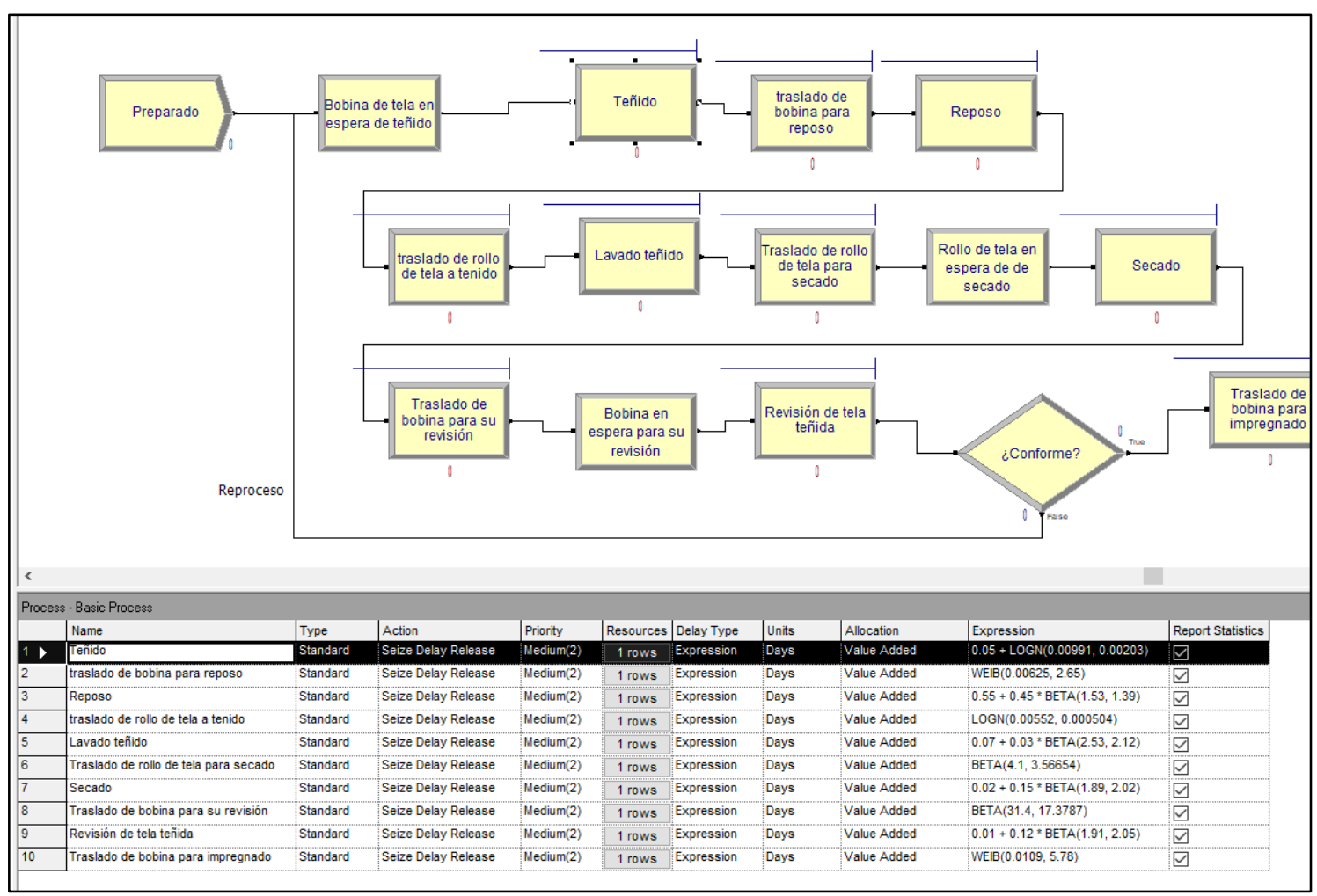

Elaboración propia 
Posteriormente se programan los tiempos de espera, con sus distribuciones equivalentes (3) y se coloca en Allocation como WAIT, como se muestra a continuación:

Figura 55: Modelo de simulación del proceso actual de teñido - Tiempos de espera

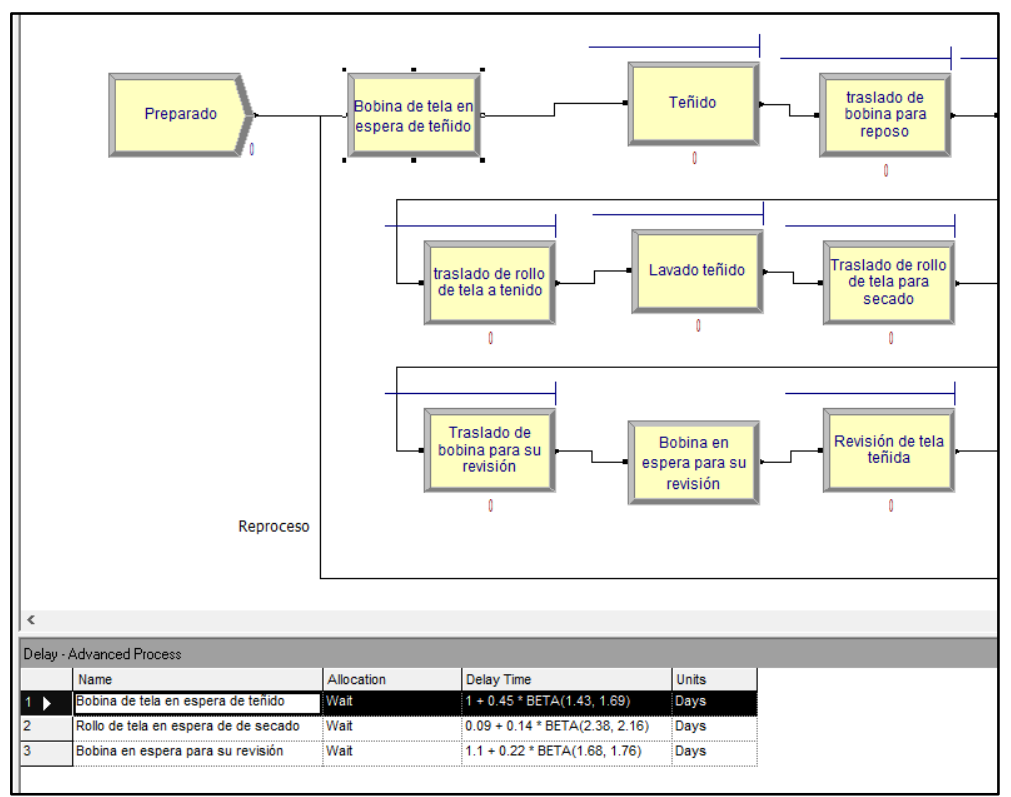

Elaboración propia

Por lo tanto, el modelo final del proceso actual de teñido se muestra a continuación:

Figura 56: Modelo de simulación del proceso actual de teñido

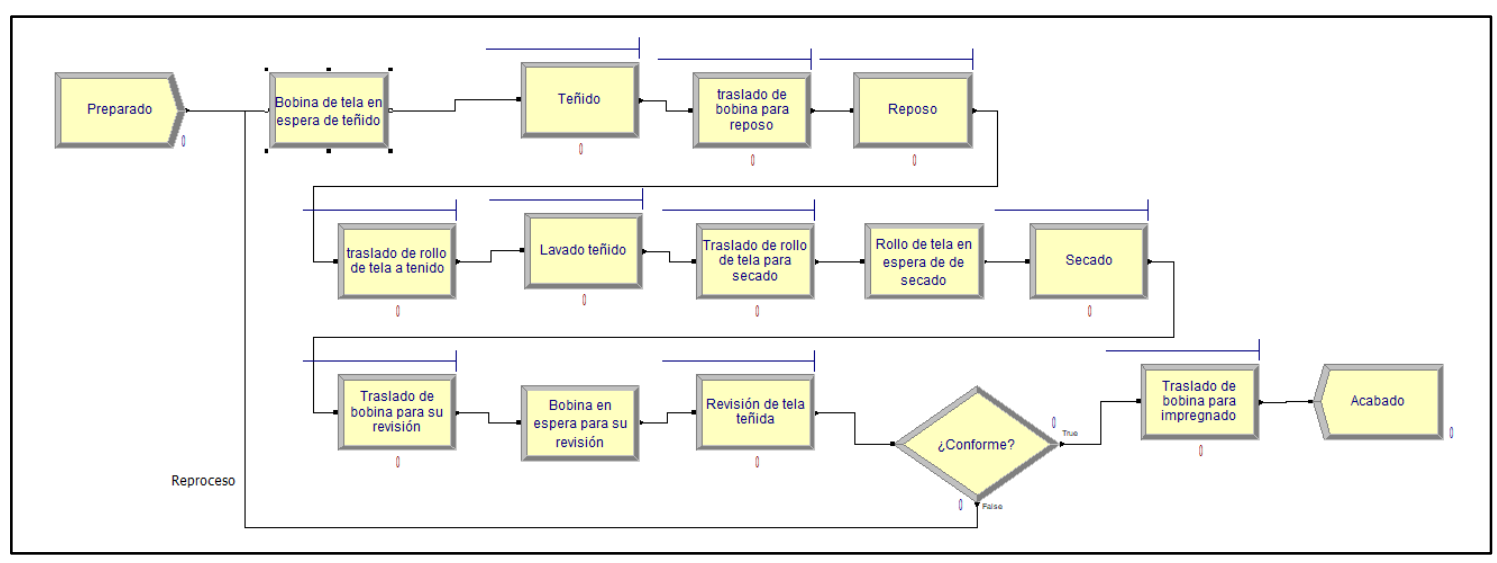

Elaboración propia

\subsubsection{Resultados}

Al ejecutar los modelos proporcionaron los siguientes resultados: 
Tabla 73: Resultados de la simulación para los procesos actual y propuesta de mejora.

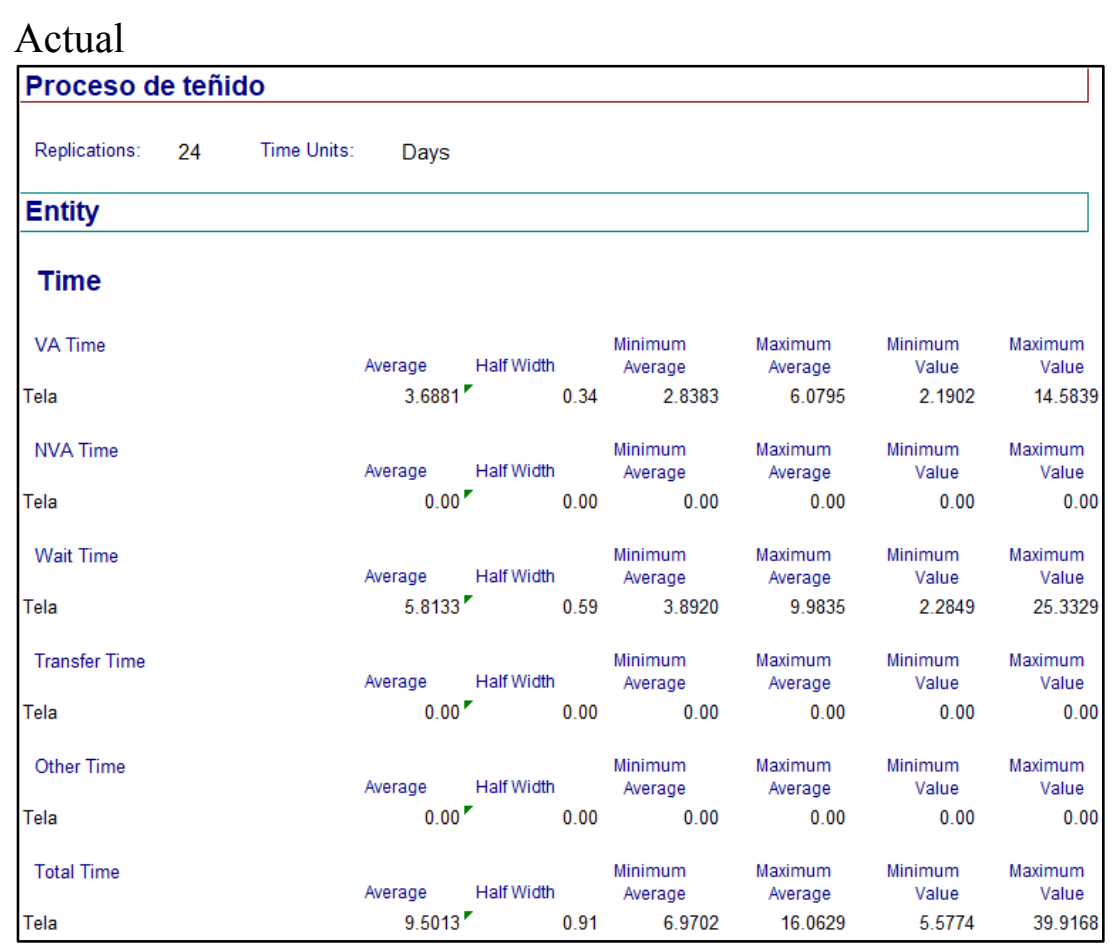

\begin{tabular}{|c|c|c|c|c|c|c|c|c|}
\hline \multicolumn{9}{|c|}{ Proceso de teñido } \\
\hline Replications: & 24 & Time Units: & Days & & & & & \\
\hline \multicolumn{9}{|l|}{ Entity } \\
\hline Time & & & & & & & & \\
\hline VA Time & & & Average & Half Width & $\begin{array}{c}\text { Minimum } \\
\text { Average }\end{array}$ & $\begin{array}{c}\text { Maximum } \\
\text { Average }\end{array}$ & $\begin{array}{c}\text { Minimum } \\
\text { Value }\end{array}$ & $\begin{array}{c}\text { Maximum } \\
\text { Value }\end{array}$ \\
\hline Tela & & & $2.6260^{\circ}$ & 0.18 & 2.0302 & 3.6715 & 1.6728 & 7.0955 \\
\hline NVA Time & & & Average & Half Width & $\begin{array}{c}\text { Minimum } \\
\text { Average }\end{array}$ & $\begin{array}{c}\text { Maximum } \\
\text { Average }\end{array}$ & $\begin{array}{c}\text { Minimum } \\
\text { Value }\end{array}$ & $\begin{array}{c}\text { Maximum } \\
\text { Value }\end{array}$ \\
\hline Tela & & & $0.00^{\prime}$ & 0.00 & 0.00 & 0.00 & 0.00 & 0.00 \\
\hline Wait Time & & & Average & Half Width & $\begin{array}{c}\text { Minimum } \\
\text { Average }\end{array}$ & $\begin{array}{c}\text { Maximum } \\
\text { Average }\end{array}$ & $\begin{array}{c}\text { Minimum } \\
\text { Value }\end{array}$ & $\begin{array}{c}\text { Maximum } \\
\text { Value }\end{array}$ \\
\hline Tela & & & $3.0939^{\prime}$ & 0.22 & 2.4547 & 4.2979 & 2.2954 & 8.5159 \\
\hline Transfer Time & & & Average & Half Width & $\begin{array}{c}\text { Minimum } \\
\text { Average }\end{array}$ & $\begin{array}{c}\text { Maximum } \\
\text { Average }\end{array}$ & $\begin{array}{c}\text { Minimum } \\
\text { Value }\end{array}$ & $\begin{array}{c}\text { Maximum } \\
\text { Value }\end{array}$ \\
\hline Tela & & & $0.00^{\prime \prime}$ & 0.00 & 0.00 & 0.00 & 0.00 & 0.00 \\
\hline Other Time & & & Average & Half Width & $\begin{array}{c}\text { Minimum } \\
\text { Average }\end{array}$ & $\begin{array}{l}\text { Maximum } \\
\text { Average }\end{array}$ & $\begin{array}{c}\text { Minimum } \\
\text { Value }\end{array}$ & $\begin{array}{c}\text { Maximum } \\
\text { Value }\end{array}$ \\
\hline Tela & & & $0.00^{\prime \prime}$ & 0.00 & 0.00 & 0.00 & 0.00 & 0.00 \\
\hline Total Time & & & Average & Half Width & $\begin{array}{c}\text { Minimum } \\
\text { Average }\end{array}$ & $\begin{array}{c}\text { Maximum } \\
\text { Average }\end{array}$ & $\begin{array}{c}\text { Minimum } \\
\text { Value }\end{array}$ & $\begin{array}{c}\text { Maximum } \\
\text { Value }\end{array}$ \\
\hline Tela & & & $5.7199^{\prime \prime}$ & 0.38 & 4.6533 & 7.4862 & 4.1746 & 15.2445 \\
\hline
\end{tabular}

Elaboración propia 
Los resultados provistos por la simulación se comparan con los que se han calculado bajo del acápite "Desarrollo de la propuesta", como se muestra a continuación:

Tabla 74: Comparación resultados de simulación vs. Cálculos de implementación

\begin{tabular}{|c|c|c|c|c|c|c|c|c|c|}
\hline \multirow[b]{2}{*}{ Resultados } & \multirow[b]{2}{*}{ Actual } & \multirow{2}{*}{\multicolumn{2}{|c|}{$\begin{array}{l}\text { SIMULACIÓN } \\
\text { Mejora }\end{array}$}} & \multirow[b]{2}{*}{ Actual } & \multicolumn{2}{|l|}{ CÁLCULOS } & \multicolumn{3}{|c|}{ DIFERENCIA } \\
\hline & & & & & Mejora & & Actual & Mejora & \\
\hline Proceso & 3.68806 & 2.62601 & días & 1.46035 & 1.12589 & días & 2.22771 & 1.50012 & días \\
\hline Tiempo de espera & 5.81326 & 3.09388 & días & 4.75000 & 2.55934 & días & 1.06326 & 0.53454 & días \\
\hline Total & 9.50132 & 5.71989 & días & 6.21035 & 3.68523 & días & 3.29097 & 2.03466 & días \\
\hline Variación & & 3.78143 & & & 2.52512 & & & 1.25631 & \\
\hline$\%$ Var & & $39.80 \%$ & & & $40.66 \%$ & & & $38.17 \%$ & \\
\hline Porcentajes & Actual & Mejora & Var\% & Actual & Mejora & Var\% & Actual & Mejora & Var\% \\
\hline Proceso & $38.82 \%$ & $45.91 \%$ & $7.09 \%$ & $23.51 \%$ & $30.55 \%$ & $7.04 \%$ & $67.69 \%$ & $73.73 \%$ & $6.04 \%$ \\
\hline Tiempo de espera & $61.18 \%$ & $54.09 \%$ & $-7.09 \%$ & $76.49 \%$ & $69.45 \%$ & $-7.04 \%$ & $32.31 \%$ & $26.27 \%$ & $-6.04 \%$ \\
\hline
\end{tabular}

Elaboración propia

En la tabla 76 se muestra que, la simulación muestra que el proceso actual es de 9.5 horas y la mejora de 5.71 horas, teniendo una variación de 3.78 horas con una mejora de $39.80 \%$, en cuanto lo que se ha calculado en el desarrollo de la propuesta de mejora, el promedio del proceso actual es de 6.21 horas y la mejora de 3.69 horas, habiendo una diferencia de 2.53 horas equivalente a una reducción de $40.66 \%$. Valor porcentual que sólo es mayor a $0.51 \%$ entre la simulación y los calculados, por lo que al considerar una confiabilidad del $95 \%$, el margen de error es de $\pm 5 \%$ y el valor de $39.80 \%$ se encuentra dentro del margen de error de los $40.66 \%$, por lo que se considera estadísticamente dentro del rango aceptable y se verifica que el proceso de mejora reduce los tiempos de producción del proceso de teñido relacionado directamente al incremento del nivel de cumplimiento de entregas a tiempo.

\subsection{Evaluación Financiera}

Para la validación financiera, se debe primero calcular el costo de oportunidad, para luego utilizarlo y calcular el valor actual neto (VAN) y la tasa interna de retorno (TIR).

Se presenta los escenarios esperado, el cual se calcula del flujo de caja con los valores calculados de inversión y ahorros, y para los escenarios pesimista y optimista se debe lograr valores aceptables de VAN y TIR. 


\subsubsection{Costo de Oportunidad}

Para calcular el costo de oportunidad (COK), se utilizará el método CAPM (Capital Asset Pricing Model), cuya fórmula es, de acuerdo a PromPerú:

$$
C A P M=R f+(\beta * R m)+R p a i ́ s
$$

En donde:

Rf: Tasa libre de riesgo

$\beta$ : $\quad$ Beta apalancada

Rm: Prima de riesgo

Rpaís: Riesgo país

La tasa libre de riesgo se toma el valor del bono del Tesoro Público de Estados Unidos a una madurez de 30 años al 23 de febrero de 2018, como se muestra a continuación:

Figura 57: Tasa libre de riesgo

\section{(8) U.S. DEPARTMENT OF THE TREASURY}

SECRETARY MNUCHIN ABOUt TREASURY POLICY ISSUES DATA SERVIIES NEWS

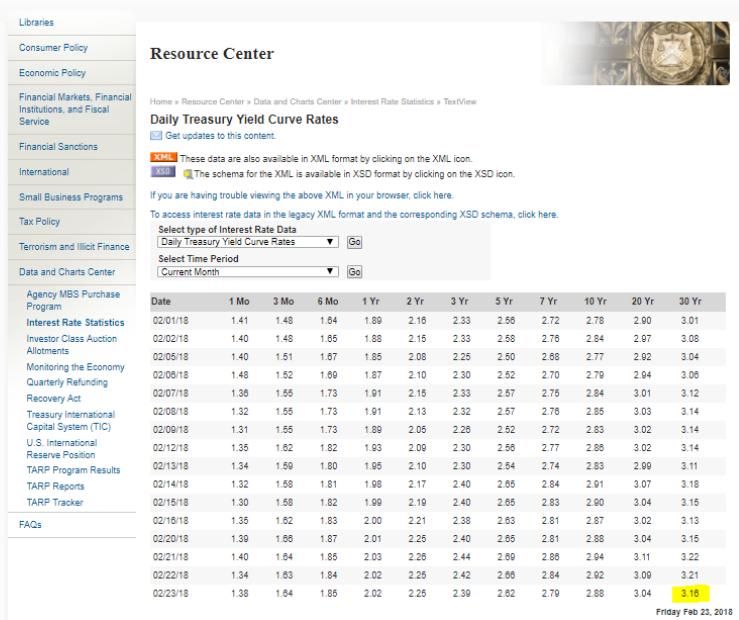

Fuente: https://www.treasury.gov/resource-center/data-chart-center/interest-rates/Pages/TextView.aspx?data=yieldYear\&year=2018

La beta apalancada se calcula de

$$
\beta=\beta \text { no apalancada } *\left(1+\left((1-T) *\left(\frac{D}{C}\right)\right)\right)
$$

En donde:

T Tasa de Renta Perú $=28 \%$

$\mathrm{D} / \mathrm{C} \quad$ Índice Deuda $/$ capital $=\mathrm{S} / 273,650.50 / 521,833.40=0.52$

La deuda es la inversión que se incurrirá para el proyecto y el capital que se considera es propio de la empresa. 
La beta no apalancada se ha tomado de la página de Damodaran para el mes de enero de 2018 de la industria de Ropa, ya que abarca la producción de la tela, es de 1.02, como se muestra a continuación:

Figura 58: Beta no apalancada

\begin{tabular}{|l|c|c|}
\hline Industry Name & Number of firms & Beta \\
\hline Advertising & 40 & 1.15 \\
\hline Aerospace/Defense & 87 & 1.08 \\
\hline Air Transport & 17 & 1.01 \\
\hline Apparel & 51 & 1.02 \\
\hline \hline
\end{tabular}

Fuente: http://pages.stern.nyu.edu/ adamodar/New_Home_Page/datafile/Betas.html

Por lo tanto,

$$
\beta=1.02 *(1+((1-28 \%) *(0.52)))=1.41
$$

La prima de riesgo, también se obtiene de la página web del Prof. Damodaran, para el país Perú de 1.23, como se muestra a continuación: 
Figura 59: Prima de Riesgo

\begin{tabular}{|c|c|c|c|c|}
\hline Pakistan & 278.91 & B3 & $6.67 \%$ & $12.58 \%$ \\
\hline Palestinian Authority & $\mathrm{NA}$ & $\mathrm{NA}$ & $1.43 \%$ & $6.69 \%$ \\
\hline Panama & 55.19 & Baa2 & $1.95 \%$ & $7.27 \%$ \\
\hline Papua New Guinea & 20.21 & B2 & $5.64 \%$ & $11.42 \%$ \\
\hline Paraguay & 27.42 & $\mathrm{Ba1}$ & $2.56 \%$ & $7.96 \%$ \\
\hline Peru & 192.21 & $\mathrm{~A} 3$ & $1.23 \%$ & $6.46 \%$ \\
\hline Philippines & 304.91 & Baa2 & $1.95 \%$ & $7.27 \%$ \\
\hline Poland & 471.36 & $\mathrm{~A} 2$ & $0.87 \%$ & $6.06 \%$ \\
\hline Portugal & 204.84 & $\mathrm{Bal}$ & $2.56 \%$ & $7.96 \%$ \\
\hline Qatar & 152.45 & $\mathrm{Aa} 3$ & $0.62 \%$ & $5.78 \%$ \\
\hline Ras Al Khaimah (Emirate of) & 5.20 & $\mathrm{~A} 2$ & $0.87 \%$ & $6.06 \%$ \\
\hline Reunion & $\mathrm{NA}$ & $\mathrm{NA}$ & $4.86 \%$ & $10.47 \%$ \\
\hline Romania & 187.59 & Baa3 & $2.26 \%$ & $7.62 \%$ \\
\hline
\end{tabular}

Fuente: http://pages.stern.nyu.edu/ adamodar/New_Home_Page/datafile/ctryprem.html

Y, por último, el valor de riesgo país de Perú al 23 de febrero de 2018, es de 1.14\%, como se muestra a continuación:

Figura 60: Riesgo país Perú

\begin{tabular}{|c|c|c|}
\hline FECHA & VALOR & VARIACION \\
\hline $23 / 02 / 2018$ & 114 & $2,70 \%$ \\
\hline $22 / 02 / 2018$ & 111 & $0,00 \%$ \\
\hline $21 / 02 / 2018$ & 111 & $0,91 \%$ \\
\hline $20 / 02 / 2018$ & 110 & $1,85 \%$ \\
\hline $16 / 02 / 2018$ & 108 & $-2,70 \%$ \\
\hline $15 / 02 / 2018$ & 111 & $-5,93 \%$ \\
\hline
\end{tabular}

Fuente: http://www.ambito.com/economia/mercados/riesgo-pais/info/?id=13

Por lo tanto, el Cálculo del COK es de $6.03 \%$, como se muestra a continuación:

Tabla 75: Cálculo del Costo de Oportunidad

\begin{tabular}{|c|c|c|c|}
\hline \multirow{3}{*}{$\mathrm{Rf}$} & \multicolumn{2}{|l|}{ Cálculo COK } & \multirow{2}{*}{$\begin{array}{l}\text { Fuente } \\
\text { Us Treasury Bond }\end{array}$} \\
\hline & Tasa libre de riesgo & $3.16 \%$ & \\
\hline & Beta no apalancada & 1.02 & Textil \\
\hline$\beta$ & Beta apalancada & 1.41 & Cálculo \\
\hline$T$ & Tasa de Renta Perú & $28 \%$ & Tasa de Renta Perú \\
\hline $\mathrm{D} / \mathrm{C}$ & Deuda y capital & 0.52 & \\
\hline $\mathrm{Rm}$ & Prima de riesgo & $1.23 \%$ & Perú \\
\hline Rpaís & Riesgo país & $1.14 \%$ & Ambito.Com \\
\hline & CAPM & $6.03 \%$ & \\
\hline
\end{tabular}

Elaboración propia

El COK, se utiliza para el flujo de caja y poder calcular el VAN y TIR. 


\subsubsection{Escenarios}

El primer escenario es el esperado, ya que se consideran los valores que se han calculado en el desarrollo de la propuesta, como la inversión de S/273,651 y los ahorros por un total de $\mathrm{S} / 528,415.22$. Estos ahorros no pueden considerarse como anuales ya que si se toma esta opción, los valores de VAN y TIR son mayores al $80 \%$, por lo que no es real para el mercado peruano. Por lo tanto, se considerará que dichos ahorros se generarán por un periodo de 5 años, con una depreciación anual de $\mathrm{S} / 8,316$ y el impuesto a la renta del $28 \%$, como se muestra a continuación:

Tabla 76: Escenario: Esperado

\begin{tabular}{|c|c|c|c|c|c|c|}
\hline ESPERADO & & & & & & \\
\hline \multicolumn{7}{|l|}{$\underline{\text { Supuestos }}$} \\
\hline Depreciación & $100 \%$ & $20 \%$ & $20 \%$ & $20 \%$ & $20 \%$ & $20 \%$ \\
\hline Impuesto (T) & $28 \%$ & & & & & \\
\hline \multirow[t]{2}{*}{ Costo de Oportunidad del Capital (COK) } & $6.03 \%$ & & & & & \\
\hline & 0 & 1 & 2 & 3 & 4 & 5 \\
\hline Ventas & & $\mathrm{S} / .105,683$ & $S / .105,683$ & $\mathrm{~S} / .105,683$ & $\mathrm{~S} / .105,683$ & $\mathrm{~S} / .105,683$ \\
\hline \multicolumn{7}{|l|}{ (-) Costos } \\
\hline \multicolumn{7}{|l|}{ (-) Gastos } \\
\hline ( - ) Depreciación & & $-5 / .8,316$ & $-5 / .8,316$ & $-S / .8,316$ & $-5 / .8,316$ & $-\mathrm{S} / .8,316$ \\
\hline$(=)$ UAll = EBIT & & $S / .97,367$ & $\mathrm{~S} / .97,367$ & $S / .97,367$ & $\mathrm{~S} / .97,367$ & $S / .97,367$ \\
\hline (-) Impuestos & & $-S / .27,263$ & $-S / .27,263$ & $-S / .27,263$ & $-S / .27,263$ & $-S / .27,263$ \\
\hline (+) Depreciación & & $\mathrm{S} / 8,316$ & $\mathrm{~S} / .8,316$ & $\mathrm{~S} / 8,316$ & $\mathrm{~S} / .8,316$ & $\mathrm{~S} / .8,316$ \\
\hline Flujo Económico de Operación (FEO) & & $\mathrm{S} / .78,420$ & $\mathrm{~S} / .78,420$ & $S / .78,420$ & $\mathrm{~S} / .78,420$ & $S / .78,420$ \\
\hline Gastos netos de capital & $-S / .273,651$ & & & & & \\
\hline Flujo de Caja de Libre Disponibilidad (FCLD) & $-S / .273,651$ & $S / .78,420$ & $S / .78,420$ & $S / .78,420$ & $S / .78,420$ & $S / .78,420$ \\
\hline VAN & $S / .56,430$ & & & & & \\
\hline TIR & $13.32 \%$ & & & & & \\
\hline
\end{tabular}

Elaboración propia

Bajo estos supuestos, se calcula un VAN de S/56,430 y una TIR de $13.32 \%$, lo cual indica que el proyecto es factible ya que el VAN $>0$ y $\mathrm{TIR}>\mathrm{COK}$.

Para el segundo escenario, Pesimista, se debe llevar al límite al TIR, lo más cercano al valor del COK, pero mayor para que se obtenga un VAN mayor que cero. Para esto se utiliza la función de Excel, llamado Goal Seek, en donde la TIR se debe ser igual a 6.04\%, por lo que los ahorros equivalen al $82.41 \%$ de los calculados $(\mathrm{S} / 528,415.22 * 82.41 \%=$ $\mathrm{S} / 435,460.01$, por lo que por año es un monto de $\mathrm{S} / 87,092$ ). 
Tabla 77: Escenario Pesimista: Suposición de la TIR $=6.04 \%$

\begin{tabular}{|l|r|l|r|}
\hline & $82.41 \%$ & & \\
\hline Función & & & \\
\hline Data & Goal Seek & TIR & $6.040 \%$ \\
\hline
\end{tabular}

Elaboración propia

Por lo tanto, el flujo de caja, da como resultado un VAN $=\mathrm{S} / 88$ mayor que cero y la TIR $>\mathrm{COK}$.

Tabla 78: Escenario Pesimista

\begin{tabular}{|c|c|c|c|c|c|c|}
\hline \multicolumn{7}{|l|}{ PESIMISTA } \\
\hline \multicolumn{7}{|l|}{ Supuestos } \\
\hline Depreciación & $100 \%$ & $20 \%$ & $20 \%$ & $20 \%$ & $20 \%$ & $20 \%$ \\
\hline Impuesto (T) & $28 \%$ & & & & & \\
\hline \multirow[t]{2}{*}{ Costo de Oportunidad del Capital (СОК) } & $6.03 \%$ & & & & & \\
\hline & 0 & 1 & 2 & 3 & 4 & 5 \\
\hline Ventas & & $\mathrm{s} / .87,092$ & $\mathrm{~s} / .87,092$ & $\mathrm{~s} / .87,092$ & $\mathrm{~S} / .87,092$ & $\mathrm{~s} / .87,092$ \\
\hline \multicolumn{7}{|l|}{$(-)$ Costos } \\
\hline \multicolumn{7}{|l|}{$(-)$ Gastos } \\
\hline (-) Depreciación & & $-S / .8,316$ & $-S / .8,316$ & $-S / .8,316$ & $-5 / .8,316$ & $-S / .8,316$ \\
\hline$\Leftrightarrow=)$ UAII = EBIT & & $\mathrm{S} / .78,776$ & $\mathrm{~s} / .78,776$ & $\mathrm{~s} / .78,776$ & $\mathrm{~s} / .78,776$ & $\mathrm{~s} / .78,776$ \\
\hline (-) Impuestos & & $-S / .22,057$ & $-S / .22,057$ & $-5 / .22,057$ & $-5 / .22,057$ & $-S / .22,057$ \\
\hline (+) Depreciación & & $\mathrm{s} / .8,316$ & $\mathrm{~s} / .8,316$ & $\mathrm{~s} / .8,316$ & $\mathrm{~s} / .8,316$ & $\mathrm{~s} / .8,316$ \\
\hline Flujo Económico de Operación (FEO) & & $s / .65,035$ & $s / .65,035$ & $s / .65,035$ & $5 / .65,035$ & $s / .65,035$ \\
\hline Gastos netos de capital & $-S / .273,651$ & & & & & \\
\hline Flujo de Caja de Libre Disponibilidad (FCLD) & $-S / .273,651$ & $s / .65,035$ & $s / .65,035$ & $s / .65,035$ & $S / .65,035$ & $s / .65,035$ \\
\hline VAN & $\mathrm{s} / .88$ & & & & & \\
\hline TIR & $6.04 \%$ & & & & & \\
\hline
\end{tabular}

Elaboración propia

Y, por último, para el tercer escenario, optimista, se realiza el mismo procedimiento, pero asumiendo una TIR de $22 \%$, lo que incrementará los ahorros en un $123 \%$, equivalente a un total de $\mathrm{S} / 647,343.59$, siendo un ahorro de $\mathrm{S} / 129,469$ anual.

Tabla 79: Escenario Optimista: Suposición de la TIR $=22 \%$

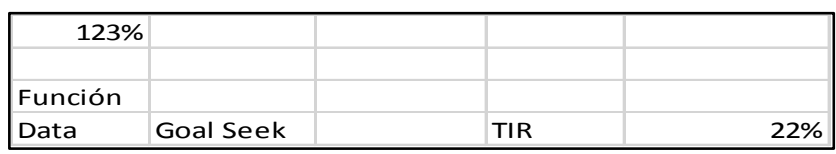

Elaboración propia

Por lo tanto, se valida que el VAN $>0$ y la TIR $>$ COK, como se muestra a continuación. 
Tabla 82: Escenario Optimista

\begin{tabular}{|c|c|c|c|c|c|c|}
\hline \multicolumn{7}{|l|}{ OPTIMISTA } \\
\hline \multicolumn{7}{|l|}{ Supuestos } \\
\hline Depreciación & $100 \%$ & $20 \%$ & $20 \%$ & $20 \%$ & $20 \%$ & $20 \%$ \\
\hline Impuesto (T) & $28 \%$ & & & & & \\
\hline \multirow[t]{2}{*}{ Costo de Oportunidad del Capital (СOK) } & $6.03 \%$ & & & & & \\
\hline & 0 & 1 & 2 & 3 & 4 & 5 \\
\hline Ventas & & $\mathrm{S} / .129,469$ & $\mathrm{~S} / .129,469$ & $\mathrm{~S} / .129,469$ & $S / .129,469$ & $\mathrm{~S} / .129,469$ \\
\hline \multicolumn{7}{|l|}{ (-) Costos } \\
\hline \multicolumn{7}{|l|}{ ( - ) Gastos } \\
\hline (-) Depreciación & & $-S / .8,316$ & $-\mathrm{S} / .8,316$ & $-\mathrm{S} / .8,316$ & $-S / .8,316$ & $-\mathrm{S} / .8,316$ \\
\hline ( = ) UAll = EBIT & & $\mathrm{S} / .121,153$ & $\mathrm{~S} / .121,153$ & $\mathrm{~S} / .121,153$ & $\mathrm{~S} / .121,153$ & $\mathrm{~S} / .121,153$ \\
\hline (-) Impuestos & & $-S / .33,923$ & $-\mathrm{S} / .33,923$ & $-\mathrm{S} / .33,923$ & $-S / .33,923$ & $-S / .33,923$ \\
\hline (+) Depreciación & & $\mathrm{s} / .8,316$ & $\mathrm{~S} / .8,316$ & $\mathrm{~s} / .8,316$ & $\mathrm{~s} / 8,316$ & $\mathrm{~S} / .8,316$ \\
\hline Flujo Económico de Operación (FEO) & & $\mathrm{S} / .95,546$ & $S / .95,546$ & $\mathrm{~S} / .95,546$ & $\mathrm{~S} / .95,546$ & S/.95,546 \\
\hline Gastos netos de capital & $-S / .273,651$ & & & & & \\
\hline Flujo de Caja de Libre Disponibilidad (FCLD) & $-S / .273,651$ & $\mathrm{~s} / .95,546$ & $S / .95,546$ & $\mathrm{~S} / .95,546$ & $S / .95,546$ & $S / .95,546$ \\
\hline VAN & $S / .128,514$ & & & & & \\
\hline TIR & $22.0 \%$ & & & & & \\
\hline
\end{tabular}

Elaboración propia

Por lo tanto se concluye, que la inversión del proyecto es factible al obtener un retorno de $11.96 \%$, mayor que el COK de $6.03 \%$. 


\section{CAPÍTULO V: CONCLUSIONES Y RECOMENDACIONES}

\subsection{Conclusiones}

- Con la implementación de SMED y VSM se ha reducido el tiempo del proceso de teñido de 6.21 a 3.69 días, disminuyendo el tiempo de espera de 4.75 a 2.56 días.

- Se concluye que la propuesta de mejora reduce la utilización del servidor de $82.54 \%$ a $48.97 \%$, lo que indica que el $48.97 \%$ de todas las bobinas que ingresan al proceso de teñido sólo tienen colas.

- Se concluye que al aplicar las herramientas de SMED y VSM, además del ordenamiento FIFO de la llegada de las porta bobinas, se eliminan los cuellos de botella y se reducen la permanencia en cola.

- La implementación de estas herramientas genera ahorros de S/528,415.22 y reduce el impacto económico (pérdidas) de S/603,666.13 a S/75,250.91

- La implementación de las herramientas de Lean Manufacturing para la mejora continua del proceso de teñido y la herramienta de gestión del proceso MRPII, incrementa el nivel de cumplimiento de entrega a tiempo de $66.76 \%$ a $94.05 \%$

- Al programar la producción con la herramienta MRPII, se observa que el proceso de mejora se encuentra dentro de la capacidad mensual de la máquina, sin tener que pasar la programación de las bobinas que no han pasado por el proceso de teñido del mes anterior al siguiente mes. Se cumple la demanda mensual y a tiempo.

- La validación de la simulación del proceso actual y de mejora confirma que los tiempos de espera y del propio proceso se encuentran dentro del margen de error de $\pm 5 \%$, siendo la variación porcentual entre el proceso actual y mejora de $39.80 \%$ para la simulación en Arena y el 40.66\% para los cálculos hallados. 


\subsection{Recomendaciones}

- Se recomienda la implementación de las herramientas como SMED y VSM, para los procesos de preparado y acabados.

- Se recomienda el uso de análisis de colas para los diferentes procesos, así como para cada máquina.

- Se recomienda la implementación del MRPII programados de manera diaria y no mensual, de esta manera los participantes tendrían la información real de inmediato y podrían realizar modificaciones en el proceso para corregir cualquier incremento de desperdicios en el proceso.

- Se recomienda que la empresa mida todos los procesos de manera diaria para lograr datos históricos y poder realizar un mejor análisis de la demanda, producción y reducción de tiempos. 


\section{BIBLIOGRAFIA}

Abdulmalek, F. A., \& Rajgopal, J. (2007). Analyzing the benefits of lean manufacturing and value stream mapping via simulation: A process sector case study. International Journal of production economics, 107(1), 223-236. https://www.sciencedirect.com/science/article/pii/S0925527306002258

Akbari, M., Gheysari, M., Mostafazadeh-Fard, B., \& Shayannejad, M. (2018). Surface irrigation simulation-optimization model based on meta-heuristic algorithms. Agricultural Water Management, 201, 46-57. https://www.sciencedirect.com/science/article/pii/S0378377418300593

Akdogan, M. A., Bayındır, Z. P., \& Iyigun, C. (2017). Location analysis of emergency vehicles using an approximate queueing model. Transportation research procedia, 22, 430-439. https://www.sciencedirect.com/science/article/pii/S2352146517301539

ALONSO, Carlos (2014). Orientaciones para Implementar una Gestión basada en Procesos. En: Ingeniería Industrial (Consulta: Julio de 2017) (http://web.b.ebscohost.com/ehost/pdfviewer/pdfviewer?vid=2\&sid=d7189fcf-0b244e2e-aea9-a7d5e96a81f8\%40sessionmgr101)

Arena Simulation (2018). What Is Simulation Software? https://www.arenasimulation.com/what-is-simulation

BLANCO, Ernesto (2012). Cuadro de mando integral los factores organizacionales también cuentan. En: Debates IESA (Consulta: Julio de 2017) (http://web.b.ebscohost.com/ehost/pdfviewer/pdfviewer?vid=4\&sid=206da966c57b4250-89d0-19d3e5de0c41\%40sessionmgr103)

Botti, L., Mora, C., \& Regattieri, A. (2017). Integrating ergonomics and lean manufacturing principles in a hybrid assembly line. Computers \& Industrial Engineering, 111, 481-491. https://www.sciencedirect.com/science/article/pii/S0360835217302152

Boucher, J. P., \& Couture-Piché, G. (2015). Modeling the number of insureds' cars using queuing theory. Insurance: Mathematics and Economics, 64, 67-76. https://www.sciencedirect.com/science/article/pii/S0167668715000712

CERVERA, H. M., HERRERA, T. F., \& De La Hoz Granadillo, E. (2011). Análisis comparativo entre las cadenas productivas del sector textil-confecciones de la provincia de Jiangsu-China y el departamento del Atlántico-Colombia. En: INGENIARE - Revista Chilena De Ingeniería, 19(3), 429-441. (Consulta: Julio de 2017) (http://web.a.ebscohost.com/ehost/pdfviewer/pdfviewer?vid=2\&sid=cf252ecac1 6b-42f5-a6a4-f4e482a599bd\%40sessionmgr4007) 
CORBIN, Thomas; Moore Larry y Walsh Leonard (2012). Visual workplace practices positively impact business processes. En: Benchmarking (Consulta: Julio de 2017) (https://search.proquest.com/docview/1018109544/fulltextPDF/E5F80AB7B5E94880P $\mathrm{Q} / 1$ ? accountid=43860)

D’Antonio, G., Bedolla, J. S., \& Chiabert, P. (2017). A Novel Methodology to Integrate Manufacturing Execution Systems with the Lean Manufacturing Approach. Procedia Manufacturing, 11, 2243-2251. https://www.sciencedirect.com/science/article/pii/S2351978917305802

DeCarolis, J. F., Babaee, S., Li, B., \& Kanungo, S. (2016). Modelling to generate alternatives with an energy system optimization model. Environmental Modelling \& Software, 79, $300-310$. https://www.sciencedirect.com/science/article/pii/S1364815215301080

DIRECCIÓN GENERAL DE ESTUDIOS ECONÓMICOS, EVALUACIÓN Y COMPETITIVIDAD TERRITORIAL DEL VICEMINISTERIO DE MYPE E INDUSTRIA. MINISTERIO DE LA PRODUCCIÓN (2017). Las Mipyme en Cifras 2014. En: Portal DEMI (Consulta: Julio de 2017) (http://demi.produce.gob.pe/publicacionDetalle?idp=543)

Godinho Filho, M. (2017). Complementing lean with quick response manufacturing: case studies. The International Journal of Advanced Manufacturing Technology, 90(5-8), 1897-1910. https://link.springer.com/article/10.1007/s00170-016-9513-4

Goyal, A., \& Agrawal, R. (2017). Advanced Manufacturing Management System for Environmental Sustainability. 496-504 06.pdf http://strategiesinemergingmarkets.com/proceedings/T4/Paper\%2055,\%20OP17

INSTITUTO DE ESTUDIOS ECONÓMICOS Y SOCIALES DE LA SOCIEDAD NACIONAL DE INDUSTRIAS (2016). Reporte Sectorial. (Consulta: Julio de 2017) (http://www.sni.org.pe/wpcontent/uploads/2017/01/Noviembre-2016-Industriade-productos-textiles.pdf)

Jablonsky, J. (2014). MS Excel based software support tools for decision problems with multiple criteria. Procedia Economics and Finance, 12, 251-258. https://www.sciencedirect.com/science/article/pii/S2212567114003426

JEVGENI, Sahno; EDUARD Shevtshenko y ROMAN Zahharov (2014) Framework for Continuous Improvement of Production Processes and Product Throughput. En: Annals of DAAAM \& Proceedings (Consulta: Julio de 2017) (http://web.b.ebscohost.com/ehost/detail/detail?vid=0\&sid=617fd04d-3ecf4921- 
8fc764f31256d52f\%40sessionmgr120\&bdata=Jmxhbmc9ZXM\%3d\#db=asn\&AN=1094 14429)

Jin, W. L. (2015). Point queue models: A unified approach. Transportation Research Part B: https://www.sciencedirect.com/science/article/pii/S0191261515000430

Kikolski, M. (2017). Study of production scenarios with the use of simulation models. Procedia Engineering, 182, 321-328. https://www.sciencedirect.com/science/article/pii/S1877705817312389

Kuhlang, P., Hempen, S., Edtmayr, T., Deuse, J., \& Sihn, W. (2013). Systematic and Continuous Improvement of Value Streams. IFAC Proceedings Volumes, 46(9), 993997. https://www.sciencedirect.com/science/article/pii/S1474667016344184

LESCANO, Yonny (2012). Proyecto de ley que modifica el régimen laboral del decreto ley 22342. En: Federación nacional de trabajadores textiles del Perú. (Consulta: Julio de 2017) (https://www.iesiperu.org.pe/)

LÓPEZ, María Isabel; LÓPEZ, Patricia (2014). Uso secuencial de herramientas de control de calidad en procesos productivos: una aplicación en el sector agroalimentario. En: PECVNIA (Consulta: Julio de 2017) (http://web.a.ebscohost.com/ehost/pdfviewer/pdfviewer?vid=13\&sid=3ca6f643493b4c47-ba85-59c83bd1e419\%40sessionmgr4010)

Luquini, E., \& Nizam, O. (2017). Rethinking exchange market models as optimization algorithms. Physica A: Statistical Mechanics and its Applications. https://www.sciencedirect.com/science/article/pii/S0378437117308634

Lv, L., Ren, F. Y., Wang, J., \& Xiao, J. (2015). Correlated continuous time random walk with time averaged waiting time. Physica A: Statistical Mechanics and its Applications, 422, 101-106. https://www.sciencedirect.com/science/article/pii/S0378437114010450

Meudt, T., Metternich, J., \& Abele, E. (2017). Value stream mapping 4.0: Holistic examination of value stream and information logistics in production. CIRP Annals, 66(1), 413-416. https://www.sciencedirect.com/science/article/pii/S0007850617300057

Miclo, R., Fontanili, F., Lauras, M., Lamothe, J., \& Milian, B. (2016). An empirical comparison of MRPII and Demand-Driven MRP. IFAC-PapersOnLine, 49(12), 17251730. https://www.sciencedirect.com/science/article/pii/S2405896316311144 
Ocampo, J. R., Hernández-Matías, J. C., \& Vizán, A. (2017). A method for estimating the influence of advanced manufacturing tools on the manufacturing competitiveness of Maquiladoras in the apparel industry in Central America. Computers in Industry, 87, 3151. https://www.sciencedirect.com/science/article/pii/S0166361517300428

Öztürk, C., \& Ornek, A. M. (2014). Operational extended model formulations for Advanced Planning and Scheduling systems. Applied Mathematical Modelling, 38(1), 181-195. https://www.sciencedirect.com/science/article/pii/S0307904X13003727

PADILLA, Ernesto (2013). Desarrollo de los aspectos metodológicos para la implementación de un sistema integrado de gestión en la industria textil y confecciones. En: Repositorio Digital de Tesis PUCP (Consulta: Julio de 2017) (http://tesis.pucp.edu.pe/repositorio/handle/123456789/1717)

Proudlove, N. C., Bisogno, S., Onggo, B. S. S., Calabrese, A., \& Ghiron, N. L. (2017). Towards fully-facilitated discrete event simulation modelling: Addressing the model coding stage. European Journal of Operational Research, 263(2), 583-595. https://www.sciencedirect.com/science/article/pii/S0377221717305209

PULIDO, Alexander, BOCANEGRA, Carlos (2015). Mitigation of defects in products manufactured. En: Ingeniería y Competitividad (Consulta: Julio de 2017) (http://web.a.ebscohost.com/ehost/pdfviewer/pdfviewer?vid=1\&sid=ef45d012-bd3048ae-b4e3-914a1fd73698\%40sessionmgr4008)

Rosa, C., Silva, F. J. G., Ferreira, L. P., \& Campilho, R. (2017). SMED methodology: The reduction of setup times for Steel Wire-Rope assembly lines in the automotive industry. Procedia Manufacturing, 13,

1034-1042. https://www.sciencedirect.com/science/article/pii/S235197891730745X

Santos, F., Nunes, I., \& Bazzan, A. L. (2017). Model-driven agent-based simulation development: A modeling language and empirical evaluation in the adaptive traffic signal control domain. Simulation Modelling Practice and Theory. https://www.sciencedirect.com/science/article/pii/S1569190X17301673

Sartal, A., Llach, J., Vázquez, X. H., \& de Castro, R. (2017). How much does Lean Manufacturing need environmental and information technologies. Journal of Manufacturing Systems, 45, $260-272$. https://www.sciencedirect.com/science/article/pii/S0278612517301395

Settanni, E., Harrington, T. S., \& Srai, J. S. (2017). Pharmaceutical supply chain models: A synthesis from a systems view of operations research. Operations Research Perspectives, 4, 74-95. https://www.sciencedirect.com/science/article/pii/S2214716016301105 
Sihn, W., \& Pfeffer, M. (2013). A method for a comprehensive value stream evaluation. CIRP Annals-Manufacturing Technology, 62(1), 427-430. https://www.sciencedirect.com/science/article/pii/S0007850613000437

SOCOLIUC, Marian; CARAMAN Stela, and GROSU, Veronica (2015). The BSC method used in achieving organisational strategic objectives. En: SEA Practical Application of Science (Consulta: Julio de 2017) (http://web.a.ebscohost.com/ehost/pdfviewer/pdfviewer?vid=2\&sid=653476e2cc7347bc-948d-55d0c8ee18c8\%40sessionmgr4008)

Tanaka, M., Yanagisawa, D., \& Nishinari, K. (2018). Exclusive queueing model including the choice of service windows. Physica A: Statistical Mechanics and its Applications, 490, 1481-1492. https://www.sciencedirect.com/science/article/pii/S0378437117308191

Zhang, W., Zhou, Y., \& Zhu, J. (2017). A comprehensive study of feature definitions with solids and voids for topology optimization. Computer Methods in Applied Mechanics and Engineering, 325, 289-313. https://www.sciencedirect.com/science/article/pii/S0045782517300695 


\section{Anexos}

Anexo 1: Muestra: 179 pedidos, equivalente a 252 bobinas

\begin{tabular}{|c|c|c|c|c|}
\hline muestra $r$ & mes & metros pedidos & Bobinas & Pedidos \\
\hline & 1 enero & 3000 & 2 & 1 \\
\hline & 2 enero & 2500 & 1 & 1 \\
\hline & 3 enero & 2500 & 1 & 1 \\
\hline & 4 enero & 2500 & 1 & 1 \\
\hline & 5 enero & 3000 & 2 & 1 \\
\hline & 5 enero & 3000 & 2 & 1 \\
\hline & 7 enero & 5000 & 2 & 1 \\
\hline & 3 febrero & 1238 & 1 & 1 \\
\hline & febrero & 2589 & 1 & 1 \\
\hline $10 \mathrm{f}$ & febrero & 4800 & 2 & 1 \\
\hline $11 \mathrm{f}$ & 1 febrero & 4500 & 2 & 1 \\
\hline $12 r$ & 2 marzo & 2000 & 1 & 1 \\
\hline $13 r$ & 3 marzo & 2000 & 1 & 1 \\
\hline $14 r$ & 4 marzo & 5000 & 2 & 1 \\
\hline $15 r$ & 5 marzo & 3000 & 2 & 1 \\
\hline $16 r$ & 5 marzo & 3000 & 2 & 1 \\
\hline $17 r$ & 7 marzo & 2000 & 1 & 1 \\
\hline $18 r$ & 8 marzo & 2500 & 1 & 1 \\
\hline $19 \mathrm{r}$ & 9 marzo & 2400 & 1 & 1 \\
\hline $20 \mathrm{r}$ & marzo & 1200 & 1 & 1 \\
\hline $21 r$ & 1 marzo & 1200 & 1 & 1 \\
\hline $22 r$ & 2 marzo & 1200 & 1 & 1 \\
\hline $23 r$ & 3 marzo & 1200 & 1 & 1 \\
\hline $24 r$ & 4 marzo & 6500 & 3 & 1 \\
\hline $25 \mathrm{r}$ & 5 marzo & 1300 & 1 & 1 \\
\hline $26 \mathrm{a}$ & 5 abril & 1300 & 1 & 1 \\
\hline $27 \mathrm{a}$ & 7 abril & 1300 & 1 & 1 \\
\hline $28 \mathrm{a}$ & 3 abril & 1300 & 1 & 1 \\
\hline $29 \mathrm{a}$ & 9 abril & 1000 & 1 & 1 \\
\hline $30 \mathrm{a}$ & abril & 1000 & 1 & 1 \\
\hline $31 \mathrm{a}$ & 1 abril & 650 & 1 & 1 \\
\hline $32 \mathrm{a}$ & 2 abril & 1201 & 1 & 1 \\
\hline $33 a$ & 3 abril & 1000 & 1 & 1 \\
\hline $34 a$ & 4 abril & 4000 & 2 & 1 \\
\hline $35 \mathrm{a}$ & 5 abril & 4000 & 2 & 1 \\
\hline $36 \mathrm{a}$ & 5 abril & 4000 & 2 & 1 \\
\hline $37 \mathrm{a}$ & 7 abril & 4000 & 2 & 1 \\
\hline $38 \mathrm{a}$ & 3 abril & 4000 & 2 & 1 \\
\hline 39 a & 9 abril & 3000 & 2 & 1 \\
\hline
\end{tabular}




\begin{tabular}{|c|c|c|c|}
\hline 40 abril & 3000 & 2 & 1 \\
\hline 41 abril & 3000 & 2 & 1 \\
\hline 42 abril & 3000 & 2 & 1 \\
\hline 43 mayo & 1200 & 1 & 1 \\
\hline 44 mayo & 1200 & 1 & 1 \\
\hline 45 mayo & 1200 & 1 & 1 \\
\hline 46 mayo & 1200 & 1 & 1 \\
\hline 47 mayo & 1200 & 1 & 1 \\
\hline 48 mayo & 1200 & 1 & 1 \\
\hline 49 mayo & 1300 & 1 & 1 \\
\hline 50 mayo & 1200 & 1 & 1 \\
\hline 51 mayo & 1200 & 1 & 1 \\
\hline 52 mayo & 1200 & 1 & 1 \\
\hline 53 mayo & 1300 & 1 & 1 \\
\hline 54 mayo & 1300 & 1 & 1 \\
\hline 55 mayo & 1300 & 1 & 1 \\
\hline 56 junio & 1200 & 1 & 1 \\
\hline 57 junio & 1200 & 1 & 1 \\
\hline 58 junio & 1200 & 1 & 1 \\
\hline 59 junio & 1200 & 1 & 1 \\
\hline 60 junio & 1200 & 1 & 1 \\
\hline 61 junio & 1200 & 1 & 1 \\
\hline 62 junio & 1200 & 1 & 1 \\
\hline 63 junio & 1200 & 1 & 1 \\
\hline 64 junio & 1200 & 1 & 1 \\
\hline 65 junio & 1300 & 1 & 1 \\
\hline 66 junio & 1300 & 1 & 1 \\
\hline 67 junio & 1300 & 1 & 1 \\
\hline 68 junio & 1300 & 1 & 1 \\
\hline 69 junio & 3500 & 2 & 1 \\
\hline 70 junio & 3500 & 2 & 1 \\
\hline 71 junio & 300 & 1 & 1 \\
\hline 72 junio & 500 & 1 & 1 \\
\hline 73 julio & 1200 & 1 & 1 \\
\hline 74 julio & 500 & 1 & 1 \\
\hline 75 julio & 900 & 1 & 1 \\
\hline 76 julio & 4019 & 2 & 1 \\
\hline 77 julio & 4029 & 2 & 1 \\
\hline 78 julio & 3764 & 2 & 1 \\
\hline 79 julio & 2500 & 1 & 1 \\
\hline 80 julio & 1600 & 1 & 1 \\
\hline
\end{tabular}




\begin{tabular}{|c|c|c|c|}
\hline 81 julio & 1500 & 1 & 1 \\
\hline 82 julio & 2118 & 1 & 1 \\
\hline 83 julio & 1712 & 1 & 1 \\
\hline 84 julio & 889 & 1 & 1 \\
\hline 85 julio & 1175 & 1 & 1 \\
\hline 86 julio & 1012 & 1 & 1 \\
\hline 87 julio & 2204 & 1 & 1 \\
\hline 88 julio & 1000 & 1 & 1 \\
\hline 89 julio & 1000 & 1 & 1 \\
\hline 90 julio & 366.5 & 1 & 1 \\
\hline 91 julio & 383.5 & 1 & 1 \\
\hline 92 agosto & 474 & 1 & 1 \\
\hline 93 agosto & 276 & 1 & 1 \\
\hline 94 agosto & 1060 & 1 & 1 \\
\hline 95 agosto & 600 & 1 & 1 \\
\hline 96 agosto & 750 & 1 & 1 \\
\hline 97 agosto & 750 & 1 & 1 \\
\hline 98 agosto & 750 & 1 & 1 \\
\hline 99 agosto & 870 & 1 & 1 \\
\hline 100 agosto & 350 & 1 & 1 \\
\hline 101 agosto & 350 & 1 & 1 \\
\hline 102 agosto & 6500 & 3 & 1 \\
\hline 103 agosto & 10410 & 4 & 1 \\
\hline 104 agosto & 750 & 1 & 1 \\
\hline 105 agosto & 1671 & 1 & 1 \\
\hline 106 agosto & 1171 & 1 & 1 \\
\hline 107 agosto & 2000 & 1 & 1 \\
\hline 108 agosto & 2000 & 1 & 1 \\
\hline 109 setiembre & 2000 & 1 & 1 \\
\hline 110 setiembre & 2000 & 1 & 1 \\
\hline 111 setiembre & 2000 & 1 & 1 \\
\hline 112 setiembre & 2000 & 1 & 1 \\
\hline 113 setiembre & 2000 & 1 & 1 \\
\hline 114 setiembre & 2000 & 1 & 1 \\
\hline 115 setiembre & 2000 & 1 & 1 \\
\hline 116 setiembre & 2000 & 1 & 1 \\
\hline 117 setiembre & 2000 & 1 & 1 \\
\hline 118 setiembre & 2000 & 1 & 1 \\
\hline 119 setiembre & 2000 & 1 & 1 \\
\hline 120 setiembre & 2000 & 1 & 1 \\
\hline
\end{tabular}




\begin{tabular}{|c|c|c|c|c|}
\hline 121 & setiembre & 2000 & 1 & 1 \\
\hline 122 & setiembre & 2000 & 1 & 1 \\
\hline 123 & setiembre & 2000 & 1 & 1 \\
\hline 124 & setiembre & 2000 & 1 & 1 \\
\hline 125 & setiembre & 2000 & 1 & 1 \\
\hline 126 & setiembre & 1500 & 1 & 1 \\
\hline 127 & setiembre & 500 & 1 & 1 \\
\hline 128 & setiembre & 500 & 1 & 1 \\
\hline 129 & setiembre & 1132 & 1 & 1 \\
\hline 130 & setiembre & 1182 & 1 & 1 \\
\hline 131 & setiembre & 500 & 1 & 1 \\
\hline 132 & octubre & 1172 & 1 & 1 \\
\hline 133 & octubre & 500 & 1 & 1 \\
\hline 134 & octubre & 4500 & 2 & 1 \\
\hline 135 & octubre & 8000 & 3 & 1 \\
\hline 136 & octubre & 15000 & 6 & 1 \\
\hline 137 & octubre & 4500 & 2 & 1 \\
\hline 138 & octubre & 250 & 1 & 1 \\
\hline 139 & octubre & 150 & 1 & 1 \\
\hline 140 & octubre & 250 & 1 & 1 \\
\hline 141 & octubre & 200 & 1 & 1 \\
\hline 142 & octubre & 200 & 1 & 1 \\
\hline 143 & octubre & 400 & 1 & 1 \\
\hline 144 & noviembre & 400 & 1 & 1 \\
\hline 145 & noviembre & 10000 & 4 & 1 \\
\hline 146 & noviembre & 3000 & 2 & 1 \\
\hline 147 & noviembre & 2661 & 1 & 1 \\
\hline 148 & noviembre & 2339 & 1 & 1 \\
\hline 149 & noviembre & 1270 & 1 & 1 \\
\hline 150 & noviembre & 5000 & 2 & 1 \\
\hline 151 & noviembre & 5000 & 2 & 1 \\
\hline 152 & noviembre & 5000 & 2 & 1 \\
\hline 153 & noviembre & 5000 & 2 & 1 \\
\hline 154 & noviembre & 2000 & 1 & 1 \\
\hline 155 & noviembre & 6000 & 3 & 1 \\
\hline 156 & noviembre & 1700 & 1 & 1 \\
\hline 157 & noviembre & 5000 & 2 & 1 \\
\hline 158 & noviembre & 5000 & 2 & 1 \\
\hline 159 & noviembre & 5000 & 2 & 1 \\
\hline 160 & diciembre & 5000 & 2 & 1 \\
\hline
\end{tabular}




\begin{tabular}{|r|r|r|r|}
\hline 161 diciembre & 2000 & 1 & 1 \\
\hline 162 diciembre & 6000 & 3 & 1 \\
\hline 163 diciembre & 1500 & 1 & 1 \\
\hline 164 diciembre & 6000 & 3 & 1 \\
\hline 165 diciembre & 6000 & 3 & 1 \\
\hline 166 diciembre & 6000 & 3 & 1 \\
\hline 167 diciembre & 6000 & 3 & 1 \\
\hline 168 diciembre & 3500 & 2 & 1 \\
\hline 169 diciembre & 6000 & 3 & 1 \\
\hline 170 diciembre & 6000 & 3 & 1 \\
\hline 171 diciembre & 750 & 1 & 1 \\
\hline 172 diciembre & 3800 & 2 & 1 \\
\hline 173 diciembre & 1220 & 1 & 1 \\
\hline 174 diciembre & 3500 & 2 & 1 \\
\hline 175 diciembre & 3500 & 2 & 1 \\
\hline 176 diciembre & 2500 & 1 & 1 \\
\hline 177 diciembre & 2500 & 1 & 1 \\
\hline 178 diciembre & 3500 & 2 & 1 \\
\hline 179 diciembre & 5000 & 2 & 1 \\
\hline
\end{tabular}




\section{Anexo 2: Tiempos registrados por la empresa de la muestra de 252 observaciones}

\begin{tabular}{|c|c|c|c|c|c|c|c|c|c|c|c|c|c|c|c|c|c|c|c|c|c|c|c|c|c|c|c|c|}
\hline \multicolumn{29}{|l|}{ Tiempos por procesos de bobina } \\
\hline Actividad & Días & Cola & & 1 & 2 & 3 & 4 & 5 & 6 & 7 & 8 & 9 & 10 & 11 & 12 & 13 & 14 & 15 & 16 & 17 & 18 & 19 & 20 & 21 & 22 & 23 & 24 & 25 \\
\hline Bobina de tela en espera de ten̂́ido & & & 2.00 & 1.09 & 1.77 & 1.28 & 1.88 & 1.31 & 2.80 & 1.75 & 1.90 & 0.66 & 1.17 & 0.73 & 0.93 & 2.27 & 1.45 & 1.22 & 2.39 & 2.79 & 2.69 & 0.92 & 1.52 & 2.48 & 1.03 & 1.52 & 1.31 & 2.90 \\
\hline Fếido frío & & -1.88 & 0.12 & 14 & 0.18 & 0.07 & 0.10 & 0.12 & 0.09 & 0.06 & 0.12 & 0.09 & 0.11 & 0.18 & 0.12 & 0.15 & 0.16 & 0.09 & 0.07 & 0.10 & 0.14 & 0.15 & 0.13 & 0.12 & 0.13 & 0.07 & 0.17 & 0.06 \\
\hline raslado de bobina para reposo & & -0.11 & 0.01 & 02 & 0.01 & 0.02 & 0.01 & 0.00 & 0.01 & 0.01 & 0.01 & 0.02 & 0.01 & 0.01 & 0.00 & 0.00 & 0.01 & 0.01 & 0.01 & 0.00 & 0.00 & 0.01 & 0.01 & 0.02 & 0.00 & 0.01 & 0.00 & 0.02 \\
\hline Reposo & & 1.44 & 1.45 & 54 & 1.55 & 1.58 & 1.79 & 1.77 & 1.72 & 1.55 & 1.11 & 1.34 & 1.72 & 1.84 & 1.55 & 1.62 & 1.09 & 1.62 & 1.54 & 1.00 & 1.67 & 1.06 & 1.61 & 1.75 & 1.02 & 1.42 & 1.42 & 1.71 \\
\hline Bobina de tela en espera de lavado de teñido & & -1.20 & 0.2 & 29 & 0.17 & 0.23 & 0.24 & 0.29 & 0.26 & 0.20 & 0.33 & 0.15 & 0.22 & 0.22 & 0.28 & 0.15 & 0.32 & 0.28 & 0.32 & 0.30 & 0.25 & 0.35 & 0.16 & 0.33 & 0.18 & 0.34 & 0.34 & 0.25 \\
\hline Traslado de bobina para lavado teñido & & -0.24 & 0.01 & 01 & 0.01 & 0.01 & 0.01 & 0.01 & 0.01 & 0.01 & 0.01 & 0.02 & 0.02 & 0.01 & 0.01 & 0.01 & 0.01 & 0.01 & 0.01 & 0.02 & 0.01 & 0.02 & 0.01 & 0.01 & 0.01 & 0.01 & 0.01 & 0.01 \\
\hline Lavado teñido & & 0.11 & 0.12 & 0.16 & 0.12 & 0.15 & 0.10 & 0.13 & 0.12 & 0.12 & 0.11 & 0.09 & 0.08 & 15 & 0.16 & 0. & 0.14 & 12 & 0.16 & 10 & 0.11 & 0.11 & 11 & 15 & 16 & 0.10 & 12 & 0.08 \\
\hline Traslado de bobina para secado & & -0.11 & 0.01 & 0.01 & 0.01 & 0.01 & 0.01 & 0.01 & 0.01 & 0.01 & 0.01 & 0.00 & 0.01 & 0.02 & 0.01 & 0.02 & 0.01 & 0.01 & 0.01 & 0.02 & 0.01 & 0.01 & 0.01 & 0.01 & .01 & 0.01 & 02 & 0.02 \\
\hline Secado & & 0.09 & 0.10 & 06 & 0.13 & 0.14 & 0.04 & 0.06 & 0.05 & 0.14 & 0.11 & 0.11 & 0.07 & 0.08 & 0.07 & 0.09 & 0.05 & 0.14 & 0.12 & 0.13 & 0.16 & 0.09 & 0.07 & 0.13 & 0.10 & 0.08 & 13 & 0.05 \\
\hline Traslado de bobina para revisión & & -0.09 & 0.01 & 0.01 & 0.01 & 0.01 & 0.01 & 0.01 & 0.01 & 0.01 & 0.01 & 0.01 & 0.01 & 0.01 & 0.01 & 0.01 & 0.01 & 0.01 & 0.01 & 0.01 & 0.01 & 0.01 & 0.01 & 0.01 & 0.01 & 0.01 & 0.01 & 0.01 \\
\hline Bobina en espera para revisión & & 0.77 & 0.78 & 0.55 & 0.77 & 1.06 & 0.95 & 0.98 & 0.97 & 0.68 & 1.02 & 0.83 & 0.63 & 0.69 & 0.60 & 0.49 & 0.68 & 0.89 & 0.46 & 0.48 & 0.97 & 0.75 & 0.80 & 0.57 & 00 & 0.86 & 03 & 0.80 \\
\hline Revisión de tela ten̂́ida & & 0.17 & 0.95 & 1.19 & 1.22 & 1.16 & 1.11 & 0.98 & 1.21 & 1.09 & 0.85 & 0.87 & 0.82 & 0.80 & 1.20 & 1.07 & 1.07 & 1.09 & 0.94 & 0.70 & 0.76 & 0.71 & 1.03 & 0.80 & 1.21 & 0.71 & 0.88 & 1.02 \\
\hline Traslado de bobina para impregn & & -0.94 & 0.01 & 0.01 & 0.01 & 0.01 & 0.01 & 0.01 & 0.01 & 0.01 & 0.01 & 0.01 & 0.01 & 0.01 & 0.01 & 0.01 & 0.01 & 0.01 & 0.01 & 0.01 & 0.01 & 0.01 & 0.01 & 0.01 & 0.01 & 0.01 & 0.01 & 0.01 \\
\hline rotal por proceso & & & 5.83 & $5.19^{\prime}$ & $5.97^{\prime}$ & $5.73^{\prime}$ & $6.26^{\prime \prime}$ & 5.68 & $7.25^{\circ}$ & $5.63^{\prime}$ & $5.59^{\prime}$ & $4.20^{\prime \prime}$ & $4.89^{\prime}$ & $4.75^{\prime}$ & $4.93^{\prime}$ & $6.02^{\prime}$ & $5.01^{\prime}$ & $5.50^{\prime}$ & $6.04^{\prime}$ & 5.65 & 6.80 & $4.18^{\prime}$ & $5.48^{\prime}$ & & & $5.13^{\prime \prime}$ & 5.44 & 6.94 \\
\hline
\end{tabular}

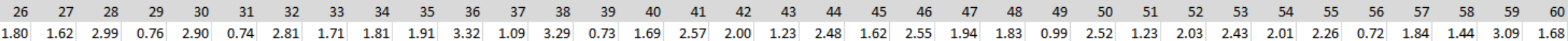
$\begin{array}{lllllllllllllllllllllllllllllllllll}0.06 & 0.18 & 0.16 & 0.09 & 0.06 & 0.15 & 0.11 & 0.14 & 0.07 & 0.18 & 0.06 & 0.09 & 0.17 & 0.06 & 0.09 & 0.09 & 0.17 & 0.11 & 0.08 & 0.14 & 0.09 & 0.06 & 0.15 & 0.08 & 0.18 & 0.15 & 0.14 & 0.18 & 0.07 & 0.08 & 0.10 & 0.15 & 0.13 & 0.07 & 0.17\end{array}$

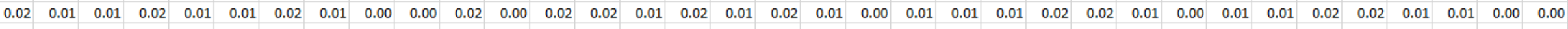

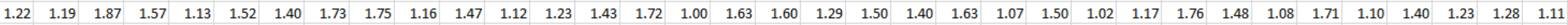

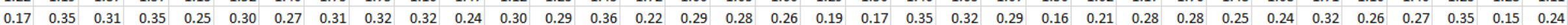

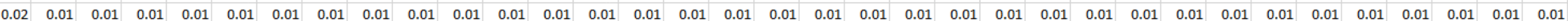

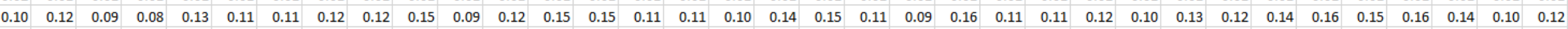

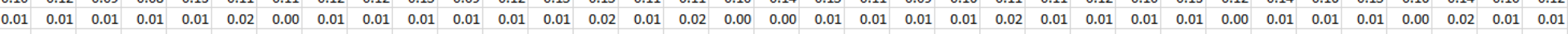

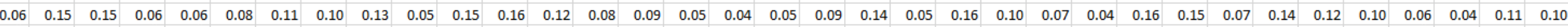
$\begin{array}{lllllllllllllllllllllllllllllllllll}0.01 & 0.01 & 0.01 & 0.01 & 0.01 & 0.01 & 0.01 & 0.01 & 0.01 & 0.01 & 0.01 & 0.01 & 0.01 & 0.01 & 0.01 & 0.01 & 0.01 & 0.01 & 0.01 & 0.01 & 0.01 & 0.01 & 0.01 & 0.01 & 0.01 & 0.01 & 0.01 & 0.01 & 0.01 & 0.01 & 0.01 & 0.01 & 0.01 & 0.01 & 0.01\end{array}$

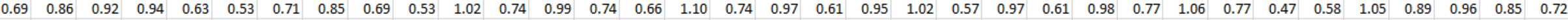

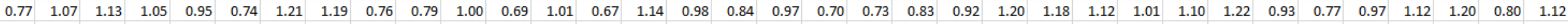

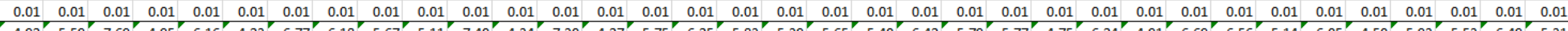


$\begin{array}{lllllllllllllllllllllllllllllllllllll}61 & 62 & 63 & 64 & 65 & 66 & 67 & 68 & 69 & 70 & 71 & 72 & 73 & 74 & 75 & 76 & 77 & 78 & 79 & 80 & 81 & 82 & 83 & 84 & 85 & 86 & 87 & 88 & 89 & 90 & 91 & 92 & 93 & 94 & 95\end{array}$

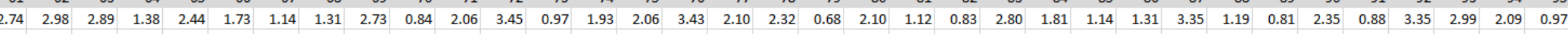

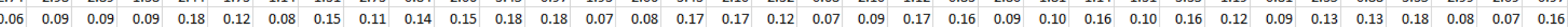

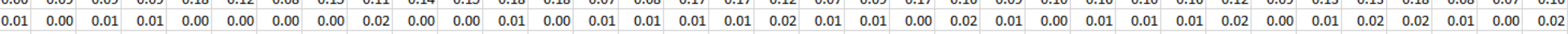

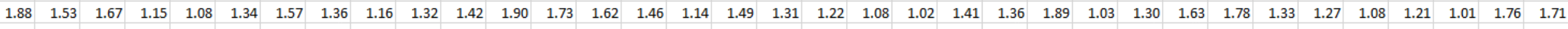
$\begin{array}{lllllllllllllllllllllllllllllllllll}0.16 & 0.34 & 0.34 & 0.35 & 0.30 & 0.29 & 0.20 & 0.27 & 0.23 & 0.16 & 0.34 & 0.28 & 0.14 & 0.26 & 0.16 & 0.15 & 0.26 & 0.35 & 0.32 & 0.28 & 0.33 & 0.31 & 0.30 & 0.23 & 0.27 & 0.29 & 0.26 & 0.21 & 0.16 & 0.35 & 0.31 & 0.19 & 0.24 & 0.26 & 0.26\end{array}$ $\begin{array}{llllllllllllllllllllllllllllllllllllll}0.01 & 0.01 & 0.01 & 0.02 & 0.01 & 0.01 & 0.01 & 0.01 & 0.01 & 0.01 & 0.01 & 0.01 & 0.01 & 0.01 & 0.01 & 0.01 & 0.01 & 0.02 & 0.01 & 0.01 & 0.01 & 0.01 & 0.01 & 0.02 & 0.01 & 0.01 & 0.01 & 0.01 & 0.01 & 0.01 & 0.01 & 0.01 & 0.01 & 0.01 & 0.01\end{array}$

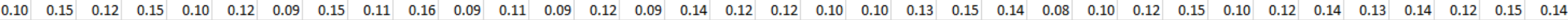

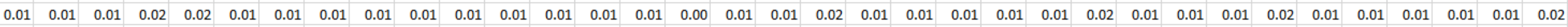

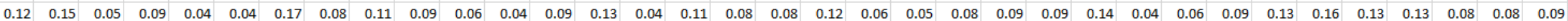

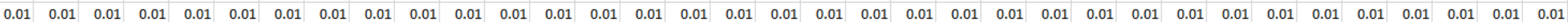

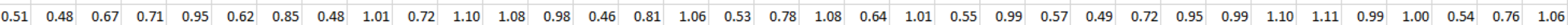

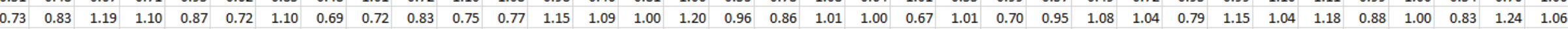

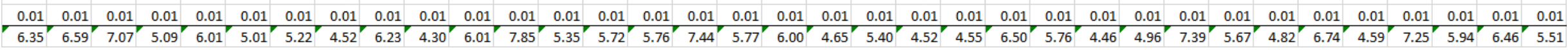

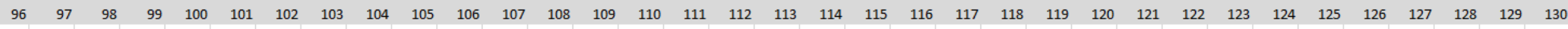

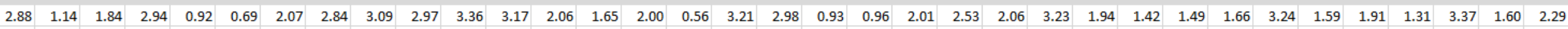

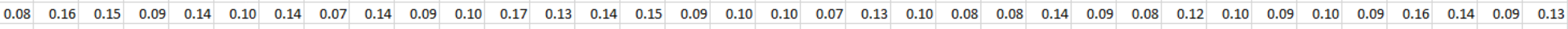
\begin{tabular}{llllllllllllllllllllllllllllllllllll}
0.02 & 0.01 & 0.02 & 0.01 & 0.01 & 0.01 & 0.01 & 0.01 & 0.01 & 0.00 & 0.01 & 0.01 & 0.02 & 0.01 & 0.02 & 0.01 & 0.01 & 0.01 & 0.02 & 0.01 & 0.01 & 0.01 & 0.01 & 0.00 & 0.00 & 0.01 & 0.01 & 0.02 & 0.00 & 0.01 & 0.01 & 0.01 & 0.01 & 0.02 & 0.01 \\
\hline
\end{tabular}

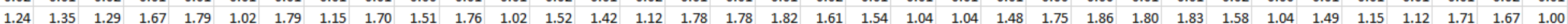

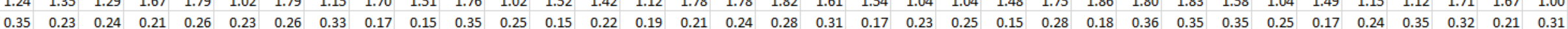

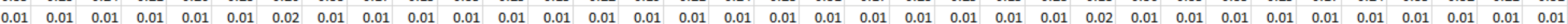

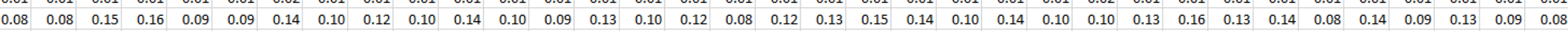

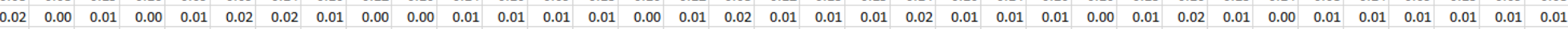

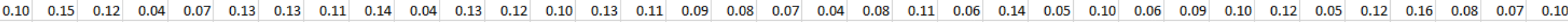
$\begin{array}{lllllllllllllllllllllllllllllllllll}0.01 & 0.01 & 0.01 & 0.01 & 0.01 & 0.01 & 0.01 & 0.01 & 0.01 & 0.01 & 0.01 & 0.01 & 0.01 & 0.01 & 0.01 & 0.01 & 0.01 & 0.01 & 0.01 & 0.01 & 0.01 & 0.01 & 0.01 & 0.01 & 0.01 & 0.01 & 0.01 & 0.01 & 0.01 & 0.01 & 0.01 & 0.01 & 0.01 & 0.01 & 0.01\end{array}$ $\begin{array}{lllllllllllllllllllllllllllllllllllll}0.67 & 0.86 & 0.86 & 0.98 & 0.67 & 0.61 & 0.63 & 0.75 & 0.76 & 0.68 & 0.56 & 0.62 & 0.62 & 0.76 & 1.01 & 0.79 & 0.55 & 0.68 & 0.84 & 0.49 & 0.51 & 0.80 & 0.70 & 0.75 & 0.73 & 1.06 & 1.05 & 1.08 & 0.79 & 0.88 & 0.88 & 0.60 & 1.02 & 0.80 & 0.92\end{array}$

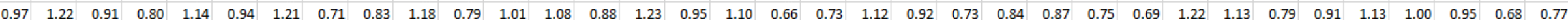

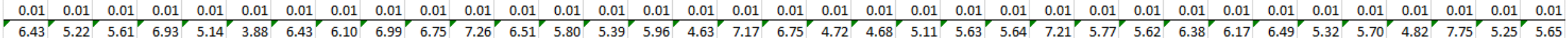




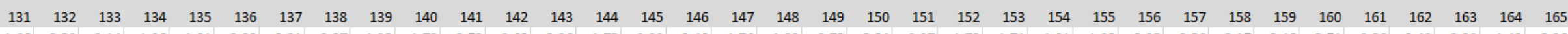

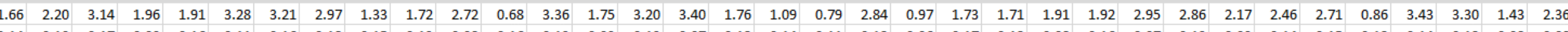

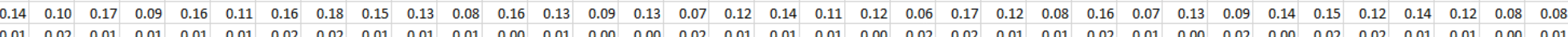

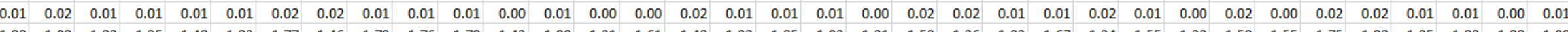

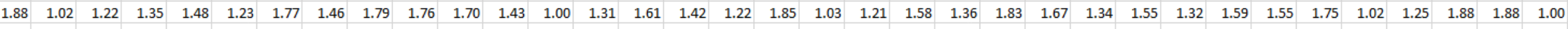
$\begin{array}{lllllllllllllllllllllllllllllllllll}0.23 & 0.32 & 0.17 & 0.17 & 0.28 & 0.19 & 0.27 & 0.21 & 0.25 & 0.31 & 0.35 & 0.28 & 0.29 & 0.16 & 0.25 & 0.23 & 0.24 & 0.23 & 0.15 & 0.32 & 0.35 & 0.14 & 0.23 & 0.20 & 0.28 & 0.34 & 0.30 & 0.19 & 0.29 & 0.21 & 0.24 & 0.34 & 0.23 & 0.18 & 0.18\end{array}$ $\begin{array}{lllllllllllllllllllllllllllllllllll}0.01 & 0.01 & 0.01 & 0.01 & 0.01 & 0.01 & 0.01 & 0.01 & 0.01 & 0.01 & 0.01 & 0.02 & 0.01 & 0.01 & 0.01 & 0.01 & 0.01 & 0.01 & 0.01 & 0.01 & 0.01 & 0.01 & 0.01 & 0.01 & 0.01 & 0.01 & 0.01 & 0.01 & 0.01 & 0.01 & 0.01 & 0.01 & 0.01 & 0.01 & 0.01\end{array}$ $\begin{array}{lllllllllllllllllllllllllllllllllll}0.14 & 0.11 & 0.13 & 0.10 & 0.15 & 0.08 & 0.14 & 0.11 & 0.11 & 0.12 & 0.13 & 0.10 & 0.16 & 0.08 & 0.12 & 0.10 & 0.10 & 0.15 & 0.10 & 0.16 & 0.09 & 0.09 & 0.14 & 0.15 & 0.15 & 0.14 & 0.14 & 0.15 & 0.12 & 0.13 & 0.10 & 0.15 & 0.08 & 0.16 & 0.12\end{array}$

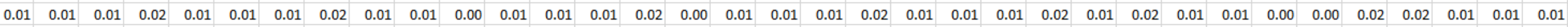

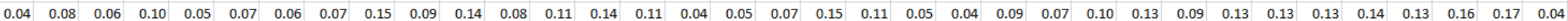

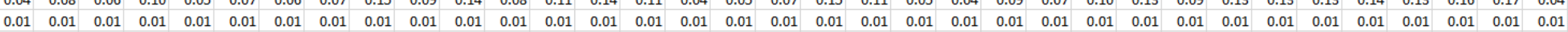

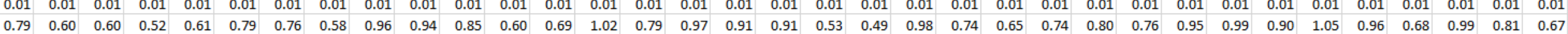
$\begin{array}{llllllllllllllllllllllllllllllllllll}0.79 & 0.60 & 0.60 & 0.52 & 0.61 & 0.79 & 0.76 & 0.58 & 0.96 & 0.94 & 0.85 & 0.60 & 0.69 & 1.02 & 0.79 & 0.97 & 0.91 & 0.91 & 0.53 & 0.49 & 0.98 & 0.74 & 0.65 & 0.74 & 0.80 & 0.76 & 0.95 & 0.99 & 0.90 & 1.05 & 0.96 & 0.68 & 0.99 & 0.81 & 0.67 \\ 1.04 & 1.23 & 0.87 & 0.84 & 0.73 & 1.12 & 0.91 & 1.11 & 0.74 & 0.68 & 0.81 & 0.82 & 0.81 & 1.10 & 0.90 & 1.03 & 1.04 & 0.79 & 0.83 & 1.14 & 1.03 & 1.03 & 1.22 & 1.06 & 1.13 & 0.92 & 0.82 & 1.02 & 0.67 & 0.67 & 0.66 & 1.24 & 0.66 & 1.11 & 0.95\end{array}$ \begin{tabular}{llllllllllllllllllllllllllllllllllllllll}
1.04 & 1.23 & 0.87 & 0.84 & 0.73 & 1.12 & 0.91 & 1.11 & 0.74 & 0.68 & 0.81 & 0.82 & 0.81 & 1.10 & 0.90 & 1.03 & 1.04 & 0.79 & 0.83 & 1.14 & 1.03 & 1.03 & 1.22 & 1.06 & 1.13 & 0.92 & 0.82 & 1.02 & 0.67 & 0.67 & 0.66 & 1.24 & 0.66 & 1.11 & 0.95 \\
0.01 & 0.01 & 0.01 & 0.01 & 0.01 & 0.01 & 0.01 & 0.01 & 0.01 & 0.01 & 0.01 & 0.01 & 0.01 & 0.01 & 0.01 & 0.01 & 0.01 & 0.01 & 0.01 & 0.01 & 0.01 & 0.01 & 0.01 & 0.01 & 0.01 & 0.01 & 0.01 & 0.01 & 0.01 & 0.01 & 0.01 & 0.01 & 0.01 & 0.01 & 0.01 \\
\hline
\end{tabular}

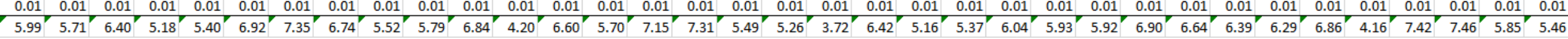

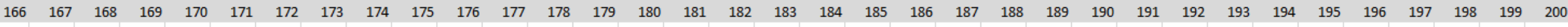
$\begin{array}{lllllllllllllllllllllllllllllllllll}1.97 & 2.02 & 1.96 & 0.85 & 2.32 & 2.66 & 2.16 & 1.06 & 2.08 & 2.63 & 2.95 & 0.69 & 2.71 & 2.64 & 0.58 & 2.45 & 2.75 & 1.58 & 2.98 & 0.92 & 2.59 & 1.40 & 2.60 & 2.99 & 1.12 & 3.00 & 1.73 & 0.73 & 1.92 & 1.28 & 3.11 & 1.00 & 2.11 & 0.89 & 2.88\end{array}$

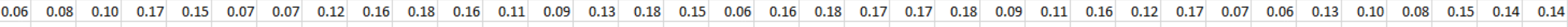
$\begin{array}{llllllllllllllllllllllllllllllllllll}0.01 & 0.01 & 0.01 & 0.01 & 0.01 & 0.01 & 0.01 & 0.00 & 0.01 & 0.02 & 0.00 & 0.01 & 0.02 & 0.02 & 0.01 & 0.02 & 0.01 & 0.02 & 0.00 & 0.01 & 0.02 & 0.02 & 0.01 & 0.00 & 0.01 & 0.01 & 0.00 & 0.00 & 0.01 & 0.01 & 0.01 & 0.02 & 0.01 & 0.01 & 0.00\end{array}$

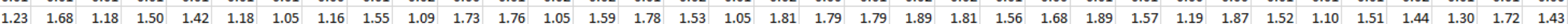

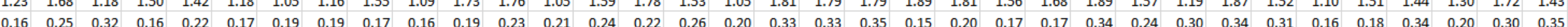

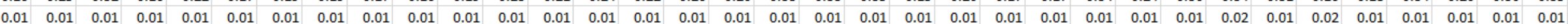

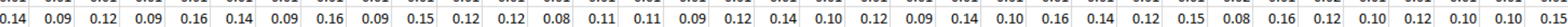
\begin{tabular}{llllllllllllllllllllllllllllllllllll}
0.00 & 0.01 & 0.01 & 0.01 & 0.01 & 0.01 & 0.01 & 0.01 & 0.02 & 0.01 & 0.01 & 0.01 & 0.01 & 0.01 & 0.01 & 0.01 & 0.01 & 0.01 & 0.01 & 0.01 & 0.00 & 0.01 & 0.01 & 0.01 & 0.01 & 0.01 & 0.02 & 0.00 & 0.00 & 0.02 & 0.01 & 0.01 & 0.01 & 0.02 & 0.00 \\
\hline
\end{tabular} $\begin{array}{lllllllllllllllllllllllllllllllllll}0.16 & 0.11 & 0.12 & 0.10 & 0.10 & 0.05 & 0.13 & 0.12 & 0.07 & 0.13 & 0.05 & 0.10 & 0.16 & 0.10 & 0.10 & 0.08 & 0.06 & 0.06 & 0.06 & 0.04 & 0.08 & 0.16 & 0.16 & 0.10 & 0.06 & 0.10 & 0.11 & 0.12 & 0.12 & 0.15 & 0.11 & 0.16 & 0.05 & 0.12 & 0.05\end{array}$ $\begin{array}{llllllllllllllllllllllllllllllllllllllll}0.01 & 0.01 & 0.01 & 0.01 & 0.01 & 0.01 & 0.01 & 0.01 & 0.01 & 0.01 & 0.01 & 0.01 & 0.01 & 0.01 & 0.01 & 0.01 & 0.01 & 0.01 & 0.01 & 0.01 & 0.01 & 0.01 & 0.01 & 0.01 & 0.01 & 0.01 & 0.01 & 0.01 & 0.01 & 0.01 & 0.01 & 0.01 & 0.01 & 0.01 & 0.01\end{array}$ $\begin{array}{llllllllllllllllllllllllllllllllllll}0.56 & 0.50 & 0.54 & 1.01 & 0.96 & 0.98 & 0.80 & 0.89 & 1.03 & 0.79 & 0.81 & 1.08 & 0.78 & 1.04 & 0.97 & 0.98 & 0.88 & 0.65 & 0.79 & 0.92 & 0.49 & 0.52 & 0.74 & 1.00 & 0.60 & 0.87 & 0.63 & 0.63 & 0.72 & 0.96 & 0.54 & 1.00 & 1.08 & 0.89 & 0.50\end{array}$

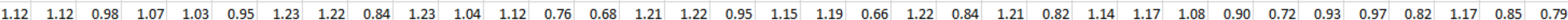

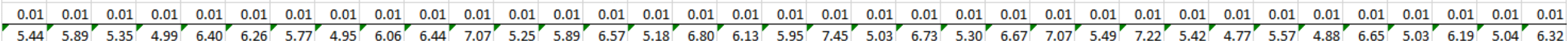




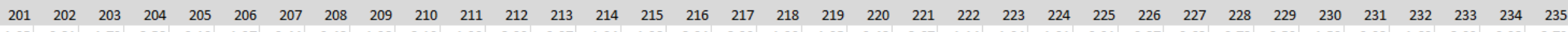

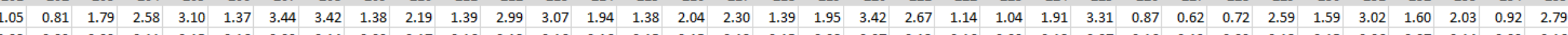
$\begin{array}{lllllllllllllllllllllllllllllllllll}0.08 & 0.09 & 0.09 & 0.11 & 0.15 & 0.16 & 0.09 & 0.14 & 0.09 & 0.17 & 0.16 & 0.18 & 0.16 & 0.16 & 0.15 & 0.15 & 0.12 & 0.15 & 0.08 & 0.07 & 0.12 & 0.16 & 0.09 & 0.18 & 0.07 & 0.16 & 0.13 & 0.09 & 0.12 & 0.15 & 0.06 & 0.07 & 0.14 & 0.09 & 0.16\end{array}$ $\begin{array}{llllllllllllllllllllllllllllllllllllll}0.02 & 0.01 & 0.01 & 0.00 & 0.02 & 0.00 & 0.01 & 0.02 & 0.01 & 0.01 & 0.01 & 0.01 & 0.02 & 0.02 & 0.01 & 0.01 & 0.01 & 0.01 & 0.01 & 0.00 & 0.01 & 0.02 & 0.02 & 0.01 & 0.02 & 0.01 & 0.02 & 0.01 & 0.01 & 0.01 & 0.01 & 0.00 & 0.01 & 0.02 & 0.01\end{array}$

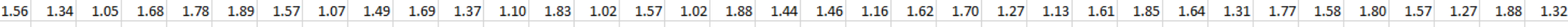
$\begin{array}{lllllllllllllllllllllllllllllllllll}0.31 & 0.35 & 0.16 & 0.24 & 0.21 & 0.32 & 0.24 & 0.30 & 0.15 & 0.29 & 0.18 & 0.35 & 0.20 & 0.34 & 0.23 & 0.32 & 0.15 & 0.36 & 0.32 & 0.29 & 0.29 & 0.20 & 0.26 & 0.29 & 0.28 & 0.17 & 0.26 & 0.26 & 0.22 & 0.33 & 0.26 & 0.24 & 0.28 & 0.29 & 0.15\end{array}$ $\begin{array}{llllllllllllllllllllllllllllllllllllll}0.01 & 0.01 & 0.01 & 0.01 & 0.01 & 0.01 & 0.01 & 0.01 & 0.01 & 0.01 & 0.01 & 0.01 & 0.01 & 0.02 & 0.01 & 0.01 & 0.01 & 0.01 & 0.01 & 0.01 & 0.01 & 0.01 & 0.01 & 0.01 & 0.01 & 0.01 & 0.01 & 0.01 & 0.01 & 0.01 & 0.01 & 0.01 & 0.01 & 0.02 & 0.02\end{array}$

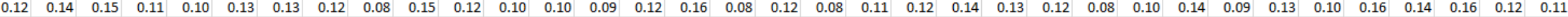
$\begin{array}{llllllllllllllllllllllllllllllllllll}0.02 & 0.01 & 0.02 & 0.01 & 0.02 & 0.00 & 0.02 & 0.01 & 0.01 & 0.00 & 0.01 & 0.02 & 0.02 & 0.01 & 0.01 & 0.01 & 0.02 & 0.01 & 0.01 & 0.01 & 0.00 & 0.01 & 0.01 & 0.01 & 0.01 & 0.02 & 0.01 & 0.01 & 0.01 & 0.01 & 0.00 & 0.00 & 0.01 & 0.01 & 0.00\end{array}$

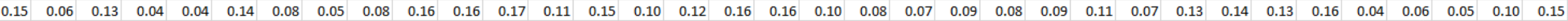

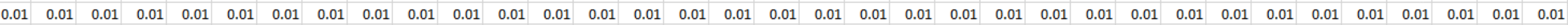

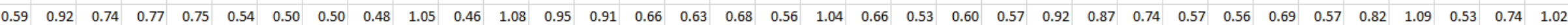

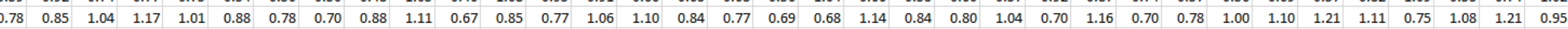

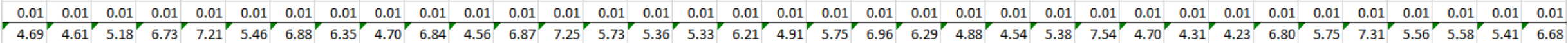

$\begin{array}{llllllllllllllllll}236 & 237 & 238 & 239 & 240 & 241 & 242 & 243 & 244 & 245 & 246 & 247 & 248 & 249 & 250 & 251 & 252 \text { Promedio Desv Std UCL }\end{array}$ $\begin{array}{llllllllllllllllllll}1.16 & 1.17 & 2.97 & 2.91 & 2.90 & 1.40 & 2.03 & 2.79 & 1.16 & 2.29 & 2.52 & 0.96 & 3.19 & 0.75 & 1.07 & 3.25 & 3.15 & 2.00 & 0.83\end{array}$ $\begin{array}{lllllllllllllllllll}0.14 & 0.07 & 0.15 & 0.07 & 0.17 & 0.12 & 0.17 & 0.12 & 0.09 & 0.07 & 0.18 & 0.09 & 0.10 & 0.10 & 0.09 & 0.13 & 0.18\end{array}$ $\begin{array}{lllllllllllllllll}0.01 & 0.01 & 0.01 & 0.00 & 0.01 & 0.02 & 0.01 & 0.01 & 0.01 & 0.00 & 0.01 & 0.01 & 0.02 & 0.01 & 0.01 & 0.01 & 0.02\end{array}$ $\begin{array}{llllllllllllllllllll}1.06 & 1.40 & 1.32 & 1.16 & 1.24 & 1.18 & 1.46 & 1.35 & 1.29 & 1.46 & 1.36 & 1.38 & 1.83 & 1.00 & 1.30 & 1.11 & 1.87\end{array}$ $\begin{array}{lllllllllllllllllllll}0.36 & 0.25 & 0.24 & 0.17 & 0.23 & 0.35 & 0.30 & 0.33 & 0.20 & 0.24 & 0.18 & 0.18 & 0.23 & 0.18 & 0.27 & 0.32 & 0.22 \\ 0.01 & 0.01 & 0.01 & 0.01 & 0.01 & 0.02 & 0.01 & 0.02 & 0.01 & 0.01 & 0.01 & 0.01 & 0.01 & 0.01 & 0.01 & 0.01 & 0.01\end{array}$

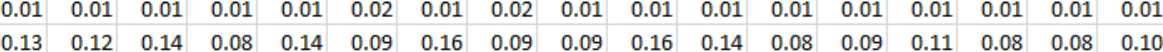
$\begin{array}{llllllllllllllllll}0.02 & 0.01 & 0.01 & 0.01 & 0.01 & 0.02 & 0.01 & 0.01 & 0.01 & 0.01 & 0.01 & 0.00 & 0.02 & 0.01 & 0.01 & 0.02 & 0.01\end{array}$ $\begin{array}{lllllllllllllllll}0.15 & 0.13 & 0.10 & 0.09 & 0.06 & 0.13 & 0.14 & 0.08 & 0.15 & 0.14 & 0.10 & 0.05 & 0.04 & 0.09 & 0.06 & 0.11 & 0.12\end{array}$ $\begin{array}{llllllllllllllllll}0.01 & 0.01 & 0.01 & 0.01 & 0.01 & 0.01 & 0.01 & 0.01 & 0.01 & 0.01 & 0.01 & 0.01 & 0.01 & 0.01 & 0.01 & 0.01 & 0.01 \\ 0.0 & 1.00 & 0.5 & 0.50 & 0.47 & 1.0 & 0.5 & 0.01 & 0.6 & 0.87 & 0.5 & 0.94 & 1.02 & 0.72 & 0.9 & 1.0 & 1.00\end{array}$ $\begin{array}{lllllllllllllllll}0.63 & 1.00 & 0.52 & 0.50 & 0.47 & 1.10 & 0.50 & 0.61 & 0.69 & 0.87 & 0.65 & 0.94 & 1.02 & 0.72 & 0.99 & 1.10 & 1.08\end{array}$ $\begin{array}{llllllllllllllllllll}0.01 & 0.01 & 0.01 & 0.01 & 0.01 & 0.01 & 0.01 & 0.01 & 0.01 & 0.91 & 0.01 & 0.01 & 0.01 & 0.801 & 0.01 & 0.81\end{array}$

\begin{tabular}{|l|l|l|l|l|l|}
\hline 2.00 & 0.83 & 2.83 & 1.17 & 57 & $23 \%$ \\
\hline 0.12 & 0.04 & 0.16 & 0.08 & 53 & $21 \%$ \\
\hline 0.01 & 0.01 & 0.02 & 0.01 & 45 & $18 \%$ \\
\hline 1.45 & 0.27 & 1.72 & 1.18 & 53 & $21 \%$ \\
\hline 0.25 & 0.06 & 0.32 & 0.19 & 54 & $21 \%$ \\
\hline 0.01 & 0.00 & 0.01 & 0.01 & 47 & $19 \%$ \\
\hline 0.12 & 0.02 & 0.14 & 0.09 & 53 & $21 \%$ \\
\hline 0.01 & 0.00 & 0.01 & 0.01 & 46 & $18 \%$ \\
\hline 0.10 & 0.04 & 0.14 & 0.06 & 49 & $19 \%$ \\
\hline 0.01 & 0.00 & 0.01 & 0.01 & 61 & $24 \%$ \\
\hline 0.78 & 0.19 & 0.97 & 0.59 & 60 & $24 \%$ \\
\hline 0.95 & 0.17 & 1.13 & 0.78 & 50 & $20 \%$ \\
\hline 0.01 & 0.00 & 0.01 & 0.01 & 72 & $29 \%$ \\
\hline
\end{tabular}




\section{Anexo 3: Tiempos Propuesta Mejora Parte 1}

\begin{tabular}{|c|c|c|c|c|c|c|c|c|c|c|c|c|c|c|c|c|c|c|c|c|c|c|c|c|c|c|}
\hline \\
\hline \multicolumn{2}{|l|}{$\begin{array}{l}\text { Tiempos por procesos de bobina } \\
\text { Actividad }\end{array}$} & 1 & \multirow{2}{*}{$\begin{array}{r}2 \\
1.09\end{array}$} & \multirow{2}{*}{$\begin{array}{r}3 \\
1.25\end{array}$} & \multirow{2}{*}{$\begin{array}{r}4 \\
0.67\end{array}$} & \multirow{2}{*}{$\begin{array}{r}5 \\
0.75\end{array}$} & \multirow{2}{*}{$\begin{array}{r}6 \\
2.25\end{array}$} & \multirow{2}{*}{$\begin{array}{r}7 \\
2.62\end{array}$} & \multirow{2}{*}{$\begin{array}{r}8 \\
2.11\end{array}$} & \multirow{2}{*}{$\begin{array}{r}9 \\
1.65\end{array}$} & \multirow{2}{*}{$\begin{array}{r}10 \\
2.48\end{array}$} & \multirow{2}{*}{$\begin{array}{r}11 \\
2.65\end{array}$} & \multirow{2}{*}{$\begin{array}{r}12 \\
2.64\end{array}$} & \multirow{2}{*}{$\begin{array}{r}13 \\
1.74\end{array}$} & \multirow{2}{*}{$\begin{array}{r}14 \\
1.61\end{array}$} & \multirow{2}{*}{$\begin{array}{r}15 \\
1.30\end{array}$} & \multirow{2}{*}{$\begin{array}{r}16 \\
1.48\end{array}$} & \multirow{2}{*}{$\begin{array}{r}17 \\
0.60\end{array}$} & \multirow{2}{*}{$\begin{array}{r}18 \\
1.07\end{array}$} & \multirow{2}{*}{$\begin{array}{r}19 \\
2.31\end{array}$} & \multirow{2}{*}{$\begin{array}{r}20 \\
1.59\end{array}$} & \multirow{2}{*}{$\begin{array}{r}21 \\
1.08\end{array}$} & \multirow{2}{*}{$\begin{array}{r}22 \\
0.83\end{array}$} & \multirow{2}{*}{$\begin{array}{r}23 \\
1.69\end{array}$} & \multirow{2}{*}{$\begin{array}{r}24 \\
0.70\end{array}$} & \multirow{2}{*}{$\begin{array}{r}25 \\
1.85\end{array}$} \\
\hline Bobina de tela en espera de teñido & 1.66 & 2.65 & & & & & & & & & & & & & & & & & & & & & & & & \\
\hline Teñido & 0.06 & 0.06 & 0.06 & 0.06 & 0.06 & 0.06 & 0.06 & 0.06 & 0.06 & 0.06 & 0.06 & 0.06 & 0.06 & 0.06 & 0.06 & 0.06 & 0.06 & 0.06 & 0.06 & 0.06 & 0.06 & 0.06 & 0.06 & 0.06 & 0.06 & 0.06 \\
\hline traslado de bobina para reposo & 0.01 & 0.01 & 0.00 & 0.00 & 0.01 & 0.01 & 0.01 & 0.01 & 0.00 & 0.00 & 0.00 & 0.01 & 0.00 & 0.01 & 0.00 & 0.00 & 0.01 & 0.00 & 0.00 & 0.00 & 0.00 & 0.01 & 0.00 & 0.01 & 0.01 & 0.01 \\
\hline Reposo & 0.78 & 0.93 & 0.95 & 0.68 & 0.71 & 0.68 & 0.63 & 0.59 & 0.81 & 0.74 & 0.70 & 0.72 & 0.86 & 0.64 & 0.95 & 0.81 & 0.64 & 0.64 & 0.70 & 0.97 & 0.69 & 0.80 & 0.88 & 0.94 & 0.66 & 0.75 \\
\hline Rollo de tela en espera de lavado teñido & 0.00 & 0.00 & 0.00 & 0.00 & 0.00 & 0.00 & 0.00 & 0.00 & 0.00 & 0.00 & 0.00 & 0.00 & 0.00 & 0.00 & 0.00 & 0.00 & 0.00 & 0.00 & 0.00 & 0.00 & 0.00 & 0.00 & 0.00 & 0.00 & 0.00 & 0.00 \\
\hline Traslado de rollo de tela & 0.01 & 0.01 & 0.01 & 0.01 & 0.01 & 0.01 & 0.01 & 0.01 & 0.01 & 0.01 & 0.01 & 0.01 & 0.01 & 0.01 & 0.01 & 0.01 & 01 & 0.01 & 0.01 & 01 & 01 & 0.01 & 01 & 01 & 01 & 0.01 \\
\hline Lavado teñido & 0.09 & 0.09 & 0.08 & 0.09 & 0.08 & 0.10 & 0.08 & 0.08 & 0.08 & 0.08 & 0.08 & 0.08 & 0.10 & 0.09 & 0.09 & 0.08 & 0.09 & 0.08 & 0.08 & 0.09 & 0.10 & 0.08 & 0.09 & 0.08 & 0.08 & 0.10 \\
\hline Traslado de rollo de tela para secado & 0.01 & 0.01 & 0.01 & 0.00 & 0.01 & 0.00 & 0.01 & 0.01 & 0.00 & 0.01 & 0.01 & 0.00 & 0.01 & 0.01 & 0.01 & 0.00 & 0.00 & 0.01 & 0.01 & 0.01 & 0.01 & 0.01 & 0.00 & 0.01 & 0.01 & 0.01 \\
\hline Rollo de tela en espera de de secado & 0.16 & 0.19 & 0.14 & 0.15 & 0.13 & 0.14 & 0.12 & 0.15 & 0.11 & 0.19 & 0.13 & 0.19 & 0.13 & 0.14 & 0.21 & 0.13 & 0.15 & 0.11 & 0.11 & 0.12 & 0.12 & 0.12 & 0.12 & 0.13 & 0.19 & 0.12 \\
\hline Secado & 0.09 & 0.11 & 0.14 & 0.08 & 0.04 & 0.09 & 0.12 & 0.11 & 0.12 & 0.13 & 0.06 & 0.14 & 0.07 & 0.07 & 0.04 & 0.09 & 0.12 & 0.15 & 0.06 & 0.13 & 0.05 & 0.15 & 0.12 & 0.12 & 0.09 & 0.14 \\
\hline Traslado de bo & 0.01 & .01 & 0.01 & 0.01 & 0.01 & 0.01 & 0.01 & 0.01 & 0.01 & 0.01 & 0.01 & 0.01 & 0.01 & 0.01 & 0.01 & 0.01 & 0.01 & 0.01 & 0.01 & 0.01 & 0.01 & 0.01 & 0.01 & 0.01 & 0.01 & 0.01 \\
\hline Bobina en espera para su revisión & 1.66 & 2.63 & 1.69 & 2.16 & 1.58 & 0.55 & 2.79 & 0.77 & 0.75 & 2.09 & 1.20 & 1.91 & 1.54 & 1.35 & 2.81 & 0.52 & 2.32 & 2.23 & 1.04 & 2.79 & 1.30 & 1.86 & 1.09 & 2.61 & 0.81 & 1.17 \\
\hline Revisión de tela teñida & 0.07 & 0.04 & 0.08 & 0.11 & 0.07 & 0.05 & 0.09 & 0.11 & 0.07 & 0.08 & 0.07 & 0.06 & 0.06 & 0.05 & 0.06 & 0.08 & 0.07 & 0.07 & 0.11 & 0.11 & 0.06 & 0.07 & 0.09 & 0.05 & 0.11 & 0.07 \\
\hline Traslado de bobina para impregnado & 0.01 & 0.01 & 0.01 & 0.01 & 0.01 & 0.01 & 0.01 & 0.01 & 0.01 & 0.01 & 0.01 & 0.01 & 0.01 & 0.01 & 0.01 & 0.01 & 0.01 & 0.01 & 0.01 & 0.01 & 0.01 & 0.01 & 0.01 & 0.01 & 0.01 & 0.01 \\
\hline & 4.60 & 6.74 & 4.26 & 4.59 & 3.37 & $2.44^{\prime}$ & $6.17^{\prime}$ & 4.52 & 4.14 & $5.05^{\prime}$ & 4.81 & $5.83^{\prime}$ & 5.48 & 4.17 & 5.87 & $3.10^{\prime}$ & 4.95 & 3.99 & 3.26 & 6.60 & $3.99^{\prime}$ & $4.25^{\prime}$ & $3.30^{\prime}$ & 5.71 & 2.73 & 4.29 \\
\hline
\end{tabular}

\footnotetext{
\begin{tabular}{rrrrrrrrrrrrrrrrrrrrrrrrrrrrrrrrrrrr}
26 & 27 & 28 & 29 & 30 & 31 & 32 & 33 & 34 & 35 & 36 & 37 & 38 & 39 & 40 & 41 & 42 & 43 & 44 & 45 & 46 & 47 & 48 & 49 & 50 & 51 & 52 & 53 & 54 & 55 & 56 & 57 & 58 & 59 & 60 \\
\hline 2.73 & 1.71 & 2.55 & 1.56 & 1.99 & 2.32 & 0.59 & 0.63 & 2.55 & 2.18 & 2.73 & 2.30 & 0.93 & 1.02 & 1.72 & 1.75 & 2.12 & 1.12 & 2.29 & 2.42 & 1.49 & 2.61 & 0.75 & 1.84 & 1.96 & 1.42 & 2.48 & 2.10 & 2.50 & 1.54 & 1.83 & 0.77 & 0.70 & 1.24 & 1.70
\end{tabular}

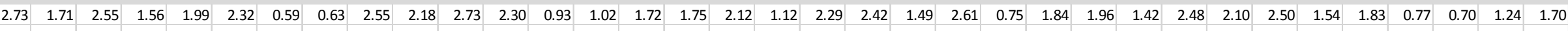

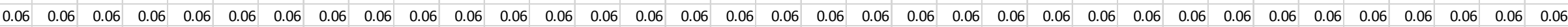
$\begin{array}{lllllllllllllllllllllllllllllllllll}0.01 & 0.01 & 0.01 & 0.01 & 0.01 & 0.00 & 0.01 & 0.01 & 0.00 & 0.00 & 0.00 & 0.01 & 0.01 & 0.01 & 0.01 & 0.01 & 0.01 & 0.01 & 0.01 & 0.00 & 0.01 & 0.00 & 0.00 & 0.00 & 0.01 & 0.00 & 0.01 & 0.01 & 0.00 & 0.00 & 0.01 & 0.00 & 0.00 & 0.00 & 0.01\end{array}$ $\begin{array}{llllllllllllllllllllllllllllllllllll}0.65 & 0.87 & 0.71 & 0.95 & 0.93 & 0.66 & 0.94 & 0.75 & 0.79 & 0.62 & 0.71 & 0.90 & 0.75 & 0.59 & 0.95 & 0.81 & 0.92 & 0.82 & 0.85 & 0.88 & 0.66 & 0.75 & 0.95 & 0.75 & 0.97 & 0.82 & 0.62 & 0.74 & 0.79 & 0.85 & 0.79 & 0.78 & 0.79 & 0.73 & 0.78\end{array}$ $\begin{array}{lllllllllllllllllllllllllllllllllllllll}0.00 & 0.00 & 0.00 & 0.00 & 0.00 & 0.00 & 0.00 & 0.00 & 0.00 & 0.00 & 0.00 & 0.00 & 0.00 & 0.00 & 0.00 & 0.00 & 0.00 & 0.00 & 0.00 & 0.00 & 0.00 & 0.00 & 0.00 & 0.00 & 0.00 & 0.00 & 0.00 & 0.00 & 0.00 & 0.00 & 0.00 & 0.00 & 0.00 & 0.00 & 0.00\end{array}$

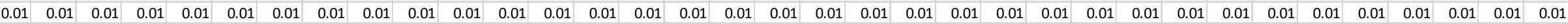

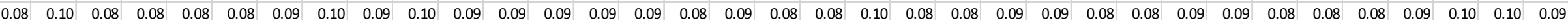

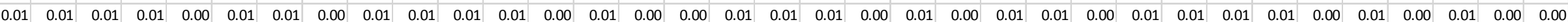

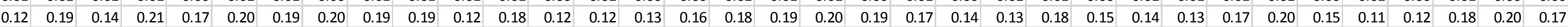

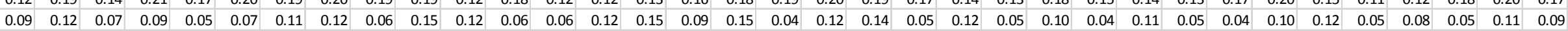

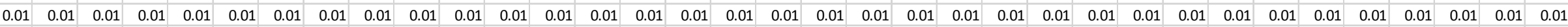

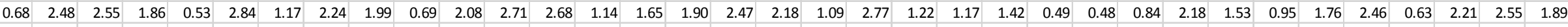
$\begin{array}{lllllllllllllllllllllllllllllllllllll}0.05 & 0.06 & 0.05 & 0.06 & 0.07 & 0.11 & 0.05 & 0.12 & 0.06 & 0.05 & 0.03 & 0.08 & 0.07 & 0.10 & 0.06 & 0.06 & 0.07 & 0.07 & 0.06 & 0.05 & 0.07 & 0.06 & 0.06 & 0.07 & 0.10 & 0.12 & 0.03 & 0.07 & 0.04 & 0.04 & 0.07 & 0.06 & 0.11 & 0.03 & 0.09\end{array}$

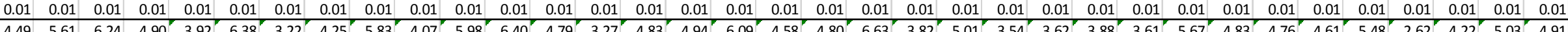


\begin{tabular}{llllllllllllllllllllllllllllllllllllll}
61 & 62 & 63 & 64 & 65 & 66 & 67 & 68 & 69 & 70 & 71 & 72 & 73 & 74 & 75 & 76 & 77 & 78 & 79 & 80 & 81 & 82 & 83 & 84 & 85 & 86 & 87 & 88 & 89 & 90 & 91 & 92 & 93 & 94 & 95 \\
\hline
\end{tabular}

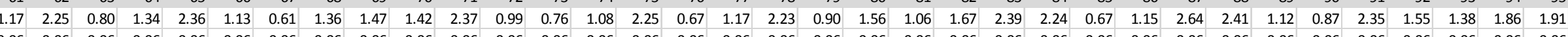
\begin{tabular}{lllllllllllllllllllllllllllllllllllll}
0.06 & 0.06 & 0.06 & 0.06 & 0.06 & 0.06 & 0.06 & 0.06 & 0.06 & 0.06 & 0.06 & 0.06 & 0.06 & 0.06 & 0.06 & 0.06 & 0.06 & 0.06 & 0.06 & 0.06 & 0.06 & 0.06 & 0.06 & 0.06 & 0.06 & 0.06 & 0.06 & 0.06 & 0.06 & 0.06 & 0.06 & 0.06 & 0.06 & 0.06 & 0.06 \\
\hline
\end{tabular}

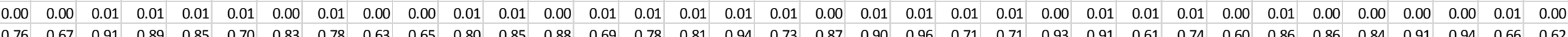

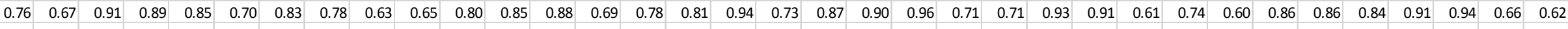
$\begin{array}{llllllllllllllllllllllllllllllllllll}0.00 & 0.00 & 0.00 & 0.00 & 0.00 & 0.00 & 0.00 & 0.00 & 0.00 & 0.00 & 0.00 & 0.00 & 0.00 & 0.00 & 0.00 & 0.00 & 0.00 & 0.00 & 0.00 & 0.00 & 0.00 & 0.00 & 0.00 & 0.00 & 0.00 & 0.00 & 0.00 & 0.00 & 0.00 & 0.00 & 0.00 & 0.00 & 0.00 & 0.00 & 0.00\end{array}$

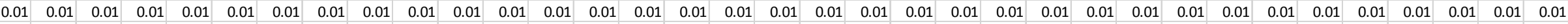

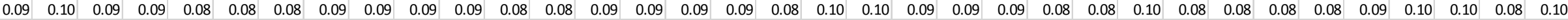

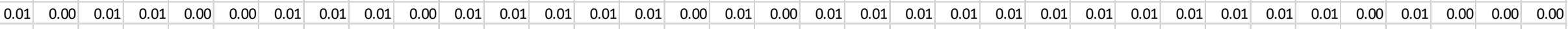

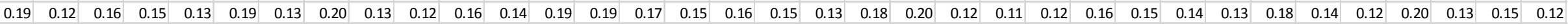

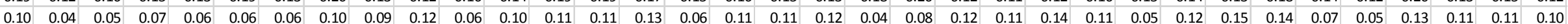

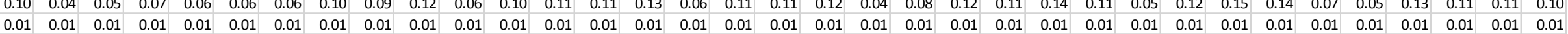

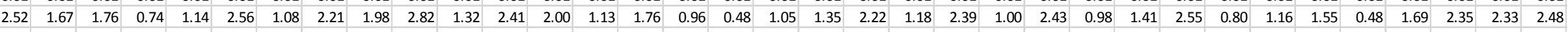

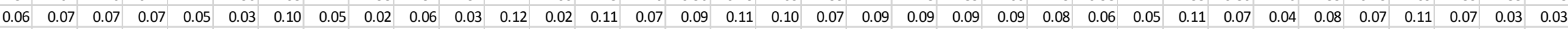

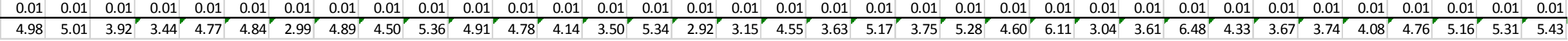

\begin{tabular}{rrrrrrrrrrrrrrrrrrrrrrrrrrrrrrrrrrr}
96 & 97 & 98 & 99 & 100 & 101 & 102 & 103 & 104 & 105 & 106 & 107 & 108 & 109 & 110 & 111 & 112 & 113 & 114 & 115 & 116 & 117 & 118 & 119 & 120 & 121 & 122 & 123 & 124 & 125 & 126 & 127 & 128 & 129 & 130 \\
\hline & 2 & 123 &
\end{tabular}

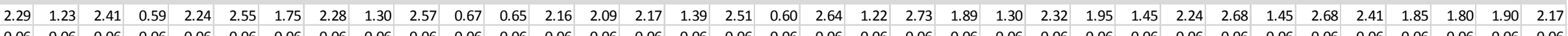
$\begin{array}{llllllllllllllllllllllllllllllllllll}0.06 & 0.06 & 0.06 & 0.06 & 0.06 & 0.06 & 0.06 & 0.06 & 0.06 & 0.06 & 0.06 & 0.06 & 0.06 & 0.06 & 0.06 & 0.06 & 0.06 & 0.06 & 0.06 & 0.06 & 0.06 & 0.06 & 0.06 & 0.06 & 0.06 & 0.06 & 0.06 & 0.06 & 0.06 & 0.06 & 0.06 & 0.06 & 0.06 & 0.06 & 0.06\end{array}$

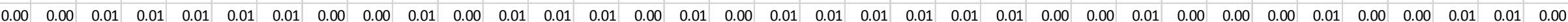

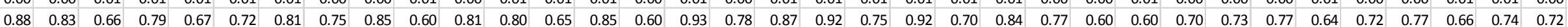
\begin{tabular}{llllllllllllllllllllllllllllllllllll}
0.88 & 0.83 & 0.66 & 0.79 & 0.67 & 0.72 & 0.81 & 0.75 & 0.85 & 0.60 & 0.81 & 0.80 & 0.65 & 0.85 & 0.60 & 0.93 & 0.78 & 0.87 & 0.92 & 0.75 & 0.92 & 0.70 & 0.84 & 0.77 & 0.60 & 0.60 & 0.70 & 0.73 & 0.77 & 0.64 & 0.72 & 0.77 & 0.66 & 0.74 & 0.72 \\
\hline
\end{tabular} $\begin{array}{lllllllllllllllllllllllllllllllllllllll}0.00 & 0.00 & 0.00 & 0.00 & 0.00 & 0.00 & 0.00 & 0.00 & 0.00 & 0.00 & 0.00 & 0.00 & 0.00 & 0.00 & 0.00 & 0.00 & 0.00 & 0.00 & 0.00 & 0.00 & 0.00 & 0.00 & 0.00 & 0.00 & 0.00 & 0.00 & 0.00 & 0.00 & 0.00 & 0.00 & 0.00 & 0.00 & 0.00 & 0.00 & 0.00 \\ 0.01 & 0.01 & 0.01 & 0.01 & 0.01 & 0.01 & 0.01 & 0.01 & 0.01 & 0.01 & 0.01 & 0.01 & 0.01 & 0.01 & 0.01 & 0.01 & 0.01 & 0.01 & 0.01 & 0.01 & 0.01 & 0.01 & 0.01 & 0.01 & 0.01 & 0.01 & 0.01 & 0.01 & 0.01 & 0.01 & 0.01 & 0.01 & 0.01 & 0.01 & 0.01\end{array}$

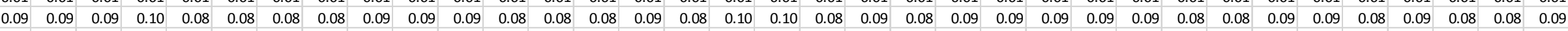
$\begin{array}{llllllllllllllllllllllllllllllllllll}0.01 & 0.01 & 0.01 & 0.01 & 0.01 & 0.01 & 0.01 & 0.01 & 0.00 & 0.01 & 0.00 & 0.00 & 0.01 & 0.00 & 0.00 & 0.01 & 0.01 & 0.01 & 0.00 & 0.01 & 0.01 & 0.01 & 0.01 & 0.01 & 0.01 & 0.00 & 0.00 & 0.01 & 0.01 & 0.01 & 0.01 & 0.00 & 0.00 & 0.01 & 0.00\end{array}$ $\begin{array}{lllllllllllllllllllllllllllllllllll}0.19 & 0.12 & 0.20 & 0.12 & 0.16 & 0.13 & 0.15 & 0.16 & 0.15 & 0.18 & 0.13 & 0.17 & 0.18 & 0.17 & 0.16 & 0.15 & 0.13 & 0.15 & 0.11 & 0.16 & 0.17 & 0.19 & 0.17 & 0.15 & 0.16 & 0.11 & 0.16 & 0.11 & 0.15 & 0.13 & 0.20 & 0.21 & 0.20 & 0.14 & 0.21\end{array}$ $\begin{array}{llllllllllllllllllllllllllllllllllllll}0.15 & 0.11 & 0.14 & 0.14 & 0.13 & 0.14 & 0.08 & 0.13 & 0.15 & 0.10 & 0.05 & 0.09 & 0.06 & 0.09 & 0.05 & 0.07 & 0.09 & 0.08 & 0.09 & 0.11 & 0.04 & 0.15 & 0.05 & 0.15 & 0.11 & 0.05 & 0.12 & 0.08 & 0.11 & 0.08 & 0.08 & 0.04 & 0.12 & 0.10 & 0.05\end{array}$ \begin{tabular}{llllllllllllllllllllllllllllllllllll}
0.01 & 0.01 & 0.01 & 0.01 & 0.01 & 0.01 & 0.01 & 0.01 & 0.01 & 0.01 & 0.01 & 0.01 & 0.01 & 0.01 & 0.01 & 0.01 & 0.01 & 0.01 & 0.01 & 0.01 & 0.01 & 0.01 & 0.01 & 0.01 & 0.01 & 0.01 & 0.01 & 0.01 & 0.01 & 0.01 & 0.01 & 0.01 & 0.01 & 0.01 & 0.01 \\
\hline
\end{tabular}

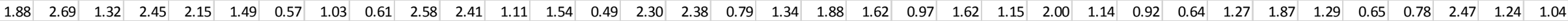

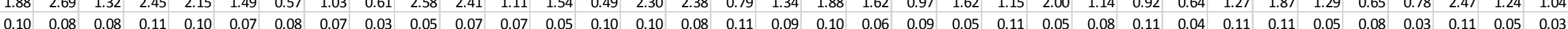

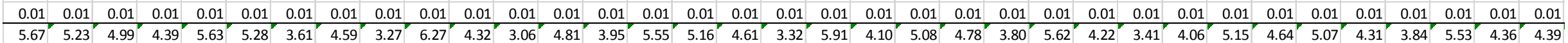




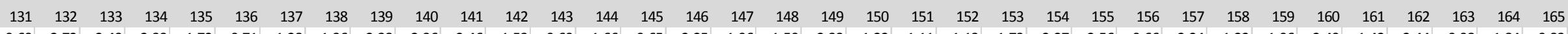

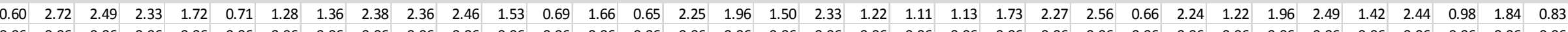
\begin{tabular}{lllllllllllllllllllllllllllllllllll}
0.06 & 0.06 & 0.06 & 0.06 & 0.06 & 0.06 & 0.06 & 0.06 & 0.06 & 0.06 & 0.06 & 0.06 & 0.06 & 0.06 & 0.06 & 0.06 & 0.06 & 0.06 & 0.06 & 0.06 & 0.06 & 0.06 & 0.06 & 0.06 & 0.06 & 0.06 & 0.06 & 0.06 & 0.06 & 0.06 & 0.06 & 0.06 & 0.06 & 0.06 & 0.06 \\
\hline
\end{tabular}

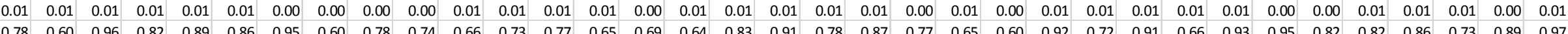

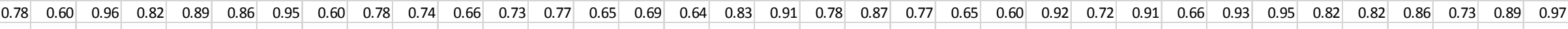
$\begin{array}{llllllllllllllllllllllllllllllllllll}0.00 & 0.00 & 0.00 & 0.00 & 0.00 & 0.00 & 0.00 & 0.00 & 0.00 & 0.00 & 0.00 & 0.00 & 0.00 & 0.00 & 0.00 & 0.00 & 0.00 & 0.00 & 0.00 & 0.00 & 0.00 & 0.00 & 0.00 & 0.00 & 0.00 & 0.00 & 0.00 & 0.00 & 0.00 & 0.00 & 0.00 & 0.00 & 0.00 & 0.00 & 0.00\end{array}$ $\begin{array}{lllllllllllllllllllllllllllllllllllllll}0.01 & 0.01 & 0.01 & 0.01 & 0.01 & 0.01 & 0.01 & 0.01 & 0.01 & 0.01 & 0.01 & 0.01 & 0.01 & 0.01 & 0.01 & 0.01 & 0.01 & 0.01 & 0.01 & 0.01 & 0.01 & 0.01 & 0.01 & 0.01 & 0.01 & 0.01 & 0.01 & 0.01 & 0.01 & 0.01 & 0.01 & 0.01 & 0.01 & 0.01 & 0.01\end{array}$ $\begin{array}{lllllllllllllllllllllllllllllllllll}0.08 & 0.10 & 0.10 & 0.09 & 0.09 & 0.08 & 0.09 & 0.09 & 0.09 & 0.09 & 0.09 & 0.09 & 0.09 & 0.08 & 0.09 & 0.08 & 0.09 & 0.09 & 0.10 & 0.09 & 0.09 & 0.09 & 0.09 & 0.08 & 0.08 & 0.09 & 0.09 & 0.09 & 0.08 & 0.08 & 0.08 & 0.08 & 0.08 & 0.08 & 0.09\end{array}$

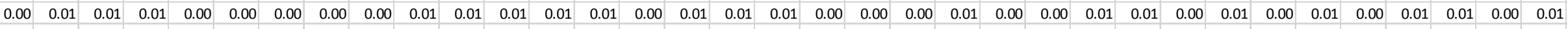

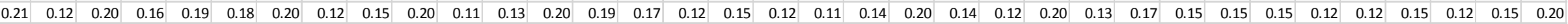

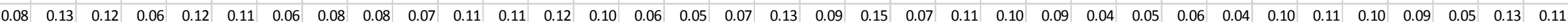

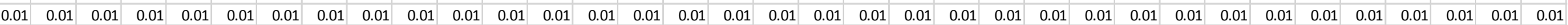

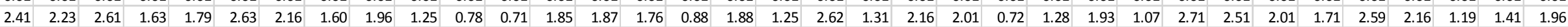

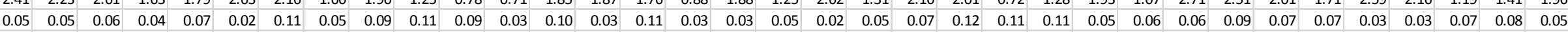

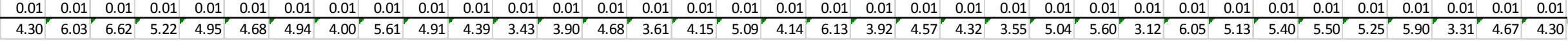

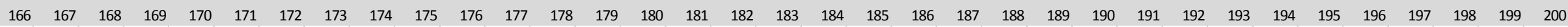

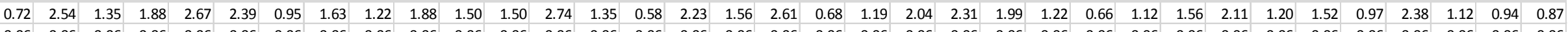
$\begin{array}{llllllllllllllllllllllllllllllllllll}0.06 & 0.06 & 0.06 & 0.06 & 0.06 & 0.06 & 0.06 & 0.06 & 0.06 & 0.06 & 0.06 & 0.06 & 0.06 & 0.06 & 0.06 & 0.06 & 0.06 & 0.06 & 0.06 & 0.06 & 0.06 & 0.06 & 0.06 & 0.06 & 0.06 & 0.06 & 0.06 & 0.06 & 0.06 & 0.06 & 0.06 & 0.06 & 0.06 & 0.06 & 0.06\end{array}$

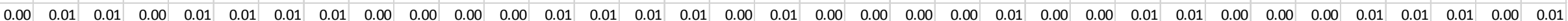

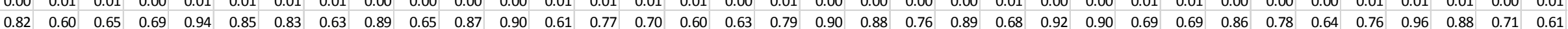
\begin{tabular}{lllllllllllllllllllllllllllllllllll}
0.82 & 0.60 & 0.65 & 0.69 & 0.94 & 0.85 & 0.83 & 0.63 & 0.89 & 0.65 & 0.87 & 0.90 & 0.61 & 0.77 & 0.70 & 0.60 & 0.63 & 0.79 & 0.90 & 0.88 & 0.76 & 0.89 & 0.68 & 0.92 & 0.90 & 0.69 & 0.69 & 0.86 & 0.78 & 0.64 & 0.76 & 0.96 & 0.88 & 0.71 & 0.61 \\
\hline
\end{tabular} $\begin{array}{llllllllllllllllllllllllllllllllllllllll}0.00 & 0.00 & 0.00 & 0.00 & 0.00 & 0.00 & 0.00 & 0.00 & 0.00 & 0.00 & 0.00 & 0.00 & 0.00 & 0.00 & 0.00 & 0.00 & 0.00 & 0.00 & 0.00 & 0.00 & 0.00 & 0.00 & 0.00 & 0.00 & 0.00 & 0.00 & 0.00 & 0.00 & 0.00 & 0.00 & 0.00 & 0.00 & 0.00 & 0.00 & 0.00 \\ 0.01 & 0.01 & 0.01 & 0.01 & 0.01 & 0.01 & 0.01 & 0.01 & 0.01 & 0.01 & 0.01 & 0.01 & 0.01 & 0.01 & 0.01 & 0.01 & 0.01 & 0.01 & 0.01 & 0.01 & 0.01 & 0.01 & 0.01 & 0.01 & 0.01 & 0.01 & 0.01 & 0.01 & 0.01 & 0.01 & 0.01 & 0.01 & 0.01 & 0.01 & 0.01\end{array}$

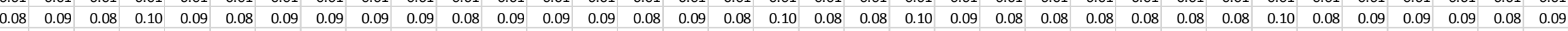
$\begin{array}{lllllllllllllllllllllllllllllllllll}0.01 & 0.01 & 0.01 & 0.01 & 0.00 & 0.00 & 0.01 & 0.01 & 0.00 & 0.01 & 0.01 & 0.01 & 0.01 & 0.01 & 0.01 & 0.01 & 0.01 & 0.00 & 0.01 & 0.00 & 0.01 & 0.01 & 0.00 & 0.01 & 0.01 & 0.01 & 0.01 & 0.01 & 0.01 & 0.00 & 0.01 & 0.01 & 0.01 & 0.00 & 0.01\end{array}$

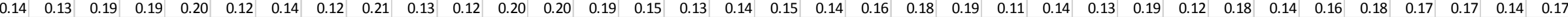
$\begin{array}{lllllllllllllllllllllllllllllllllll}0.14 & 0.04 & 0.07 & 0.08 & 0.04 & 0.05 & 0.06 & 0.09 & 0.08 & 0.10 & 0.09 & 0.13 & 0.09 & 0.07 & 0.11 & 0.07 & 0.08 & 0.06 & 0.14 & 0.14 & 0.09 & 0.05 & 0.12 & 0.13 & 0.07 & 0.08 & 0.14 & 0.08 & 0.11 & 0.12 & 0.13 & 0.03 & 0.03 & 0.09 & 0.12\end{array}$

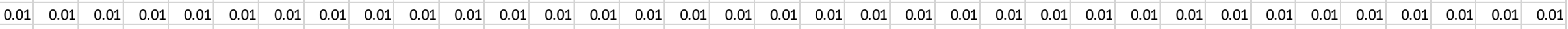
$\begin{array}{lllllllllllllllllllllllllllllllllll}2.25 & 0.98 & 1.29 & 2.42 & 0.52 & 0.94 & 1.41 & 2.41 & 1.40 & 1.16 & 2.40 & 1.38 & 2.76 & 0.51 & 1.19 & 2.29 & 2.07 & 1.73 & 0.83 & 1.92 & 1.24 & 2.68 & 0.52 & 1.39 & 2.59 & 2.36 & 2.57 & 0.94 & 2.71 & 2.11 & 1.97 & 2.72 & 0.68 & 2.40 & 0.67\end{array}$

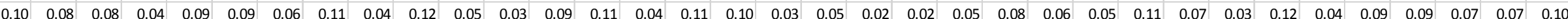

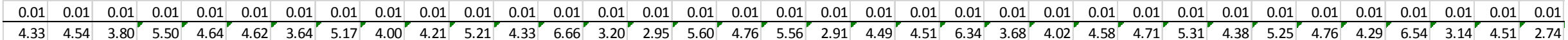


\begin{tabular}{rrrrrrrrrrrrrrrrrrrrrrrrrrrrrrrrrrrrr}
201 & 202 & 203 & 204 & 205 & 206 & 207 & 208 & 209 & 210 & 211 & 212 & 213 & 214 & 215 & 216 & 217 & 218 & 219 & 220 & 221 & 222 & 223 & 224 & 225 & 226 & 227 & 228 & 229 & 230 & 231 & 232 & 233 & 234 & 235 \\
\hline
\end{tabular} $\begin{array}{lllllllllllllllllllllllllllllllllllllll}0.78 & 1.19 & 2.18 & 1.39 & 0.90 & 1.17 & 1.45 & 1.46 & 1.98 & 1.50 & 2.52 & 1.28 & 0.90 & 1.61 & 1.45 & 0.62 & 1.39 & 1.61 & 0.65 & 1.58 & 2.15 & 2.34 & 1.53 & 1.23 & 0.94 & 2.64 & 1.79 & 1.56 & 1.36 & 1.33 & 1.96 & 2.60 & 0.76 & 2.31 & 1.44\end{array}$ \begin{tabular}{llllllllllllllllllllllllllllllllllllllll}
0.06 & 0.06 & 0.06 & 0.06 & 0.06 & 0.06 & 0.06 & 0.06 & 0.06 & 0.06 & 0.06 & 0.06 & 0.06 & 0.06 & 0.06 & 0.06 & 0.06 & 0.06 & 0.06 & 0.06 & 0.06 & 0.06 & 0.06 & 0.06 & 0.06 & 0.06 & 0.06 & 0.06 & 0.06 & 0.06 & 0.06 & 0.06 & 0.06 & 0.06 & 0.06 \\
\hline
\end{tabular}

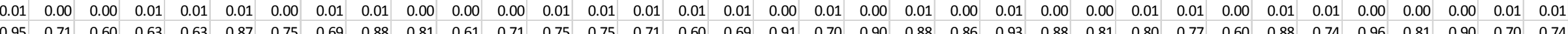

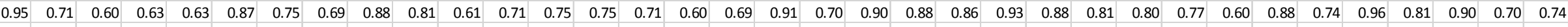
$\begin{array}{lllllllllllllllllllllllllllllllllll}0.00 & 0.00 & 0.00 & 0.00 & 0.00 & 0.00 & 0.00 & 0.00 & 0.00 & 0.00 & 0.00 & 0.00 & 0.00 & 0.00 & 0.00 & 0.00 & 0.00 & 0.00 & 0.00 & 0.00 & 0.00 & 0.00 & 0.00 & 0.00 & 0.00 & 0.00 & 0.00 & 0.00 & 0.00 & 0.00 & 0.00 & 0.00 & 0.00 & 0.00 & 0.00\end{array}$

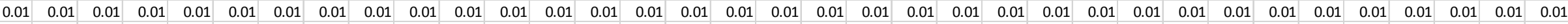
$\begin{array}{llllllllllllllllllllllllllllllllllll}0.09 & 0.09 & 0.08 & 0.09 & 0.08 & 0.08 & 0.09 & 0.09 & 0.08 & 0.08 & 0.10 & 0.09 & 0.09 & 0.08 & 0.08 & 0.08 & 0.09 & 0.08 & 0.09 & 0.10 & 0.08 & 0.08 & 0.08 & 0.08 & 0.08 & 0.08 & 0.08 & 0.08 & 0.08 & 0.08 & 0.08 & 0.08 & 0.09 & 0.08 & 0.09\end{array}$

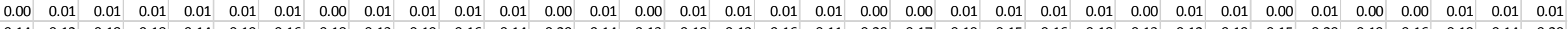

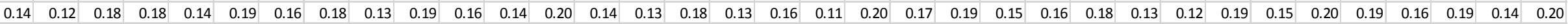
$\begin{array}{lllllllllllllllllllllllllllllllllll}0.12 & 0.15 & 0.05 & 0.13 & 0.04 & 0.06 & 0.09 & 0.05 & 0.12 & 0.08 & 0.12 & 0.04 & 0.10 & 0.11 & 0.10 & 0.10 & 0.13 & 0.13 & 0.04 & 0.08 & 0.14 & 0.13 & 0.08 & 0.04 & 0.09 & 0.04 & 0.07 & 0.09 & 0.15 & 0.12 & 0.04 & 0.06 & 0.05 & 0.07 & 0.04\end{array}$

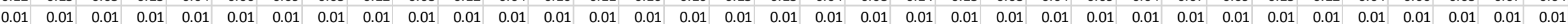

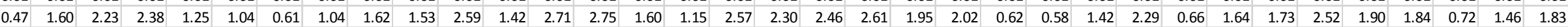

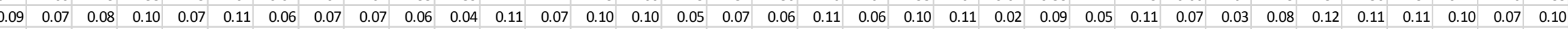

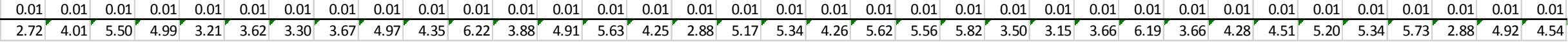

\begin{tabular}{|r|r|r|r|r|r|r|r|r|r|r|r|r|r|r|r|r|}
\hline 236 & 237 & 238 & 239 & 240 & 241 & 242 & 243 & 244 & 245 & 246 & 247 & 248 & 249 & 250 & 251 & 252 \\
\hline 1.64 & 2.12 & 1.94 & 1.16 & 1.37 & 1.79 & 1.40 & 2.24 & 2.58 & 1.35 & 0.61 & 1.25 & 2.76 & 2.33 & 1.25 & 1.03 & 1.08 \\
\hline 0.06 & 0.06 & 0.06 & 0.06 & 0.06 & 0.06 & 0.06 & 0.06 & 0.06 & 0.06 & 0.06 & 0.06 & 0.06 & 0.06 & 0.06 & 0.06 & 0.06 \\
\hline 0.01 & 0.00 & 0.01 & 0.01 & 0.00 & 0.01 & 0.01 & 0.00 & 0.01 & 0.01 & 0.00 & 0.01 & 0.00 & 0.01 & 0.00 & 0.01 & 0.00 \\
\hline 0.96 & 0.86 & 0.92 & 0.78 & 0.69 & 0.86 & 0.68 & 0.88 & 0.90 & 0.96 & 0.92 & 0.66 & 0.71 & 0.79 & 0.91 & 0.64 & 0.81 \\
\hline 0.00 & 0.00 & 0.00 & 0.00 & 0.00 & 0.00 & 0.00 & 0.00 & 0.00 & 0.00 & 0.00 & 0.00 & 0.00 & 0.00 & 0.00 & 0.00 & 0.00 \\
\hline 0.01 & 0.01 & 0.01 & 0.01 & 0.01 & 0.01 & 0.01 & 0.01 & 0.01 & 0.01 & 0.01 & 0.01 & 0.01 & 0.01 & 0.01 & 0.01 & 0.01 \\
\hline 0.09 & 0.09 & 0.08 & 0.09 & 0.08 & 0.09 & 0.10 & 0.09 & 0.08 & 0.08 & 0.09 & 0.09 & 0.08 & 0.09 & 0.08 & 0.09 & 0.10 \\
\hline 0.01 & 0.01 & 0.01 & 0.00 & 0.01 & 0.01 & 0.00 & 0.01 & 0.01 & 0.01 & 0.01 & 0.00 & 0.00 & 0.00 & 0.00 & 0.01 & 0.01 \\
\hline 0.13 & 0.13 & 0.16 & 0.12 & 0.14 & 0.11 & 0.17 & 0.11 & 0.14 & 0.19 & 0.19 & 0.17 & 0.18 & 0.13 & 0.13 & 0.17 & 0.12 \\
\hline 0.06 & 0.12 & 0.06 & 0.05 & 0.09 & 0.08 & 0.07 & 0.14 & 0.09 & 0.13 & 0.12 & 0.08 & 0.10 & 0.13 & 0.07 & 0.10 & 0.13 \\
\hline 0.01 & 0.01 & 0.01 & 0.01 & 0.01 & 0.01 & 0.01 & 0.01 & 0.01 & 0.01 & 0.01 & 0.01 & 0.01 & 0.01 & 0.01 & 0.01 & 0.01 \\
\hline 2.42 & 0.89 & 1.76 & 0.70 & 2.66 & 0.85 & 2.65 & 0.82 & 1.57 & 1.30 & 1.19 & 0.60 & 2.33 & 1.97 & 1.94 & 1.14 & 2.00 \\
\hline 0.10 & 0.11 & 0.10 & 0.07 & 0.09 & 0.11 & 0.07 & 0.11 & 0.10 & 0.03 & 0.09 & 0.08 & 0.05 & 0.10 & 0.07 & 0.08 & 0.10 \\
\hline 0.01 & 0.01 & 0.01 & 0.01 & 0.01 & 0.01 & 0.01 & 0.01 & 0.01 & 0.01 & 0.01 & 0.01 & 0.01 & 0.01 & 0.01 & 0.01 & 0.01 \\
\hline 5.49 & 4.40 & 5.10 & 3.05 & 5.21 & 3.08 & 5.23 & 4.49 & 5.55 & 4.13 & 3.30 & 3.01 & 6.30 & 5.61 & 4.52 & 3.34 & 4.42
\end{tabular}




\section{Anexo 4: Tiempos Propuesta Mejora Parte 2}

\begin{tabular}{|c|c|c|c|c|c|c|c|c|c|c|c|c|c|c|c|c|c|c|c|c|c|c|c|c|c|c|}
\hline \multicolumn{27}{|l|}{ Tiempos por procesos de bobina } \\
\hline Actividad & & 1 & 2 & 3 & 4 & 5 & 6 & 7 & 8 & 9 & 10 & 11 & 12 & 13 & 14 & 15 & 16 & 17 & 18 & 19 & 20 & 21 & 22 & 23 & 24 & 25 \\
\hline Bobina de tela en espera de teñido & 1.20 & 1.38 & 1.37 & 1.14 & 1.10 & 1.22 & 1.11 & 1.31 & 1.13 & 1.35 & 1.07 & 1.38 & 1.15 & 1.36 & 1.23 & 1.28 & 1.09 & 1.34 & 1.18 & 1.15 & 1.20 & 1.14 & 1.22 & 1.39 & 1.39 & 1.23 \\
\hline Teñido & 0.06 & 0.06 & 0.06 & 0.06 & 0.06 & 0.06 & 0.06 & 0.06 & 0.06 & 0.06 & 0.06 & 0.06 & 0.06 & 0.06 & 0.06 & 0.06 & 0.06 & 0.06 & 0.06 & 0.06 & 0.06 & 0.06 & 0.06 & 0.06 & 0.06 & 0.06 \\
\hline traslado de bobina para reposo & 0.01 & 0.01 & 0.01 & 0.01 & 0.00 & 0.01 & 0.01 & 0.00 & 0.01 & 0.00 & 0.01 & 0.01 & 0.01 & 0.01 & 0.01 & 0.01 & 0.01 & 0.01 & 0.01 & 0.01 & 0.01 & 0.01 & 0.01 & 0.01 & 0.01 & 0.00 \\
\hline Reposo & 0.78 & 0.76 & 0.90 & 0.93 & 0.72 & 0.72 & 0.87 & 0.72 & 0.97 & 0.97 & 0.68 & 0.96 & 0.73 & 0.65 & 0.93 & 0.96 & 0.77 & 0.70 & 0.70 & 0.85 & 0.77 & 0.90 & 0.87 & 0.71 & 0.74 & 0.95 \\
\hline Rollo de tela en espera de lavado teñido & 0.00 & 0.00 & 0.00 & 0.00 & 0.00 & 0.00 & 0.00 & 0.00 & 0.00 & 0.00 & 0.00 & 0.00 & 0.00 & 0.00 & 0.00 & 0.00 & 0.00 & 0.00 & 0.00 & 0.00 & 0.00 & 0.00 & 0.00 & 0.00 & 0.00 & 0.00 \\
\hline Traslado de rollo de tela para lavado teñido & 0.01 & 0.01 & 0.01 & 0.01 & 0.01 & 0.01 & 0.01 & 0.01 & 0.01 & 0.01 & 0.01 & 0.01 & 0.01 & 0.01 & 0.01 & 0.01 & 0.01 & 0.01 & 0.01 & 0.01 & 0.01 & 0.01 & 0.01 & 0.01 & 0.01 & 0.01 \\
\hline Lavado teñido & 0.09 & 0.08 & 0.09 & 0.09 & 0.10 & 0.09 & 0.10 & 0.09 & 0.10 & 0.08 & 0.08 & 0.10 & 0.10 & 0.10 & 0.09 & 0.08 & 0.08 & 0.08 & 0.10 & 0.10 & 0.09 & 0.08 & 0.08 & 0.10 & 0.09 & 0.08 \\
\hline Traslado de rollo de tela para secado & 0.01 & 0.01 & 0.00 & 0.00 & 0.01 & 0.00 & 0.01 & 0.01 & 0.01 & 0.00 & 0.01 & 0.01 & 0.01 & 0.01 & 0.01 & 0.01 & 0.01 & 0.01 & 0.00 & 0.00 & 0.01 & 0.00 & 0.01 & 0.01 & 0.01 & 0.01 \\
\hline Rollo de tela en espera de de secado & 0.16 & 0.19 & 0.18 & 0.14 & 0.11 & 0.17 & 0.11 & 0.17 & 0.14 & 0.16 & 0.12 & 0.13 & 0.17 & 0.14 & 0.12 & 0.15 & 0.14 & 0.19 & 0.18 & 0.20 & 0.18 & 0.16 & 0.14 & 0.15 & 0.19 & 0.18 \\
\hline Secado & 0.09 & 0.07 & 0.11 & 0.12 & 0.06 & 0.12 & 0.12 & 0.13 & 0.08 & 0.10 & 0.11 & 0.10 & 0.08 & 0.09 & 0.12 & 0.14 & 0.12 & 0.11 & 0.15 & 0.06 & 0.15 & 0.08 & 0.09 & 0.10 & 0.07 & 0.05 \\
\hline Traslado de & 01 & 0.01 & 0.01 & 0.01 & 0.01 & 0.01 & 0.01 & 0.01 & 0.01 & 0.01 & 0.01 & 0.01 & 0.01 & 0.01 & 0.01 & 01 & 0.01 & 0.01 & 0.01 & 0.01 & 0.01 & .01 & 0.01 & 0.01 & .01 & 0.01 \\
\hline Bobina en espera para su revisión & 1.20 & 1.22 & 1.17 & 1.18 & 1.20 & 1.22 & 1.13 & 1.26 & 1.28 & 1.23 & 1.27 & 1.13 & 1.14 & 1.15 & 1.18 & 1.28 & 1.19 & 1.19 & 1.22 & 1.16 & 1.20 & 1.15 & 1.16 & 1.24 & 1.17 & 1.22 \\
\hline Revisión de tela teñida & 0.07 & 0.09 & 0.04 & 0.05 & 0.11 & 0.02 & 0.05 & 0.10 & 0.07 & 0.06 & 0.06 & 0.05 & 0.08 & 0.11 & 0.08 & 0.05 & 0.07 & 0.05 & 0.09 & 0.09 & 0.10 & 0.07 & 0.10 & 0.05 & 0.10 & 0.08 \\
\hline Traslado de bobina para & 0.01 & 0.01 & 0.01 & 0.01 & 0.01 & 0.01 & 0.01 & 0.01 & 0.01 & 0.01 & 0.01 & 0.01 & 0.01 & 0.01 & 0.01 & 0.01 & 0.01 & 0.01 & 0.01 & 0.01 & 0.01 & 0.01 & 0.01 & .01 & .01 & 0.01 \\
\hline Total por proceso & 3.69 & 3.89 & 3.94 & 3.75 & 3.47 & 3.65 & 3.59 & 3.86 & 3.85 & 4.04 & 3.47 & 3.94 & 3.54 & 3.68 & 3.85 & 4.03 & 3.55 & 3.75 & 3.71 & 3.70 & 3.79 & 3.67 & 3.75 & 3.84 & 3.85 & 3.88 \\
\hline
\end{tabular}

$\begin{array}{lllllllllllllllllllllllllllllllllllllll}26 & 27 & 28 & 29 & 30 & 31 & 32 & 33 & 34 & 35 & 36 & 37 & 38 & 39 & 40 & 41 & 42 & 43 & 44 & 45 & 46 & 47 & 48 & 49 & 50 & 51 & 52 & 53 & 54 & 55 & 56 & 57 & 58 & 59 & 60\end{array}$

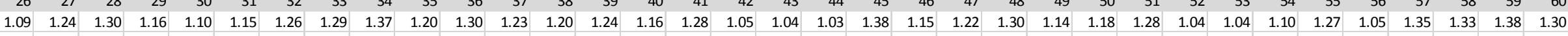
$\begin{array}{lllllllllllllllllllllllllllllllllll}0.06 & 0.06 & 0.06 & 0.06 & 0.06 & 0.06 & 0.06 & 0.06 & 0.06 & 0.06 & 0.06 & 0.06 & 0.06 & 0.06 & 0.06 & 0.06 & 0.06 & 0.06 & 0.06 & 0.06 & 0.06 & 0.06 & 0.06 & 0.06 & 0.06 & 0.06 & 0.06 & 0.06 & 0.06 & 0.06 & 0.06 & 0.06 & 0.06 & 0.06 & 0.06\end{array}$ $\begin{array}{lllllllllllllllllllllllllllllllllllll}0.01 & 0.00 & 0.00 & 0.00 & 0.01 & 0.01 & 0.01 & 0.01 & 0.00 & 0.01 & 0.00 & 0.01 & 0.01 & 0.01 & 0.01 & 0.00 & 0.00 & 0.00 & 0.01 & 0.00 & 0.00 & 0.01 & 0.01 & 0.01 & 0.01 & 0.01 & 0.00 & 0.01 & 0.00 & 0.01 & 0.00 & 0.01 & 0.01 & 0.01 & 0.00\end{array}$

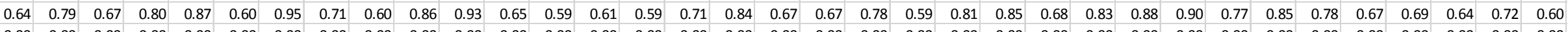

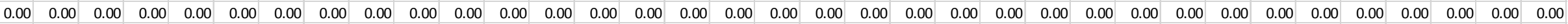

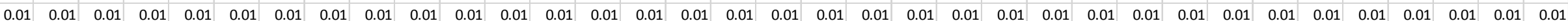

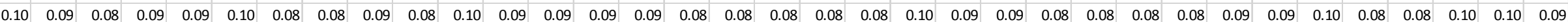

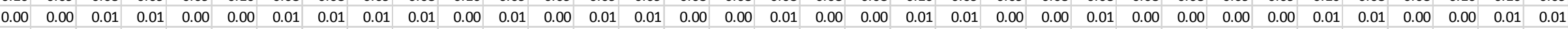

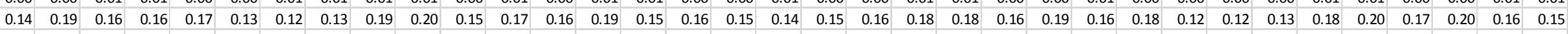

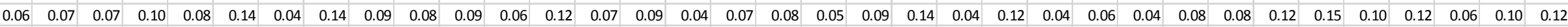

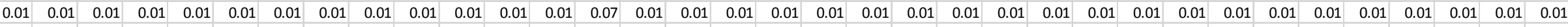

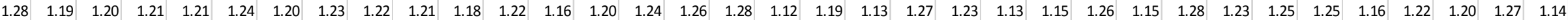
$\begin{array}{lllllllllllllllllllllllllllllllllllll}0.06 & 0.07 & 0.05 & 0.03 & 0.11 & 0.02 & 0.04 & 0.05 & 0.10 & 0.06 & 0.08 & 0.10 & 0.02 & 0.09 & 0.05 & 0.05 & 0.06 & 0.02 & 0.04 & 0.10 & 0.06 & 0.04 & 0.04 & 0.03 & 0.09 & 0.03 & 0.04 & 0.05 & 0.05 & 0.09 & 0.06 & 0.07 & 0.06 & 0.11 & 0.11\end{array}$ \begin{tabular}{lllllllllllllllllllllllllllllllllll}
0.01 & 0.01 & 0.01 & 0.01 & 0.01 & 0.01 & 0.01 & 0.01 & 0.01 & 0.01 & 0.01 & 0.01 & 0.01 & 0.01 & 0.01 & 0.01 & 0.01 & 0.01 & 0.01 & 0.01 & 0.01 & 0.01 & 0.01 & 0.01 & 0.01 & 0.01 & 0.01 & 0.01 & 0.01 & 0.01 & 0.01 & 0.01 & 0.01 & 0.01 & 0.01 \\
\hline
\end{tabular}

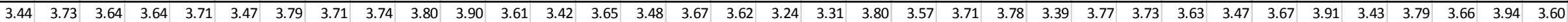




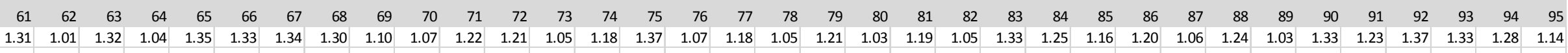

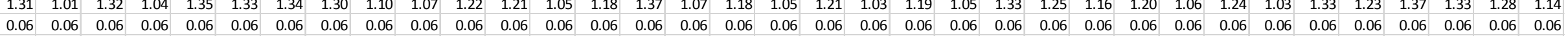

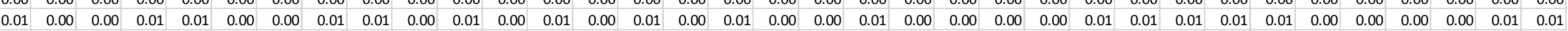

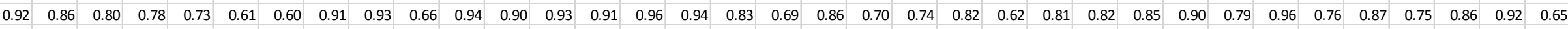
$\begin{array}{llllllllllllllllllllllllllllllllllll}0.00 & 0.00 & 0.00 & 0.00 & 0.00 & 0.00 & 0.00 & 0.00 & 0.00 & 0.00 & 0.00 & 0.00 & 0.00 & 0.00 & 0.00 & 0.00 & 0.00 & 0.00 & 0.00 & 0.00 & 0.00 & 0.00 & 0.00 & 0.00 & 0.00 & 0.00 & 0.00 & 0.00 & 0.00 & 0.00 & 0.00 & 0.00 & 0.00 & 0.00 & 0.00\end{array}$ \begin{tabular}{lllllllllllllllllllllllllllllllllllll}
0.01 & 0.01 & 0.01 & 0.01 & 0.01 & 0.01 & 0.01 & 0.01 & 0.01 & 0.01 & 0.01 & 0.01 & 0.01 & 0.01 & 0.01 & 0.01 & 0.01 & 0.01 & 0.01 & 0.01 & 0.01 & 0.01 & 0.01 & 0.01 & 0.01 & 0.01 & 0.01 & 0.01 & 0.01 & 0.01 & 0.01 & 0.01 & 0.01 & 0.01 & 0.01 \\
\hline
\end{tabular} $\begin{array}{llllllllllllllllllllllllllllllllllll}0.09 & 0.08 & 0.08 & 0.09 & 0.09 & 0.08 & 0.09 & 0.09 & 0.09 & 0.08 & 0.09 & 0.08 & 0.09 & 0.09 & 0.08 & 0.08 & 0.08 & 0.09 & 0.08 & 0.10 & 0.09 & 0.08 & 0.09 & 0.09 & 0.09 & 0.10 & 0.09 & 0.08 & 0.09 & 0.09 & 0.10 & 0.08 & 0.08 & 0.09 & 0.09\end{array}$

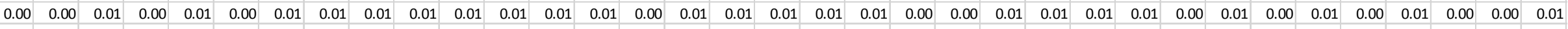

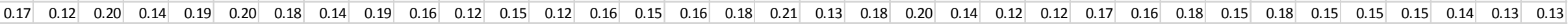

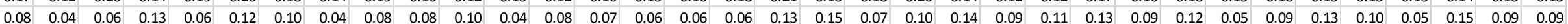

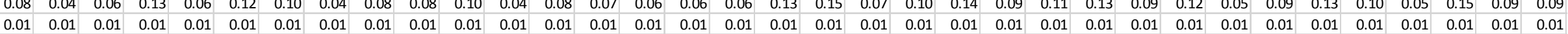

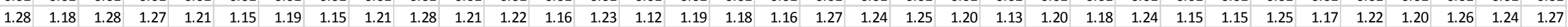

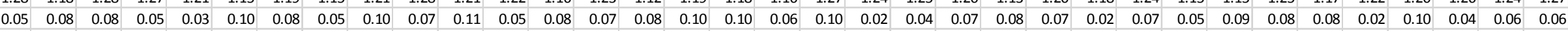

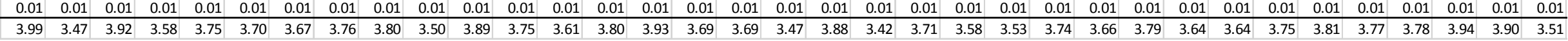

$\begin{array}{rrrrrrrrrrrrrrrrrrrrrrrrrrrrrrrrrrr}96 & 97 & 98 & 99 & 100 & 101 & 102 & 103 & 104 & 105 & 106 & 107 & 108 & 109 & 110 & 111 & 112 & 113 & 114 & 115 & 116 & 117 & 118 & 119 & 120 & 121 & 122 & 123 & 124 & 125 & 126 & 127 & 128 & 129 & 130\end{array}$

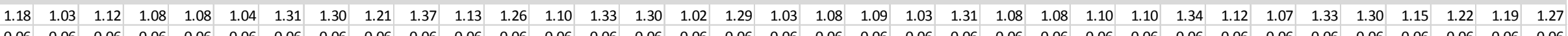
$\begin{array}{lllllllllllllllllllllllllllllllllll}0.06 & 0.06 & 0.06 & 0.06 & 0.06 & 0.06 & 0.06 & 0.06 & 0.06 & 0.06 & 0.06 & 0.06 & 0.06 & 0.06 & 0.06 & 0.06 & 0.06 & 0.06 & 0.06 & 0.06 & 0.06 & 0.06 & 0.06 & 0.06 & 0.06 & 0.06 & 0.06 & 0.06 & 0.06 & 0.06 & 0.06 & 0.06 & 0.06 & 0.06 & 0.06\end{array}$

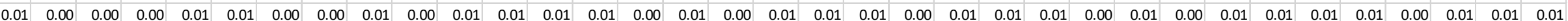

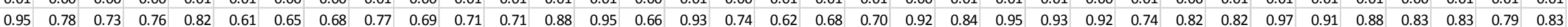
\begin{tabular}{lllllllllllllllllllllllllllllllllllll}
0.95 & 0.78 & 0.73 & 0.76 & 0.82 & 0.61 & 0.65 & 0.68 & 0.77 & 0.69 & 0.71 & 0.71 & 0.88 & 0.95 & 0.66 & 0.93 & 0.74 & 0.62 & 0.68 & 0.70 & 0.92 & 0.84 & 0.95 & 0.93 & 0.92 & 0.74 & 0.82 & 0.82 & 0.97 & 0.91 & 0.88 & 0.83 & 0.83 & 0.79 & 0.83 \\
\hline
\end{tabular} $\begin{array}{llllllllllllllllllllllllllllllllllll}0.00 & 0.00 & 0.00 & 0.00 & 0.00 & 0.00 & 0.00 & 0.00 & 0.00 & 0.00 & 0.00 & 0.00 & 0.00 & 0.00 & 0.00 & 0.00 & 0.00 & 0.00 & 0.00 & 0.00 & 0.00 & 0.00 & 0.00 & 0.00 & 0.00 & 0.00 & 0.00 & 0.00 & 0.00 & 0.00 & 0.00 & 0.00 & 0.00 & 0.00 & 0.00 \\ 0.01 & 0.01 & 0.01 & 0.01 & 0.01 & 0.01 & 0.01 & 0.01 & 0.01 & 0.01 & 0.01 & 0.01 & 0.01 & 0.01 & 0.01 & 0.01 & 0.01 & 0.01 & 0.01 & 0.01 & 0.01 & 0.01 & 0.01 & 0.01 & 0.01 & 0.01 & 0.01 & 0.01 & 0.01 & 0.01 & 0.01 & 0.01 & 0.01 & 0.01 & 0.01\end{array}$

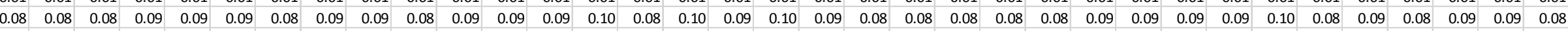
$\begin{array}{lllllllllllllllllllllllllllllllllllll}0.01 & 0.00 & 0.01 & 0.01 & 0.00 & 0.01 & 0.01 & 0.01 & 0.00 & 0.01 & 0.00 & 0.01 & 0.00 & 0.01 & 0.00 & 0.00 & 0.01 & 0.01 & 0.00 & 0.00 & 0.01 & 0.00 & 0.00 & 0.01 & 0.00 & 0.01 & 0.01 & 0.01 & 0.01 & 0.00 & 0.01 & 0.01 & 0.01 & 0.00 & 0.01\end{array}$ $\begin{array}{lllllllllllllllllllllllllllllllllll}0.18 & 0.17 & 0.15 & 0.15 & 0.17 & 0.19 & 0.20 & 0.14 & 0.20 & 0.13 & 0.18 & 0.15 & 0.16 & 0.13 & 0.16 & 0.18 & 0.19 & 0.18 & 0.17 & 0.18 & 0.12 & 0.14 & 0.17 & 0.16 & 0.15 & 0.20 & 0.14 & 0.12 & 0.14 & 0.13 & 0.17 & 0.15 & 0.15 & 0.18 & 0.18\end{array}$ $\begin{array}{llllllllllllllllllllllllllllllllllllllll}0.06 & 0.11 & 0.11 & 0.05 & 0.09 & 0.11 & 0.04 & 0.15 & 0.11 & 0.09 & 0.08 & 0.11 & 0.04 & 0.12 & 0.13 & 0.11 & 0.14 & 0.12 & 0.07 & 0.10 & 0.12 & 0.08 & 0.09 & 0.12 & 0.14 & 0.07 & 0.06 & 0.08 & 0.09 & 0.04 & 0.11 & 0.14 & 0.05 & 0.14 & 0.07\end{array}$

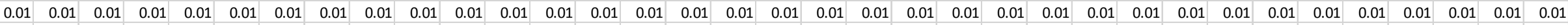

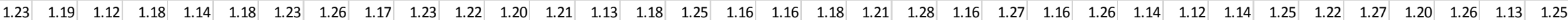

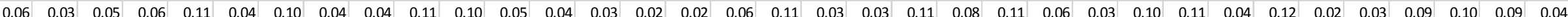

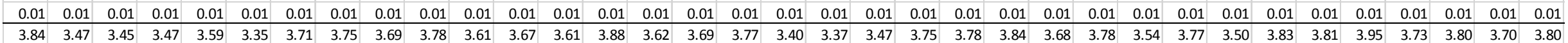




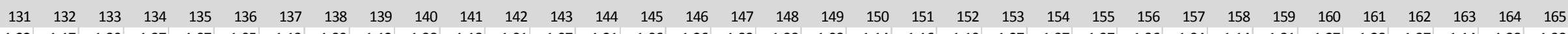
$\begin{array}{lllllllllllllllllllllllllllllllllll}1.22 & 1.17 & 1.30 & 1.37 & 1.07 & 1.05 & 1.13 & 1.39 & 1.12 & 1.38 & 1.18 & 1.01 & 1.07 & 1.21 & 1.06 & 1.26 & 1.33 & 1.38 & 1.08 & 1.14 & 1.16 & 1.10 & 1.27 & 1.37 & 1.37 & 1.36 & 1.04 & 1.14 & 1.31 & 1.27 & 1.28 & 1.37 & 1.14 & 1.38 & 1.38 \\ 0\end{array}$ \begin{tabular}{lllllllllllllllllllllllllllllllllllll}
0.06 & 0.06 & 0.06 & 0.06 & 0.06 & 0.06 & 0.06 & 0.06 & 0.06 & 0.06 & 0.06 & 0.06 & 0.06 & 0.06 & 0.06 & 0.06 & 0.06 & 0.06 & 0.06 & 0.06 & 0.06 & 0.06 & 0.06 & 0.06 & 0.06 & 0.06 & 0.06 & 0.06 & 0.06 & 0.06 & 0.06 & 0.06 & 0.06 & 0.06 & 0.06 \\
\hline
\end{tabular}

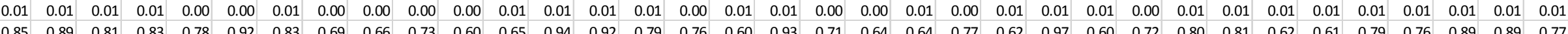

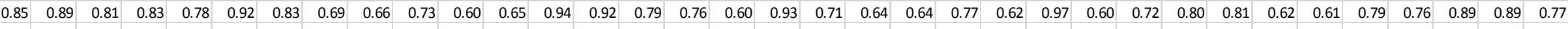

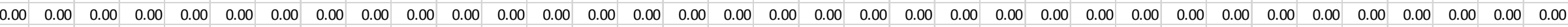
$\begin{array}{llllllllllllllllllllllllllllllllllllll}0.01 & 0.01 & 0.01 & 0.01 & 0.01 & 0.01 & 0.01 & 0.01 & 0.01 & 0.01 & 0.01 & 0.01 & 0.01 & 0.01 & 0.01 & 0.01 & 0.01 & 0.01 & 0.01 & 0.01 & 0.01 & 0.01 & 0.01 & 0.01 & 0.01 & 0.01 & 0.01 & 0.01 & 0.01 & 0.01 & 0.01 & 0.01 & 0.01 & 0.01 & 0.01\end{array}$ $\begin{array}{lllllllllllllllllllllllllllllllllll}0.09 & 0.08 & 0.09 & 0.09 & 0.08 & 0.08 & 0.09 & 0.10 & 0.09 & 0.09 & 0.08 & 0.08 & 0.09 & 0.09 & 0.08 & 0.09 & 0.09 & 0.09 & 0.09 & 0.08 & 0.10 & 0.08 & 0.09 & 0.08 & 0.10 & 0.08 & 0.09 & 0.09 & 0.09 & 0.08 & 0.10 & 0.08 & 0.10 & 0.10 & 0.08\end{array}$

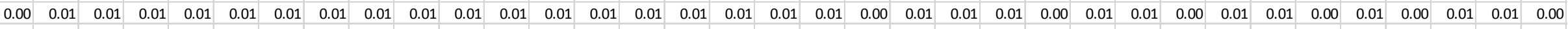

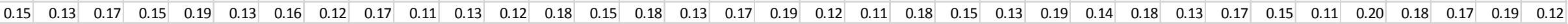

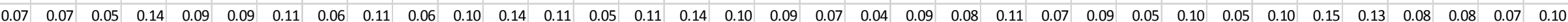

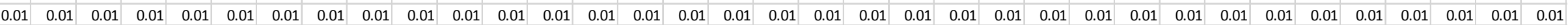

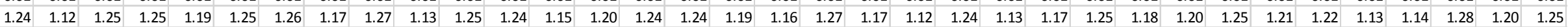

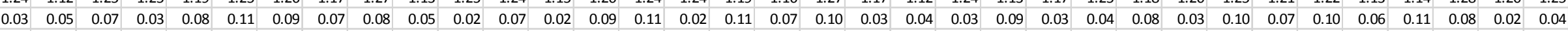

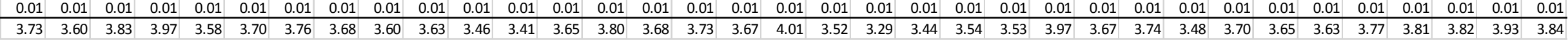

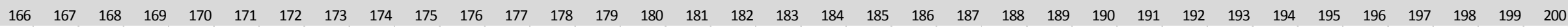

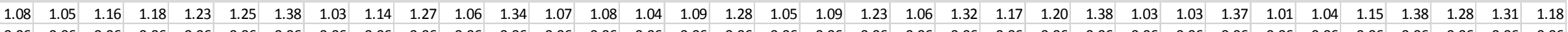
$\begin{array}{lllllllllllllllllllllllllllllllllll}0.06 & 0.06 & 0.06 & 0.06 & 0.06 & 0.06 & 0.06 & 0.06 & 0.06 & 0.06 & 0.06 & 0.06 & 0.06 & 0.06 & 0.06 & 0.06 & 0.06 & 0.06 & 0.06 & 0.06 & 0.06 & 0.06 & 0.06 & 0.06 & 0.06 & 0.06 & 0.06 & 0.06 & 0.06 & 0.06 & 0.06 & 0.06 & 0.06 & 0.06 & 0.06\end{array}$

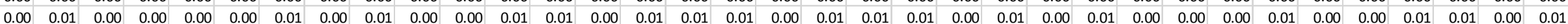

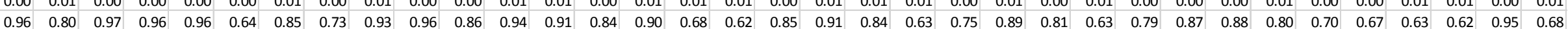
\begin{tabular}{llllllllllllllllllllllllllllllllllll}
0.96 & 0.80 & 0.97 & 0.96 & 0.96 & 0.64 & 0.85 & 0.73 & 0.93 & 0.96 & 0.86 & 0.94 & 0.91 & 0.84 & 0.90 & 0.68 & 0.62 & 0.85 & 0.91 & 0.84 & 0.63 & 0.75 & 0.89 & 0.81 & 0.63 & 0.79 & 0.87 & 0.88 & 0.80 & 0.70 & 0.67 & 0.63 & 0.62 & 0.95 & 0.68 \\
\hline
\end{tabular} $\begin{array}{lllllllllllllllllllllllllllllllllllllll}0.00 & 0.00 & 0.00 & 0.00 & 0.00 & 0.00 & 0.00 & 0.00 & 0.00 & 0.00 & 0.00 & 0.00 & 0.00 & 0.00 & 0.00 & 0.00 & 0.00 & 0.00 & 0.00 & 0.00 & 0.00 & 0.00 & 0.00 & 0.00 & 0.00 & 0.00 & 0.00 & 0.00 & 0.00 & 0.00 & 0.00 & 0.00 & 0.00 & 0.00 & 0.00 \\ 0.01 & 0.01 & 0.01 & 0.01 & 0.01 & 0.01 & 0.01 & 0.01 & 0.01 & 0.01 & 0.01 & 0.01 & 0.01 & 0.01 & 0.01 & 0.01 & 0.01 & 0.01 & 0.01 & 0.01 & 0.01 & 0.01 & 0.01 & 0.01 & 0.01 & 0.01 & 0.01 & 0.01 & 0.01 & 0.01 & 0.01 & 0.01 & 0.01 & 0.01 & 0.01\end{array}$

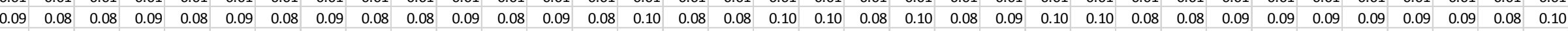

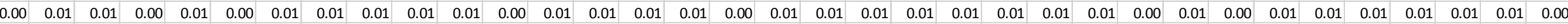
$\begin{array}{lllllllllllllllllllllllllllllllllll}0.19 & 0.17 & 0.15 & 0.20 & 0.12 & 0.20 & 0.17 & 0.19 & 0.12 & 0.16 & 0.13 & 0.16 & 0.18 & 0.12 & 0.18 & 0.13 & 0.14 & 0.17 & 0.19 & 0.16 & 0.13 & 0.20 & 0.19 & 0.12 & 0.18 & 0.18 & 0.14 & 0.18 & 0.19 & 0.14 & 0.18 & 0.11 & 0.17 & 0.13 & 0.16\end{array}$ $\begin{array}{lllllllllllllllllllllllllllllllllllllllll}0.04 & 0.06 & 0.12 & 0.08 & 0.13 & 0.12 & 0.11 & 0.10 & 0.11 & 0.04 & 0.05 & 0.14 & 0.13 & 0.14 & 0.06 & 0.04 & 0.05 & 0.12 & 0.12 & 0.15 & 0.14 & 0.06 & 0.06 & 0.10 & 0.06 & 0.07 & 0.07 & 0.13 & 0.04 & 0.10 & 0.09 & 0.15 & 0.08 & 0.05 & 0.06\end{array}$ \begin{tabular}{lllllllllllllllllllllllllllllllllll}
0.01 & 0.01 & 0.01 & 0.01 & 0.01 & 0.01 & 0.01 & 0.01 & 0.01 & 0.01 & 0.01 & 0.01 & 0.01 & 0.01 & 0.01 & 0.01 & 0.01 & 0.01 & 0.01 & 0.01 & 0.01 & 0.01 & 0.01 & 0.01 & 0.01 & 0.01 & 0.01 & 0.01 & 0.01 & 0.01 & 0.01 & 0.01 & 0.01 & 0.01 & 0.01 \\
\hline
\end{tabular}

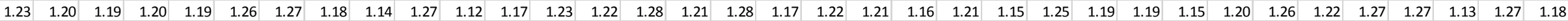

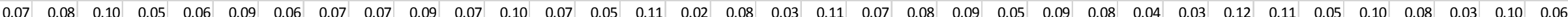

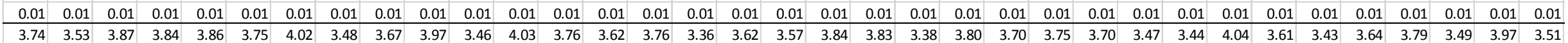




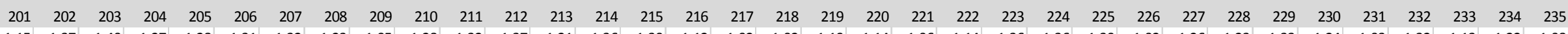
\begin{tabular}{lllllllllllllllllllllllllllllllllllll}
1.15 & 1.37 & 1.40 & 1.27 & 1.28 & 1.31 & 1.32 & 1.23 & 1.05 & 1.28 & 1.32 & 1.37 & 1.21 & 1.36 & 1.30 & 1.12 & 1.02 & 1.02 & 1.19 & 1.14 & 1.06 & 1.14 & 1.36 & 1.36 & 1.39 & 1.02 & 1.26 & 1.23 & 1.33 & 1.24 & 1.03 & 1.32 & 1.13 & 1.22 & 1.08 \\
\hline
\end{tabular}

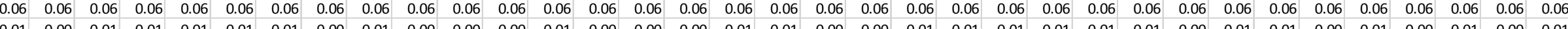

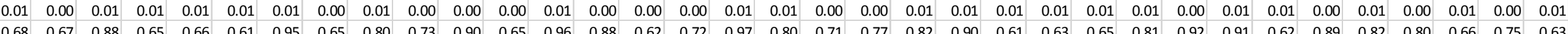

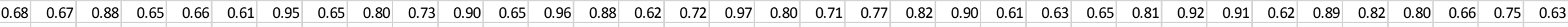
$\begin{array}{lllllllllllllllllllllllllllllllllll}0.00 & 0.00 & 0.00 & 0.00 & 0.00 & 0.00 & 0.00 & 0.00 & 0.00 & 0.00 & 0.00 & 0.00 & 0.00 & 0.00 & 0.00 & 0.00 & 0.00 & 0.00 & 0.00 & 0.00 & 0.00 & 0.00 & 0.00 & 0.00 & 0.00 & 0.00 & 0.00 & 0.00 & 0.00 & 0.00 & 0.00 & 0.00 & 0.00 & 0.00 & 0.00\end{array}$ \begin{tabular}{lllllllllllllllllllllllllllllllllllll}
0.01 & 0.01 & 0.01 & 0.01 & 0.01 & 0.01 & 0.01 & 0.01 & 0.01 & 0.01 & 0.01 & 0.01 & 0.01 & 0.01 & 0.01 & 0.01 & 0.01 & 0.01 & 0.01 & 0.01 & 0.01 & 0.01 & 0.01 & 0.01 & 0.01 & 0.01 & 0.01 & 0.01 & 0.01 & 0.01 & 0.01 & 0.01 & 0.01 & 0.01 & 0.01 \\
\hline
\end{tabular}

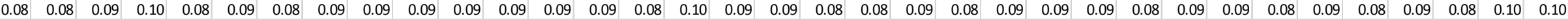

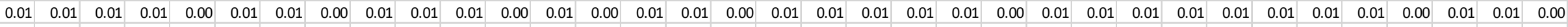

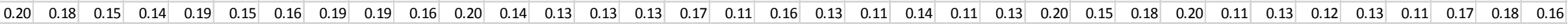

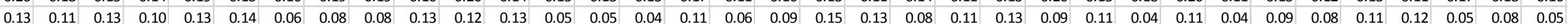

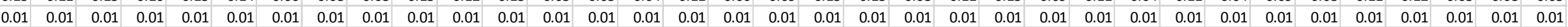

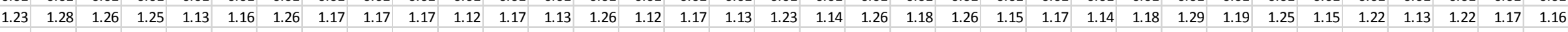

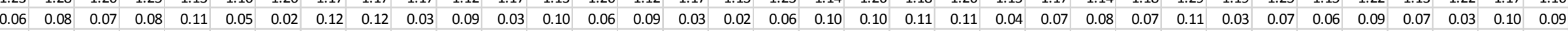

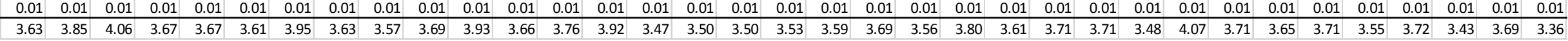

\begin{tabular}{|r|r|r|r|r|r|r|r|r|r|r|r|r|r|r|r|r|r|r|r|r|r|}
\hline 236 & 237 & 238 & 239 & 240 & 241 & 242 & 243 & 244 & 245 & 246 & 247 & 248 & 249 & 250 & 251 & 252 \\
\hline 1.39 & 1.25 & 1.08 & 1.27 & 1.10 & 1.14 & 1.06 & 1.37 & 1.33 & 1.09 & 1.34 & 1.14 & 1.21 & 1.17 & 1.08 & 1.05 & 1.26 \\
\hline 0.06 & 0.06 & 0.06 & 0.06 & 0.06 & 0.06 & 0.06 & 0.06 & 0.06 & 0.06 & 0.06 & 0.06 & 0.06 & 0.06 & 0.06 & 0.06 & 0.06 \\
\hline 0.01 & 0.01 & 0.01 & 0.00 & 0.01 & 0.01 & 0.01 & 0.00 & 0.01 & 0.01 & 0.01 & 0.00 & 0.00 & 0.00 & 0.00 & 0.01 & 0.01 \\
\hline 0.70 & 0.71 & 0.71 & 0.85 & 0.73 & 0.96 & 0.68 & 0.68 & 0.60 & 0.85 & 0.62 & 0.65 & 0.75 & 0.88 & 0.65 & 0.64 & 0.84 \\
\hline 0.00 & 0.00 & 0.00 & 0.00 & 0.00 & 0.00 & 0.00 & 0.00 & 0.00 & 0.00 & 0.00 & 0.00 & 0.00 & 0.00 & 0.00 & 0.00 & 0.00 \\
\hline 0.01 & 0.01 & 0.01 & 0.01 & 0.01 & 0.01 & 0.01 & 0.01 & 0.01 & 0.01 & 0.01 & 0.01 & 0.01 & 0.01 & 0.01 & 0.01 & 0.01 \\
\hline 0.09 & 0.08 & 0.09 & 0.09 & 0.09 & 0.09 & 0.09 & 0.08 & 0.09 & 0.08 & 0.09 & 0.10 & 0.10 & 0.10 & 0.09 & 0.08 & 0.09 \\
\hline 0.00 & 0.01 & 0.00 & 0.01 & 0.00 & 0.00 & 0.01 & 0.01 & 0.01 & 0.01 & 0.00 & 0.00 & 0.00 & 0.01 & 0.00 & 0.00 & 0.01 \\
\hline 0.13 & 0.18 & 0.15 & 0.12 & 0.17 & 0.20 & 0.15 & 0.18 & 0.17 & 0.13 & 0.15 & 0.18 & 0.18 & 0.19 & 0.12 & 0.16 & 0.12 \\
\hline 0.11 & 0.12 & 0.12 & 0.07 & 0.08 & 0.06 & 0.13 & 0.08 & 0.04 & 0.14 & 0.09 & 0.07 & 0.11 & 0.06 & 0.10 & 0.05 & 0.07 \\
\hline 0.01 & 0.01 & 0.01 & 0.01 & 0.01 & 0.01 & 0.01 & 0.01 & 0.01 & 0.01 & 0.01 & 0.01 & 0.01 & 0.01 & 0.01 & 0.01 & 0.01 \\
\hline 1.17 & 1.22 & 1.14 & 1.21 & 1.18 & 1.19 & 1.15 & 1.27 & 1.14 & 1.12 & 1.19 & 1.28 & 1.25 & 1.27 & 1.25 & 1.19 & 1.27 \\
\hline 0.03 & 0.05 & 0.09 & 0.11 & 0.11 & 0.04 & 0.04 & 0.04 & 0.07 & 0.11 & 0.09 & 0.10 & 0.02 & 0.03 & 0.05 & 0.11 & 0.10 \\
\hline 0.01 & 0.01 & 0.01 & 0.01 & 0.01 & 0.01 & 0.01 & 0.01 & 0.01 & 0.01 & 0.01 & 0.01 & 0.01 & 0.01 & 0.01 & 0.01 & 0.01 \\
\hline 3.71 & 3.70 & 3.47 & 3.80 & 3.55 & 3.76 & 3.40 & 3.78 & 3.53 & 3.61 & 3.68 & 3.60 & 3.70 & 3.78 & 3.42 & 3.38 & 3.83 \\
\hline
\end{tabular}

